\title{
The Essays on Competitiveness, EFFICIENCY, AND PRODUCTIVITY: \\ Methodological Issues AND APPLiCATIONS
}

\author{
Dissertation \\ zur Erlangung des Doktorgrades \\ der Fakultät für Agrarwissenschaften \\ der Georg-August-Universität Göttingen
}

vorgelegt von

Oleg Nivievskyi

geboren in der Ukraine in der Stadt Khmelnytskyi

Göttingen, Dezember 2009 
D7

1. Referent/Referentin: Prof. Dr. Stephan von Cramon-Taubadel

2. Korreferent/Korreferentin: Prof. Dr. Alfons Oude Lansink

Tag der mündlichen Prüfung: 28. Januar 2010 


\section{Acknowledgements}

I would like to express my gratitude to all those who made this thesis possible. First and foremost I offer my sincerest gratitude to my supervisor, Prof. Dr. Stephan von Cramon-Taubadel, who supported and inspired me throughout my PhD studies with his patience, knowledge, experience and ideas whilst allowing me the room to work in my own way. Without him this thesis would not have been completed.

I am very grateful to Prof. Bernhard Brümmer for his excellent support and collaboration. His outstanding expertise and continuous willingness for feedback motivated me very much. I thank Prof. Alfons Oude Lansink for his valuable feedback as a second supervisor.

My gratitude goes to Prof. Dr. Walter Zucchini and to Prof. Dr. Stefan Sperlich. I have benefited a lot from their lectures in terms of the statistical background. Furthermore, I am thankful to the Zentrum für Statistik for the financial support $i$ was granted to present some of the papers at the conferences in New York (USA) and in Beijing (China).

I want to thank all of the colleagues of the 'Lehrstuhl Agrarpolitik' for an excellent working and friendly atmosphere. My special thanks go to Rico Ihle with whom i have been sharing the office. Thank you for a stimulating and friendly environment in our office.

I am especially grateful to my wife Tania and children Ivasyk and Marichka for being continuous source of energy to keep my work going.

I окремо, хочу щиро подякувати батькам за постійну підтримку у всіх моїх успіхах та невдачах. 


\section{Contents}

$\begin{array}{ll}\text { Contents } & 2\end{array}$

List of Figures $\quad 5$

$\begin{array}{ll}\text { List of Tables } & 7\end{array}$

1 Introduction 9

2 Overview and Discussion of the Research Papers 13

2.1 Ukraine: Agricultural Competitiveness . . . . . . . . . . . . 13

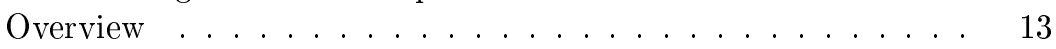

Discussion . . . . . . . . . . . . . . . . . . 14

2.2 The Determinants of Dairy Farming Competitiveness in Ukraine 16

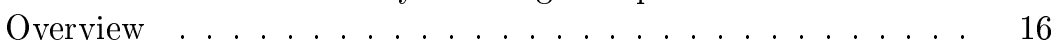

Discussion . . . . . . . . . . . . . . . 17

2.3 Price Support, Performance and Technical Progress in Ukrainian

Dairy Farms: a Spatial Analysis . . . . . . . . . . . . . . 18

Overview . . . . . . . . . . . . . . . . . . 18

Discussion . . . . . . . . . . . . . . . . . . 20

2.4 Belarus: Agricultural Productivity and Competitiveness. Impact of State Support and Market Intervention . . . . . . . . 22

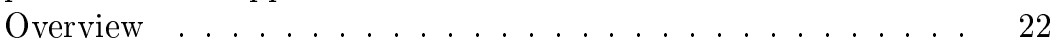

Discussion . . . . . . . . . . . . . . . . 24

2.5 Measuring and Comparing the Competitiveness of Heterogeneous Production Systems in Agriculture: a Note . . . . . . . . 25

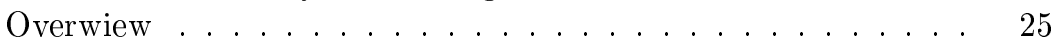

Discussion . . . . . . . . . . . . . . . 27

2.6 Efficiency, Productivity Growth and Competitiveness: a Note . 28

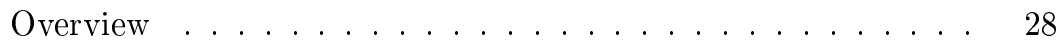

Discussion . . . . . . . . . . . . . . . . . . . . . . . . . . . . . . . . . . . . 29

2.7 References . . . . . . . . . . . . . . . 30

3 Ukraine: Agricultural Competitiveness 33

3.1 The current status of Ukrainian agricultural competitiveness . 33

Indicators of agricultural competitiveness . . . . . . . . . 33

The current status of Ukrainian agricultural competitiveness . 36

3.2 The Domestic Resource Costs Method and the Calculation of

DRC Distributions . . . . . . . . . . . . . . . . . 41

The DRC method . . . . . . . . . . . . . 41 


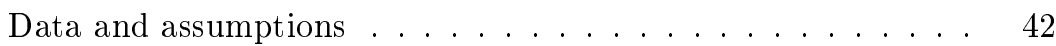

3.3 References .................... 47

4 The Determinants of Dairy Farming Competitiveness in Ukraine 53

4.1 Introduction . . . . . . . . . . . . . . . . 53

4.2 The profile of dairy farming in Ukraine . . . . . . . . . . . 54

4.3 The competitiveness of Ukraine's milk production . . . . . . . . 59

Describing the competitiveness of milk production in Ukraine . $\quad 59$

The determinants of competitiveness in Ukrainian milk production 60

4.4 Conclusions .................... 62

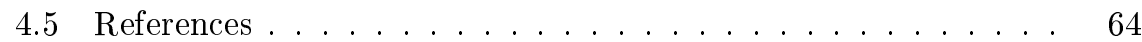

5 Price Support, Performance and Technical Progress in Ukrainian

Dairy Farms: a Spatial Analysis $\quad 65$

5.1 Introduction . . . . . . . . . . . . . . . . . 65

5.2 Dairy Sector Profile in Ukraine . . . . . . . . . . . . . . . 66

5.3 Methods and Data . . . . . . . . . . . . . . . 68

Measurement of Individual Efficiency and Productivity Growth 68

Spatial analysis of performance and technical progress determinants ................... 69

Data and Variables Description _........... . . . 70

5.4 Empirical Findings . . . . . . . . . . . . . . . . . . . . 73

Spatial Clusters . . . . . . . . . . . . . . 73

Model selection and estimation results . . . . . . . . . 78

5.5 Conclusions ...................... 83

5.6 References .................... 84

6 Belarus: Agricultural Productivity and Competitiveness. Im$\begin{array}{ll}\text { pact of State Support and Market Intervention } & 87\end{array}$

6.1 Aggregate output . . . . . . . . . . . . . . 87

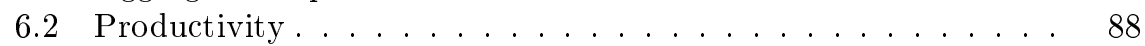

Partial productivity indicators at farm level . . . . . . . . 88

Aggregate (partial) sector productivity . . . . . . . . . . 90

Total factor productivity . . . . . . . . . . . . . . . . . . 92

6.3 Competitiveness . . . . . . . . . . . . . . . 97

Crop production in general . . . . . . . . . . . 97

The special case of sugar beet . . . . . . . . . . . . . . . . . . . . . . . . 199

Livestock production . . . . . . . . . . . . . . . 100

The special case of dairy production . . . . . . . . . . 100

6.4 The impact of subsidies on performance at the farm level . . . 103

6.5 References . . . . . . . . . . . . . . . 105

6.6 Technical Appendix 1: Total factor productivity (TFP) analysis 109

6.7 Technical Appendix 2: Analysis of farm competitiveness . . . . 118

7 Measuring and Comparing the Competitiveness of Heterogeneous Production Systems in Agriculture: a Note 133

7.1 Introduction . . . . . . . . . . . . . . . . . . 133

7.2 Competitiveness Measurement: Open Questions . . . . . . . . 134

Distributions versus averages . . . . . . . . . . . . 134

Accuracy of the estimates . . . . . . . . . . . . 137 
Ranking and/or Comparison . . . . . . . . . . . . . 138

7.3 Contrasting the Ranking Methods . . . . . . . . . . . . 141

7.4 Conclusions . . . . . . . . . . . . . . . . . . . 143

7.5 References . . . . . . . . . . . . . . . . . . 143

8 Efficiency, Productivity Growth and Competitiveness: a Note 145

8.1 Introduction . . . . . . . . . . . . . . . . 145

8.2 Competitiveness decomposition I . . . . . . . . . . . . . 147

8.3 Competitiveness decomposition II . . . . . . . . . . . . . . 150

8.4 Conclusions . . . . . . . . . . . . . . . . . . . 151

8.5 References . . . . . . . . . . . . . . . . . 151 


\section{List of Figures}

3.1 The share of households in total production of agricultural products,

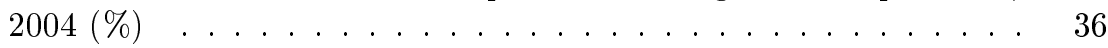

3.2 Domestic resource cost distributions for major crop products in Ukraine, $2005 \ldots \ldots \ldots$. . . . . . . . . . . . 37

3.3 Domestic resource cost distributions for major crop products in Ukraine, $2004 \ldots \ldots \ldots$. . . . . . . . . . . . . 37

3.4 Domestic resource cost (DRC) distributions for major livestock products in Ukraine, 2005 . . . . . . . . . . . . . . . . .

3.5 Domestic resource cost (DRC) distributions for major livestock products in Ukraine, $2004 \ldots \ldots$. . . . . . . . . . . . . .

3.6 Social cost benefit (SCB) distributions for major crop products in Ukraine, $2005 \ldots \ldots \ldots \ldots$. . . . . . . . . . . . 4 44

3.7 Social cost benefit (SCB) distributions for major crops products in Ukraine, $2004 \ldots \ldots \ldots \ldots \ldots$. . . . . . . . . . . 45

3.8 Social cost benefit (SCB) distributions for major livestock products in Ukraine, 2005 . . . . . . . . . . . . . . . . . 46

3.9 Social cost benefit (SCB) distributions for major livestock products in Ukraine, $2004 \ldots \ldots \ldots$. . . . . . . . . . . . 4 46

4.1 Monthly raw milk production by households and farms (2005-2006) 55

4.2 Dairy Production/Export ratio . . . . . . . . . . . . . 56

4.3 Dairy Export from Ukraine . . . . . . . . . . . . . . 56

4.4 Oblast's share in the national raw milk production, $2006 \ldots \ldots .57$

4.5 The distribution of milk yields by herd size on dairy farms in Ukraine

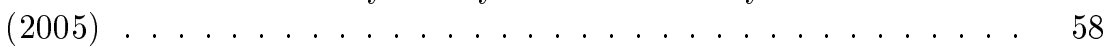

4.6 Distribution of competitiveness scores for dairy farms . . . . . 60

5.1 Dairy processing industry performance . . . . . . . . 67

5.2 Dairy farming sector performance . . . . . . . . . . . . 67

5.3 Order-m efficiency and TFP growth estimates distributions . . . 76

5.4 Spatial Clustering of efficiency scores, $2004 / 05 \ldots \ldots \ldots \ldots 77$

5.5 Spatial clustering of technical change scores, 2004/05 . . . . 78

6.1 Gross agricultural output in Belarus and selected transition countries $(1990=100) \ldots \ldots \ldots \ldots \ldots$. . . . . . . . 88

6.2 Dynamics of wheat yields in Belarus, averages across all farm types

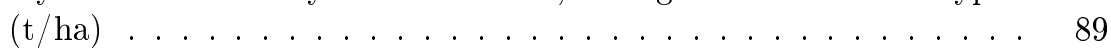

6.3 Labor and fixed capital productivity in Belarusian agriculture relative to the rest of the economy $\ldots \ldots \ldots \ldots$ 
6.4 Distributions of yield (tons of crop/hectare and tons of milk/cow) on the large commercial farms in Belarus, 2003-2007 . . . . . . . 90

6.5 The shares of agriculture and the food industry in Belarus in GDP, employment, and fixed assets in Belarus (2000-2007, in \%) . . . . .

6.6 Changes in total factor productivity and its components for commercial farms in Belarus between 2003 and 2007 (order-m model) .

6.7 Technical efficiency distributions for commercial farms in Belarus .

6.8 Global price fluctuation and medium-term development for selected crops, daily data, 2000-2009 . . . . . . . . . . . .

6.9 Changes in the production of major agricultural products in Belarus - three-year averages (1995-1997, 2000-2002 and 2005-2007) (1995$1997=100) \ldots \ldots \ldots \ldots \ldots$

6.10 Social cost benefit (SCB) distributions for crop products in Belarus

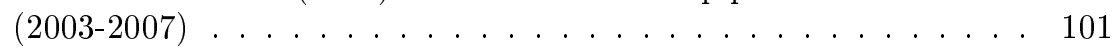

6.11 Social cost benefit (SCB) distributions for livestock products in Be-

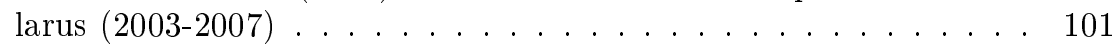

6.12 Scatter plots of TFP change and its components against the volume of subsidies received between 2003 and 2007 . . . . . . . . . . . 104

6.13 The distance function . . . . . . . . . . . . . . . . 112

6.14 TFP components: Catch-up and frontier-shift . . . . . . . . . . . 114

6.15 Kernel Estimates of Density of Order-m Efficiency . . . . . . . . . 117

6.16 Changes in total factor productivity and its components for commercial farms in Belarus between 2003 and 2007 (DEA model) . . 118

6.17 Private and social cost-benefit (PCB, SCB) calculations for a sample

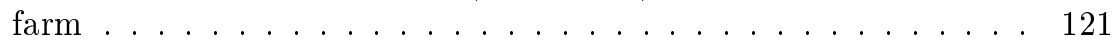

7.1 DRC and SCB ratios distributions for wheat and sunflower seeds in Ukraine, 2005 . . . . . . . . . . . . . . . . . 136

7.2 The estimated proportion of the sample with $\mathrm{DRC}<0$, and corresponding confidence intervals, for different sample sizes . . . . . . . 139

7.3 Aggregate SCB scores for wheat and corresponding confidence intervals, for different sample sizes . . . . . . . . . . . . . 141

8.1 SCB decomposition - output orientation . . . . . . . . . . . . 149

8.2 SCB decomposition - input orientation . . . . . . . . . . 149 


\section{List of Tables}

3.1 The Policy Analysis Matrix $(\mathrm{PAM}) \ldots \ldots \ldots \ldots$

3.2 Summary of DRC results for major crop products $\ldots \ldots \ldots 38$

3.3 Summary of DRC results for major livestock products . . . . . . 41

3.4 Data description . . . . . . . . . . . . . . 43

3.5 Cost shares for inputs in crop and livestock production in Ukraine, 2004 and $2005(\%) \ldots \ldots \ldots \ldots \ldots \ldots \ldots$

3.6 Calculation of conversion factors for revenues . . . . . . . . 44

4.1 Characteristics of raw milk production in Ukraine (1990-2008) . . 55

4.2 Quality standards for raw cow milk for food production in Ukraine,

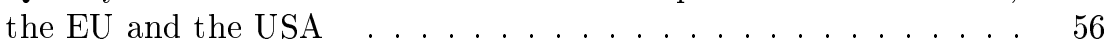

4.3 Summary of DRC results for dairy farms in Ukraine . . . . . . 60

4.4 Variable definitions and summary statistics . . . . . . . . 61

4.5 Fixed-effect panel regression estimates . . . . . . . . . . 63

5.1 Order-m frontier estimation - summary statistics $\ldots \ldots \ldots \ldots$

5.2 Technical progress SAR model - summary statistics . . . . . . . 73

5.3 Performance SAR model - summary statistics . . . . . . . . . 75

5.4 SAR regressions results $\ldots \ldots \ldots \ldots \ldots$

6.1 Crop yields (tons per hectare) and milk yields (tons per cow) on large commercial farms in Belarus . . . . . . . . . . 9 90

6.2 Share of agriculture in GDP, employment, and capital in Belarus, and corresponding measures of labor and capital productivity . . . 91

6.3 Ranges of technical efficiency (TE) scores by quartile of the efficiency distribution . . . . . . . . . . . . . 94

6.4 The average size of large commercial farms in selected CIS countries (in hectares) . . . . . . . . . . . . . . .

6.5 The shares of farms with competitive crop production in Belarus that are competitive at financial $(0<\mathrm{PCB}<1)$ and economic $(0$ $<\mathrm{SCB}<1$ ) prices in costs (in $\%, 2003-2007) \ldots \ldots \ldots . . .$.

6.6 The shares of crop production (by marketed volumes of production) in Belarus that is competitive at financial $(0<\mathrm{PCB}<1)$ and economic $(0<\mathrm{SCB}<1)$ prices in costs (in \%, 2003-2007) . . . .

6.7 The shares of farms with competitive livestock production in Belarus that are competitive at financial $(0<\mathrm{PCB}<1)$ and economic $(0<\mathrm{SCB}<1)$ prices in costs (in $\%, 2003-2007) \ldots \ldots \ldots 102$ 
6.8 The shares of livestock production (by marketed volume of production) in Belarus that is competitive at financial $(0<\mathrm{PCB}<1)$ and economic $(0<\mathrm{SCB}<1)$ prices in costs (in \%, 2003-2007) . . . .

6.9 Regression of TFP change and its components on farm characteristics and subsidies received by farms . . . . . . . . . . . . 104

6.10 Descriptive statistics for the variables used in the regression analysis of order-m TFP change and its components . . . . . . . . . . . . 111

6.11 Data description and summary statistics . . . . . . . . . . . 116

6.12 Total Belarusian agricultural exports (thousand tons), and the share of these exports that is destined for Russia (\%), by product . . . . 119

6.13 Private and social cost benefit (PCB, SCB) calculations for a sample farm (US\$/hectare) . . . . . . . . . . . . . . . 122

6.14 Factors for converting financial to economic costs in SCB analysis* 122

6.15 The Policy Analysis Matrix (PAM) . . . . . . . . . . . . . 123

6.16 Data description . . . . . . . . . . . . . . . . 124

6.17 Cost shares for inputs in crop and livestock production in Belarus,

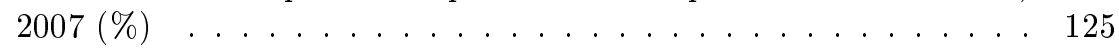

6.18 Financial (farm gate) prices, economic (border) prices, and the calculation of conversion factors for revenues (prices in BYR/ton) . . 125

6.19 Calculation of conversion factors for fertilizers . . . . . . . . . . 126

6.20 The calculation of economic interest rates . . . . . . . . . . . . 127

6.21 Calculation of conversion factors for gas costs . . . . . . . . . 127

6.22 Calculation of conversion factors for electricity costs . . . . . . . 128

6.23 Market price support tables for selected crop products . . . . . . . 130

6.24 Market price support tables for selected livestock products . . . . . 131

6.25 Major economic and agricultural indicators for Belarus . . . . . . . 132

7.1 The Policy Analysis Matrix $(\mathrm{PAM}) \ldots \ldots . \ldots . . \ldots . . \ldots 135$

7.2 Summary of DRC results for wheat . . . . . . . . . . . . 137

7.3 Summary of DRC and SCB results for major crop products for Ukraine, 2005 ......................... 142 


\section{Chapter 1}

\section{Introduction}

This $\mathrm{PhD}$ thesis consists of six papers that could be divided into two groups. The first group comprises four papers that deal with assessing and explaining performance of agricultural sector in Ukraine and Belarus. The second group comprises two papers that deal with some methodological and conceptual issues generated in the course of preparing the first group of papers.

In the first paper 'Ukraine: Agricultural Competitiveness' we perform a disaggregated competitiveness analysis for major individual agricultural products in Ukraine. This paper is a part of the World Bank Policy Note that was prepared in the context of the World Bank research project 'Ukraine: Agricultural Competitiveness' (see von Cramon-Taubadel et. al., 2008a; Chapter III) ${ }^{1}$. Domestic Resource Cost (DRC) and Social Cost Benefit Ratio (SCB) indicators using a Ukraine-wide farms accounting dataset are employed in the paper to generate DRC and SCB distributions that demonstrate the competitiveness of Ukrainian agriculture. The main conclusion is that Ukrainian agriculture demonstrates a clear lack of international competitiveness and competitive farms account for a disproportionate share of Ukraine's total output of agricultural products.

In the second paper 'The Determinants of Dairy Farming Competitiveness in Ukraine' we essentially continue the analysis performed in the first paper and focus on the determinants of dairy farming competitiveness in Ukraine. Dairy has been highlighted by the Minister of Agriculture Policy of Ukraine as a branch of agriculture that can be expected to face especially difficult challenges as Ukraine became a WTO member in 2008 and started negotiations on a free trade agreement (FTA) with the $\mathrm{EU}^{2}$. In particular we look at the impact of the farm size, productivity, labor intensity, arable land and subsidies on competitiveness.

In the third paper 'Price Support, Performance and Technical Progress in Ukrainian Dairy Farms: a Spatial Analysis' we perform a spatial analysis of the determinants of performance and technological improvements in Ukrainian dairy farming. In contrast with the second paper introduced above, here we measure performance using efficiency and productivity analysis methods. A particular attention in the analysis is drawn to the impact of price subsidies and the influence of agglomeration economies on farm-level performance. Subsidies are of considerable interest to policy making in Ukraine in light of WTO

\footnotetext{
${ }^{1}$ For simplicity we keep the title of the Policy Note for the paper.

${ }^{2}$ Interfax-Ukraine news agency, January 31st, 2008 ww. interfax.com.ua
} 
commitments on the domestic support ceiling. The agglomeration economies literature suggests different channels through which neighborhood effects and proximity to resources or consumers pools affect performance and technology diffusion patterns (Eberts and McMillen, 1999; World Bank/IBRD, 2009). The empirical analysis in the paper employs a farm-level accounting data on input use, outputs and subsidies in 2004 and 2005, respectively.

The fourth paper 'Belarus: Agricultural Productivity and Competitiveness. Impact of State Support and Market Intervention' is a part of the World Bank Policy Note that was prepared in the context of the World Bank research project "Belarus: Agricultural Productivity and Competitiveness. Impact of State Support and Market Intervention" (see von Cramon-Taubadel et. al., 2009; Chapter $\mathrm{C})^{3}$. In the paper we study the patterns and possible determinants of agricultural sector performance in Belarus. Using a Belarus-wide farm-level accounting data we look at the performance of Belarusian agriculture by measuring competitiveness of major individual agricultural products. On the other side we also analyse the efficiency and productivity of farms in the sector and the effect of a massive state support to agriculture. One of the most important results of the analysis is that despite a significant TFP growth, there is no evidence of 'across the board' improvements in competitiveness in Belarusian agriculture between 2003 and 2007.

In the fifth paper 'Measuring and Comparing the Competitiveness of Heterogeneous Production Systems in Agriculture: a Note' we develop further some of the ideas generated in the course of preparing the first paper 'Ukraine: Agricultural Competitiveness'. In particular, using Ukraine-wide accounting data on the population of crop farms we demonstrate the weakness of inferences based on aggregated/average measures of competitiveness (or based on 'typical/representative' farm data). In contrast to this the competitiveness distributions make it possible to determine for each product a) what proportion of the farms producing it is competitive, and b) what proportion of the total production/output value of this product occurs on competitive farms. Moreover, we suggest nonparametric bootstrap techniques to estimate the precision of the estimates of these proportions in the sample data setting. Further, since policy makers and applied researches are often interested in ranking of sectors' or/and groups' of producers according to competitiveness criteria, we propose and contrast distribution- and aggregate-based approaches for ranking the activities.

The last paper 'Efficiency, Productivity Growth and Competitiveness: a Note' wraps up this $\mathrm{PhD}$ thesis by linking the two strands of analysis on economic performance. The first strand focuses on the analysis of comparative advantages and/or competitiveness. The second strand of literature focuses on efficiency and productivity analysis, where technical efficiency and Total Factor Productivity (TFP) concepts are of the main interest. This taxonomy is also observed in this $\mathrm{PhD}$ thesis. In the paper we propose a static and dynamic decompositions of the SCB measure using a distance function approach that demonstrate the relationship between competitiveness, efficiency and productivity.

This $\mathrm{PhD}$ thesis is organized as follows. Chapter 2 provides an extensive discussion and a summary of results of the papers contained in the thesis. The research papers themselves are presented in Chapters $3-8$.

\footnotetext{
${ }^{3}$ For simplicity we keep the title of the Policy Note for the paper.
} 


\section{References}

Eberts, R.W., And D.P.McMillen (1999). Agglomeration Economies and Urban Public Infrastructure. In CheshiRe., P. AND Mills, E.S. eds.: Handbook of Regional and Urban Economics, Vol 3 Applied Economics, Chap. 38. New York: North-Holland, 1999.

von Cramon Taubadel, S., Nivyevskiy, O., and M. Grueninger (2008). Ukraine: Agricultural Competitiveness. World Bank Policy Note No. 44843UA.

von Cramon Taubadel, S., M. Grueninger, O. Nivievskyi, and D. Prikhodko (2009). Belarus: Agricultural Productivity and Competitiveness. Impact of State Support and Market Intervention. World Bank Policy Note No 48335-BY

World BAnK/IBRD (2009): World Developing Report 2009: Reshaping Economic Geography. The World Bank, Washington DC. 



\section{Chapter 2}

\section{Overview and Discussion of the Research Papers}

\subsection{Ukraine: Agricultural Competitiveness ${ }^{1}$}

\section{Overview}

In this section we overview and discuss a study on individual agricultural products competitiveness that was prepared in the context of the World Bank research project 'Ukraine: Agricultural Competitiveness' (see von CramonTaubadel et. al., 2008a; Chapter III).

In the study we perform a disaggregated competitiveness analysis for major individual agricultural products in Ukraine. Domestic Resource Cost (DRC) and Social Cost Benefit Ratio (SCB) indicators are employed as measures of competitiveness. DRC compares the cost of domestic resources measured at social prices to value added measured in social prices. $0<\mathrm{DRC}<1$ indicates comparative advantage (the social opportunity cost of domestic resources used is smaller that the corresponding social value added). The opposite is true for the $\mathrm{DRC}>1$. If the $\mathrm{DRC}$ is smaller than 0 , then revenue does not even suffice to cover tradable input costs, let alone domestic inputs. In this case, production of the good in question is clearly not competitive. SCB compares total costs at social prices to the social value of output. The SCB ratio is always greater than 0 , and a SCB less than (greater than) 1 indicates that total input costs are less than (greater than) revenue and that production is (is not) competitive.

DRC and SCB distributions are generated using a farm-level Ukraine-wide farm accounting data provided by the State Statistics Committee of Ukraine. This dataset is an unbalanced panel of 17,906 observations over the period 20042005. For each observation in the dataset (representing a farm in one of the two years) it was possible to get/generate information on disaggregated input use and output of each individual farm product. Conversion from private to social prices and costs was based on a variety of assumptions and sources of data.

The results demonstrate that many Ukrainian farms are able to produce wheat,

\footnotetext{
${ }^{1}$ with Stephan von Cramon-Taubadel and Matthias Grueninger. The paper is published as a World Bank Policy Note No. 44843-UA, 2008
} 
sunflower seed, barley, eggs, beef and milk competitively. In 2005, for example, $44 \%$ of all Ukrainian farms that produced wheat did so competitively. Corresponding shares for sunflower seed (41\%), barley (25\%), eggs $(40 \%)$, beef $(22 \%)$ and milk $(20 \%)$ are lower but point to a sizeable competitive core. The lowest shares are found for maize $(13 \%)$, rapeseed $(10 \%)$, soybeans $(8 \%)$, pork $(8 \%)$, potatoes $(6 \%)$, poultry $(4 \%)$ and sugarbeet $(2 \%)$. For all products, the majority of the farms in Ukraine are not able to produce sufficient surplus to cover the costs of domestic and tradable inputs. For many farms and products, the value of production does not even suffice to cover the cost of tradable inputs, indicating that production is subtracting, not adding value. Competitive farms account for a disproportionate share of Ukraine's total output of agricultural products; the $44 \%$ of the wheat producing farms that were competitive in 2005 , for example, accounted for almost $56 \%$ of Ukraine's wheat production in that year. This suggests that competitive production takes place mainly on a large scale in Ukraine.

\section{Discussion}

In the process of performing DRC and SCB analysis we were confronted with several methodological and applied issues. First, there exist numerous indicators of competitiveness and/or comparative advantages in the empirical literature. After a detailed investigation of the pros and cons of these indicators, and since we focus on individual agricultural products in the study, we employed DRC and SCB as measures of competitiveness. DRC is a well-known concept that is incorporated in a well established Policy Analysis Matrix (PAM) framework by Monke and Pearson (1989). 'Revealed Comparative Advantage' (RCA) indeces (Liesner, 1958; Balassa, 1965) could be an alternative to DRC. However, RCA indeces are usually justified if most policy-induced distortions are on the import side, which is not the case in Ukraine (see e.g. von CramonTaubadel et al, 2008b). Also, Banance et al (1987) demonstrate that there is a high degree of inconsistency among alternative RCA indeces, and that inferences are correspondingly sensitive to the particular index chosen. Moreover, Siggel (2006) provides a rather comprehensive survey and discussion of variety measures of comparative advantage. He concludes that DRC criterion is the only measure that qualifies as a true measure of comparative advantage. He justifies his statement based on the fact that DRC can be derived from the Recardian trade model and it uses shadow prices. Still, DRC understates the competitiveness of activities with intensive usage of domestic factors and it is biased against classification of inputs and rankings of activities (Masters and Winter-Nelson, 1995). For this reason we also employ "unbiased" measure SCB proposed by Masters and Winter-Nelson (1995). Nonetheless, DRC is still attractive since it identifies farms with revenue that does not even suffice to cover tradable input costs, i.e. with $\mathrm{DRC}<0$.

In the study we performed a disaggregated analysis that allowed us to construct the distributions of DRC and SCB scores for each individual product. Surprisingly, such an approach turned out to be quite innovative, since by the time we finished the study, we could not find any similar one in the field. Usually the DRC or SCB indicators are calculated using the data for average or "representative" farms. As one might expect, such an "aggregated or representative" indicator suffers from several important problems. Monke and Pearson (1989) 
have shown that several representative systems may exist simultaneously for a given population of farms. Therefore, competitiveness scores and rankings will be conditioned on which of these systems is selected and inter/intra-country comparison of production systems will produce ambiguous conclusions about comparative advantage as a result. Furthermore, if the farms that are summarised in this manner are highly heterogeneous, inferences based on aggregated measures of competitiveness can be very misleading. For example, it can be shown that the average ton of wheat was produced at a DRC of 1.37 in 2005. This result, taken at face value, would suggest that there are problems with the competitiveness of wheat production in Ukraine, obscuring the fact that $44 \%$ of all wheat producing farms, and $56 \%$ of all the wheat produced in the country, are competitive.

A proper aggregation of individual DRC and SCB scores to the group level aggregate scores was another problem. The first reaction to this problem was to use the weighted averaging with output shares as weights. This approach, however, produced senseless results for DRC scores, since the DRC distribution is discontinuous at 0 , with values slightly greater than 0 reflecting very competitive farms, and values slightly below reflecting very uncompetitive farms. So there was a need in a proper aggregation methodology for DRC and SCB indicators. This and the issue of disaggregated DRC and SCB analysis were developed in details in Nivievskyi and von Cramon-Taubadel (2009) paper, which is also available in the chapter 7 of this thesis.

Since we performed a disaggregated competitiveness analysis in the study, a further evident follow-up work suggested performing the statistical analysis of the determinants of competitiveness. The available evidence suggests, however, that efficient and inefficient farms often exist side-by-side even in the most agriculturally favoured regions of Ukraine. So more detailed analysis - for example using information on the location of individual farms in the dataset, their degrees of specialisation, factor intensities etc. - was required to determine what factors influence farms' competitiveness. This aspect is explored in details in further two papers, where we study the determinants of dairy farming performance in Ukraine (see Nivievskyi and von Cramon-Taubadel, 2008; Nivievskyi et. al., 2009). These two papers are also included in this thesis, see chapters 4 and 5, respectively.

An interesting follow-up work could also be to look at the overall farm competitiveness. Usually Ukrainian farms produce multiple outputs. So the incentives for efficient farming of a certain agricultural product might vary depending on, for example, specialization or technological requirements. Some crops, for instance, might be kept in farming due to crop rotation requirements. To test whether the overall and individual product competitiveness analysis produce consistent results, one might compare the distributions of competitiveness scores for each individual product and for the whole farm. Based on a corollary to Koopman's (1957) theorem on profit functions (i.e. the industry maximal profit is the sum of its firms' profits) the expectation is that a farm competitive in each individual product should also be overall competitive, and vise verse, the overall competitive farm is expected to be competitive in each individual product. 


\subsection{The Determinants of Dairy Farming Competitiveness in Ukraine ${ }^{2}$}

\section{Overview}

This paper might be seen as an extension of the analysis performed in the paper 'Ukraine: Agricultural Competitiveness' (von Cramon-Taubadel et al., 2008a; see section 2.1 for a detailed discussion). In that paper using the Ukraine-wide farm-level data we demonstrate a clear lack of competitiveness in Ukrainian agriculture. In particular, only $44 \%$ of all Ukrainian farms that produced wheat did so competitively in 2005. Corresponding shares for other crops and livestock products are lower. That means that for all products, the majority of the farms in Ukraine are not able to produce sufficient surplus to cover the costs of domestic and tradable inputs.

The natural question arising in such a situation is "Why?". What determines such low rates of international competitiveness in Ukraine's agriculture? The question became even more acute after Ukraine joined the WTO in the early February 2008 and started negotiations on a free trade agreement (FTA) with the EU. These two challenges imply not only changes in the trade and institutional regime for Ukraine, but also structural changes in Ukraine's agriculture and adjustments at the farm level to improve efficiency and competitiveness. In this paper we focus on the determinants of dairy farming competitiveness in Ukraine. Dairy, together with sugar and fruit and vegetable production, was highlighted by the Minister of Agriculture Policy of Ukraine as a branch of agriculture that can be expected to face especially difficult challenges as Ukraine opens its agricultural markets ${ }^{3}$. Dairy farming sector produces 12-14 $\mathrm{m}$ tons of raw milk annualy over the last decade, compared with $24.5 \mathrm{~m}$ tons in 1990. The corresponding contraction of total output was mostly on the commercial farms' side, as a result of transformation from the planned Soviet to market economy. The competitiveness analysis revealed, that only $14.4 \%$ of commercial dairy farms had comparative advantage in producing milk in 2006, compared with $20.1 \%$ and $15.8 \%$ in 2005 and 2004 respectively. These farms accounted for about $36 \%, 49 \%$ and $42 \%$ of the total raw milk output in those years, respectively.

The analysis of the determinants is carried out using Ukraine-wide farm-level accounting data. We estimate a fixed-effect panel regression based on unbalanced panel of 10,043 milk producing farms over the period 2004-2005. As expected, the size of the farm has a strong positive and non-linear effect on competitiveness. Combining the estimated coefficients suggests that the largest positive impact on competitiveness is reached for a herd size of roughly 900 cows. However, the impact of productivity (milk yields) on competitiveness is found to be much stronger. One additional ton of milk per cow and year increases competitiveness by over 50 times as much as increasing the herd size by one cow does. Labor intensity and arable land per cow have a negative effect on competitiveness. Finally, total subsidies received by farms are found to have a negative impact on competitiveness. This impact does not differ significantly

\footnotetext{
${ }^{2}$ with Stephan von Cramon-Taubadel. The paper was presented as a Contributed paper at the 12th Congress of European Association of Agricultural Economists, August 2008, Ghent, Belgium

${ }^{3}$ Interfax-Ukraine news agency, January 31st, 2008 www. interfax.com.ua
} 
between farms of different herd size.

\section{Discussion}

From the policy making point of view these results suggest termination of the current subsidy mechanism for the dairy farming of Ukraine to improve the sector's competitiveness. Instead, the developing of technology promotion (e.g. avoid taxation of inputs and excessive regulation procedures, etc) and human capacity building policies would have a positive impact on productivity, herd size and labor-to-capital ratios thus improving competitiveness.

The results and policy implications above might be limited to some extend by the following issues. In the analysis we focused on the competitiveness of individual product, i.e. as if a farm produces only milk. In fact, 'pure' dairy farms in Ukraine are rather exemption than a rule. According to Sabluck (2003), the cattle farming in Ukraine has a beef-dairy focus. Dairy farming (with more than $75 \%$ of the milking cows in the cattle herd) is located mainly in the Forest agriculture zone. Moreover, majority of dairy farms produce their own feed (Lischka, 2004). So generally speaking dairy farms produce many outputs, and milk production might not be the main focus of farming. In other words, probably it makes sense considering milk production coupled with production of other outputs on a farm. Beef production would be a natural candidate for that. The competitiveness analysis in von Cramon-Taubadel et al (2008a) revealed that about $21 \%$ and $30 \%$ of commercial farms had comparative advantage in beef production in 2005 and 2004 respectively (see also chapter 3 ). If these farms also have competitive milk production in that period, the conclusions of the analysis of the determinants above should not change than. However, in case the beef competitive farms have uncompetitive milk production, the aggregate outcome is ambiguous and might influence the conclusions of the analysis. In the next paper (see the overview and the full paper in the section 2.3 and in the chapter 5, respectively) we take more general approach, and measure the performance of dairy farms (using efficiency and productivity analysis methods) as multi-output production units.

An important limitation of the paper might be a neglect of a location. In a sense, our analysis of the determinants of competitiveness is 'spatially blind'. However, the recent World Development Report (World Bank/IBRD, 2009) provides a vast evidence on the importance of location and neighborhood environment for the development. According to the regional economics literature, firms might benefit from so called 'agglomeration economies' that can be generated in many ways (Eberts and McMillen, 1999). The performance of a dairy farm, for instance, might be influenced by the behavior of its neighbors or some local environment. Such spillovers may happen because of the local, industryspecific infrastructure, information, and services that influence the performance of each neighboring dairy farm through the lower transactions costs and easier diffusion of financial, technology and market information. Another types of spillovers might come from more general sector infrastructure, when livestock sectors might benefit from the same pool of specialists, or specific services suppliers applicable for the entire livestock sector. The critical ingredient of such an analysis is availability of data on the location of firms. Unfortunately by the time we finished the analysis, the data on the location of dairy farms was not available, so no spatial analysis was possible at that time. In the next 
paper (see the overview and the full paper in the section 2.3 and in the chapter 5 , respectively) we collected the necessary spatial information and specifically focused on the effect of agglomeration economies on the performance of dairy farms. Instead of competitiveness, we looked at technical efficiency as a measure of dairy farms' performance. The spatial analysis in this paper revealed a substantial spatial dependence in the efficiency patterns, as well as we found an evidence of the existence of agglomeration economies in the sector. Spatial dependency in technical efficiency scores, however, does not automatically imply spatial dependency in competitiveness scores. As we derived it in the paper presented in the chapter 8 , technical efficiency indeed contributes to competitiveness. However, there are other components in the static competitiveness measure decomposition (see expression 8.10) that prevent competitiveness and efficiency from following a one-to-one relationship.

From statistical point of view the OLS estimator, for instance, is biased and inconsistent for the parameters in the presence of a spatially lagged dependent variable (Anselin, 1988; p. 59). More specifically, the coefficients of the OLS regression are simply inflated by $(1-\rho)$, where $\rho$ is a coefficient of a spatial lag parameter in a spatial autoregressive model (see e.g model 5.1 in the chapter 5 ). $\rho$ reflects the extent of spatial interactions across the neighboring dairy farms due to some unobserved factors. From interpretation point of view this means that an effect of a particular explanatory variable is attributed to some practice styles or behaviours among the nearest neighbouring farms. For instance if $\rho$ equals 0.14 , than each 1 unit change in explanatory variables derives about $16 \%$ of their impact from some common unobserved neighbouring behavioural pattern (the spatial multiplier is $\frac{1}{1-\rho}$ ). Based on these we may conclude that estimates of a fixed-effect panel regression are biased in this paper, should there be a spatial autocorrelation in the competitiveness scores. The estimates, of the coefficients in the standard fixed effect model will be equal the estimates of the coefficients in the spatial fixed-effect model multiplied by $(1-\rho)$. However, qualitatively our conclusions would not change, since $\frac{1}{1-\rho}$ term does not change the sign of the estimated coefficients $(-1 \leq \rho \leq 1)$. Still, given the availability of data on the locations of farms, the spatial analysis of the competitiveness determinants seems very interesting follow-up/extension of the paper.

\subsection{Price Support, Performance and Technical Progress in Ukrainian Dairy Farms: a Spatial Analysis ${ }^{4}$}

\section{Overview}

This paper deals with a spatial analysis of the determinants of performance and technical improvements in Ukrainian dairy farming. Particular attention in the analysis is drawn to the impact of subsidies and the influence of agglomeration economies on farm-level performance. Subsidies are of considerable interest to policy making in Ukraine in light of WTO commitments on the domestic support ceiling. The subsidy analysed in the paper takes the form of premium

\footnotetext{
${ }^{4}$ with Stephan von Cramon-Taubadel and Bernhard Brümmer. Earlier versions of this paper were presented as Contributed papers at: Vth North American Productivity Workshop 25-27 June 2008, New-York, USA; IAMO Forum - 2009, June 2009, Halle (Saale), Germany; 27th IAAE Conference, 16-22 August 2009, Beijing, China.
} 
per each liter of raw milk supplied to the dairy processor. A conventional expectation in the literature, starting from Leibenstein (1966) points to the negative impact of the support measures on efficiency, mainly via a weakening of managerial efforts. Still, there is no consensus on the exact mechanism of the impact. For example, Kalaitzandonakes and Bredahl $(1993,1994)$ conclude that the effect of protectionism on productivity is a priori ambiguous. They argued that protection may positively influence productivity growth for low income industries via encouraged investments and technical progress; however, for the high income industries, protection is likely to have an adverse effect by generating technical and scale inefficiencies. Sunding and Zilberman (2001; p.250) emphasize different mechanisms through which price supports can influence technology adoption on farms of different sizes. For instance, smaller farms may increase their technology adoption via better credit access as a result of subsidies when the ability to obtain credit depends on expected income. The agglomeration economies literature suggests different channels through which neighborhood effects and proximity to resources or consumers pools affect performance and technology diffusion patterns. They are traditionally divided into 'internal scale economies', 'localization' and 'urbanization economies' (Eberts and McMillen, 1999; World Bank/IBRD, 2009). Internal scale economies are the conventional economies of scale that arise from a more efficient use of fixed costs due to a larger size of operation. Localization economies imply that the performance of one dairy farm might be influenced by the behavior of its neighbors or some local environment. Such spillover may happen because of the local, sector-specific infrastructure, information, and services that influence the performance of each neighboring dairy farm through the lower transactions costs and easier diffusion of financial, technology and market information. Urbanization economies benefits might arise from a more general livestock or up- and downstream infrastructure, allowing drawing from the same pool of technicians, specific services suppliers applicable for the entire dairy and livestock sector. In particular, it is hypothesized that location near to milk processing facilities that have been modernized will have a positive impact on the performance of dairy farms, mainly via improvements in technologies.

The empirical analysis in the paper employs a farm-level accounting data on input use, outputs and subsidies containing 5970 and 5067 milk producing farms in 2004 and 2005 respectively. The estimation strategy follows a conventional two-stage approach. In the first stage we estimated performance and technological change indicators in Ukrainian dairy farming. The performance of dairy farms is measured by order-m output technical efficiency (see Cazals et al., 2002), while technological improvement is measured by the technical change component in the decomposition of order-m TFP growth index (see Wheelock and Wilson, 2003). Order-m estimator allows us to circumvent the drawbacks shared by conventional DEA/FDH estimators in high-dimensional problems, as well as it is more robust to extreme values, noise or outliers (Cazals et al., 2002). In the second stage we perform a spatial analysis of the determinants of performance and technological improvements using Bayesian heteroscedastic spatial autoregressive model - SAR (LeSage, 1997).

In the first stage we differentiate between two technologies (dairy and beefdairy technologies) that are identified according to agro-climatic zones. The distributions of estimated efficiency scores demonstrate a noticeable improve- 
ment in performance of dairy farms between 2004 and $2005.64 \%$ and slightly less than $50 \%$ of dairy farms in the dairy and beef-dairy zones, respectively experienced an improvement in TFP. Technical change was the main source of TFP change in 2004-2005 periods.

The analysis of local patterns of spatial autocorrelation using LISA test (Anselin, 1995) revealed a substantial spatial dependence in the technical change and efficiency scores. In particular, we identified high efficiency clusters in each zone, and these clusters tend to persist over time. On the technical change side, each zone has clusters of high and low performers. The dairy zone is characterized mainly by low technical change clusters, while the beef-dairy zone is characterized mainly by high technical change clusters. The analysis of the determinants across zones confirms that farms benefit from proximity in terms of the technical change and efficiency. The magnitude of spatial interaction is not substantial though. The value of the spatial lag coefficient in SAR models ranges from 0.023 to 0.14 . Better sector-specific infrastructure and services also show a sign of benefiting dairy farms in both zones. The location near to dairy plants that have been investing, channels a positive impact on dairy farms mainly via technical progress.

The impact of other variables is consistent across the performance models, while somewhat controversial in the technical change models. As expected, arable land, herd size, and specialization have positive (non-linear) impact on farms' efficiency in both regions at the sample mean. There seems to be a consistent pattern regarding the impact of a farm's distance from the regional centers. Dairy farms benefit more the closer they are located to the market centers (regional centers in our application). Price support is positively associated with dairy farms' efficiency at the mean herd size. However, the effect diminishes with increasing herd size and even turns into negative for relatively large farms. For instance, the combined effect of subsidies turns to negative for herd size greater than 1,000 (550-800) cows in the performance models for the dairy (beef-dairy) zone. As for the determinants of the technical change (in addition to the agglomeration economies), they demonstrate mainly the opposite impacts across zones. For instance, in the dairy zone the price support is negatively associated with technical change at the mean herd size, while the association is positive in the beef-dairy zone. The same concerns the arable land, herd size, and specialization. Better market access proved to be important driver of efficiency in both zones.

\section{Discussion}

From the policy making point of view the results summarised above bode well for policy priorities suggested in the recent World Bank/IBRD (2009) report (Ch.8). A significant but still relatively low level of benefits arising from spatial interactions suggests for 'spatially blind institutions'. Fluid farm land market might be one of the instruments in this category. The lack of a fully-fledged farm land market in Ukraine (Demyanenko, 2009) prevents the farm land from freely 'moving' from less efficient to the more efficient farmer. Moreover, it contributed to the underdevelopment of agricultural credit markets in Ukraine (von Cramon-Taubadel et al, 2008a). In terms of the results of the study outlined above, the lack of fluid farm land markets prevents dairy sector from having more and spatially wider clusters of high efficiency and technologicaly 
advanced farms. Education programs also fall into the category of spatially blind institutions. As it is mentioned in von Cramon-Taubadel et al (2008a, pp. 27,28), 'Underlying and accentuating all of the barriers to agricultural competitiveness in Ukraine is a shortage of human capital. ... The root of this shortage of human capital is an outdated and closed agri-food education and research establishments'. In the analysis of local patterns of spatial autocorrelation in technical change (see section 5.4 in chapter 5 ), we identified a cloud of high performers in the region of Vinnytsia oblast (Central Ukraine). Although it requires a further detailed analysis, but this might be attributed to the 'Vinnytsya Dairy Supply Chain Development Project' that (among other things) provided extension services to farms. The project was implemented by IFC in $2005-2008^{5}$ and aimed at improving farm management, access to credits, and increasing production of high quality milk for commercial and household farms. In general, there is overwhelming evidence that investments in research and development and in education generate $40 \%$ returns on average (World Bank, 2008).

A positive association between sector-specific infrastructure and efficiency of dairy farms identified in the paper calls for 'spatially connective infrastructure'. Development of interregional transport infrastructure, market information and communication systems fall in this category. As it is discussed in von CramonTaubadel et al (2008a), expensive infrastructure between the farm gate and export positions is an important component of the difference between Ukraine and Germany in terms of the farm-gate prices measured as a percentage of FOB price. So developing the transport infrastructure would 'move' dairy farms closer to demand and supply markets. For dairy farms it might mean, for instance, increasing the procurement radius of dairy plants. Now, partly due to the bad roads, the average procurement radius is about $50 \mathrm{~km}$ (Popova, 2007: p.129). Information and communication services also fall into this category, and lack of reliable information statistics and systems is considered as one of the major problems in Ukrainian agriculture (IER, 2007). Information asymmetries often put farmers at a disadvantage vis-a-vis traders, processors. Information asymmetries, despite limiting producers' marketing options, lowering farm-gate prices, can also lead to problems of adverse selection, reducing incentives to invest in new technologies etc (von Cramon-Taubadel et al, 2008a). The results of improving information services in Ukraine could be multiplicative due to a knowledge spillovers effects that is part of the spatial autocorrelation we identified in the paper.

Since the determinants in the technical change models demonstrate mainly the opposite impact across zones, one might call for 'spatially targeted incentives', wherein dairy farms in dairy and beef-dairy zones are provided with different incentives for technical progress. Price supports effects suggest for more targeted support policies instead of uniform subsidization. The evidence on specific area incentives, however, have produced mixed results in the empirical literature (World Bank/IBRD, 2009). So it would be helpful if any 'small area' incentive program design and implementation was to precede with a careful study why, for example, technology change incentives in the area of interest are being bypassed by the market.

In the paper we perform analysis using a large dataset but only for two years.

${ }^{5} \mathrm{http}: / /$ ww .ifc.org/ifcext/eca.nsf/Content/Ukraine_AdvisoryProjects_Completed 
Therefore the implications of the study are informative but should be cautiously interpreted. Especially it concerns the determinants of technological improvements patterns in dairy farming sector. The process of technology adoption/diffusion usually takes longer (Sunding and Zilberman, 2001; p.228)), thus requiring a longer panel of the data to be more secure about the implications.

A possible follow-up work, given the availability of a sufficiently long panel, could be investigation of the performance patterns in Ukrainian agriculture as the country transformed from planned to market economy. In the former Soviet Union, the central planners decided where firms should locate. Often without a due economic rational they tried to spread economic activity throughout the country's territory (World Bank/IBRD, 2009; Ch.8). As Fay et al. (2008) have demonstrated, due to changes in spatial location patterns and improved market access of firms in Russia, the annual productivity growth was $2.5 \%$ between 1989 and 2004. We can also expect similar result in Ukrainian agriculture context.

\subsection{Belarus: Agricultural Productivity and Competitiveness. Impact of State Support and Market Intervention ${ }^{6}$}

\section{Overview}

In this section we overview and discuss a study on the patterns and possible determinants of agricultural sector performance in Belarus. It was prepared in the context of a World Bank research project "Belarus: Agricultural Productivity and Competitiveness. Impact of State Support and Market Intervention" (see von Cramon-Taubadel et. al., 2009; chapter C).

In the study we look at the performance of Belarusian agriculture from two sides. On the one side we analyse the competitiveness of major individual agricultural products. On the other side we analyse the efficiency and productivity patterns in the sector. In empirical analysis we use Belarus-wide farm-level accounting data provided by the State Statistics Committee of Belarus. The data is an unbalanced panel of 9232 observations over the period 2003-2007.

Agricultural competitiveness of individual agricultural products in Belarus is measured using Social Cost Benefit (SCB) ratio concept. The SCB criterion compares the total input costs at social prices to the social value of output. The SCB ratios less or equal one, indicate competitive production: the social opportunity cost of resources used in production is smaller that the corresponding social gain (revenue). The opposite is true for the SCB greater than one. The choice of SCB is justified by the focus of the study, where we deal with a farm-level individual product data. Moreover, SCB can be derived from the Recardian comparative advantage framework, and it uses equilibrium or shadow prices. This allows SCB to qualify for a true measure of comparative advantage (Siggel, 2006). SCB is also superior to Domestic Resource Cost (DRC) indicator, which is another widely applied indicator of comparative advantages (see discussion in section 2.1 above). In contrast to DRC, the activity with

\footnotetext{
${ }^{6}$ with Stephan von Cramon Taubadel, Matthias Grueninger, and Dmytro Prokhodko. The paper is published as a World Bank Policy Note No. 48335-BY, 2009.
} 
minimum SCB scores maximizes the social profits, so it is 'unbiased' indicator of competitiveness.

Agricultural competitiveness in Belarus shows large differences between crops, years, and farms. Wheat was Belarus' most competitive crop in 2007, capturing this position from barley and potatoes which saw a decline in competitiveness between 2003 and 2007. In 2007, about $65 \%$ of the wheat production, $48 \%$ of the potato production and $45 \%$ of the milk production was internationally competitive. Sugar beet production is not competitive. In general, livestock production is less competitive than crop production from both the economic and financial perspectives. With nearly half of its dairy products being exported, primarily to Russia, much of Belarus' state support provided to dairy production effectively becomes an export subsidy and (to some extent) a subsidy paid by Belarusian taxpayers to the importing country. The large difference between (economic) competitiveness and (financial) profitability indicates that the net effect of market and price distortions in Belarus is in support of the sector, taxing the rest of the economy. The results of analysis also demonstrate that there is no evidence of 'across the board' improvements in competitiveness in Belarusian agriculture between 2003 and 2007.

Productivity analysis of agriculture in Belarus uses conventional partial (e.g. yields, labour and capital productivity) productivity measures as well as more comprehensive Total Factor Productivity (TFP) growth indicators. The TFP growth is measured by the order-m Malmquist Output Productivity Index (see Wheelock and Wilson, 2003) between 2003 and 2007. It is estimated based on the order-m expected maximum output frontier proposed by Cazals et al (2002). The main idea of this method is to estimate a frontier which does not envelop all the data points, so it is partial or so-called robust frontier. The order-m estimator has a number of desirable properties compared with conventional nonparametric frontier estimators (e.g. DEA/FDH estimators). Order-m estimator is more robust to extreme values, noise or outliers and it does not suffer from the curse of dimensionality problem shared by DEA and FDH estimators (Cazals et al., 2002). As we have a relatively high dimensional problem ( 2 outputs and 12 inputs model), these problems are potentially acute in our application. We decompose TFP index into three components. Pure Efficiency Change component captures the change in the 'pure' technical efficiency between times 2003 and 2007. Scale Efficiency Change demonstrates whether production unit approaches or moves away from its optimal production scale, i.e. from the Constant Returns to Scale technology (CRS). Technical Change component measures the change of production technology. For these three components values greater than 1 indicate positive change, and negative otherwise (see Wheelock and Wilson, 2003 for details of estimation).

The analysis of productivity revealed that agricultural yields and aggregate output have experienced considerable growth in Belarus between 2003 and 2007, but this result was achieved at high cost to taxpayers and the economy overall. Despite a massive allocation of capital to agriculture, labor productivity and capital productivity in the agriculture sector increased less than in the rest of the economy. The majority of the large commercial farms in Belarus have experienced an increase in technical (pure) efficiency, albeit with considerable variation, and three quarters of all large commercial farms experienced positive technical change. But many farms are not evolving in the direction of more efficient size. Together, these effects resulted in total factor productivity im- 
provements for two thirds of all large commercial farms, with a $3.3 \%$ annual increase for the median farm. While this is an impressive result, reflecting significant (state) investments in the sector, it masks the fact that many farms cannot keep up with the pace of technical change and that about one third of all farms experienced a net reduction in TFP. Factors other than capital investments seem to be key constraints to Belarus' agricultural development. The estimated components of the TFP growth index are then regressed on a set of possible explanatory variables. The key focus here is on the effect of a massive state support to agriculture. Direct state support provided to large commercial farms appears to have a significant and positive, albeit small, effect on total factor productivity change on these farms; and the less efficient a farm, the less pure efficiency change and total factor productivity change it experiences, resulting in an increasing efficiency disparity. By inference this could also mean (but requires further analysis) that state subsidies are directed towards the more efficient farms, at least to some extent. If the observed performance dichotomy evolves further, possibly even fueled by the state's subsidy allocation mechanism, the sector will reach a point where many highly inefficient farms that can only survive with state support co-exist with comparatively efficient farms. At that point, adjustments to the structure of the state support system will become desirable even if the option of broader reforms is not considered. However, the low coefficients of determination of the regressions indicate that the few significant effects identified here explain only a very small portion of the variation in changes in TFP and its components.

\section{Discussion}

The bottom line of the study results is that despite a significant TFP growth, there is no evidence of 'across the board' improvements in competitiveness in Belarusian agriculture between 2003 and 2007. This conclusion, generally speaking, is in contrast with an existing in the literature conventional perception on economic performance. 'Productivity and efficiency growth enhances competitiveness' is what we know from the trade and growth theory models. Krugman (1994), for instance, argues that '... for an economy with very little international trade, 'competitiveness' would turn out to be a funny way of saying 'productivity'. What could explain such a 'puzzle'?

First, we must mention that the analysis of competitiveness and productivity growth is performed on different aggregation levels, albeit at the farm level. Competitiveness analysis is performed for each individual agricultural product, while productivity analysis is performed for each individual farm. To be more sure about the puzzle it is necessary to do competitiveness and efficiency analysis for either each individual product or for each individual farm. The later approach looks preferable because of at least two reasons. First, when measuring competitiveness of individual products, for example, a researcher is very often confronted with a problem of product-specific inputs allocation since some of the inputs (e.g. fixed assets) are not product-specific. This inevitably leads to assumptions regarding the allocation mechanism that might in some circumstances overstate or understate the competitiveness of individual products.

Second, farms usually produce multiple outputs. So the incentives for the efficient production of a certain output might vary on a farm. Some outputs might 
be kept in farming only due to technological requirements, e.g. in the crop rotation schemes, etc. Even when a farmer produces the products in technically efficient way, this does not automatically imply a competitive production of these products. As we derived in the paper presented in chapter 8, technical efficiency contributes to competitiveness, however, there are other components in the static SCB decomposition (see expression 8.10 in chapter 8) that prevent competitiveness and efficiency from following a one-to-one relationship. On the whole farm level, however, a profit maximizing manager should be able to choose an output and input bundles that maximize the (social) profit of the whole farm making a farm overall competitive.

Coming back to the question about the puzzle, a one way of explaining it would be to estimate a regression with competitiveness regressed on a set of possible explanatory variables, including TFP. This approach would provide an empirical evidence on the relationship between competitiveness and productivity. For instance in the chapter 4 in the Ukrainian context, we found that increase in yields by $1 \mathrm{t} / \mathrm{cow}$ increases competitiveness (measured by SCB) of milk production by 0.25 standard deviations. This approach, however, is 'ad-hoc', in a sense it lacks a clearly formulated model or formal relationship. After searching in the literature for a formal relationship we have not found much in this regard. Early attempts to link competitiveness, productivity and efficiency in a formal way date back to Page (1980) and Nishimizu and Page (1986). In a single-output setup they proposed a DRC decomposition showing that improvements in productivity contribute to competitiveness growth. Still, there are important open questions. As it is already mentioned above, Masters and Winter-Nelson (1995) and Siggel (2006) show analytically that the SCB criterion is superior to DRC. The interesting question in this regard is whether the relationship between DRC and TFP growth derived by Nishimizu and Page (1986) holds for the SCB and how it looks like in a multi-output setting. In the chapter 8 (see section 2.6 for an overview) we formally derive these relationships using a distance functions approach.

\subsection{Measuring and Comparing the Competitiveness of Heterogeneous Production Systems in Agriculture: a Note ${ }^{7}$}

\section{Overwiew}

In this paper we develop further some of the ideas discussed in the section 2.1. In particular we focus on the advantages of disaggregated competitiveness analysis. We employ Domestic Resource Cost (DRC) and Social Cost-Benefit (SCB) ratios as competitiveness indicators. DRC compares the cost of domestic resources measured at social prices to value added measured in social prices, while SCB compares total costs at social prices to the social value of output. $0<\mathrm{DRC}<1(0<\mathrm{SCB}<1)$ indicates comparative advantage, i.e. the social opportunity cost of domestic (all) resources used is smaller that the corresponding social value added (revenue). The opposite is true for the DRC

\footnotetext{
${ }^{7}$ with Stephan von Cramon-Taubadel. The paper was published in the Outlook on Agriculture journal, Vol 38, No 1, 2009, pp 31-37. Earlier version of this paper was presented as a Contributed paper at the IAMO Forum - 2008, June 2008, Halle (Saale), Germany.
} 
$>1(\mathrm{SCB}>1)$. If the $\mathrm{DRC}$ is smaller than 0 , then revenue does not even suffice to cover tradable input costs, let alone domestic inputs. Thus production of the good in question is clearly not competitive. The justification of using DRC as a competitiveness measure as well as how it compares with SCB measure is briefly summarized in the section 2.1 .

One of the well-known disadvantages of these indicators is that they are usually calculated using data for average or 'typical/representative' farms. As Monke and Pearson (1989) have shown, several representative systems may exist simultaneously for a given population of farms, depending on the policy or research question at hand. Therefore, competitiveness scores and rankings will be conditioned on which of these systems is selected and inter/intra-country comparison of production systems will produce ambiguous conclusions about comparative advantage as a result. Furthermore, if the farms that are summarised in this manner are highly heterogeneous, inferences based on aggregated measures of competitiveness can be very misleading. Further statistical inference about the determinants of competitiveness is hardly possible in this setting.

We generate DRC and SCB distributions using Ukraine-wide accounting data on the population of crop farms in 2005. This dataset contains 7631 wheat and 4319 sunflower seed producing farms. For each observation in the dataset (representing a farm) we get/generate information on disaggregated input use and output of each individual farm product. Conversion from private to social prices and costs was based on a variety of assumptions and sources of data (see von Cramon-Taubadel et al, 2008a or chapter 3 for details).

DRC and SCB distributions make it possible to determine for each product a) what proportion of the farms producing it is competitive, and b) what proportion of the total production/output value of this product occurs on competitive farms. For example, while DRC score based on average revenue and cost data for wheat equal 1.37, suggesting that wheat production is uncompetitive, DRC distributions based on disaggregated data indicate that $44 \%$ of the farms in fact produced wheat competitively in 2005 .

Since in most of the cases researchers deal with sample data, it is desirable to know the precision of the estimates of these proportions. One natural way of dealing with this is to construct confidence intervals around the sample estimates. The nonparametric standard percentile-based and bias-corrected and accelerated (BCa) bootstrap confidence intervals are of particular interest in this case since they do not require any assumptions about the distribution of the shares and they preserve the range of estimates (Efron and Tibshirani, 1993). In our case a range preserving property is very important since proportions can take the values only between 0 and 1 . Based on the stratified randomly drawn samples of wheat farms, we compared resulting confidence intervals. BCa and standard percentile-based confidence intervals contain the true value, but they differ for smaller samples and almost coincide for larger samples.

Often, policy makers and applied researches are interested in the competitiveness ranking of sectors' or/and groups of producers. In the paper we suggest two approaches for generating such rankings based on micro-data. The first is a distribution-based method that directly derives from the competitiveness distribution and uses proportions as a ranking criterion, e.g. proportion of total competitive production/output value/farms etc. The other method is aggregates-based. Using a corollary to Koopman's (1957) theorem on profit functions and the net social profit as an ideal measure for comparing mutually 
exclusive alternatives, we show two ways of deriving the aggregate DRC or SCB scores. One way is to consider the sector as one big farm and calculate its DRC and SCB as we would for an individual farm. Revenues and costs of this 'big farm' equal the sums of revenues and costs of the individual farms in the sector, respectively. The other way of generating aggregated DRC and SCB measures is to aggregate individual DRC and SCB scores. We demonstrate that aggregate DRC is simply a weighted average of the individual farms' DRCs, with each farm's weight equal to its share in total value added. For the aggregated SCB the weights are simply shares in total output value. The confidence intervals for the aggregate competitiveness measures can be constructed using the nonparametric bootstrap method mentioned above. The only complication is that the nonparametric method does not work for the DRC aggregate because of its discontinuity at 0 .

Applying the developed aggregation techniques, we showed that one can rank the activities differently depending on the ranking criteria chosen. We first discarded the ranking based on the DRC criterion, since it is distorted by the discontinuity and biased with respect to ranking (Masters and Winter-Nelson, 1995). Next, generally speaking, we identified not much difference between the distribution-based and aggregates-based methods based on SCB indicator. Based on this we recommend using either one, (or, as a consistency check, both). However, the distribution-based ranking looks more flexible and, probably, more attractive. Depending on the objectives of the research, several proportion criteria could be developed to explore an issue from different perspectives.

\section{Discussion}

The ideas and tools developed in the paper mainly contribute to the policy analysis toolkit. It is important that policy makers make informative decisions based on theoretically and statistically sound analysis. In the paper we suggest focusing more on analysing the distributions of competitiveness measurements, since, generally speaking, they contain much more information than an average value.

The ideas advanced in the paper could be easily adapted to other measures of interest calculated from the Policy Analysis Matrix. For instance, the subsidy ratio to producers (SRP) compares a difference between private and social profits to the social revenue. The SRP shows the proportion of revenues in world prices that would be required if a single subsidy or tax were substituted for the entire set of commodity and macroeconomic policies (Monke and Pearson, 1989; p. 28). This incentive indicator employs essentially the same components of the Policy Analysis Matrix (see Table 3.1) as do DRC or SCB indicators. So one should be able to generate SRP distributions based on the same set of data to show how the overall policy effect is distributed in the sector, e.g. what proportion of the farms is subsidizes or taxed due to the cumulative effect of all policies in the sector.

In the paper we demonstrated how one can make statistical inferences on the aggregated competitiveness indicators. One may also think about the accuracy of the individual competitiveness indicators. Researchers have usually been performing sensitivity analysis to see the variability of competitiveness scores subject to changes mainly in conversion factors (from private to social prices), 
which is essentially the change or variability in social prices. This procedure gives only rough ideas about the accuracy of competitiveness indicators, since it does not allow to quantify the precision in conventional statistical terms. The other problem is that sensitivity analysis shows the picture only partially, since variability in competitiveness scores is conditioned on changes in one of the many components only (e.g. in electricity shadow prices) holding all other components fixed. To quantify the variability of competitiveness indicator in statistical terms, we have to think first about the sources of indicators' variability. The above short discussion on sensitivity analysis suggests prices for this role, since inputs and output quantities might be assumed to be under farmers' control. We can assume that prices in our system are generated by random processes, i.e. by a collection of random variables. The associated random variables assumed to have generated the input and output prices' observations over the farms. In this setting it is possible to draw the inferences for the overall farm competitiveness (see discussion in the previous section), for example. In the case of SCB indicator, we have a linear combinations of input and output prices in the nominator and denominator, respectively. Using the Central Limit Theorem we can assume the nominator and denominator to be normally distributed. Based on this one can apply the Fieller's method to get the confidence intervals of individual overall competitiveness score (see e.g. Heitjan, 2000 for more detail discussion of the method).

\subsection{Efficiency, Productivity Growth and Competitiveness: a Note $^{8}$}

\section{Overview}

It is often maintained in the literature that productivity growth enhances competitiveness (e.g. Link and Siegel, 2003, p.1), but is there a mathematically formulated relationship between these concepts? The literature on the economic performance has tended to be divided along two lines of analysis. The first strand focuses on the analysis of comparative advantage and/or competitiveness. Among numerous concepts and measures of comparative advantages/competitiveness, the Domestic Resource Cost (DRC) criterion is probably one of the most well-known and widely applied concept (e.g. von CramonTaubadel et al, 2008a and 2009). DRC compares the cost of domestic resources measured at social prices to value added measured in social prices. It can be derived from the Recardian comparative advantage framework, as well as the use of social (or equilibrium) prices throughout ensures that DRC qualifies for the true comparative advantage (Siggel, 2006).

The second strand of literature focuses on efficiency and productivity analysis, where technical efficiency and Total Factor Productivity (TFP) concepts have been of the main interest. Krugman (1994), for instance, argues that '... for an economy with very little international trade, 'competitiveness' would turn out to be a funny way of saying 'productivity'. The TFP measures the relationship between a farm's aggregate input use and its aggregate output, while efficiency measures the extent to which a maximum possible outputs (mini-

\footnotetext{
${ }^{8}$ The paper has been accepted for an oral presentation at the 54th Australian Agricultural and Resource Economics Society Annual Conference, February 2010, Adelaide, Australia
} 
mum possible inputs) have been achieved with a given level of resources (of output). The theoretical background of these concepts is well established in the literature (e.g. Färe and Primont, 1995).

Attempts to relate technical efficiency, productivity and competitiveness go back to Page (1980) and Nishimizu and Page (1986) who proposed a DRC criterion decomposition for the single output case that formally relates improvements in productivity to improvements in a DMU's comparative advantage. Nevertheless, important open questions remain to be addressed. Masters and Winter-Nelson (1995) and Siggel (2006) have shown that DRC understates the competitiveness of activities with intensive usage of domestic factors. The Social Cost Benefit Ratio (SCB), proposed by Masters and Winter-Nelson (1995), does not contatin this flaw. This (unbiased) measure compares total domestic costs at social prices to the social value of output.

In this paper we propose a static and dynamic decompositions of the SCB measure for the general multi-input and multi-output case. In the static case we decompose the SCB measure into two components that could be termed as micro-, and macro-level sources of competitivenes. The first component, a product of technical efficiency and (profit) allocative efficiency, belongs to the micro-level sources, since efficiency is pertinent to the firm behaviour. In other words, it is in frms' discretion how efficiently they utilize a given technology as well as whether they choose their input-output mix to maximize the profits. The second component, a product of (negative) maximum profit and inverse revenue, is a mixture of macro- and micro sources. Profit frontier is considered as macro-source, since by consruction it is conditioned on prices and technology, which are given to firms in competitive setting.

In the dynamic case the competitiveness growth, measured by SCB, is decomposed using a distance function framework used in Brümmer et al (2002). The first component of the decomposition, factor costs effect, accounts for the change in input prices. The second component, term of trade effect, accounts for the chance in output prices. The third component captures the scale effect. The fourth component, technical change, accounts for a change in technologies. The fifth component accounts for technical efficiency changes. The two last components, allocative affects, inform whether firms choose their inputs and output bundles according to the price signals (i.e. maximize profits). The third through the last components make up TFP growth.

\section{Discussion}

In the paper we have derived the formal relationship between the levels of competitiveness and efficiency, where efficiency contributes to competitiveness. In the dynamic case we derived a decomposition of SCB change in the multioutput and multi-input case using the distance function framework. In particular we demonstrated that TFP growth enhances the competitiveness, thus confirming the conventional perception that exists in the literature.

With this (dynamic) decomposition now it is interesting to come back to the TFP-competitiveness 'puzzle' that is mentioned in section 2.4. Recall that one of the conclusions of the study is that despite a significant TFP growth, there is no evidence of 'across the board' improvements in competitiveness in Belasusian agriculture between 2003 and 2007. Two components in the dynamic decomposition of SCB might be responsible for that. It could happen either 
due to the increase in the factor shadow costs, or due to the decrease of the output shadow prices, or both. At this stage it is early to make conclusions on that since it requires a detailed analysis, which might be an interesting application and extension of the paper.

\section{$2.7 \quad$ References}

Anselin, L. (1988). Spatial Econometrics: Methods and Models. Kluwer Academic Publishers, Dordrecht, The Netherlands.

Anselin, L. (1995). Local indicators of spatial association - LISA, Geographical Analysis, 27(2):93-115.

Balance, R., H. Forstner and T. Murray (1987). Consistency Tests of Alternative Measures of Comparative Advantage. Review of Economics and Statistics, Vol. 69: 157-161.

Brümmer, B., T. Glauben, and G. ThiJssen (2002). Decomposition of Productivity Growth Using Distance Functions: The Case of Dairy Farms in Three European Countries. American Journal of Agricultural Economics, 84(3): 628-644.

Cazals C., Florens J.P., Simar L. (2002) Nonparametric frontier estimation: a robust approach. Journal of Econometrics, 106: 1-25

Demyanenko, S. (2009). Agricultural Land Market in Ukraine: Allow or Forbid? . In Strubenhoff H., Burakovskyy I., Movchan V. (eds) (2009) Agriculture, Bioenergy and Food Policy in Ukraine - Analyses, Conclusions and Recommendations. ADEF-Ukraine. Kyiv

Färe, R. AND D. Primont (1995). Multi-Output Production and Duality: Theory and Applicaions. Boston: Kluwer Academic Publishers.

Institute for Economic Research And Policy Consulting (IER). Ukrainian agriculture needs reliable information systems. MEMU Supplement No. 8-2007 http://ierpc.org/ierpc/memu/memu_s_35_aug_07_en.pdf

Leibenstein, H. (1966). Allocative efficiency vs X-efficiency, American Economic Review, 56, pp. 392-415.

Liesner, H.H. (1958). The European Common Market and British Industry. Economic Journal, Vol. 68: 302-16.

Link, A.N., And D.S. Siegel (2003). Technological Change and Economic Performance. New-York: Taylor \& Francis Group.

Masters, W.A., And A. Winter-Nelson (1995). Measuring the Comparative Advantage of Agricultural Activities: Domestic Resource Costs and the Social Cost-Benefit Ratio. American Journal of Agricultural Economics, Vol. 77: $243-50$

Monke, E. A. and S. R. Pearson (1989). The Policy Analysis Matrix for Agricultural Development, Ithaca NY: Cornell University Press.

Kalaitzandonakes, N.G. And M.E. Bredahl (1994). Market Liberalization and Productiv-ity Growth: An Empirical Analysis. In: I. SHELdon, AND P. Авотт (eds): Empirical Studies of Industrial Organization and Trade in the Food and Related Industries. Westview Press.

Koopman, T. (1957). Three Essays on the State of Economic Science, McGrawHill, New York.

LeSAgE, JAmes P. (1997). Bayesian Estimation of Spatial Autoregressive Models, International Regional Science Review, Vol. 20, pp. 113-129. 
SigGel, E. (2006). International Competitiveness and Comparative Advantage: A Survey and a Proposal for Measuremen. Journal of Industry Competition and Trade. Vol 6(2), pp. 137-159

von Cramon Taubadel, S., Nivyevskiy, O., and M. Gruenninger (2008a). Ukraine: Agricultural Competitiveness. World Bank Policy Note No. 44843-UA.

von Cramon Taubadel, S., Nivyevskiy, O., E. von der Malsburg, and V. Movchan (2008b). Distortions to Agricultural Incentives in Ukraine. in Anderson, K. And J. Swinnen (eds.) (2008), Distortions to Agricultural Incentives in Europe's Transition Economics, Washington DC: World

von Cramon Taubadel, S., M. Gruenninger, O. Nivievskyi, and D. Prikhodko (2009). Belarus: Agricultural Productivity and Competitiveness. Impact of State Support and Market Intervention. World Bank Policy Note No 48335-BY

Nivievskyi, O., and S. von Cramon-Taubadel (2009). Measuring and Comparing the Competitiveness of Heterogeneous Production Systems in Agriculture: a Note. Outlook on Agriculture, Vol 38, No 1, pp. 31-37.

Efron, B. and Tibshirani, R. J. (1993), An Introduction to the Bootstrap methods, New York: Chapman \& Hall

Eberts, R.W., and D.P.McMillen (1999) Agglomeration Economies and Urban Public Infrastructure. In Cheshire., P. AND Mills, E.S. eds.: Handbook of Regional and Urban Economics, Vol 3 Applied Economics, Chap. 38. New York: North-Holland, 1999.

Koopman, T. (1957). Three Essays on the State of Economic Science, McGrawHill, New York.

Liefert, W. (2002), 'Comparative (Dis?) Advantage in Russian Agriculture, American Journal of Agricultural Economics, Vol 84(3): 762-767.

Nishimizu, M. And J.M. JR. Page (1986): Productivity change and dynamic comparative advantage. The Review of Economics and Statistics, Vol 68 (2), pp. 241-247

PAGE, J.M. JR. (1980): Technical efficiency and economic performance: some evidence from Ghana. Oxford Economic Papers, Vol 32(2), pp. 319-339

Heituan, D. F. (2000) Fieller's Method and Net Health Benefits. Health Economics. Vol 9: 327-335.

Popova, O. (2007). Mlechnyy Put (Milky Way). Biznes 11/12.03.07

Wheelock, D.C. AND P.W. Wilson (2003): Robust Nonparametric Estimation of Effi-ciency and Technical Change in U.S. Commercial Banking. Working paper, De-partment of Economics, University of Texas, Austin.

World Bank (2008): World Developing Report 2008: Agriculture for Development. The World Bank, Washington DC.

World Bank/IBRD (2009): World Developing Report 2009: Reshaping Economic Geography. The World Bank, Washington DC. 



\section{Chapter 3}

\section{Ukraine: Agricultural Competitiveness ${ }^{1}$}

\subsection{The current status of Ukrainian agricultural competitiveness}

\section{Indicators of agricultural competitiveness}

Numerous indicators of competitiveness have been developed and applied by economists. One approach, going back to seminar work by Liesner (1958) and Balassa (1965) is based on the idea that competitiveness will be 'revealed' by a country's actual trade performance compared with other countries, regions or the world. A variety of 'Revealed Comparative Advantage' (RCA) indices have been developed based on this idea. RCA indices are usually justified on the grounds that most policy-induced distortions are on the import side, and that export performance will therefore provide a genuine reflection of competitiveness. However, as is demonstrated below, this is not the case in Ukraine, where there are significant distortions on the export side as well. Furthermore, Banance et. al. (1987) demonstrate that there is a high degree of inconsistency among alternative RCA indices, and that inferences are correspondingly sensitive to the particular index chosen. These concerns, coupled with the facts that Ukrainian trade statistics are often of dubious quality and that trade has been very volatile for many key agricultural products, make us wary of the RCA method in the context of Ukrainian agriculture.

A second approach to measuring competitiveness is causal and attempts to measure factors that influence competitiveness, such as the institutional environment, infrastructure, macroeconomic stability and cost structures. At an aggregated level, this has led to indices such as the 'Growth Competitiveness Indicator' (GCI) developed by Sachs and McArthur, and the 'Business Competitiveness Indicator' (BCI) developed by Porter, both of which can be found in the World Economic Forum's Global Competitiveness Report (e.g. WEF, 2006). These 'broad brush' measures are certainly interesting, but our focus here is on individual agricultural products.

For these reasons, we employ Domestic Resource Cost (DRC) analysis to cast light on the competitiveness of Ukrainian agriculture. The DRC is one of many

\footnotetext{
${ }^{1}$ Copyright c 2008 The World Bank. Reproduced by permission.
} 
Table 3.1: The Policy Analysis Matrix (PAM)

\begin{tabular}{|c|c|c|c|c|}
\hline & \multirow[t]{2}{*}{ Revenue } & \multicolumn{2}{|c|}{ Costs } & \multirow[t]{2}{*}{ Profits } \\
\hline & & Tradable inputs & Domestic factors & \\
\hline $\begin{array}{l}\text { Accounting in Private } \\
\text { (Financial) Prices }\end{array}$ & $\boldsymbol{A}=P_{t}^{P}$ & $B=\sum_{j=1}^{k} a_{j} P_{j}^{p}$ & $C=\sum_{j=k+1}^{n} a_{i j} V_{j}^{p}$ & $D=A-B-C$ \\
\hline $\begin{array}{l}\text { Accounting in Social } \\
\text { (Economic) Prices }\end{array}$ & $E=P_{i}^{s}$ & $\boldsymbol{F}=\sum_{j=1}^{k} a_{i j} P_{j}^{s}$ & $G=\sum_{j=k+1}^{n} a_{b} V_{j}^{s}$ & $H=E-F-G$ \\
\hline $\begin{array}{c}\text { Effects of Policy and } \\
\text { Market Failures }\end{array}$ & $I=A-E$ & $J=B-F$ & $K=C-G$ & $\begin{array}{l}L=D-H= \\
=I-J-K\end{array}$ \\
\hline
\end{tabular}

Source: Monke and Pearson (1989)

Notes: the subscript $i$ refers to outputs and the subscript $j$ to inputs;

$a_{i j}$ for $(j=1$ to $k$ ) are technical coefficients for traded inputs in the production of $i$;

$a_{i j}$ for $(j=k+1$ to $n)$ are technical coefficients for domestic inputs in the production of $i$;

$P_{i}^{*}$ is the price of output $i$, evaluated privately ("* $"=p$ ) or socially ("* $\left.=s\right)$;

$P_{j}^{*}$ is the price of traded input $j$, evaluated privately (" * " $=p$ ) or socially (" * " $\left.=s\right)$;

$V_{j}^{*}$ is the price of domestic input $j$, evaluated privately $(" *=p$ ) or socially $(" * "=s)$;

$I$ measures output transfers; $J$ measures input transfers;

$K$ measures factor transfers;

$D(=A-B-C)$ measures net private profits;

$H(=E-F-G)$ measures net social profits; and

$L$ measures net transfers.

indicators that can be calculated using the Policy Analysis Matrix (PAM) framework developed by Monke and Pearson (1989). The PAM is a product of two accounting identities, one defining profitability as the difference between revenues and costs, and the other measuring the effects of divergences (distorting policies and market failures) as the difference between observed private values and social values that would prevail if the divergences were removed. The structure of the PAM is presented in Table 3.1, and detailed definitions of the terms in it as well as information on the calculation of the DRCs presented below are provided in section 3.2 .

The DRC method compares the cost of domestic resources measured at social prices (in the numerator) to value added measured at social prices (in the denominator), calculated as the ratio of $\mathrm{G}$ to (E-F) in Table 3.1. The use of social prices throughout ensures that the DRC measures whether employing scarce domestic inputs in the production of a good i generates a positive return for the country as a whole. $0<\mathrm{DRC}<1$ indicates comparative advantage: the social cost of domestic resources used is smaller than the corresponding social gain (value added). The opposite is true for the $\mathrm{DRC}>1$. If the $\mathrm{DRC}$ is smaller than 0 , then the denominator (E-F) must be negative, in which case revenue does not even suffice to cover tradable input costs, let alone domestic inputs. In this case, production of the good in question is clearly not competitive.

A weakness of the DRC method as it is usually applied is that it is based on average or 'typical' data for a sector or industry. The conclusions that can be drawn on the basis of average or typical indicators become progressively weaker as the heterogeneity of the underlying population grows. Evidence from numerous studies that apply empirical efficiency analysis techniques (data envelopment analysis - DEA; stochastic frontier analysis - SFA) to farm level data in Ukraine and other FSU countries points to a very significant heterogeneity, 
with many farms operating at a great distance from the frontier defined by the best-practice farms. ${ }^{2}$ For example, the results of Lissitsa and Odening's (2005) DEA analysis indicate that the distribution of efficiency among large farms in Ukraine in 1999 was bimodal, with one peak in the 30-40\% efficiency range, a mean efficiency of $46 \%$, and a second, smaller peak of "star performers" operating at $90-100 \%$ efficiency relative to the best practice frontier. Comparing these 1999 results with results from earlier years, the authors also find that the efficiency distribution has grown more heterogeneous over time, and that the most (in)efficient farms have tended to remain most (in)efficient. This evidence corroborates the observations of farm management specialists who have practical experience with conditions in Ukrainian farming (e.g. Lischka, 2005). For this reason, and as outlined in section 3.2, farm-level data are used to calculate DRC distributions for major crop and livestock products in Ukraine. ${ }^{3}$ This procedure makes it possible to determine for each product what proportions of the farms in Ukraine are characterised by DRCs less than 0, DRCs between 0 and 1 , and DRCs greater than 1, and what proportions of Ukraine's total production of these products occurs on the farms in each category. The calculation of DRC distributions is a purely descriptive technique, but its use here is motivated by the hypothesis that Ukraine has the potential to be internationally competitive in most important temperate crop and livestock products if barriers to competitiveness are removed so that many more farms are able to operate at the levels of efficiency that currently only the very best attain. The data employed are Ukraine-wide farm-level accounting data from 2004 and 2005 provided by the State Statistics Committee of Ukraine. In Ukraine, all corporate farms are required to file standardised reports on their input use, production and sales each year. This is in contrast to most OECD countries, for example, where much more detailed data are collected from representative samples of farms. Data quality is an important issue in analyses of this nature. Farm managers may distort their reports if they believe that this might influence their tax burdens or eligibility for subsidies. There is no information available on such distortions in the data employed here. But clearly Ukraine would be well-advised to implement a modern collection system for farm accountancy data such as that employed in the EU, for example. This would provide policy makers with more detailed, accurate and timely data. Some conditions have changed in Ukrainian agriculture since 2005, but most of the factors that affect competitiveness have not. Hence, the main results presented below, and their interpretation, remain valid. Clearly, the competitiveness of grains and oilseeds production will have benefited from higher world market prices in recent months, although this effect has been mitigated by export restrictions that depress domestic prices for these products. Data for 2006 only recently became available, and ongoing work is studying changes in competitiveness at the farm level using spatial panel econometric techniques.

A limitation of the DRC analysis employed here is that it is based exclusively on the large corporate farms in Ukraine, and does not consider the individual

\footnotetext{
${ }^{2}$ See, for example, Galushko et al. (2004), Kurkalova and Jensen (2002) and Lissitsa and Odening (2005).

${ }^{3}$ A separate Policy Note on The Competitiveness of Bio-Energy in Ukraine is currently being prepared (an advanced draft is available as of July 2008). That Note illustrates in detail competitiveness aspects along the value chain from agricultural raw products to the biofuel end-products.
} 
Figure 3.1: The share of households in total production of agricultural products, $2004(\%)$

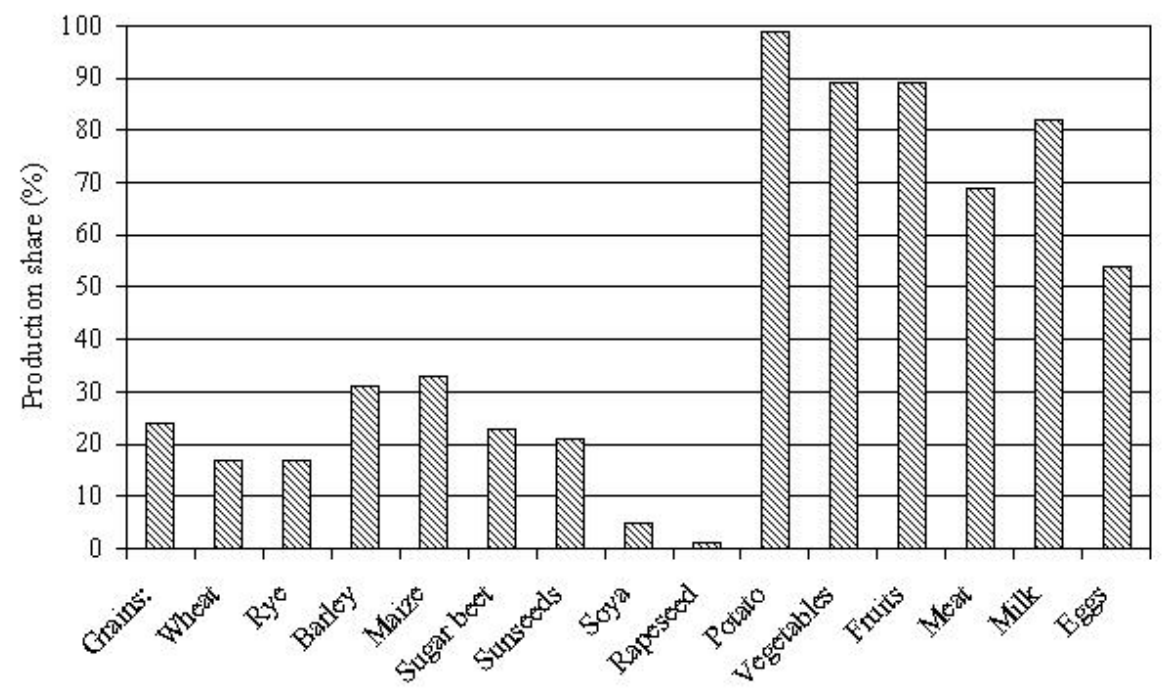

Source: Own calculations

farms (household plots or peasant farms). This is not an important omission for the major cereals and oilseeds, which are primarily produced on large corporate farms (Figure 3.1). However, household plots are responsible for a much larger share of the potato, fruit, vegetable and livestock production in Ukraine. Unfortunately, detailed data on methods and costs of production for household plots is not available. This may not be such a handicap for competitiveness analysis, however, as it is arguably the large corporate farms that will determine the international competitiveness of Ukrainian agriculture, while the household plots, which market only one-fifth of their output (Lerman et al., 2006) remain largely subsistence-oriented. ${ }^{4}$

\section{The current status of Ukrainian agricultural competitiveness}

Results of the DRC analysis for major crop products in 2005 and 2004 are presented in Figure 3.2 and Figure 3.3, and key results are summarised in table 3.2. Results for 2005 and 2004 are qualitatively similar, and the following discussion focuses on 2005. The distributions reveal that for wheat (44\%), sunseed $(41 \%)$ and barley (25\%), relatively large proportions of the farms in Ukraine produce competitively. For maize (13\%), rapeseed (10\%), soybean $(8 \%)$ and potato $(6 \%)$, the corresponding proportions are smaller. For all of these products, the competitive farms account for a disproportionately large share of the total production by corporate farms in Ukraine. This effect is especially extreme in the case of potato production. However, since corporate farms account for less

\footnotetext{
${ }^{4}$ This is not so say that household plots and peasant farms have no role to play in the future of Ukrainian agriculture; some will certainly take advantage of niches and the flexibility that goes along with being small to develop into successful enterprises.
} 
Figure 3.2: Domestic resource cost distributions for major crop products in Ukraine, 2005
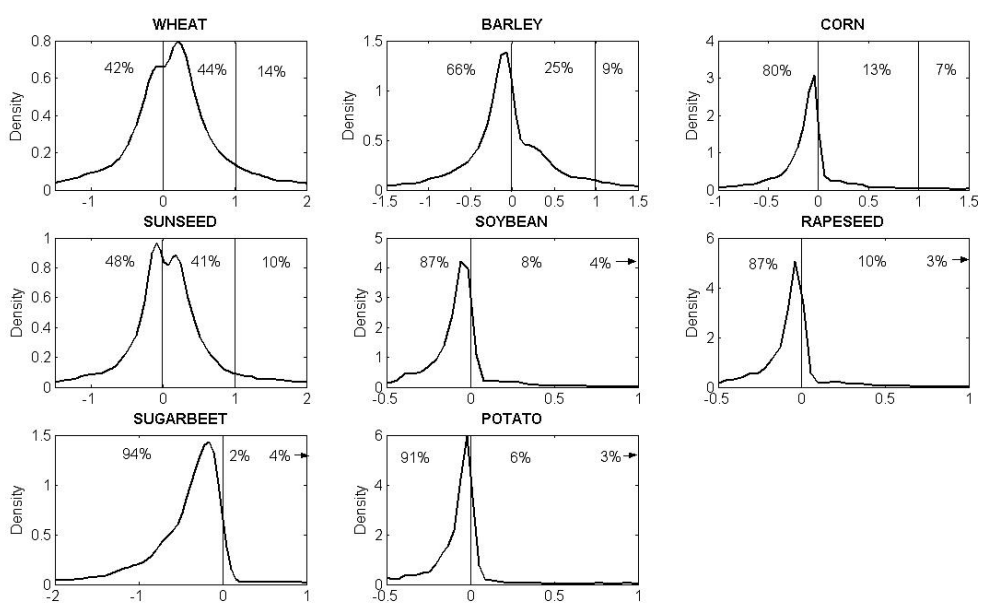

Source: Own calculations

Figure 3.3: Domestic resource cost distributions for major crop products in Ukraine, 2004
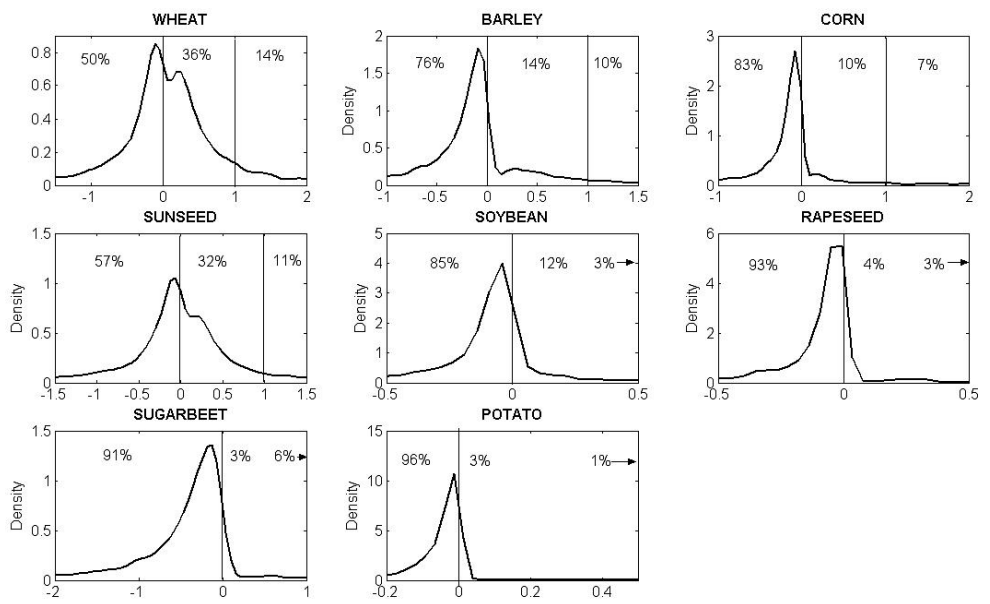

Source: Own calculations

than $5 \%$ of all potato production in Ukraine (Figure 3.1), this result - which suggests that a small number of large farms are heavily concentrated in potato production, perhaps for seed and special processing uses - is not representative.

Before proceeding with the discussion of these results, we briefly note the contrast between the distributions presented here and average DRCs that would result from the use of aggregated data. For wheat in 2005, for example, it can 
Table 3.2: Summary of DRC results for major crop products

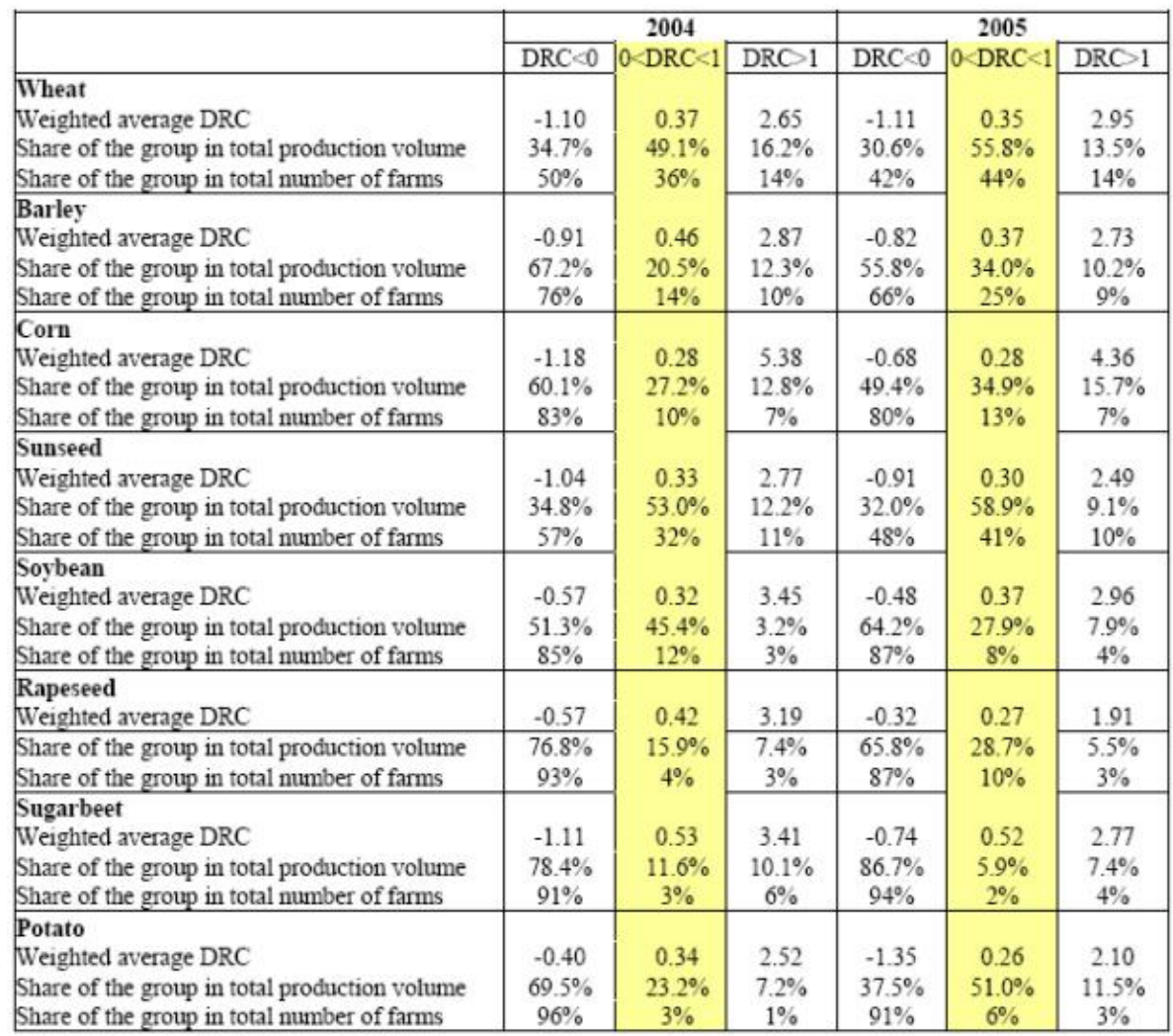

Source: Own calculations

be shown that the average ton of wheat was produced at a DRC of 1.37. This result, taken at face value, would suggest that there are problems with the competitiveness of wheat production in Ukraine, obscuring the fact that $44 \%$ of all wheat producing farms, and $56 \%$ of all the wheat produced in the country, are competitive. This highlights the main advantage of the disaggregated DRC distribution analysis presented here. 35 . For sugarbeet, only $2 \%$ of the farms in Ukraine are competitive, and these account for only $6 \%$ of all sugarbeet production. This confirms the results of earlier analyses (e.g. Strubenhoff and Nivyevskiy, 2006; von Cramon-Taubadel, 1999) that demonstrate that sugarbeet production is only competitive under very limited circumstances in Ukraine. 36. DRCs for major livestock products in 2004 and 2005 are presented in Figures 3.4and 3.5 and Table 3.3. Across the range of livestock products, the shares of competitive farms are similar to the shares for crop products. $40 \%$ of the farms that produce eggs have DRCs between 0 and 1 ; corresponding shares for beef, milk, pork and poultry are 22, 20, 8 and $4 \%$. These competitive farms again account for a disproportionately large share of the production of these products (eggs $93 \%$; milk $49 \%$; pork $35 \%$ and poultry $21 \%$ ). The only exception is milk, where the $22 \%$ of the farms that are competitive account for only $16 \%$ of the production by corporate farms in Ukraine. This might be evidence that among the corporate farms that produce milk in Ukraine, those that are 
Figure 3.4: Domestic resource cost (DRC) distributions for major livestock products in Ukraine, 2005
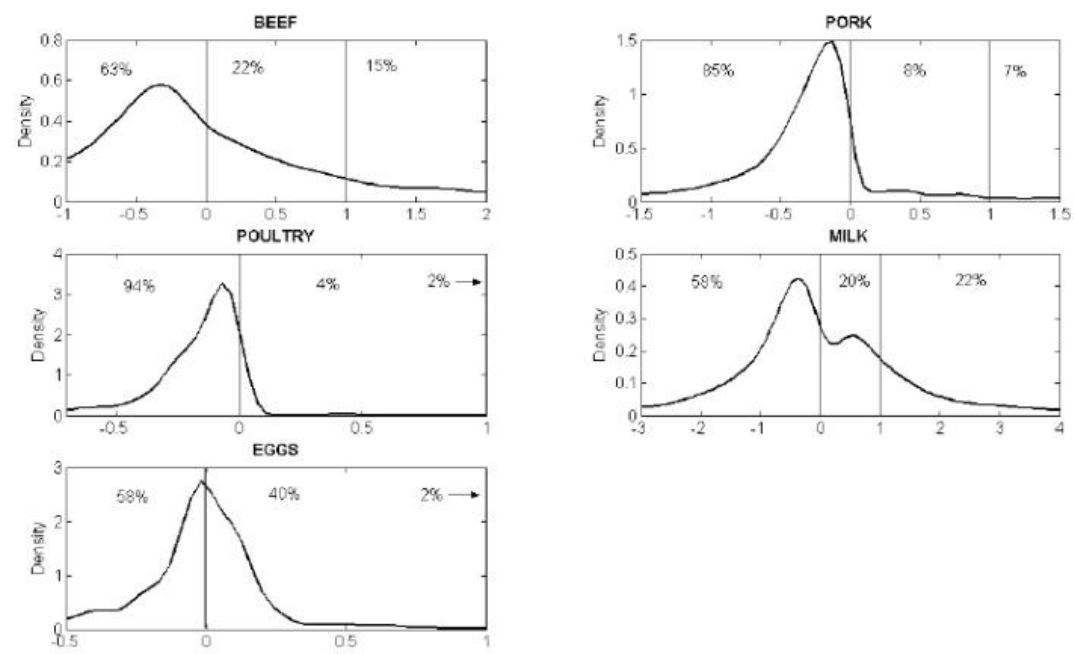

Source: Own calculations

relatively small tend to be more competitive than many larger ones.

In 2004 and 2005, and for all crops and livestock products except wheat in 2005, the modal DRC is less than 0. This indicates that for a large group of farms revenue does not even suffice to cover the costs of tradable inputs, let alone domestic inputs. These farms are subtracting and not adding social value by producing the products in question. Even if the resulting products are being exported, Ukraine is on balance losing foreign exchange in the process. More detailed analysis - for example using information on the location of individual farms in the dataset, their degrees of specialisation, factor intensities, locations etc. - is required to determine what factors influence whether a farm is competitive. ${ }^{5}$ The available evidence suggests, however, that efficient and inefficient farms often exist side-by-side even in the most agriculturally favoured regions of Ukraine. It is a well-known phenomenon in agriculture that unprofitable farms can continue to operate, at least for a while. Especially older owner-operators who see few alternatives outside farming will implicitly accept a low effective compensation for their labour and management inputs or a below-market rate of return on the capital tied up in own equity (buildings and land); the farm's capital stock will be allowed to run down (negative net investment); in extreme cases, plots of land may be sold to provide periodic liquidity injections. There are limits to this under market conditions, however, especially for larger corporate farms that depend on loans and must pay hired labour. In the case of the Ukraine, the fact that large numbers especially of value subtracting corporate farms continue to operate suggests that both positive incentives and market

\footnotetext{
${ }^{5}$ Nivyevskiy and von Cramon-Taubadel (2008) analyze factors that affect the competitiveness and efficiency of milk producing farms in Ukraine using spatial econometric techniques. The results indicated that spillovers between neighboring farms take place, and that proximity to milk processing plants that have invested has a positive impact on competitiveness.
} 
Figure 3.5: Domestic resource cost (DRC) distributions for major livestock products in Ukraine, 2004
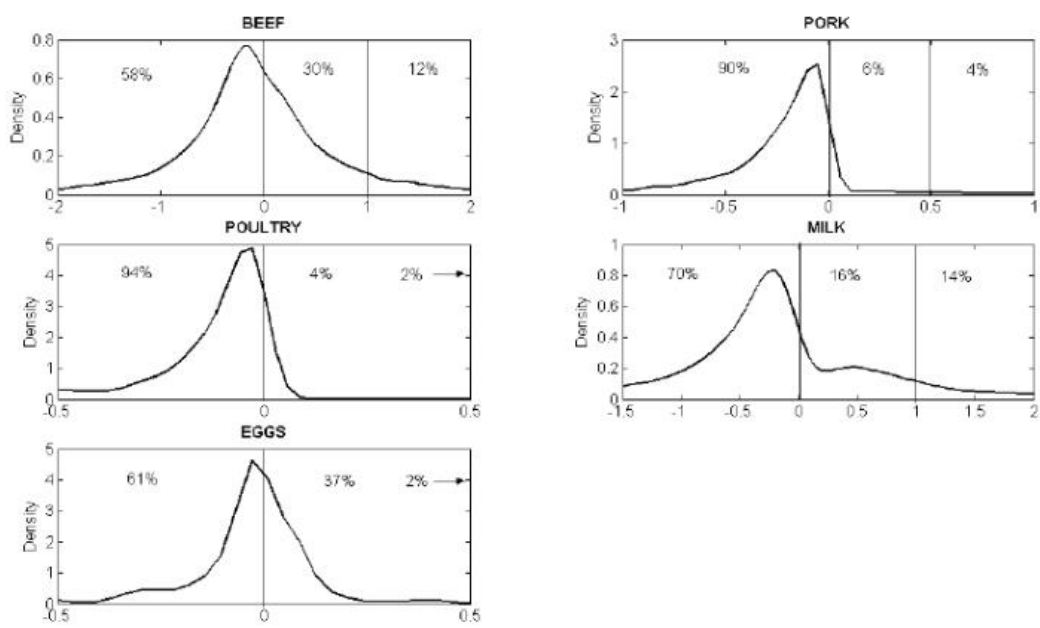

Source: Own calculations

disciplines are needed to ensure that less efficient farms either improve or exit, freeing up resources for more efficient use by others.

The empirical analysis presented here demonstrates that many Ukrainian farms are able to produce wheat, sunflower seed, barley, eggs, beef and milk competitively. The same is true for maize, rapeseed, soybeans, and pork, but for smaller proportions of the producing farms. For all products, the majority of the farms in Ukraine are currently not able to produce sufficient surplus to cover the costs of domestic and tradable inputs. In many cases, the value of production does not even suffice to cover the cost of tradable inputs, indicating that production is subtracting, and not adding value. Overall, the findings here correspond well with Lischka's (2004, p. 110) estimate that roughly one-half of the farms in Ukraine are "... severely threatened ... [e]nterprises of highly questionable viability".

The fact that many farms are able to produce competitively bodes well for Ukraine's international competitiveness in major temperate agricultural products and processed foods. Realizing Ukraine's competitive potential (in other words, shifting the distributions presented here) is a matter of (i) increasing the efficiency of production so that the great majority of farms in Ukraine can produce as efficiently tomorrow as the best farms do today, and (ii) developing marketing and processing systems so that Ukraine's ability to produce competitive raw products on the farm is translated into competitiveness on world markets and for high-value added agri-food products.

The following chapters IV and V present factors constraining agricultural competitiveness and measures to increase it. The coverage of the sectoral issues and potential remedies presented in these chapters is broader than what the DRCbased analysis of sectoral competitiveness (chapters I - III) alone can support. By drawing on evidence from other recent analyses (von Cramon-Taubadel and 
Table 3.3: Summary of DRC results for major livestock products

\begin{tabular}{|c|c|c|c|c|c|c|}
\hline & & 2004 & & & 2005 & \\
\hline & $\mathrm{DRC}<0$ & $0<\mathrm{DRC}<1$ & $\mathrm{DRC}>1$ & $\mathrm{DRC}<0$ & $0<\mathrm{DRC}<1$ & $\mathrm{DRC}>1$ \\
\hline Beef & & & & & & \\
\hline Weighted average DRC & -0.92 & 0.42 & 2.71 & -1.27 & 0.51 & 2.94 \\
\hline Share of the group in total production volume & $55.1 \%$ & $30.4 \%$ & $14.5 \%$ & $67.2 \%$ & $15.8 \%$ & $17.0 \%$ \\
\hline Share of the group in total number of farms & $58 \%$ & $30 \%$ & $12 \%$ & $63 \%$ & $22 \%$ & $15 \%$ \\
\hline Pork & & & & & & \\
\hline Weighted average DRC & -0.70 & 0.27 & 2.26 & -0.58 & 0.34 & 2.16 \\
\hline Share of the group in total production volume & $67.5 \%$ & $21.2 \%$ & $11.4 \%$ & $58.8 \%$ & $34.7 \%$ & $6.5 \%$ \\
\hline Share of the group in total number of farms & $90 \%$ & $6 \%$ & $4 \%$ & $85 \%$ & $8 \%$ & $7 \%$ \\
\hline Poultry & & & & & & \\
\hline Weighted average DRC & -0.34 & 0.58 & 1.94 & -0.18 & 0.46 & 1.62 \\
\hline Share of the group in total production volume & $80.9 \%$ & $18.8 \%$ & $0.2 \%$ & $69.9 \%$ & $21.0 \%$ & $9.1 \%$ \\
\hline Share of the group in total number of farms & $94 \%$ & $4 \%$ & $2 \%$ & $94 \%$ & $4 \%$ & $2 \%$ \\
\hline Milk & & & & & & \\
\hline Weighted average DRC & -1.24 & 0.46 & 2.48 & -1.70 & 0.49 & 2.49 \\
\hline Share of the group in total production volume & $42.4 \%$ & $42.0 \%$ & $15.6 \%$ & $28.3 \%$ & $49.1 \%$ & $22.6 \%$ \\
\hline Share of the group in total number of farms & $70 \%$ & $16 \%$ & $14 \%$ & $58 \%$ & $20 \%$ & $22 \%$ \\
\hline Eggs & & & & & & \\
\hline Weighted average DRC & -0.44 & 0.07 & 2.66 & -1.79 & 0.11 & 1.26 \\
\hline Share of the group in total production volume & $3.1 \%$ & $96.4 \%$ & $0.5 \%$ & $6.6 \%$ & $93.3 \%$ & $0.2 \%$ \\
\hline Share of the group in total number of farms & $61 \%$ & $37 \%$ & $2 \%$ & $58 \%$ & $40 \%$ & $2 \%$ \\
\hline
\end{tabular}

Source: Own calculations

Raiser, 2006; von Cramon-Taubadel et al., 2007; World Bank and OECD, 2004; World Bank, 2008b; Zorya, 2006), however, the DRC analysis is integrated into the broader picture of overall sector development.

\subsection{The Domestic Resource Costs Method and the Calculation of DRC Distributions}

\section{The DRC method}

To measure the competitiveness of Ukrainian agriculture, Domestic Resource Costs (DRC) are calculated for major crop and livestock products. The DRC is one of many indicators that can be calculated using the Policy Analysis Matrix (PAM) framework developed by Monke and Pearson (1989). The PAM is a product of two accounting identities, one defining profitability as the difference between revenues and costs and the other measuring the effects of divergences (distorting policies and market failures) as the difference between observed private values and social values that would exist if the divergences were removed. The structure of the PAM is presented in Table 3.1.

$\mathrm{DRC}$ is calculated as the ratio of $\mathrm{G}$ to $(\mathrm{E}-\mathrm{F})$ in the table above. Hence, it compares the cost of domestic resources measured at social prices (in the numerator) to value added measured in social prices (in the denominator). The use of social prices throughout ensures that DRC measures whether employing scarce domestic inputs in the production of good $i$ is really resulting in a positive return to the country in question. $\mathrm{DRC}<1$ indicates comparative advantage - the social opportunity costs in terms of domestic resources used are smaller that the corresponding social gain in terms of value added generated. The opposite is true for the $\mathrm{DRC}>1$. DRC $=1$ indicates that the economy neither gains nor loses from employment of resources in the production of $i$. 
The DRC method has the advantage of being intuitively clear, reasonably easy to use and well established in applied economics. It also has several weaknesses. In particular, it is based on the assumption of fixed technical coefficients. Hence, it ignores possible factor substitution and cross price effects that could be expected to result from shifting production away from the observed point of production characterised by private prices, to the hypothetical point characterised by social prices. Depending on the strength of these effects, the DRC will be biased. The DRC may also be biased against activities that rely heavily on domestic inputs such as land and labour, and it is sensitive to the classification of inputs into domestic and tradable (Masters and Winter-Nelson, 1995).

Note, however, that there is an inherent discontinuity in the DRC distribution at 0 , with values slightly greater than 0 reflecting very competitive farms, and values slightly below reflecting very uncompetitive farms. The kernelbased algorithm used to estimate the DRC distributions presented in this paper smoothes this discontinuity and, hence, creates the false impression of a relatively high frequency of observations close to and equal to 0 .

For this reason, social cost benefit ratio (SCB: Masters and Winter-Nelson, 1995) distributions are also calculated and presented in Figures 3.6 through 3.9 below. The SCB is based on the same PAM components as the DRC. It equals the ratio of the sum of tradable and domestic input costs to the price of the good in question, or $(F+G)$ divided by $\mathrm{E}$ in Table 3.1 above. The SCB is always greater than 0 , and a SCB less than (greater than) 1 indicates that total input costs are less than (greater than) revenue and that production is (is not) competitive. The SCB is not sensitive to the classification of inputs into domestic and tradable, and it is not subject to the discontinuity that affects the DRC distribution. However, unlike the DRC, it does not distinguish between uncompetitive production that is merely unable to cover the opportunity costs of domestic factors (DRC $>1$ ) and uncompetitive production that is not even able to cover the costs of tradable inputs $(\mathrm{DRC}<0)$. As the results presented in this paper make clear, this distinction is relevant in the case of Ukrainian agriculture.

\section{Data and assumptions}

The empirical analysis described above is carried out using Ukraine-wide farmlevel accounting data provided by the State Statistics Committee of Ukraine. This dataset is an unbalanced panel of 17,906 observations over the period 2004-2005. For each observation in the dataset (representing a farm in one of the two years), information on total input costs for each farm product is available, as is information on the breakdown of input costs for each of the output aggregates 'crop' and 'livestock' products. In order to generate disaggregated input use data for each individual farm product, the share of each individual product in total farm costs is used. In other words, if the data show that wheat accounted for $25 \%$ of total input costs in crop production for a specific farm, then $25 \%$ of the labour allocated to crop production on that farm is assumed to have been spent on wheat, $25 \%$ of the fertiliser, etc. An alternative would be to allocate inputs according to acreage shares, but this would i) probably be less accurate as more profitable crops (such as sunflower and sugarbeet, for example) tend to be produced more intensively than others, and ii) not be helpful for 
Table 3.4: Data description

\begin{tabular}{|c|c|c|c|c|c|c|c|c|c|c|c|c|c|}
\hline & 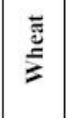 & 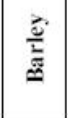 & E & 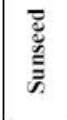 & $\frac{\bar{E}}{\frac{\delta}{3}}$ & 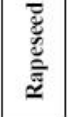 & 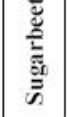 & 总 & Фัّ & 产 & 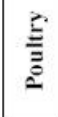 & 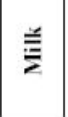 & $\begin{array}{l}\text { gh } \\
\text { 호 }\end{array}$ \\
\hline \multicolumn{14}{|c|}{ Number of farms producing } \\
\hline 2004 & 8282 & 7725 & 4067 & 4772 & 876 & 697 & 2445 & 671 & 6596 & 5498 & 490 & 6018 & 357 \\
\hline 2005 & 7631 & 6865 & 2942 & 4319 & 1057 & 1004 & 2546 & 461 & 5523 & 4810 & 472 & 5113 & 363 \\
\hline \multicolumn{14}{|c|}{ Inputs used } \\
\hline Seeds & + & + & + & + & + & + & + & + & - & - & - & - & - \\
\hline Fertilizers & + & + & + & + & + & + & + & + & - & - & - & - & - \\
\hline Diesel and gasoline & + & + & + & + & + & + & + & + & + & + & + & + & + \\
\hline Gas & + & + & + & + & + & + & + & + & + & + & + & + & + \\
\hline Electricity & + & + & + & + & + & + & + & + & + & + & + & + & + \\
\hline Spare parts, renovation costs & + & + & + & + & + & + & + & + & + & + & + & + & + \\
\hline Labour & + & + & + & + & + & + & + & + & + & + & + & + & + \\
\hline Other inputs (manure, litter etc) & + & + & + & + & + & + & + & + & + & + & + & + & + \\
\hline Land & + & + & + & + & + & + & + & + & - & - & - & - & - \\
\hline Capital & + & + & + & + & + & + & + & + & + & + & + & + & + \\
\hline Fodder & - & - & - & - & - & - & - & - & + & + & + & + & + \\
\hline
\end{tabular}

Source: Own calculations

Table 3.5: Cost shares for inputs in crop and livestock production in Ukraine, 2004 and $2005(\%)$

\begin{tabular}{|l|c|c|c|c|}
\hline \multirow{2}{*}{ Input } & \multicolumn{2}{|c|}{ Crop } & \multicolumn{2}{c|}{ Livestock } \\
\cline { 2 - 5 } & $\mathbf{2 0 0 4}$ & $\mathbf{2 0 0 5}$ & $\mathbf{2 0 0 4}$ & $\mathbf{2 0 0 5}$ \\
\hline Labour & 13.6 & 15.3 & 16.1 & 17.4 \\
\hline Seeds and grafts & 13.6 & 11.7 & - & - \\
\hline Other inputs (manure, litter, eggs for incubation etc) & 1.3 & 1.1 & 3.5 & 4.0 \\
\hline Fertilizers & 10.6 & 12.3 & - & - \\
\hline Fuel: diesel and gasoline & 16.2 & 17.6 & 4.9 & 4.9 \\
\hline Electricity & 1.3 & 1.2 & 3.4 & 3.2 \\
\hline Fuel: gas & 1.1 & 1.2 & 0.6 & 0.8 \\
\hline Spare parts, renovation & 7.5 & 7.4 & 3.6 & 3.5 \\
\hline Outside services employed & 11.3 & 10.8 & 4.5 & 6.9 \\
\hline Depreciation & 5.1 & 5.4 & 3.9 & 4.1 \\
\hline Other costs: including & 18.4 & 16.0 & 3.7 & 3.5 \\
\hline Land rent (as\% of other costs) & 12.5 & 11.2 & - & - \\
\hline property costs (as \% of other costs) & 0.4 & 0.4 & 0.2 & 0.2 \\
\hline Fodder & - & - & 55.9 & 51.9 \\
\hline
\end{tabular}

Source: Own calculations

acreage-independent livestock products. Table 3.4 provides an overview of the resulting data structure and numbers of observations, and Table 3.5 provides information on average input cost shares for crop and livestock production in the sample of farms employed in the DRC analysis.

Conversion from private to social prices and costs is based on a variety of assumptions and sources of data:

- Factors for converting revenue from the sale of agricultural output from a private to a social price basis are calculated using information from the World Bank Agricultural Distortions Project Ukraine Case Study undertaken by von Cramon-Taubadel et al. (2007), which draws heavily on the OECD's PSE tables (OECD, 2005). Border reference prices (border prices corrected for marketing costs) are compared with farm-gate prices to calculate conversion factors 
Table 3.6: Calculation of conversion factors for revenues

\begin{tabular}{|c|c|c|c|c|c|c|}
\hline \multirow[t]{2}{*}{ Product } & \multicolumn{3}{|c|}{2004} & \multicolumn{3}{|c|}{2005} \\
\hline & $\begin{array}{c}\text { Farm gate price } \\
(\mathrm{UAH} / \mathrm{t})\end{array}$ & $\begin{array}{c}\text { Reference } \\
\text { border price } \\
(\mathrm{UAH} / \mathrm{t})\end{array}$ & $\begin{array}{l}\text { Conversion } \\
\text { factor }\end{array}$ & $\begin{array}{c}\text { Farm gate price } \\
(\mathrm{UAH} / \mathrm{t})\end{array}$ & $\begin{array}{c}\text { Reference } \\
\text { border price } \\
(\mathrm{UAH} / \mathrm{t})\end{array}$ & $\begin{array}{c}\text { Conversion } \\
\text { factor }\end{array}$ \\
\hline \multicolumn{7}{|c|}{ Crops } \\
\hline Wheat & 493 & 620 & 1.26 & 414 & 502 & 1.21 \\
\hline Barley & 387 & 429 & 1.11 & 489 & 561 & 1.15 \\
\hline Corn & 438 & 573 & 1.31 & 371 & 389 & 1.05 \\
\hline Sunseed & 1151 & 1247 & 1.08 & 981 & 1213 & 1.24 \\
\hline Soybean & 778 & 1093 & 1.40 & 989 & 981 & 0.99 \\
\hline Rapeseed & 1163 & 1228 & 1.06 & 1135.7 & 1207 & 1.06 \\
\hline Potato & 530 & 596 & 1.12 & 684 & 820 & 1.20 \\
\hline \multicolumn{7}{|c|}{ Livestock } \\
\hline Beef & 4359 & 5588 & 1.28 & 5882 & 5402 & 0.92 \\
\hline Pork & 7196 & 5722 & 0.80 & 10198 & 7688 & 0.75 \\
\hline Poultry & 4974 & 3217 & 0.65 & 6495 & 3746 & 0.58 \\
\hline Milk & 835 & 988 & 1.18 & 1120 & 1138 & 1.02 \\
\hline Eggs & 4225 & 6417 & 1.52 & 4486 & 5575 & 1.24 \\
\hline
\end{tabular}

Source: Own calculations with von Cramon-Taubadel et al. (2007).

Figure 3.6: Social cost benefit (SCB) distributions for major crop products in Ukraine, 2005
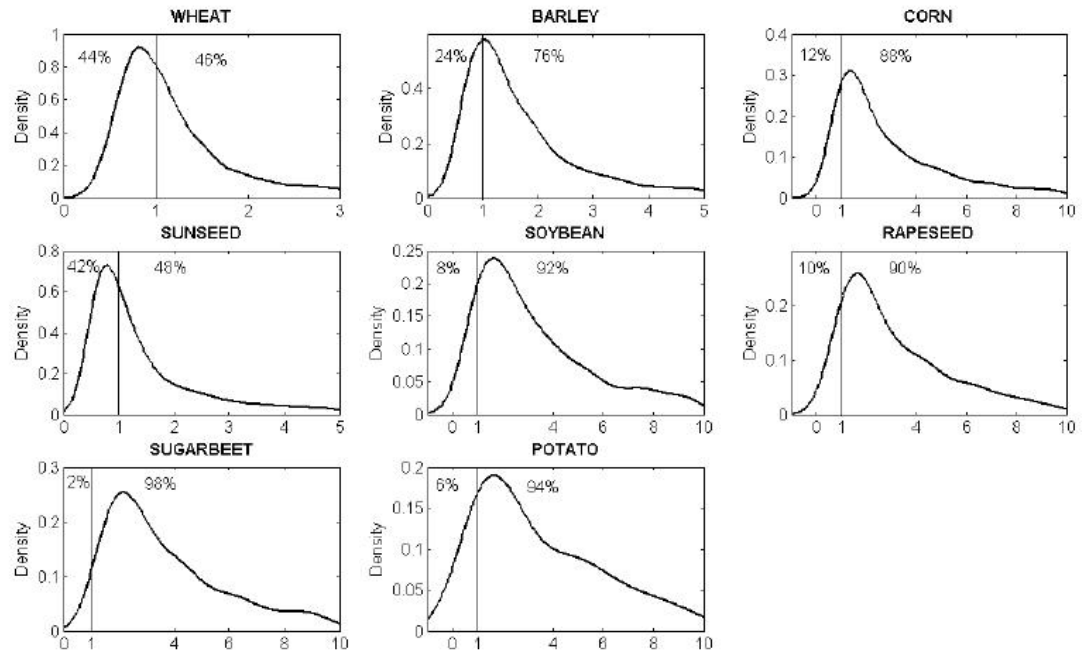

Source: Own calculations

(Table 3.6) that are multiplied with actual reported revenues to estimate hypothetical social revenues. The case of sugar is somewhat more complicated because farmers sell sugarbeet while world trade is in raw or white sugar. Technical extraction coefficients are used to convert the border price for white sugar into a sugarbeet price, and comparison with the corresponding farm gate price results in a conversion factor of 0.73 (0.57) for 2004 (2005).

- Social costs for seeds, fertilisers and fodder are based on private costs corrected for the impact of tariff and non-tariff barriers (NTBs). Tariffs are taken 
from official tariff schedules, and NTBs are assumed to be equivalent to $2 \%$ ad valorem tariffs based on IER (2006a). For fertiliser, conversion factors of 0.93 and 0.95 are used in 2004 and 2005, respectively. For all seeds except barley, sugarbeet and potato, a conversion factor of 0.98 is used in both years (in other words, only the assumed $2 \%$ NTB is corrected). For barley and sugarbeet, 0.95 and 0.33 are used in both years. For potato, the conversion factors used in 2004 is 0.53 , and in 20050.78 . For fodder and eggs for incubation, conversions factors of 0.95 are used in both years.

- Capital input is measured as the sum of depreciation (i.e. the reduction in the value of assets arising from wear and tear), and the forgone return on financial capital tied up in the value of assets. A conversion factor for capital costs is calculated as the product of a conversion factor for capital assets value and a conversion factor for capital recovery (see Guba (2000) for details). The factor for capital assets value is assumed to equal 0.95 based on information in IER (2006a) about tariffs and NTBs applied to agricultural machinery and equipment imports. The conversion factor for capital recovery is estimated using the relationship between private and social interest rates. The private real interest rate is calculated using nominal interest rates and the rate of inflation. The social interest rate is estimated using macroeconomic data (GDP and factor income shares) based on the assumption that under competitive conditions the ratio of a factor's marginal to average value product should equal its share of total income (Monke and Pearson, 1989). The result of these calculations is a conversion factor for capital recovery of 0.52 in 2004 and 0.64 in 2005 . Hence, the conversion factor for capital costs is 0.50 in 2004, and 0.61 in 2005.

- Private fuel costs are corrected for two types of distortion to arrive at a social valuation. The first distortion is due to the fact that Ukraine has paid considerably less than world market prices for gas as a result of special arrange-

Figure 3.7: Social cost benefit (SCB) distributions for major crops products in Ukraine, 2004
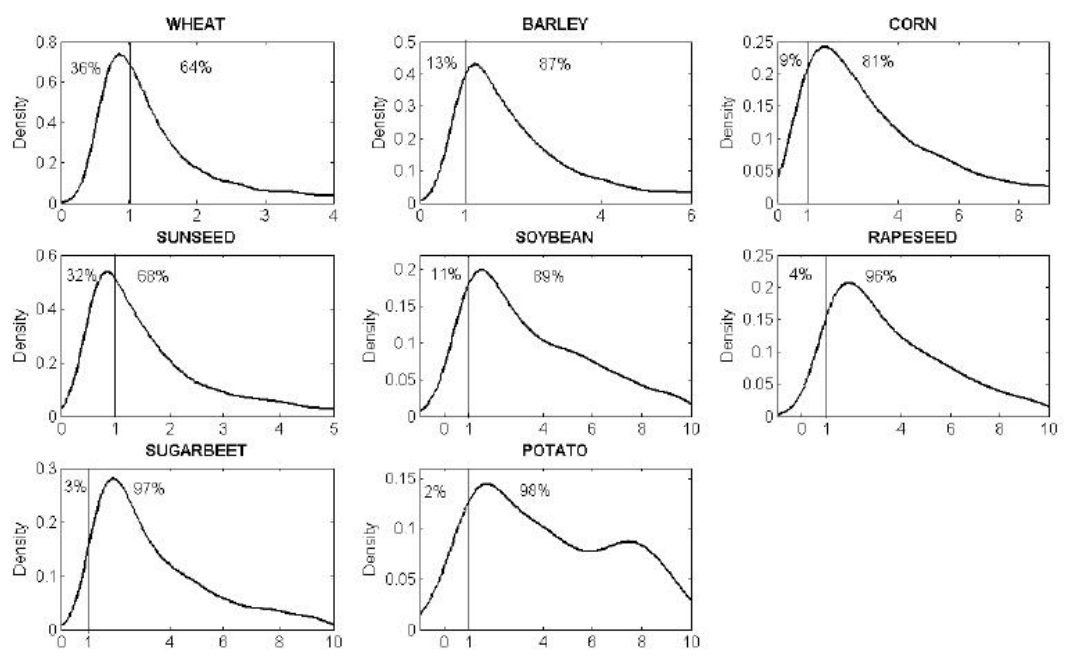

Source: Own calculations 
Figure 3.8: Social cost benefit (SCB) distributions for major livestock products in Ukraine, 2005
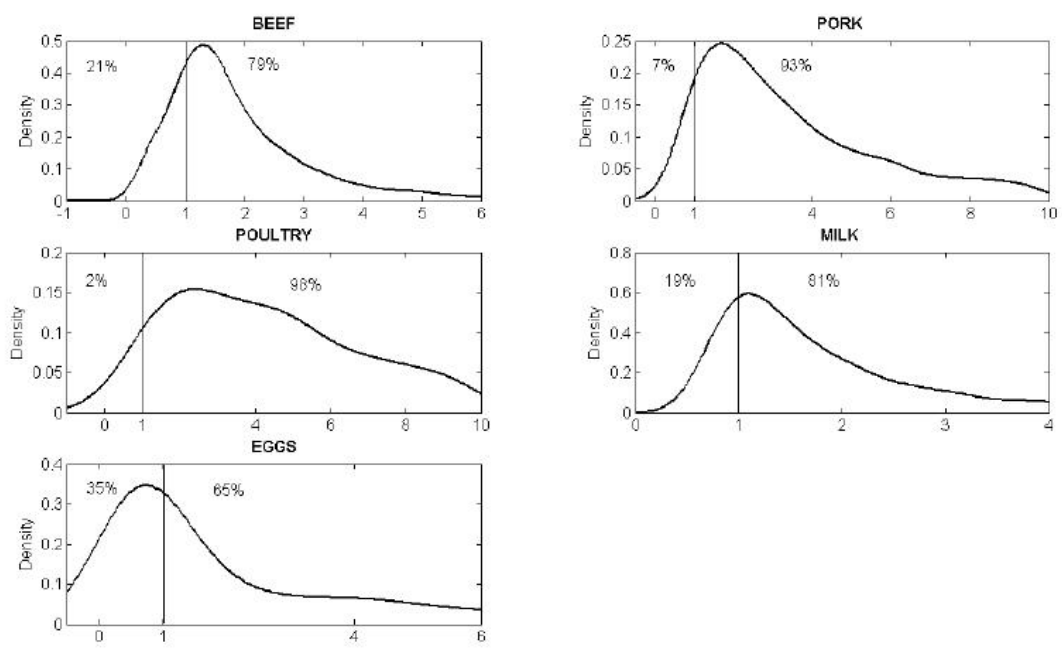

Source: Own calculations

Figure 3.9: Social cost benefit (SCB) distributions for major livestock products in Ukraine, 2004
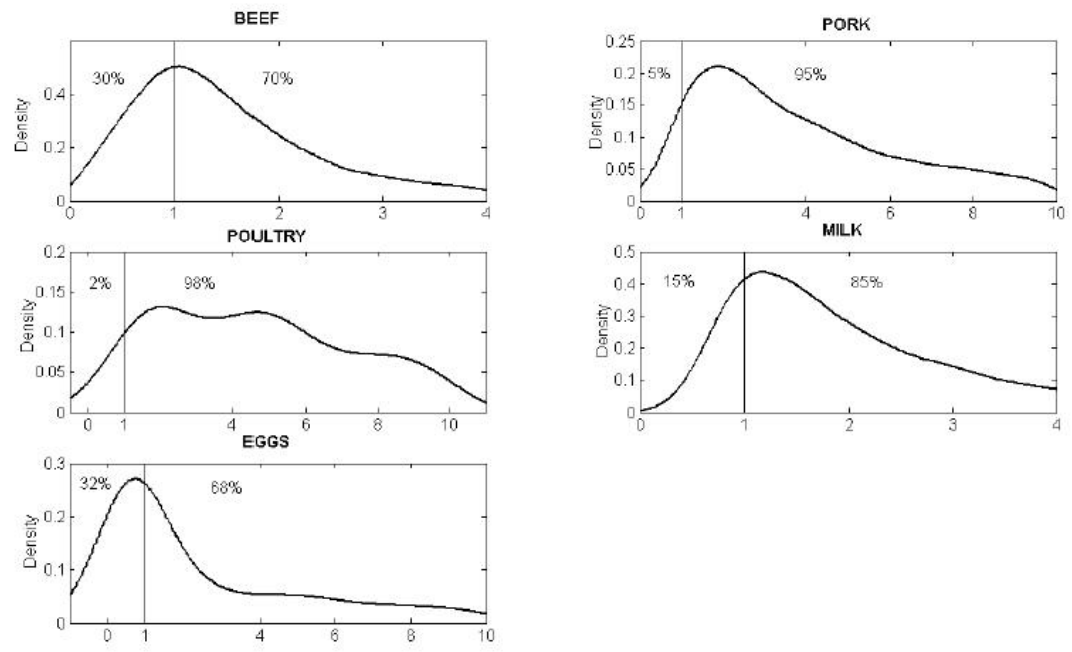

Source: Own calculations 
ments with Russia (which have been the subject of much recent controversy). Pavel and Chukhai (2006) argue that an economically justifiable gas price for Ukraine can be calculated as the EU market price minus the cost of gas transit from Ukraine to the EU. According to this calculation, the price in Ukraine in mid-2006 should have been $277 \mathrm{US} \$ / \mathrm{tm}^{\mathbf{3}}$ rather than the actual $95 \mathrm{US} \$ / \mathrm{tm}^{3}$. On this basis, private-to-social cost conversion factors for gas use are determined to be 2 and 2.5 in 2004 and 2005, respectively. The second distortion is the result of memoranda signed between the Government of Ukraine and the fuel industry according to which the latter supplied 360,000 and 600,000 tons of fuel (diesel and gasoline) at a discount to farmers in 2004 and 2005, respectively. Based on information about the discount rates and prices for fuel in other countries, conversion factors of 1.11 and 1.09 for diesel and gasoline inputs are determined for 2004 and 2005.

- For electricity, social costs are assumed to equal private costs based on a description of the Ukrainian electricity market in Pavel and Poltavets (2006). Ukraine generates its own electricity and even exports it, and there is no differentiation between electricity prices in agriculture and in other sectors of economy, with the exception of a partial electricity cost refund program that concerns only rice producers and some other minor products not considered here.

- Social valuation of land is estimated as in Monke and Pearson (1989) by comparing profits before land costs for as many crops as possible on each farm, and setting farm-specific social land costs equal to the highest profits before land costs observed. An alternative would be to use land lease prices, as there is an active land lease market in Ukraine. However, this market is not strictly cashbasis (land owners are often partly paid in kind or in the form of services), and regional average lease rates will not account for farm-specific conditions (e.g. irrigation, particular soil qualities, etc.). The assumption made here is biased in that it implicitly assumes that $100 \%$ of a farm's land could be allocated to the production of the most profitable crop in any given year, which ignores crop rotation restrictions. Hence, it may tend to over-value land and underestimate competitiveness as a result. This effect is likely limited, however, as the share of land in total factor costs is low (Table 3.5).

- Social costs are assumed to equal private costs for labour. Wages have been increasing with economic growth since 2000 and will likely continue to increase in the future. While we are aware of no major distortions on labour markets in Ukraine, market wages could be subject to some distortions. For example, if protection of labour-intensive products does inflate market wage rates in Ukraine, the assumed equality of social and private labour costs will bias the magnitude of the calculated DRCs upward and correspondingly reduce the shares of competitive farms and production, especially for labour-intensive agricultural products.

- Finally, social costs are also assumed to equal private costs for other inputs such as manure and litter.

\subsection{References}

Anderson, K. (1993). Intersectoral Changes in Former Socialist Economies: Distinguishing Initial from Longer-Term Responses. Centre for International 
Economics Studies Reprint No. 26, University of Adelaide.

Balassa, B. (1965). Trade Liberalisation and 'Revealed' Comparative Advantage. The Manchester School, Vol. 33: 99-123.

Balance, R., H. Forstner and T. Murray (1987). Consistency Tests of Alternative Measures of Comparative Advantage. Review of Economics and Statistics, Vol. 69: 157-161.

Breburda, J. (1990). Land-Use Zones and Soil Degradation in the Soviet Union. In: Wädekin, K.-E. (ed.): Communist Agriculture - Farming in the Soviet Union and Eastern Europe. Routledge, New York.

BMZ (Bundesministerium für wirtschaftliche Zusammenarbeit und Entwicklung, (2007). Africa Newsletter, Nr. $02 / 2007$.

Borodina, O. (2006). Derzhavna pidtrymka silskogo gospodarstva: koncepcia, mekhanismy, effektyvnist (State Support to Agriculture: concept, mechanisms, and efficiency). Ekonomika ta Prognozuvannia, Vol. 1, p. 106-125

von Cramon-Taubadel, S. (1999). Der Markt für Zucker in der Ukraine: Gestern, Heute und Morgen. In: von Cramon-Taubadel, S., and L. Striewe (eds.): Die Transformation der Landwirtschaft in der Ukraine: Ein weites Feld. Wissenschaftsverlag Vauk Kiel.

von Cramon-Taubadel, S., and E. Lakemeyer (2006). Renewable Energy Policy in Ukraine. IER Policy Paper No. V6, Kiev http://ierpc.org/ ierpc/papers/v6_en.pdf

von Cramon-Taubadel, S., And M. Raiser (2006). The Quotas on Grain Exports in Ukraine: Ineffective, Inefficient and non-Transparent. World Bank Country Office Ukraine and the Institute for Economic Research and Policy Consulting, Kiev. http://www-wds.worldbank.org

von Cramon-Taubadel, S., E. Elsner von der Malsburg, V. Movchan And O. Nivyevskiy (2007). Poverty Reduction Through Reducing Distortions to Agricultural Incentives: Ukraine Case Study. World Bank Agricultural Distortions Working Paper 06, Washington D.C. www.worldbank.org/ agdistortions

Demyanenko, S., And S. Zorya (2004). Taxation and Ukrainian Agriculture. In: von Cramon-Taubadel, S., S. Demyanenko \& A. Kuhn (eds.): Ukrainian Agriculture - Crisis and Recovery. Shaker, Aachen. FAO (Food and Agriculture Organisation of the United Nations) (2006).

FAO Statistical Yearbook 2005-2006. Rome.

FAPRI (Food and Agricultural Policy Research Institute) (2006). FAPRI 2006

U.S. And World Agricultural Outlook. FAPRI Staff Report 06-FSR 1, Ames, Iowa.

Galushko, V.,B. Brümmer and S. Demyanenko (2004). Measuring the Productive Efficiency of Ukrainian Farms. In: von Cramon-Taubadel, S., S. Demyanenko \& A. Kuhn (eds.): Ukrainian Agriculture - Crisis and Recovery. Shaker, Aachen.

Guba, W. (2000). Competitiveness of Polish Milk Processing Industry During the Integration to the European Union - Analysis of Dynamic Comparative Advantages. PhD Thesis. University of Göttingen.

IER (Institut for Economic Research) (2006a). Barriers to Investment in the Agriculture and Food Sector in Ukraine. Policy Paper No. 5, Kiev.

IER (Institute For Economic Research) (2006B). Agricultural Land Market in Ukraine: Allow or Forbid? German-Ukrainian Policy Dialog in Agriculture Policy Paper No. 8, Kiev. 
IER (Institute for Economic Research) (2007). The World Biofuel Boom and Ukraine - How to Reap the Benefits. German-Ukrainian Policy Dialog in Agriculture Policy Paper No. 7, Kiev.

IMF (International Monetary Fund) (2006a). World Economic Outlook Database. http: //www.imf .org/external/pubs/ft/weo/2006/02/data/weoselagr . aspx (accessed January 18, 2007).

IMF (International Monetary Fund) (2006b). World Economic Outlook: Financial Systems and Economic Cycles. Washington D.C.

Krueger, A.O., A. Valdéz And M. Schiff (eds.) (1991). The Political Economy of Agricultural Pricing Policy. Johns Hopkins University Press.

Kurkalova, L., And H. Jensen (2002). Technical Efficiency of Grain Production in Ukraine: An Analysis Using Farm-Level Data. Journal Paper No. J-17036 of the Iowa Agriculture and Home Economics Experiment Station. Leamer, E.E. (1987). Paths of Development in the Three-Factor, n-Good General Equilibrium Model. Journal of Political Economy, Vol. 95: 961-999. Lerman, Z., D. Sedik, N. Pugachev and A. Goncharuk (2006). Rethinking Agricultural Reform in Ukraine. FAO, Rome.

Liesner, H.H. (1958). The European Common Market and British Industry. Economic Journal, Vol. 68: 302-16.

Lischka, G. (2004). Farm Management Challenges in Ukrainian Agriculture. In: von Cramon-Taubadel, S., S. Demyanenko \& A. Kuhn (eds.): Ukrainian Agriculture - Crisis and Recovery. Shaker, Aachen.

Lissitsa, A., AND M. Odening (2005). Efficiency and total factor productivity in Ukrainian agriculture in transition. Agricultural Economics, Vol. 32(3): 311-325.

López, R. And G.I. Galinato (2007). Should governments stop subsidies to private goods? Evidence from rural Latin America. Journal of Public Economics, Vol. 91: 1071-1094.

Masters, W.A., And A. Winter-Nelson. (1995). Measuring the Comparative Advantage of Agricultural Activities: Domestic Resource Costs and the Social Cost-Benefit Ratio. American Journal of Agricultural Economics, Vol. 77: 243-50.

Melitz, M.J. (2003). The impact of trade on intra-industry reallocations and aggregate industry productivity. Econometrica, Vol. 71(6): 1695-1725.

Monke, E. A. And S. R. Pearson (1989). The Policy Analysis Matrix for Agricultural Development, Ithaca NY: Cornell University Press.

Nivyevskiy, O. \& S. von Cramon-Taubadel (2007). Subsidies and Efficiency: The Case of Ukrainian Dairy Farms. Institute for Economic Reform and Policy Consulting (IER) Working Paper, Kiev.

Nivyevskiy, O. \& S. von Cramon-Taubadel (2008). Subsidies, Efficiency and Technological Change of Ukrainian Dairy Farms: Spatial Dependence in the Components of Productivity Growth. Institute for Economic Reform and Policy Consulting (IER) Working Paper, Kiev.

OECD (Organisation for Economic Cooperation and Development) (2005). Detailed PSE Tables for Ukraine. Provided with kind permission by the OECD. OECD (Organisation for Economic Cooperation and Development) and FAO (Food and Agriculture Organisation of the United Nations) (2006). OECDFAO Agricultural Outlook - Database (2006-2015). http://www.oecd.org/ document $/ 23 / 0,2340$, en_2649_33783_37426007_1_1_1_1,00.html (accessed January 17, 2007). 
Pavel, F., And A. Chukhai (2006). Ukrainian Gas Imports: Towards secure and economically reasonable transactions. IER Policy Paper No. V12, Kiev. http://ier.org.ua/papers_en/v12_en.pdf

Pavel, F., And I. Poltavets (2006). EU Energy Sector Reforms: A benchmark for Ukraine! IER Policy Paper No V7, Kiev. http://ier.org.ua/ papers_en/v7_en.pdf

Penkaitis, N. (1994). Entwicklungstendenzen der Agrarstrukturen in der Ukraine. Giessener Abhandlungen zur Agrar- und Wirtschaftsforschung des Europäischen Ostens, Vol. 201. Duncker \& Humblot, Berlin.

Rosenblatt, M. (1956). Remarks on Some Nonparametric Estimates of a Density Function. Annals of Mathematical Statistics, Vol. 27: 643-669.

Schoreit, B. (2004). A Comparison of the Agricultural Education Systems in Ukraine and Germany. Masters Thesis, Department of Agricultural Economics and Rural Development, University of Göttingen.

Sonneveld, H. (2005). Mission Report on Standards and Certification. Project $\mathrm{N}^{\circ}$ EuropeAid/114025/C/SV/UA: Establishment of an agricultural standards certification and control mechanism in line with WTO-SPS requirements, reporting period: April-May 2005. GFA Terra Systems GmbH, Hamburg.

SpaAR, D. \& P. Schuhmann (2000). Natürliche Grundlagen der Pflanzenproduktion in den Ländern der Gemeinschaft Unabhängiger Staaten und des Baltikums. AgriMedia, Bergen/Dumme, Germany.

State Statistics Committee of Ukraine (continuously updated). Statistical Information Online. http://www.ukrstat.gov.ua/

Striewe L. And S. von Cramon-Taubadel (1999). Die Getreideproduktion der Ukraine: Verpaßte Chancen und dringender Handlungsbedarf. In: von Cramon-Taubadel, S., and L. Striewe (eds.): Die Transformation der Landwirtschaft in der Ukraine: Ein weites Feld. Wissenschaftsverlag Vauk Kiel.

Striewe, L., I. Chapko and A. Starikov (2001). Rural Finance in Ukraine - Extending the Frontier. In: von Cramon-Taubadel, S., S. Zorya \& L. Striewe (eds.): Policies and Agricultural Development in Ukraine. Shaker Verlag, Aachen.

Strubenhoff, H.-W., And O. Nivyevskiy (2006). Restructuring of the Sugar Sector in Ukraine. IER Agricultural Working Paper No. 1, Kiev. http: //www.ier.kiev.ua/English/WP/2006/wp2006_eng.pdf

Tarassevych, O. (2006a). Ukraine Retail Food Sector - Retail Chains on the Rise. United States Department of Agriculture Foreign Agricultural Service (USDA/FAS) GAIN Report No. UP6020. Washington D.C.

Tarassevych, O. (2006b). Ukraine Exporter Guide - Food Market Developments in 2006. United States Department of Agriculture Foreign Agricultural Service (USDA/FAS) GAIN Report No. UP6017. Washington D.C.

Tiffin, A. (2006). Ukraine: The Cost of Weak Institutions. International Monetary Fund (IMF) Working Paper WP/06/167. Washington D.C.

UkrAgroConsult (weekly). Agrinews. Kiev.

United Nations Statistics Division (2007). Population density and urbanization statistics - Table 3: Population by sex, rate of population increase, surface area and density. Online under http://unstats . un.org/unsd/demographic/ products/dyb/DYB2003/Table03.pdf, accessed June 2007.

World BAnk (1996). Poverty in Ukraine. Report No. 15602-UA. Washington D.C.

World BAnK \& OECD (2004). Achieving Ukraine's Agricultural Potential - 
Stimulating Agricultural Growth and Improving Rural Life. The World Bank, Washington D.C.

World BANK (annual). World Development Indicators. Online data base, http: //devdata.worldbank.org/wdi2006/contents/index2.htm, accessed February 2004 .

World BAnK (2007a). Ukraine Food Safety and Sanitary and Phytosanitary Measures in the context of WTO Accession and EU Partnership. Unpublished Paper. Washington D.C.

World Bank (2007b). Ukraine: Poverty Update. Report No. 39887 - UA. Washington D.C.

World BAnK (2008a). World Development Report 2008. Washington D.C. World BAnK (2008b). Competitive Agriculture or State Control: Ukraine's Response to the Global Food Crisis. May 2008, Washington D.C. World Economic Forum (WEF) (2006). Global Competitiveness Report 2006-2007.

ZorYA, S. (2003). Interdependencies Between Agriculture and Macroeconomics in Ukraine. PhD Thesis, University of Göttingen.

Zorya, S. (2006). Improving Agricultural Fiscal Policy in Ukraine. World Bank Environmentally and Socially Sustainable Development (ECSSD) Working Paper No. 44. Washington D.C. 



\title{
Chapter 4
}

\section{The Determinants of Dairy Farming Competitiveness in Ukraine}

\begin{abstract}
WTO accession and the expected free trade agreement with the EU pose significant challenges for Ukrainian agriculture, implying structural changes for the sector as well as adaptations at the farm level to improve efficiency and competitiveness. However, a recent study by von CramonTaubadel et al. (2008) demonstrates a clear lack of competitiveness. In particular, in the paper we demonstrate that only about $14-20 \%$ of dairy farms produce at competitive level. Then using a fixed-effect panel regression we analyze the determinants of competitiveness in Ukrainian dairy farming. The size of the farm, productivity and labor intensity have a strong positive effect on competitiveness, while arable land per head has negative effect. Finally, total subsidies received by farms are found to have a negative impact on competitiveness, and this impact does not depend on the farm size.

Keywords: competitiveness; dairy farming; Ukraine
\end{abstract}

\subsection{Introduction}

In early February 2008, the WTO General Council by approving the Protocol on Accession gave the green light to Ukraine's membership. WTO accession was set by the EU as the major condition for negotiations on a free trade agreement (FTA) with Ukraine. Both WTO accession and the expected FTA with the EU represent major challenges for Ukrainian agriculture. They imply not only changes in the trade and institutional regime for Ukraine but also structural changes in Ukraine's agriculture and adjustments at the farm level to improve efficiency and competitiveness. However, a recent study by von Cramon-Taubadel et al (2008) demonstrates a clear lack of competitiveness. The authors show that for virtually every product more than half of the farms in Ukraine produce at a non-competitive level. At the same time, for most products a certain share of farms is found to be competitive. This directs attention to the forces that drive competitiveness in Ukrainian agriculture. 
In this regard, dairy farming deserves particular attention. It is one of the main sources of income for the rural population, and of raw material supply for dairy processing. The whole dairy sector has been one of the most fast growing branches of the Ukrainian agro-food sector, producing about $4 \%$ of the total national output. Although most domestically produced dairy products are sold on the domestic market, approximately one-third of the raw milk processed by dairy plants is exported in the form of cheese, butter, skimmed milk powder etc. The further development of the dairy sector depends on the availability of sufficient, relatively inexpensive and high-quality raw milk, in other words, on the competitiveness of dairy farming. Dairy, together with sugar and fruit and vegetable production, has been highlighted by the Minister of Agriculture Policy of Ukraine as a branch of agriculture that can be expected to face especially difficult challenges as Ukraine opens its agricultural markets. Moreover, in a view of increased world demand for livestock products in particular, Ukraine is seen as a place where supply could increase significantly (FAO/EBRD, 2008).

In this paper we analyze the profile and the determinants of competitiveness of dairy farming in Ukraine using farm-level panel data. In the following we begin with a brief description of the dairy farming profile in Ukraine, paying more attention to the perceived current bottlenecks of the sector. Then we proceed with an empirical analysis in which we measure the competitiveness of dairy farming and study the farm-level determinants of this competitiveness. Section 4 closes with conclusions.

\subsection{The profile of dairy farming in Ukraine}

Ukraine has been producing 12-14 m tons of raw milk annually over the last 6-7 years (see Table 4.1). The great majority of this milk is produced by households. As Table 4.1 shows, the share of households in the total raw milk production increased from $24 \%$ in 1990 to $82 \%$ in 2008 . The corresponding rapid contraction of the share of commercial dairy farms ('farms' in the following) was a result of the transformation from the Soviet planned to the market economy (Zorya and von Cramon-Taubadel, 1999). The under- and unemployed rural population, often members of former collective farms, used subsistence production of milk as a 'social buffer' against transformations taking place in the transition period. However, households cannot exploit economies of scale and they make it much more difficult to capture economies of scale up- and -downstream from dairy farming. This adds costs to the value chain, making it less competitive internationally.

As Figure 4.1 shows, the production of raw milk by households follows a pronounced seasonal pattern. Seasonality of raw material supply has a big impact on dairy processors' strategies and costs. In the summer there is sufficient supply, and the quality of this milk can be reasonably controlled. However in the winter supply falls dramatically, so processors are ready to pay more even for the milk of worse quality, just to ensure enough raw material supply.

The quality of domestic raw milk has been one of the major problems for the sector. As Table 4.2 shows, Ukrainian raw milk quality standards are far from Western standards. Milk from households is usually of 2 nd grade according to Ukrainian system. The EU and USA do not use such milk for food produc- 
Table 4.1: Characteristics of raw milk production in Ukraine (1990-2008)

\begin{tabular}{|c|c|c|c|c|c|c|c|c|}
\hline & 1990 & 1995 & 2001 & 2004 & 2005 & 2006 & 2007 & 2008 \\
\hline \multicolumn{9}{|c|}{ Cows in milk, mill. head: } \\
\hline Dairy farms & 6.2 & 4.6 & 1.7 & 0.9 & 0.9 & 0.8 & 0.7 & 0.6 \\
\hline Households & 2.2 & 2.9 & 3.2 & 3.0 & 2.8 & 2.6 & 2.4 & 2.3 \\
\hline Total & 8.4 & 7.5 & 4.9 & 3.9 & 3.6 & 3.4 & 3.1 & 2.9 \\
\hline \multicolumn{9}{|c|}{ Yield, t/cow: } \\
\hline Dairy farms & 3.0 & 1.9 & 2.1 & 2.5 & 2.9 & 3.2 & 3.2 & 3.5 \\
\hline Households & 2.7 & 2.7 & 3.1 & 3.4 & 3.6 & 3.9 & 4.2 & 4.2 \\
\hline Total & 2.9 & 2.2 & 2.7 & 3.2 & 3.5 & 3.6 & 3.7 & 4.1 \\
\hline \multicolumn{9}{|c|}{ Fluid Milk, mill. t: } \\
\hline Dairy farms & 18.6 & 9.4 & 3.6 & 2.5 & 2.6 & 2.5 & 2.2 & 2.1 \\
\hline Households & 5.9 & 7.8 & 9.8 & 11.2 & 11.1 & 10.8 & 10.1 & 9.7 \\
\hline Total & 24.5 & 17.3 & 13.4 & 13.7 & 13.7 & 13.3 & 12.3 & 11.8 \\
\hline
\end{tabular}

Source: Own calculations.

Figure 4.1: Monthly raw milk production by households and farms (2005-2006)

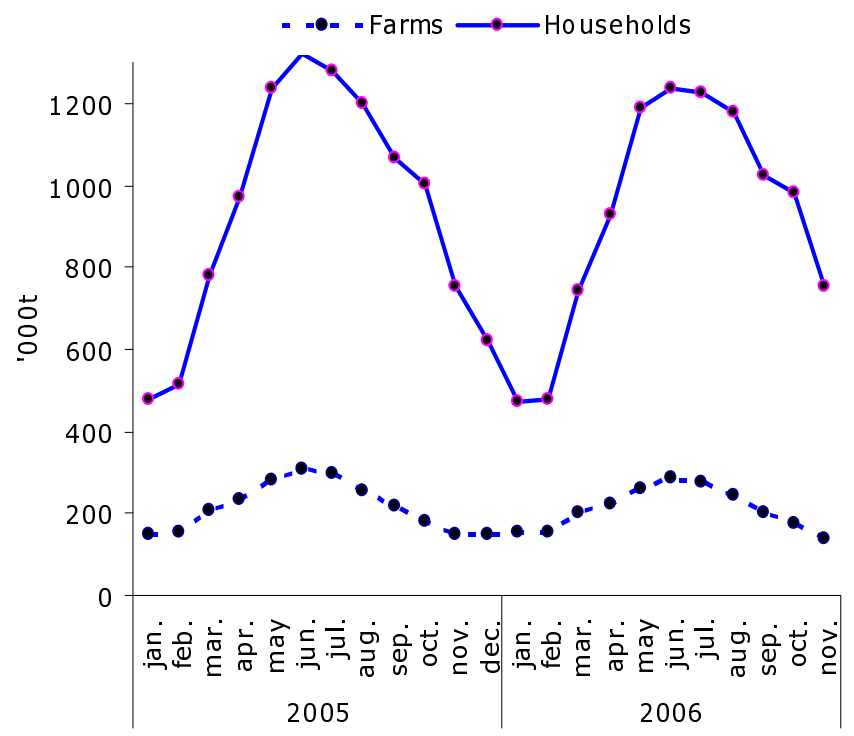

Source: Own calculations. 
Table 4.2: Quality standards for raw cow milk for food production in Ukraine, the EU and the USA

\begin{tabular}{lcccccc}
\hline & EU & \multicolumn{3}{c}{ USA } & \multicolumn{3}{c}{ Ukraine } \\
\cline { 3 - 6 } & & Federal & California & $\begin{array}{l}\text { Extra } \\
\text { grade }\end{array}$ & $1^{\text {st }}$ grade & $2^{\mathrm{d}}$ grade \\
\hline $\begin{array}{l}\text { Plate count } 30{ }^{\circ} \mathrm{C} \\
(\text { '000 per ml) }\end{array}$ & $\leq 100$ & $\leq 100$ & $\leq 50$ & $\leq 300$ & $\leq 500$ & $\leq 3000$ \\
$\begin{array}{l}\text { Somatic cell count } \\
\text { ('000 per ml) }\end{array}$ & $\leq 400$ & $\leq 750$ & $\leq 600$ & $\leq 400$ & $\leq 600$ & $\leq 800$ \\
\hline
\end{tabular}

Source: EU Council Directive 92/46/EEC, Chapter IV, A; Grade "A" Pasteurized Milk Ordinance revised 2003,Press releases; DSTU 3662-97.

Figure 4.2: Dairy Production/Export ratio

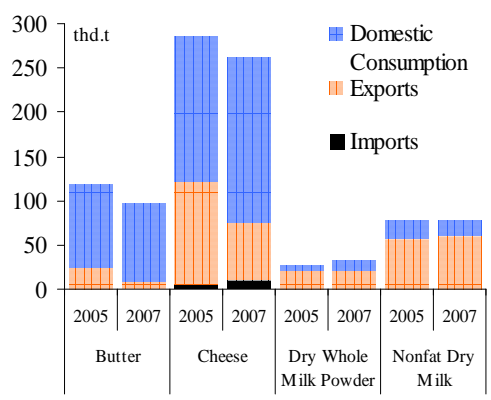

Source: Statistic Committee of
Figure 4.3: Dairy Export from Ukraine

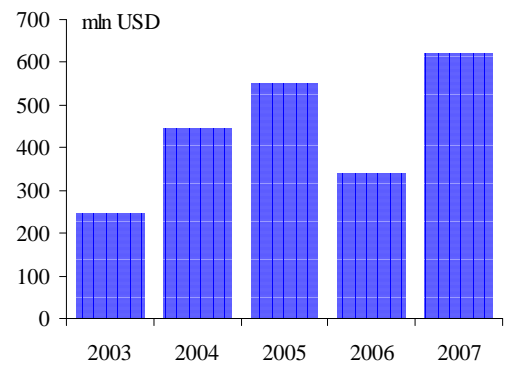

Source:USDA

Ukraine.

tion at all. The situation looks better on dairy farms, which deliver mostly 1ST and 'Extra' class milk. Because of incompliance of Ukraine's food safety and quality standards with international standards, Ukraine's export of dairy products has been destined mostly to former Soviet republics. Approximately one-third of the raw milk processed by dairy plants is exported in the form of cheese, butter, skimmed milk powder etc (Figure 5.2a). Russia has traditionally been the largest export market, accounting for $64 \%$ of Ukraine's total dairy exports in 2005. In that year Ukraine supplied nearly $50 \%$ of the Russian cheese market. However, in early 2006, Russia temporarily lifted a ban on imports of Ukrainian livestock products (including dairy), decreasing this share and export revenues considerably (Figure 4.3). Ukraine's dairy exports to Western countries are limited, and consist mostly of non-fat and skimmed milk powders used for non-human consumption.

In terms of geographical location, Figure 4.4 shows that raw milk production data reveal no clear 'belts' or 'zones' of production. Some Oblasts contribute considerably more than others to total production. A group of 'core' Oblasts consists of Vinnitsa, Kyiv, Poltava, Kharkiv, Chernihiv, Lviv and Cherkassy. These oblasts are located in all three agro-climatic zones of Ukraine - steppe, forest-steppe and forest - which suggests that agro-climatic conditions do not play a major role in the regional distribution of dairy farming in Ukraine. 
Figure 4.4: Oblast's share in the national raw milk production, 2006

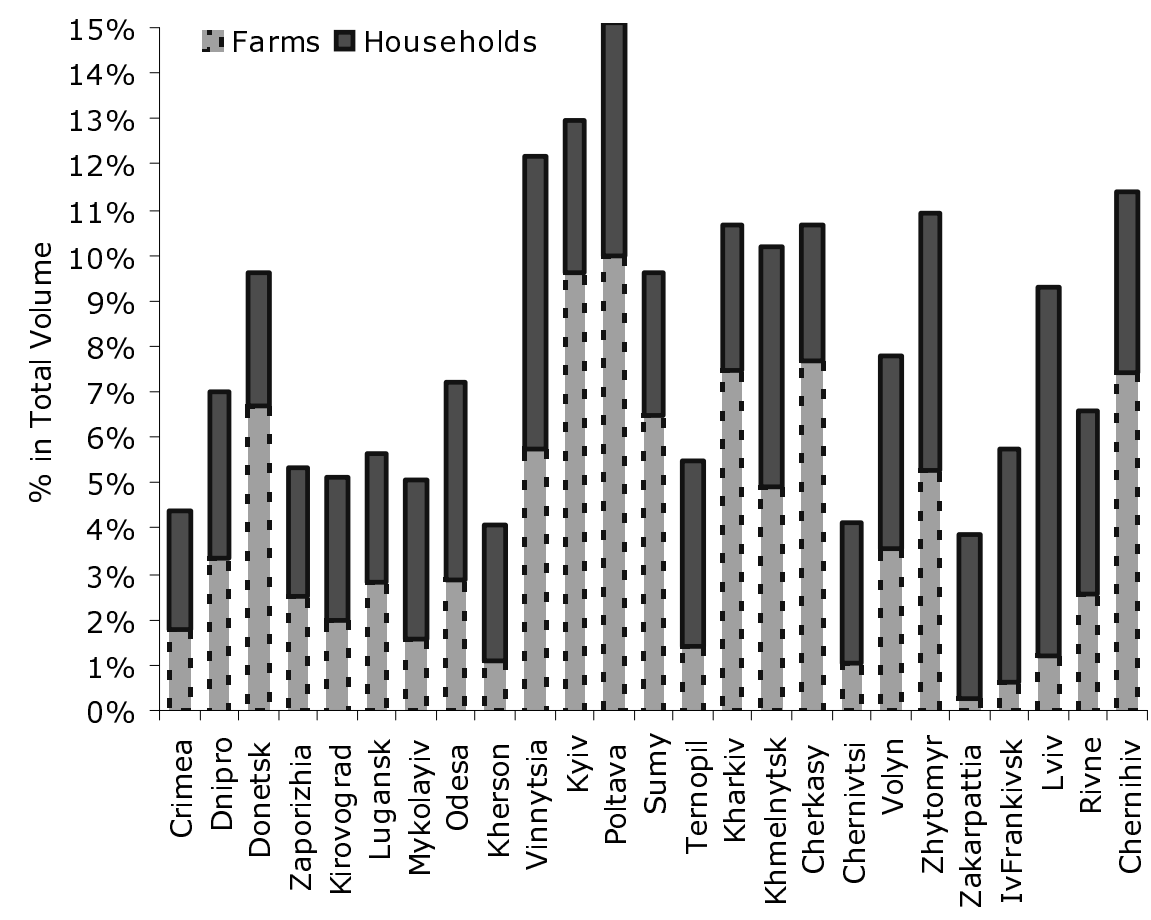

Source: State Statistic Committee of Ukraine.

Productivity of cows per lactation is very low in Ukraine by Western standards (see Table 4.1). The average productivity in Germany, for example, is in the range 6-7 tons/year; in Israel it is about 11-12 t/cow. On the other hand, Figure 5 shows that some dairy farms in Ukraine are able to reach Western yield levels. Although in 2005 the average cow yield (see Table 4.1) for dairy farms was 2.9 tons, Figure 4.5 demonstrates that the modal yield was only 1.7 tons. Also, as Figure 4.5 demonstrates, productivity grows as herd size increases, making large-scale production more advantageous, on average.

Feed makes up a biggest share (50-70\%) in milk production costs, and farms mostly produce their own feed. However, Lischka (2004) argues that feed production for dairy cows on Ukrainian farms generally takes place on a very extensive basis. Optimising feed production for dairy cows could reduce land requirements by $30-50 \%$ and decrease feed costs correspondingly. Furthermore, Ukraine's dairy farms have much less capital equipment than farms in Central and Western Europe. This implies a lack of investments in dairy farming. There are different reasons for that, but the most important are taxation of inputs (seeds, agrochemicals, machinery etc) via tariff and tariff import barriers, excessive regulation (e.g. certification), a lack of a market for farm land, a lack of market and marketing information and infrastructure, and a glaring shortage of human capital (see Nivievskyi and Strubenhoff, 2006; von Cramon-Taubadel et al., 2008). These barriers do not allow farmers to boost productivity thus decrease production costs. 
Figure 4.5: The distribution of milk yields by herd size on dairy farms in Ukraine (2005)

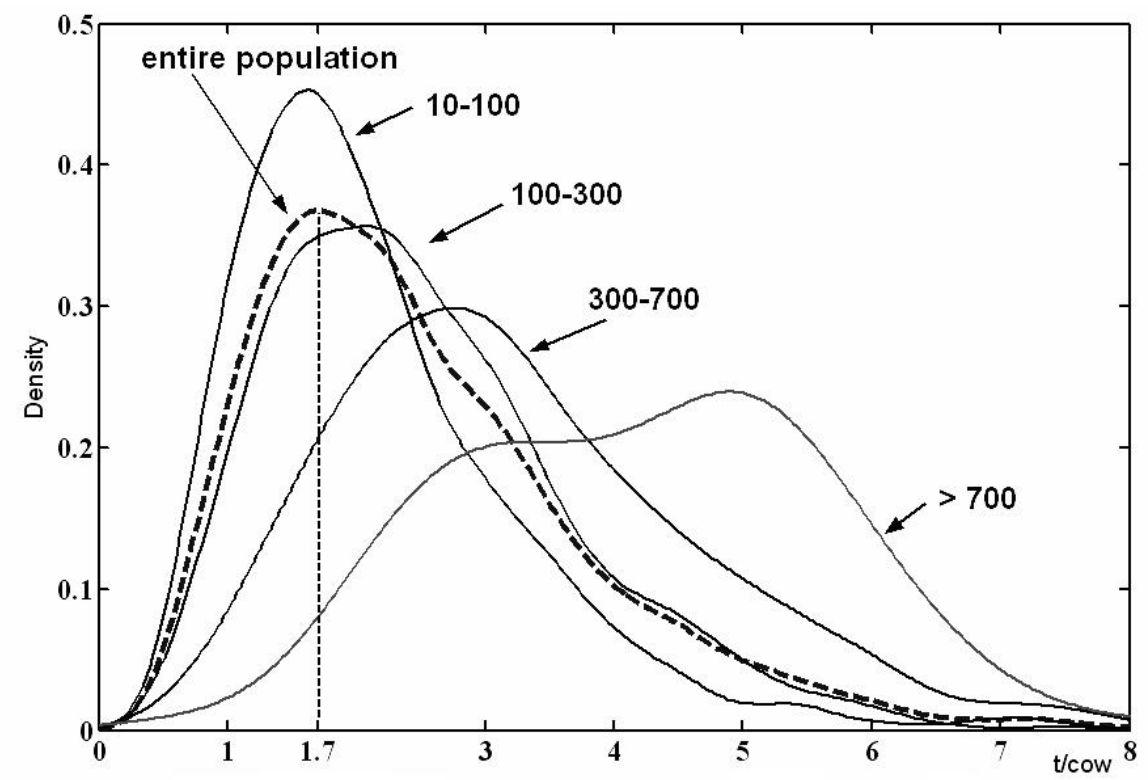

Source: State Statistic Committee of Ukraine.

Note: figures in the figure refer to the range of the herd size for the corresponding group. For example, "> 700" refers to dairy farms with more than 700 cows.

A possible additional source of uncompetitveness is subsidies. Dairy farms receive subsidies based on the quantity of milk delivered to dairy plants, so they do not comply with WTO requirements. These subsidies might limit the ability of dairy farms to adjust their behavior and operate more efficiently, as well as to employ more advanced technologies or to improve the implementation of the existing technologies. The whole literature starting from Leibenstein (1966) points to the negative impact of the support measures on efficiency, mainly via weakening the managerial efforts (e.g., Bergsman, 1974; Balassa, 1975; Lassaad, 1994; Giannakas et al., 2001). On the other hand, McCloud and Kumbhakar (2007) find subsidy has a positive impact on technical efficiency. Sunding and Zilberman (2001; p.250) emphasize on different mechanisms through which price supports impact the technology adoption of farms of different sizes. For instance, smaller farms may increase their technology adoption via better credit access when the ability to obtain credit depends on expected income. In the empirical analysis below we also study the impact of subsidies on competitiveness. Having briefly described the main characteristics and shortcomings of dairy farming in Ukraine, we proceed with an empirical analysis of the barriers to competitiveness in milk production. 


\subsection{The competitiveness of Ukraine's milk production}

\section{Describing the competitiveness of milk production in Ukraine}

To measure the competitiveness of dairy farming we employ Domestic Resource Cost (DRC) and Social Costs Benefit ratio analysis (SCB: Masters and Winter-Nelson, 1995). The DRC and SCB are two of many indicators that can be calculated using the Policy Analysis Matrix (PAM) framework developed by Monke and Pearson (1989). The DRC compares the cost of domestic resources measured at social prices with value added measured at social prices. The use of social prices throughout ensures that the DRC measures whether employing scarce domestic inputs in the production of a good generates a positive return for the country in question. $0<\mathrm{DRC}<1$ indicates comparative advantage: the social opportunity cost of domestic resources used is smaller than the corresponding social gain (value added). The opposite is true for the DRC > 1. If the DRC is smaller than 0 , then the denominator must be negative, in which case revenue does not even suffice to cover tradable input costs, let alone domestic inputs. In this case, production of the good in question is clearly not competitive.

The SCB is defined as the ratio of the sum of tradable and domestic input costs to the price of the good in question. The SCB is always greater than 0 , and a SCB less than (greater than) 1 indicates that total input costs are less than (greater than) revenue and that production is (is not) competitive. Unlike the DRC, the SCB does not distinguish between uncompetitive production that is merely unable to cover the opportunity costs of domestic factors (DRC > 1) and uncompetitive production that is not even able to cover the costs of tradable inputs $(\mathrm{DRC}<0)$. However, SCB is robust to the classification of inputs bias (Masters and Winter-Nelson, 1995).

The DRC and SCB analysis presented here is carried out using Ukraine-wide farm-level accounting data provided by the State Statistics Committee of Ukraine. This dataset is an unbalanced panel of 26,790 observations, including 15,353 farms producing raw milk, over the period 2004-2006. Estimates of univariate DRC and SCB density functions across all relevant farms are calculated using the kernel-based estimate. Note, however, that there is an inherent discontinuity in the DRC distribution at 0 , with values slightly greater than 0 reflecting very competitive farms, and values slightly below reflecting very uncompetitive farms. The kernel-based algorithm smoothes this discontinuity and, hence, creates the false impression of a relatively high frequency of observations close to and equal to 0 . For more detailed description of methodology and results for other than milk products please refer to von Cramon-Taubadel et al (2008).

Results of the DRC and SCB analysis for dairy products in 2005 and 2004 are presented in Figures $4.7 \mathrm{a}$ and $4.7 \mathrm{~b}$, and the key results are summarised in Table 4.3. The distributions of DRCs reveal that $14.4 \%$ of dairy farms produced milk competitively in 2006, compared with $20.1 \%$ and $15.8 \%$ in 2005 and 2004 respectively. These competitive dairy farms produced about $36 \%, 49 \%$ and $42 \%$ of the total production volume, respectively. Hence, these dairy farms are relatively large-scale. SCB distributions are consistent with DRC distributions (slight differences in the shares of competitive farms are caused by smoothing). The decrease of competitive farms' share in 2006 might be explained by Russia ban on Ukrainian dairy imports, which clearly reduced the profitability of the 
Figure 4.6: Distribution of competitiveness scores for dairy farms

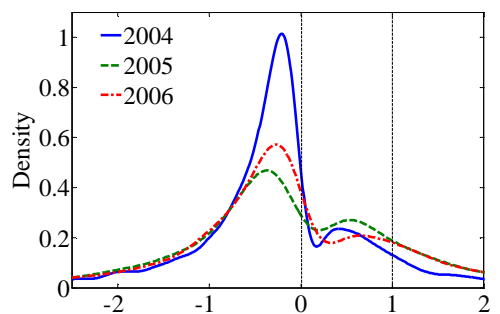

(a) DRC

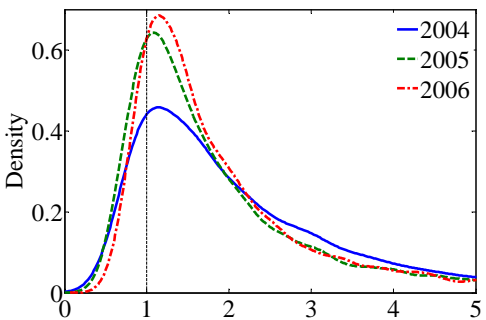

(b) SCB

Source: State Statistic Committee of Ukraine.

Table 4.3: Summary of DRC results for dairy farms in Ukraine

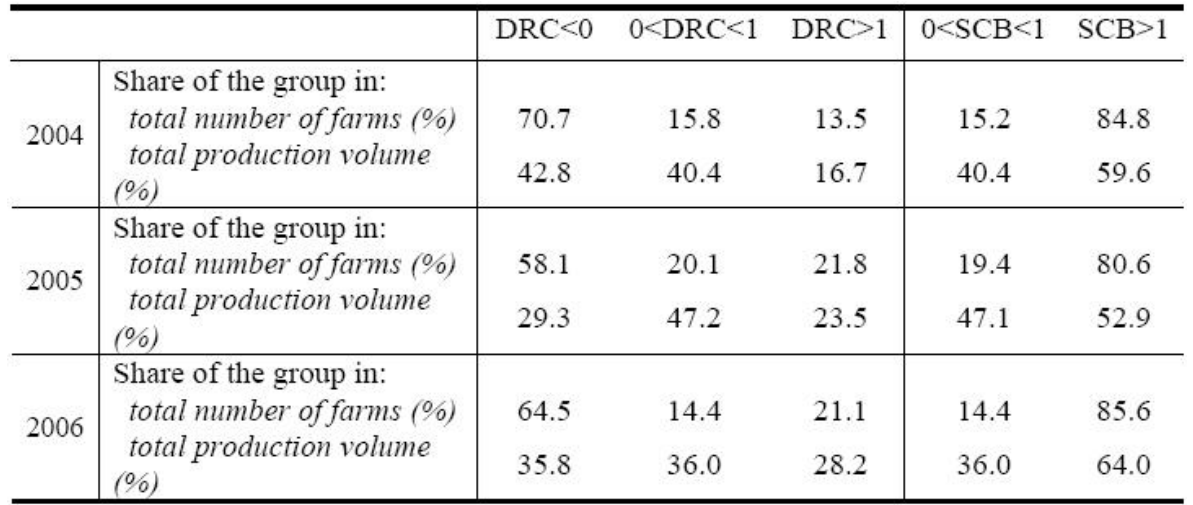

Source: Own calculations.

dairy farming.

\section{The determinants of competitiveness in Ukrainian milk production}

As a next step we explore the determinants of the dairy farming competitiveness. We continue working with the unbalanced panel data for 2004 and 2005 only, since we cannot identify the codes of farms in 2006 dataset. In total we have 11,131 observations on competitiveness and other relevant variables for 2004 and 2005 (see Table 4.4 for more detailed description and summary statistics). Prior to further analysis, we removed outliers from the data. Here all observations were detected as outliers if the variable of interest (e.g. milk yield, labor intensity, SCB) lied outside the interval $\left[q_{0.25}-2 * i q r ; q_{0.75}-2 * i q r\right]$, where $i q r$ and $q$ are the intequartile range and corresponding quantile, respectively. Note, that usually boxplot identify possible outliers for the $1.5 * i q r$, so with $2 * i q r$ we aimed at really extreme observations. This left 10043 observations (farms). Eliminated farms turned out to be marginal farms, in the sense that their total raw milk output accounted for only roughly $2 \%$ of the total 
Table 4.4: Variable definitions and summary statistics

\begin{tabular}{lrcccc}
\hline Variable & \multicolumn{1}{c}{ Definition } & Mean & $\begin{array}{c}\text { Std. } \\
\text { deviation }\end{array}$ & Min & Max \\
\hline SCB & Social cost benefit ratio & 2.287 & 0.661 & 0.196 & 14.902 \\
Herd size & Number of cows & 163.881 & 23.129 & 2.0 & 2705 \\
Labor & Labor per cow, in '000 man- & 0.291 & 0.079 & 0.007 & 3.6 \\
Productivity & Milk yield, t/cow & 2.360 & 0.414 & 0.559 & 10.757 \\
Feed & Land cultivated per cow, & 8.514 & 4.267 & 0.0004 & 284.4 \\
Subsidy & Total subsidies, 000 UAH & 59.636 & 37.489 & 0.0 & 3653.7 \\
\hline
\end{tabular}

Source: Own calculations.

Notes: UAH - Ukrainian currency, 1 USD =5.05UAH in 2006.

sector output.

The basic model we employ is a fixed effects panel regression in which a farm's SCB score is the dependent variable. As was mentioned in the previous section, larger values of the SCB imply less competitiveness. Since the DRC is discontinuous, estimation and inference based on DRC scores would be problematic. As the SCB scale is not easy to interpret, we transform it into the standardized SCB, which makes it possible to measure changes in the SCB in standard deviations from the mean. Independent variables (see Table 4.4) are chosen based on theoretical considerations (see the discussion in section 4.2) and data availability. The labor intensity variable also was standardized to ease interpretation.

Table 4.5 shows the results of the fixed-effects regression. Random effects are considered unlikely, because unobservable factors that influence competitiveness - such as management quality - are probably correlated with yields and other independent variables in the model. This is confirmed by the Hausman test, which rejects the hypothesis of orthogonally of the random effects and the regressors at the $1 \%$ significance level. Therefore, we proceed with the fixedeffect model.

Model 1 in the Table 4.5 demonstrates that, as one might expect, average cow milk yield has a statistically significant positive impact on the competitiveness of raw milk production. The results indicate that increasing the average milk yield by $1 \mathrm{t} /$ cow increases competitiveness by 0.25 standard deviations. With the variable herd size we test whether competitiveness increases with the scale of the farm operation, and with herd size squared we test whether this relationship is non-linear. Both variables are significant at the $1 \%$ level, implying the existence of a non-linear impact. Increasing the herd size by 1 cow increases competitiveness by only 0.0047 standard deviations, which is much weaker than the impact of productivity increases. Combining the estimated coefficients suggests that the largest positive impact on competitiveness is reached for a herd size of roughly 900 cows. However, this result should be interpreted carefully, since in our model we allow for the interaction between total subsidy and herd size variables. With this interaction term we test the impact of subsidies on the competitiveness of dairy farms at different herd sizes. The underlying hypothesis is that subsidies have different impacts on farms with different herd 
size. Taking the interaction term into account, the effect of the herd size on competitiveness discussed just above only applies to farms that receive no subsidies. However, as the Model 2 in Table 4.5 shows, the effect of the herd size at the mean subsidy does not change. In fact, the subsidy alone turns out to have a negative impact on competitiveness. At the mean herd size, every $1,000 \mathrm{UAH}$ pumped into a farm increase the competitiveness score (i.e. reduce competitiveness) by 0.0008 standard deviations.

The variable 'Labor intensity' reflects the level of technological equipment on dairy farms. It is standardized in the model. The assumption is that the more labor is spent per cow, the less equipped a farm is. As expected, the impact is negative and statistically significant. Each additional standard deviation of labor intensity reduces competitiveness by 0.0375 standard deviations.

In the previous section we pointed out that dairy farms in Ukraine mostly produce their own feed. However, they allocate too much land for feed crops, thereby increasing costs of feed production and decreasing competitiveness. To test this we include land per cow in the regression. However, the records in our dataset do not allow us to distinguish between land allocated to feed production and other land. We therefore assume that all grain produced on the farm that was not sold was fed to animals, and use the share of this unsold grain to calculate the share of land used for feed production. The regression results confirm our hypothesis. Each additional hectare of arable (feed) land per cow decreases competitiveness by 0.009 standard deviations from the mean SCB. Decreasing this ratio would have the opposite effect, as extension specialists suggest (see e.g. Lischka, 2004).

Lastly we test the impact of subsidies at different levels of the herd size. Results (see Other Models column of the Table 4.5) show no statistically significant differences. Although the impact of subsidies at herd size 10 is almost 3 times larger than for herd size 700 , inspection of the $95 \%$ confidence intervals for these coefficients show that this difference is statistically insignificant. The key result is that subsidies appear to have negative impact on competitiveness across all herd sizes.

\subsection{Conclusions}

The successful completion of WTO negotiations, combined with expected FTA negotiations with the EU, will take Ukraine's agriculture into a new phase of its development. These two big challenges imply not only change in the trade regime for Ukraine but also significant structural changes in Ukraine's agriculture sector as well as adjustments at the farm level to achieve greater efficiency and competitiveness. Therefore Ukrainian policy makers need a better understanding of the determinants of agricultural competitiveness in their country. In this paper we study the determinants of competitiveness in milk production, a major part of Ukrainian livestock sector, and a branch of agriculture that is likely to come under intense competitive pressure as Ukraine opens its markets.

First we measure the competitiveness of the dairy farming using DRC and SCB analysis and Ukraine-wide farm-level accounting data provided by the State Statistics Committee of Ukraine. This dataset is an unbalanced panel of 26,790 observations, including 15,353 farms producing raw milk, over the 
Table 4.5: Fixed-effect panel regression estimates

\begin{tabular}{|c|c|c|c|c|c|}
\hline & \multicolumn{5}{|c|}{ Dependent variable is standardized SCB score } \\
\hline & & odel 1 & & odel 2 & Other models \\
\hline Herd size & -0.0047 & $7(0.0004)$ & -.0047 & $(0.0004)$ & $-0.0047(0.0004)$ \\
\hline Herd size squared ${ }^{* * *}$ & $2.55 \mathrm{e}-06$ & $6(4.36 \mathrm{e}-07)$ & $2.55 \mathrm{e}-06$ & (4.36e-07) & $2.55 \mathrm{e}-06(4.36 \mathrm{e}-07)$ \\
\hline Productivity $(\mathrm{t} / \text { cow })^{* * *}$ & -0.2527 & $7(.01552)$ & -.2527 & $(0.01552)$ & $-0.2527(0.01552)$ \\
\hline Labor intensity (standardized) $\div * *$ & 0.0375 & $5(.01340)$ & 0.0375 & $(0.01340)$ & $0.03745(0.01340)$ \\
\hline Subsidy $* \div ;$ & 0.0008 & $(.0002)$ & 0.0008 & $(0.0002)$ & - \\
\hline Subsidy $\times$ Herd size (at the mean) & $-8.19 \mathrm{e}-07$ & $(2.52 \mathrm{e}-07)$ & & - & - \\
\hline $\begin{array}{l}\text { Subsidy (at the mean) } \times \text { Herd size (at } \\
\text { the mean) }\end{array}$ & & - & $-8.19 e-07$ & $(2.52 \mathrm{e}-07)$ & - \\
\hline Subsidy(at herd size $=10$ cows $) * * *$ & & - & & - & $\begin{array}{c}.0009014 \\
{[.000403 \quad .0013998]}\end{array}$ \\
\hline Subsidy (at herd size $=\mathbf{5 0}$ cows) $* * *$ & & - & & - & $\begin{array}{c}.0008686 \\
{[.0003861 \quad .0013511]}\end{array}$ \\
\hline Subsidy (at herd size $=100$ cows) $* * *$ & & - & & - & $\begin{array}{c}.0008276 \\
{[.0003645 \quad .0012908]}\end{array}$ \\
\hline Subsidy (at herd size $=300$ cows) & & - & & - & $\begin{array}{c}.0006638 \\
{[.0002723 \quad .0010553]}\end{array}$ \\
\hline Subsidy (at herd size $=700$ cows) & & - & & - & {$\left[\begin{array}{cc}00003361 \\
{[.0000373} & .000635]\end{array}\right.$} \\
\hline Feed land $(\text { ha/cow })^{* * *}$ & .009 & $(.00123)$ & .009 & $(.00123)$ & $.009(.00123)$ \\
\hline Intercept ${ }^{*}$ & 1.1 & $(.071)$ & 1.1 & $(.071)$ & $1.1(.071)$ \\
\hline Number of obs: 10043 & Log likelih & cood: -3056.9 & Prob > & F: 0.000 & R-sq: 0.22 \\
\hline
\end{tabular}

Source: Own calculations.

Notes: *** denote significance at 1\%; Hausman test rejected the hypothesis of the random effect model at 1\%. Standard errors are in brackets. For Other Models column, the $95 \%$ confidence intervals are in squared brackets.

period 2004-2006. The DRC and SCB analysis reveals that $14.4 \%$ of dairy farms produced milk competitively in 2006, compared with $20.1 \%$ and $15.8 \%$ in 2005 and 2004 respectively. These competitive dairy farms produced about $36 \%, 49 \%$ and $42 \%$ of the total production volume, respectively. This implies a relatively large scale of these farms.

Using a fixed-effect panel regression we then analyze the determinants of competitiveness in Ukrainian dairy farming. As expected, the size of the farm has a strong positive and non-linear effect on competitiveness. Combining the estimated coefficients suggests that the largest positive impact on competitiveness is reached for a herd size of roughly 900 cows. However, the impact of productivity (milk yields) on competitiveness is found to be much stronger. One additional ton of milk per cow and year increases competitiveness by over 50 times as much as increasing the herd size by one cow does. Labor intensity has a negative effect on competitiveness. Since dairy farms produce most of their feed themselves, it is important to keep arable land per animal equivalent as low as possible to increase competitiveness. The analysis confirms this. Finally, total subsidies received by farms are found to have a negative impact on competitiveness. This impact does not differ significantly between farms with different herd size.

From the policy making point of view these results suggest termination of the current subsidy mechanism for the dairy farming of Ukraine to improve the sector's competitiveness. Instead, the developing of technology promotion (e.g. avoid taxation of inputs and excessive regulation procedures, etc) and human capacity building policies would have a positive impact on productivity, herd size and labor-to-capital ratios thus improving the competitiveness. 


\subsection{References}

Balassa, B. (1975). Trade, Protection, and Domestic Production: A Comment, International Trade and Finance: Frontiers of Research. P.B. KENNEN (Ed)., Cambridge University Press.

Bergsman, J. (1974). Commercial Policy, Allocative Efficiency, and X-efficiency. Quarterly Journal of Economics, 88, pp. 409-33.

FAO/EBRD (2008). Fighting food inflation through sustainable investments. 10 March, London

Giannakas, K., R. Schoney, V. Tzouvelekas (2001). Technical Efficiency, technological change and output growth of wheat farms in Saskatchewan. Canadian Journal of Agricultural Economics, 49, pp. 135-152.

LasaAd, L. (1994). Subsidies, Endogenous Technical Efficiency and the Measurement of Productivity Growth. Journal of Agricultural and Applied Economics, 26 (1), July, 1994: 299-310

Leibenstein, H. (1966). Allocative efficiency vs X-efficiency. American Economic Review, 56, pp. 392-415.

LischKa, G. (2004). Farm Management Challenges in Ukrainian Agriculture. In von Cramon-Taubadel, S., S. Demyanenko and A. Kuhn (Eds.). Ukrainian Agriculture - Crisis and Recovery. Shaker, Aachen.

Masters, W.A., And A. Winter-Nelson (1995). Measuring the Comparative Advantage of Agricultural Activities: Domestic Resource Costs and the Social Cost-Benefit Ratio. American Journal of Agricultural Economics, Vol. 77: 243-50.

McCloud, N., and Kumbhakar, S.C. (2007). Does Subsidy Drive Productivity? A Cross-Country Analysis of Nordic Dairy Farms. In SidDharThA Chib, Gary Koop, and Bill Griffiths (Eds.): Advances in Econometrics: Bayesian Econometrics. Vol. 23.

Monke, E. A. And S. R. Pearson (1989). The Policy Analysis Matrix for Agricultural Development. Cornell University Press, New York.

Nivyevskiy, O., Strubenhoff, H. (2006). Barriers to Investment in the Agriculture and Food Sector in Ukraine. IER Policy Paper. http://ierpc. org/ierpc/papers/agpp5_en.pdf

Sunding, D., And Zilberman, D. (2001). The Agricultural Innovation Process: Research and Technology Adoption in a Changing Agricultural Sector. In: Gardner, B.L., And Rausser, G.L. (eds.): Handbook of Agricultural Economics. Vol. 1A. Elsevier Science B.V., Amsterdam: North-Holland von Cramon Taubadel, S., Nivyevskiy, O. , and Grueninger, M. (2008). Ukraine: Agricultural Competitiveness. World Bank Policy Note No. 44843-UA.

von Cramon-Taubadel, S., Nivyevskiy, O., von der Malsburg, E., Movchan, V. (2008). Distortions to Agricultural Incentives in Ukraine. In Anderson, K. and J. Swinnen (Eds.), 2008. Distortions to Agricultural Incentives in Europe's Transition Economics. Washington DC: World Bank. von Cramon-Taubadel, S., Zorya, S. (1999). Die Wettbewerbsfähigkeit der Milcherzeugung in der Ukraine. IER policy paper S12.http://ierpc.org/ ierpc/papers/s12_en.pdf 


\title{
Chapter 5
}

\section{Price Support, Performance and Technical Progress in Ukrainian Dairy Farms: a Spatial Analysis}

\begin{abstract}
Even after more than 15 years of transition from plan to market, agriculture in Ukraine still faces many challenges in terms of its structure. The evidence in the literature points to significant heterogeneity of technical efficiency and productivity scores in Ukraine. Moreover, both the recently approved WTO accession, and the ongoing negotiations on a free trade agreement with the EU will require further improvements in productivity and competitiveness at the farm level. Using farm-level data for 2004-2005, we perform a spatial analysis of the determinants of performance and technology diffusion patterns in the dairy farming sector of Ukraine. One of the most important results is that there are agglomeration effects in the sector. Dairy farms benefit from spatial proximity, local environment and sector-specific infrastructure. Location near to dairy plants that have been investing has a positive impact on the technical progress in dairy farms. Price supports have a positive impact on small and medium farms' performance, but a negative impact on the performance of large farms.

Key words: Ukraine, dairy farming, order-m frontier, spatial dependence, agglomeration, price supports
\end{abstract}

\subsection{Introduction}

Even after more than 15 years of transition from plan to market economy, agriculture in Ukraine still faces many challenges in terms of its structure. The evidence in the empirical literature based on either data envelopment (DEA) or stochastic frontier analysis (SFA) points to significant heterogeneity of technical efficiency and total factor productivity (TFP) scores in Ukraine, with strong regional differences in the distance from the frontier (e.g. Lissitsa and Odening, 2005; Galushko et al, 2004). Moreover, both the recently approved WTO accession, and the ongoing negotiations on a free trade agreement with the EU will require further improvements in productivity and competitiveness at the farm level. However, the drivers underlying the performance and technological 
Price Support, Performance and Technical Progress in Ukrainian Dairy Farms: a Spatial

progress patterns in Ukrainian agriculture have not been explicitly studied yet. This issue is equally important in the global context. Given increasing world demand for food products, Ukraine is a place where food production could increase significantly at comparatively low environmental cost (FAO/EBRD, 2008).

Using farm-level data for 2004-2005, this paper investigates the determinants of performance and technological improvements in Ukrainian dairy farming. Dairy farming has been selected as it is one of the main income generating sources for the rural population in Ukraine, while the fast growing dairy processing industry needs stable and relatively cheap resource supply. Particular attention in the analysis is drawn to the impact of subsidies and the influence of agglomeration economies on farm-level performance. Subsidies are of considerable interest to policy making in Ukraine in light of WTO commitments on the domestic support ceiling. The agglomeration economies literature suggests different channels through which neighborhood effects and proximity to resources or consumers pools affect performance and technology diffusion patterns. The agglomeration economies are traditionally divided into 'internal scale economies', 'localization' and 'urbanization economies' (Eberts and McMillen, 1999; World Bank/IBRD, 2009). Internal scale economies are the conventional economies of scale that arise from a more efficient use of fixed costs due to a larger size of operation. Localization economies imply that the performance of one dairy farm might be influenced by the behavior of its neighbors or some local environment. Such spill-over may happen because of the local, sector-specific infrastructure, information, and services that influence the performance of each neighboring dairy farm through the lower transactions costs and easier diffusion of financial, technology and market information. Urbanization economies benefits might arise from a more general livestock or upand downstream infrastructure, allowing drawing from the same pool of technicians, specific services suppliers applicable for the entire dairy and livestock sector. In particular, it is hypothesized that location near to milk processing facilities that have been modernized will have a positive impact on the performance of dairy farms, mainly via improvements in technologies.

The paper is organized as follows. Section 2 briefly discuses some stylized facts about the dairy sector of Ukraine. Section 3 focuses on methodology and data issues. Then we proceed with empirical findings, and conclusions wrap up the paper.

\subsection{Dairy Sector Profile in Ukraine}

Ukraine produces about 13-14 m tons of raw milk per year. About half of the total raw milk supply in Ukraine is processed into dairy products and significant share of these products is exported (Figure 5.2a). However, Ukraine's exports of dairy products have been destined mostly to the former Soviet republics, with Russia accounting for $64 \%$ of Ukraine's total dairy exports in 2005. Aside from a temporary interruption caused by a ban on livestock imports (including dairy) imposed by Russia in early 2006, Ukrainian dairy exports have grown steadily in recent years. Ukraine's dairy exports to Western countries are limited, and consist mostly of non-fat and skimmed milk powders for non-human consumption. 
Figure 5.1: Dairy processing industry performance

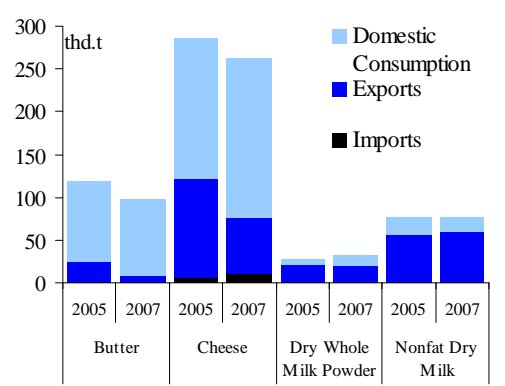

(a) Dairy Production/Export ratio in 2005

Source: State Statistic Committee of Ukraine.

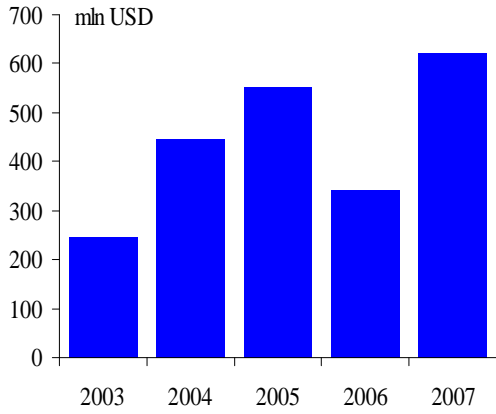

(b) Dairy Export from Ukraine

Figure 5.2: Dairy farming sector performance

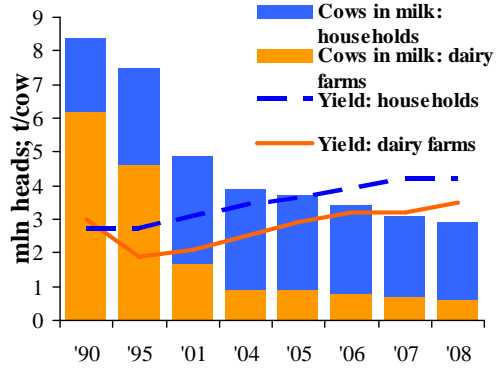

(a) Cows in milk and the development of yields in Ukraine

Source: State Statistic Committee of Ukraine.

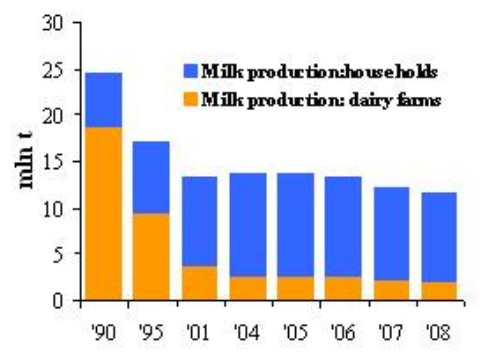

(b) The development of milk production in Ukraine

The average productivity of cows per lactation is low in Ukraine compared, for example, with 6-7 tons/year in Germany (see Figure 5.3a). On the other hand, some dairy farms are able to reach Western yields levels (Nivievskyi and von Cramon-Taubadel, 2008), reflecting a huge scope for productivity improvements.

More than $60 \%$ of the total milk output is produced in households, and the rest is produced on commercial farms (see Figures 5.3a and 5.3b). This low share of commercial farms is a legacy of the transformation from the Soviet planned to the market economy (Zorya and von Cramon-Taubadel, 1999). Households, however, are largely subsistence-oriented and cannot exploit economies of scale in production. They also make it more difficult to capture economies of scale up- and -downstream from dairy farming due to higher costs of collection. The pronounced seasonality and low quality of milk supply from households adds further costs to the value chain (Nivievskyi and von Cramon-Taubadel, 2008). Commercial farms, on the contrary, according to international experience, con- 
Price Support, Performance and Technical Progress in Ukrainian Dairy Farms: a Spatial

Analysis

stitute a basis for competitive retail and export markets. As the growing dairy processing sector in Ukraine will require a stable and high-quality supply of raw milk, we expect that share of households in milk production will decline over the next decade, while commercial dairy farming regains its former dominance. Because of this in the following analysis we focus exclusively on commercial farms ('farms' in the following).

\subsection{Methods and Data}

\section{Measurement of Individual Efficiency and Productivity Growth}

The performance of dairy farms is measured by output technical efficiency. Assume $n$ firms operate in the sector at question. Each firm $k(k=\overline{1, n})$ uses $p$ inputs, $x^{k}=\left(x_{1}^{k}, \ldots, x_{p}^{k}\right)^{\prime} \in \mathbb{R}_{+}^{p}$, to produce $q$ outputs, $y^{k}=\left(y_{1}^{k}, \ldots, y_{q}^{k}\right)^{\prime} \in \mathbb{R}_{+}^{q}$. We assume that all $n$ firms have access to the same technology $T$, defined as $T \equiv\left\{\left(x^{k}, y^{k}\right): x^{k}\right.$ can produce $\left.y^{k}\right\}$, that satisfies standard regularity axioms of production theory (e.g. Chambers, 1988). Under these assumptions, the output technical efficiency can be measured by the output-oriented distance function $D_{o}^{k}: \mathbb{R}_{+}^{p} \times \mathbb{R}_{+}^{q} \rightarrow \mathbb{R}_{+}^{1}$, defined as $D_{o}^{k}\left(x^{k}, y^{k}\right) \equiv \inf \left\{\theta>0:\left(x^{k}, y^{k} / \theta\right) \in T\right\}$ (Shephard, 1970). This function measures how far each firm $k$ produces from the best-practice frontier $f\left(x^{k}\right)$, the outer bound of the technology set $T$. The best-practice frontier, and hence distance functions, are commonly estimated using the Free Disposal Hull (FDH) method or the Data Envelopment Analysis (DEA) method (Daraio and Simar, 2007).

The main limitations of the FDH and DEA methods are the curse of dimensionality and sensitivity to outliers (e.g. Kneip et al, 2003; Daraio and Simar, 2007). As we estimate a relatively high dimensional model, these problems are potentially acute in our application. For instance, in one case we estimate 2 outputs and 5 inputs model on 1364 observations. Since the FDH estimator, for example, converges at rate of $n^{-\frac{1}{p+q}}$, it is not difficult to show that this nonparametric estimator is roughly equivalent to that of a corresponding fully parametric model estimated with only 17 observations.

As an alternative, partial or so-called robust frontiers can be estimated based on the order-m expected maximum output frontier proposed by Cazals et al (2002). The main idea of this method is to estimate a frontier which does not envelop all the data points. In the output-oriented case, the order-m frontier is defined as $\varphi_{m}(x)=E[\max (Y) \mid X \leq x]$. It represents the expected maximum value of the output among a fixed number of $m$ farms drawn from the population of farms with at most the level $x$ of input use. The parameter $m$ can be treated as a trimming parameter. If $m=100$, for example, then $\hat{\varphi}_{m, n}(x)$ is the estimated maximum possible output among 100 random farms that use no more than input level $x$. As $m$ increases, the order-m estimator approaches FDH estimator. These partial frontiers are robust to extreme points. Also since the order-m estimator converges at a rate of $n^{-\frac{1}{2}}$, it does not suffer from the curse of dimensionality problem shared by DEA and FDH estimators. Also it allows us to avoid complications with second-stage estimation, when we regress order-m efficiency scores on a set of environmental variables. The advantages of the order-m method are summarized in Daraio and Simar (2007). 
Technical progress is measured by the Technical Change component in the TFP growth decomposition. See Wheelock and Wilson (2003) for details of order-m TFP growth estimation. TFP growth is measured by the Malmquist Output Productivity Index and decomposed into two components, i.e. technical change and efficiency change (see Färe et al (1994)). The technical change component measures the change of production technology between times $\mathrm{s}$ and t. Values greater than 1 indicate positive change, and negative otherwise. More complicated decompositions of the TFP index have been proposed, for example to isolate the scale components of TFP growth (e.g. Simar and Wilson, 1998). In our application we are indifferent whether, for instance, technological improvements come from a 'pure' shift of the technology frontier or from changes in its shape.

\section{Spatial analysis of performance and technical progress determinants}

In modeling the determinants of individual farm-level performance and technical progress (measured by output technical efficiency and by technical change, respectively), we explicitly allow for their spatial dependence that stems from hypothesized agglomeration effects. A standard tool for addressing this is the spatial autoregressive model - SAR (Aselin, 1988), where the observed outcomes are simultaneously determined with the outcomes of neighboring observations. In this paper we estimate Bayesian variant of SAR to allow for non-constant variance across the space as well as outliers (LeSage, 1997). The Bayesian heteroscedastic SAR is formally stated as:

$$
\begin{aligned}
y & =\rho W y+X \beta+e \\
e & \sim N\left(0, \sigma^{2} V\right) V=\operatorname{diag}\left(v_{1}, \ldots, v_{k}\right) \\
\pi(\beta) & \sim N(c, T) \\
\pi\left(r / v_{i}\right) & \sim i i d_{\chi^{2}(r)} \\
\pi\left(1 / \sigma^{2}\right) & \sim \Gamma(d, v) \\
\pi(\rho) & \sim U[0,1]
\end{aligned}
$$

where $y$ is a vector of observations on the dependent variable, $W$ is a spatial weight matrix, $X$ is a design matrix with ones in the first column, and $W y$ is a spatial lag. The coefficient at the spatial lag, $\rho$, measures the magnitude of spatial dependency (interaction) in $y_{s}$. The spatial weights matrix, $W$, is a positive matrix which specifies neighbors for each observation. By convention, an observation is assumed not to be a neighbor to itself, so the diagonal elements of the weight matrix are set to zero $\left(w_{i i}=0\right)$. The spatial weight matrix is row-standardized so that the sum of elements in each row is one. $\pi(\cdot)$ in expression 5.1 denotes assumed prior distribution on parameters. $r$ is a parameter of $\chi^{2}(r) / r$ distribution - the prior distribution for the $v_{i}$ (variance scalars).

In our application, this specification is used to model farm level efficiency and technical change in y as a function of a series of covariates in $X$ while accounting for spatial lag structures to capture possible spill-over effects as well as for spatial heterogeneity in errors. 
Price Support, Performance and Technical Progress in Ukrainian Dairy Farms: a Spatial

Table 5.1: Order-m frontier estimation - summary statistics

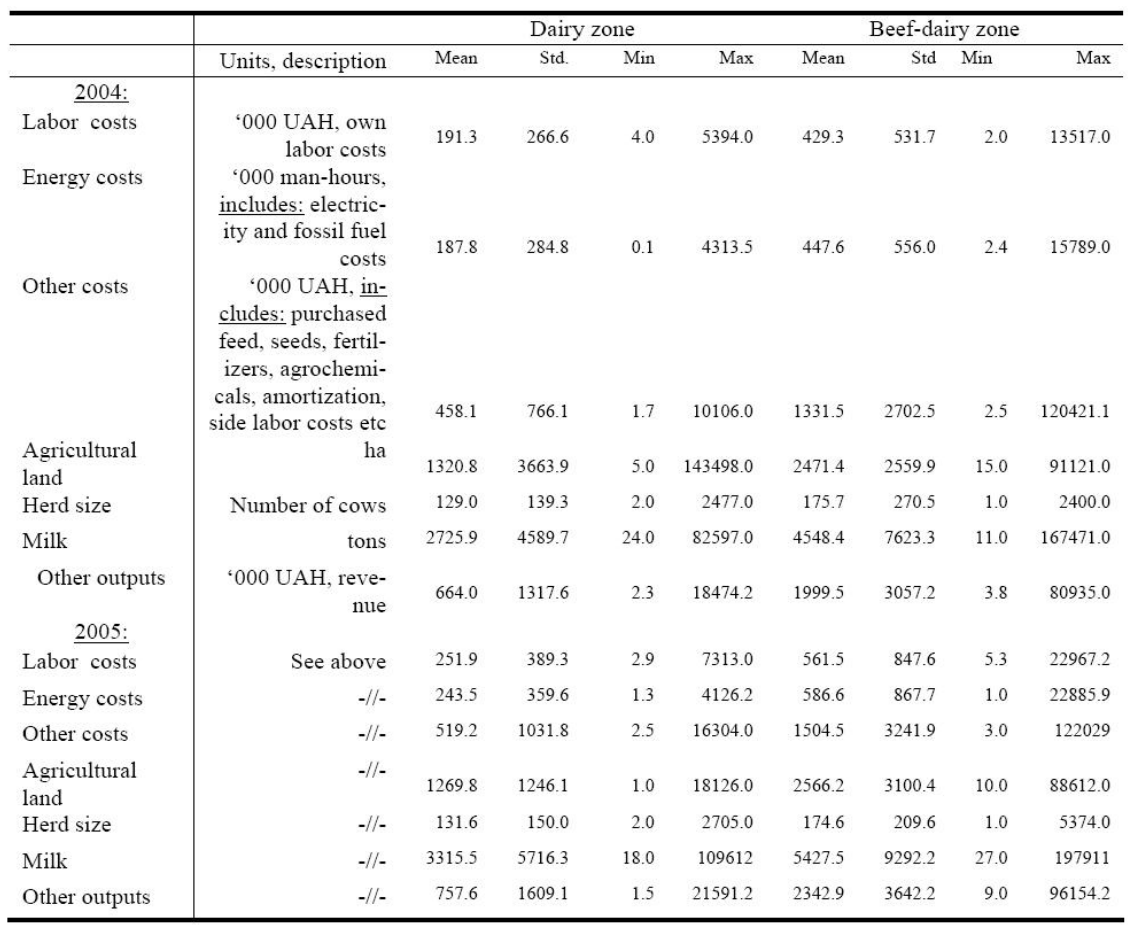

Source: Own presentation.

\section{Data and Variables Description}

The empirical analysis employs Ukraine-wide farm-level accounting data on input use and outputs for all commercial farms in 2004 and 2005. Information on subsidies is also available in this dataset. From this Ukraine-wide dataset we extracted a smaller dataset containing 5970 and 5067 milk producing farms in 2004 and 2005 respectively. The farms in the smaller dataset produce milk and generate revenues from this; they report non-zero milk production costs as well as positive numbers of cows. Also from different sources (e.g., Holovko, 2003) we have compiled information on the locations of these dairy farms as well as on the locations, processing capacities, and investments (between 2001 and 2005) of 463 dairy plants.

\section{Dependent Variable}

The dependent variables are the natural logarithm of the performance measure - order-m efficiency levels, and of the technical progress measure - technical change component of the order-m TFP growth. These two measures are calculated using a model with five inputs (herd size, agricultural land, labor costs, energy costs, and the aggregate of other costs) and two outputs (milk and revenue from other outputs). See Table 5.1 for more detailed description. 


\section{Agglomeration variables}

As it was already mentioned above, we expect that the behavior of dairy farms is influenced by the behavior of its neighbors or some local environment through lower transaction costs and easier diffusion of technical and market information. This view is consistent with Mansfield's (1963) models and others that viewed technical progress as a process of imitation wherein contacts with others led to the spread of technology (see Sunding and Zilberman, 2001; p.231). The spatial lag (SpilloverEff) variable in the SAR model 5.1 is used to capture this effect.

Dairy farms may also benefit from a more general infrastructure that facilitates the whole livestock sector production. If a dairy farm is located in the area of intensive livestock production, it gives a dairy farm an opportunity to draw from the same pool of workers, technicians, and services suppliers whose skills are applicable to the entire livestock sector. To proxy the size of the livestock (let alone the dairy farming) sector in the area for each farm, we use total 'local' farm livestock receipts less total 'local' raw milk receipts (Rlivestock) (see Roe et al, 2002). The total local values of livestock and milk receipts are the weighted average of all farms' livestock and milk receipts. The weights are the corresponding inverse squared distances between a farm of interest and all other farms in the dataset. Using inverse squared distances we give more weight to closer farms and less to farther ones. The term 'local' here does not denote a closed territory, but rather an indicator of intensity of (other than dairy farming) livestock production in the area around farm. The other alternative would be to measure this indicator within a certain distance from a farm. However, the choice of the threshold distance would be rather discretionary and it might differ across the territory of Ukraine. For instance, the size of farms tends to grow from the West to the East, implying the threshold distance should also increase in that direction; otherwise it will not be representative. The other alternative could be a county's total livestock receipts less dairy farming receipts (as in Roe et al, 2002). However, this measure would not reflect adequately the situation for farms located near the counties' borders, for instance. It might be the case that a dairy farm benefits in a certain way from a neighboring pig farm that is located in the neighboring county. In this case a county-based measure will not capture this interaction.

Links between dairy farms and processors might also give rise to urbanization economies (Paul, 2003). To secure a dependable supply of high quality raw milk, a processor might want to provide farms with extension, cooling tanks or some other assistance. Dairy plants that have invested in new processing equipment will be especially interested in securing a stable supply of highquality milk. Hence, we hypothesize that location near to dairy plants that have been investing will have a positive impact on dairy farms performance. For each dairy farm we identified the closest dairy plant(s) with its total investment level. We assign one to the dummy variable InvDairy if investment activities on the identified closest plant(s) were observed over 2003-2005. If there are more than two equidistant plants, the variable InvDairy might take values greater than 1 .

Some theoretical models imply lower technology adoption rates in regions that are farther from commercial centers. New technologies are more likely to be adopted near market centers where professional support is easily available, 
e.g. extension centers, dealers, and complementary inputs access (Sunding and Zilberman, 2001; p.249). Distance from a farm to the closest regional center (DistRegCenter) is used to test for such a relationship in our data. The squared term DistRegCenter2 captures possible non-linearity in this relationship.

\section{Market access and competition}

Technical change might be embodied in the inputs into food processing that may be driven by food processing demand and market structure patterns (Paul, 2003). To measure the degree of processing demand and local competition among dairy plants for raw milk supply, we include the total number of dairy processing plants (Dairies $50 \mathrm{~km}$ ) within $50 \mathrm{~km}$ from a dairy farm ${ }^{1}$. Quadratic term Dairies50km2 is included to capture possible nonlinearities.

\section{Farm Specific Variables}

The threshold models of technology adoption conclude that only farms with a size greater than a certain threshold size will adopt innovations (Sunding and Zilberman, 2001; p.250). In our application we expect that herd size (Herd) proxies farm size and should be positively associated with performance and technical change variables. The relationship might not be linear, so the herd size squared (Herd2) is also included.

Increase in farm productivity/performance is partly associated with increased specialization (Chavas, 2001; p.275) via more focused application of managers' skills. Specialization also allows farms and food marketing firms to become better organized spatially, thus contributing to lower transportation and marketing costs. To proxy the effect of specialization, we calculate the percentage of raw milk receipts in the total farm receipts (Spec).

Dairy farms in Ukraine mostly produce their own feed (Lischka, 2004), and for this they need land. As Pingali (2007; p.2795) shows, aggregate area expansion might be the driving force for a transition to more intensified mechanization thus generating productivity increases. Total farm arable land (ArableLand) is included to test for this. To account for the starting positions of the farms we include the 2004 order-m efficiency (Eff04) as a determinant of technical change and expect positive association between them.

\section{Price Supports}

Dairy farms in Ukraine receive a subsidy per liter of milk supplied to dairy processors. This subsidy is paid from value added tax (VAT) collected by dairy plants from sales of dairy products. This VAT is not paid to the budget by dairy plants but is retained on a special bank account and returned to primary milk producers in the form of premium (Zorya, 2006, p.12). A vast literature starting from Leibenstein (1966) points to the negative impact of the support measures on efficiency, mainly via a weakening of managerial efforts (e.g., Bergsman, 1974; Balassa, 1975; Lassaad, 1994; Giannakas et al., 2001). However, Kalaitzandonakes and Bredahl (1993, 1994) conclude that the effect

\footnotetext{
${ }^{1} 50 \mathrm{~km}$ is the average procurement radius of dairy plants in Ukraine (Popova, 2007: p.129)
} 
Table 5.2: Technical progress SAR model - summary statistics

\begin{tabular}{|c|c|c|c|c|c|c|c|c|c|}
\hline \multirow[t]{2}{*}{ Variable } & \multirow[t]{2}{*}{ Description } & \multicolumn{4}{|c|}{ Dairy zone } & \multicolumn{4}{|c|}{ Beef-dairy zone } \\
\hline & & Mean & Std & Min & Max & Mean & Std & Min & Max \\
\hline$T C$ & Technical change & 1.05 & 0.12 & 0.50 & 1.53 & 0.98 & 0.15 & 0.40 & 2.03 \\
\hline Eff4 & $\begin{array}{r}\text { Order-m efficiency } \\
\text { in } 2004\end{array}$ & 0.82 & 0.34 & 0.22 & 3.69 & 0.65 & 0.25 & 0.17 & 3.15 \\
\hline InvDairy & Dummy & 0.69 & 0.65 & 0.00 & 2.00 & 0.59 & 0.54 & 0.00 & 3.00 \\
\hline Subsidy & $\begin{array}{r}\text { Subsidies, '000 } \\
\text { UAH }\end{array}$ & 96.08 & 186.9 & 0.00 & 1552.5 & 256.4 & 595.7 & 0.00 & 13783 \\
\hline ArableLand & Arable land, ha & 991.8 & 903.5 & 0.1 & 9802.5 & 2274 & 1694 & 0.1 & 21053 \\
\hline Herd & Number of cows & 139.0 & 133.4 & 3.00 & 891.00 & 186.0 & 183.7 & 2.00 & 1842.5 \\
\hline Spec & $\begin{array}{r}\text { Share of milk in total } \\
\text { farm revenues }\end{array}$ & 0.28 & 0.18 & 0.00 & 0.99 & 0.17 & 0.16 & 0.00 & 0.98 \\
\hline Dairies $50 \mathrm{~km}$ & $\begin{array}{r}\text { Number of dairy } \\
\text { plants }\end{array}$ & 4.39 & 2.24 & 0.00 & 11.00 & 4.92 & 2.10 & 0.00 & 14.00 \\
\hline DistRegCenter & $\begin{array}{l}\text { Distance to the clos- } \\
\text { est region center, km }\end{array}$ & 267.2 & 90.98 & 3.64 & 1202.9 & 539.9 & 178.8 & 11.60 & 3880.1 \\
\hline Rlivestock & $\begin{array}{r}\text { Total local livestock } \\
\text { receipts less dairy } \\
\text { receipts, '000UAH }\end{array}$ & 80.65 & 43.55 & 0.01 & 214.69 & 84.42 & 43.69 & 0.01 & 271.96 \\
\hline
\end{tabular}

Source: Own presentation; Note: $1 U S D=5.3 U A H$

of protectionism on productivity is a priori ambiguous. They argue that protection may positively influence productivity growth for low income industries via encouraged investments and technical progress; however, for the high income industries, protection is likely to have an adverse effect by generating technical and scale inefficiencies. McCloud and Kumbhakar (2007) study the impact of direct payments on dairy farms productivity in Denmark, Sweden and Finland. They find that these subsidies have a positive impact on technical efficiency. Sunding and Zilberman (2001; p.250) emphasize different mechanisms through which price supports can influence technology adoption on farms of different sizes. For instance, smaller farms may increase their technology adoption via better credit access as a result of subsidies when the ability to obtain credit depends on expected income. We included the PPI (Producer Price Index) adjusted total amount of subsidies a farm received in 2004 and 2005 (Subsidy) and interacted it with farm's herd size (Herd $\times$ Subsidy), to differentiate the impact of the price support on farms of different sizes. See Tables 5.2 - 5.3 for summary statistics.

\subsection{Empirical Findings}

\section{Spatial Clusters}

To begin we test whether all dairy farms have access to the same technology. From the literature on the livestock sector in Ukraine (e.g. Sabluck, 2003) we know that mainly dairy and beef-dairy cattle farming prevail in Ukraine. Dairy cattle farming is mainly located in the North-Western Forest agro-climatic zone where enough rich fodder is available, while beef-dairy farming is located on the rest of the territory, i.e. in the Forest-Steppe and Steppe zones to the South and East. To test for technological heterogeneity between the two zones (Forest versus pooled Forest-Steppe and Steppe zones), we estimate flexible trans-log production functions for the Forest, pooled Forest-Steppe and Steppe agro- 
Price Support, Performance and Technical Progress in Ukrainian Dairy Farms: a Spatial

Analysis

climatic zones, as well as pooled model for all two zones ${ }^{2}$. The null hypothesis of poolability across zones is rejected using a LR-test at $1 \%$ significance level ${ }^{3}$. So in the following we perform a separate analysis for the farms in the Forest zone and for the farms in the Steppe and Forest-Steppe zones (dairy and beefdairy zones/technologies in the following).

Dairy farms in Ukraine usually produce multiple outputs. So the incentives for efficient dairy farming might vary depending on, for example, farm specialization. To account for this, in the following we estimate efficiency based on 2 outputs (milk in physical units and revenue generated by other outputs) and 5 inputs (labour, energy and other production costs, as well as the herd size and agricultural land; see Table 5.1 for details). Using this 7-dimensional model, we first check our dataset for outliers using the Simar (2003) method. The percentage of the identified outliers identified in this manner is far less than $1 \%$ in both 2004 and 2005 .

Next, we compute order-m efficiency scores for the dairy and beef-dairy groups of farms in 2004 and in 2005 using the FEAR package in R (Wilson, 2008). The important point here is choosing an appropriate value of $m$. Since we have a relatively large-dimensional problem, the approach suggested in Cazals et al (2002) is not really informative ${ }^{4}$ because almost all farms in the two groups have FDH efficiency estimates equal to 1 . So in the order-m frontier framework almost all farms lay above the frontier and the percentage of outlying farms approaches 0 as $m$ increases, but efficiency scores approach 1 . That is why we follow the approach of Wheelock and Wilson (2003) and study the distributions of order-m efficiency estimates as $m$ ranges from 10 to 300 . Based on this we chose $m=15$ and $m=40$ for the dairy and beef-dairy zones respectively, which is about $1 \%$ of the sample size in the corresponding group.

Figure 5.3 shows the distributions of order-m and TFP growth components estimates. Order-m efficiency estimates distributions look very similar for both groups of farms in both periods (see Figure 5.3.a). In 2005 there was a noticeable shift/improvement of efficiency distributions in both groups compared to 2004. The 2005 distributions become wider with more probability mass (more farms) in the higher efficiency region.

As Figures 5.3.b shows, the efficiency change distributions peak slightly to the right of one; about $52 \%$ and $55 \%$ of the dairy farms experienced positive efficiency change in the dairy and beef-dairy zones, respectively. The technical change distributions differ drastically between the two groups of farms. Only $37 \%$ of the milk producers in the beef-dairy zone experienced technical progress, while in the dairy zone this figure is $72 \%$. Together, these effects result in TFP improvements of $64 \%$ and slightly less than $50 \%$ for dairy farms in the dairy and beef-dairy zones, respectively. As Figures 5.3.b-d demonstrate, the technical change was the main source of TFP change in 2004-2005.

Figures 5.4 - 5.5 shows clusters of the technical change and efficiency estimates,

\footnotetext{
${ }^{2}$ Our database contains information on milk output and specific inputs (herd size, gross variable costs, and labor) at the farm level. With these variables we are able to estimate a parametric production function to test for the presense of a unique technology. In subsequent steps, however, we employ the non-parametric efficiency estimation techniques outlined above (m-order) to better account for multi-output nature of the dairy farms in Ukraine.

${ }^{3}$ See Brümmer et al (2002) for details on the test

${ }^{4}$ Cazals et al (2002) and Simar (2003) propose choosing $\mathrm{m}$ based on the percentage of observations lying outside the frontier, and $\mathrm{m}$ should be a relatively small number.
} 
Table 5.3: Performance SAR model - summary statistics

\begin{tabular}{|c|c|c|c|c|c|c|c|c|c|}
\hline \multirow[t]{2}{*}{ Variable } & \multirow[t]{2}{*}{ Description } & \multicolumn{4}{|c|}{ Dairy zone } & \multicolumn{4}{|c|}{ Beef-dairy zone } \\
\hline & & Mean & Std & Min & Max & Mean & Std & Min & Max \\
\hline \multicolumn{10}{|l|}{2004} \\
\hline Eff & $\begin{array}{r}\text { Order-m } \\
\text { efficiency }\end{array}$ & 2.2 & 1.3 & 0.5 & 18.4 & 1.7 & 0.8 & 0.4 & 12.8 \\
\hline InvDairy & Dummy & 0.7 & 0.7 & 0.0 & 2.0 & 0.6 & 0.5 & 0.0 & 3.0 \\
\hline Subsidy & $\begin{array}{l}\text { Subsidies, } \\
\text { '000 UAH }\end{array}$ & 63.6 & 122.0 & 0.0 & 942.0 & 90.2 & 273.9 & 0.0 & 11784 \\
\hline ArableLand & $\begin{array}{r}\text { Arable land, } \\
\text { ha }\end{array}$ & 1011.9 & 1033.4 & 0.1 & 14123 & 2307.3 & 2016.6 & 0.1 & 37685 \\
\hline Herd & $\begin{array}{r}\text { Number of } \\
\text { cows }\end{array}$ & 139.8 & 144.6 & 2.0 & 2477.0 & 183.9 & 185.4 & 2.0 & 2400.0 \\
\hline Spec & $\begin{array}{r}\text { Share of } \\
\text { milk in total } \\
\text { farm reve- } \\
\text { nues }\end{array}$ & 0.2 & 0.1 & 0.0 & 0.9 & 0.1 & 0.1 & 0.0 & 0.9 \\
\hline Dairies $50 \mathrm{~km}$ & $\begin{array}{l}\text { Number of } \\
\text { dairy plants }\end{array}$ & 4.4 & 2.2 & 0.0 & 11.0 & 4.9 & 2.1 & 0.0 & 14.0 \\
\hline Rlivestock & $\begin{array}{r}\text { Total local } \\
\text { livestock } \\
\text { receipts less } \\
\text { dairy re- } \\
\text { ceipts, } \\
\text { '000UAH }\end{array}$ & 204.6 & 63.3 & 5.3 & 906.0 & 430.7 & 125.2 & 0.0 & 1263.0 \\
\hline DistRegCenter & $\begin{array}{r}\text { Distance to } \\
\text { the closest } \\
\text { region cen- } \\
\text { ter, } 10 \mathrm{~km}\end{array}$ & 8.02 & 4.39 & 0.0 & 21.59 & 8.45 & 4.40 & 0.0 & 27.20 \\
\hline \multicolumn{10}{|l|}{2005} \\
\hline Eff & See above & 2.2 & 1.6 & 0.6 & 21.0 & 1.7 & 0.7 & 0.4 & 12.5 \\
\hline InvDairy & $-/ /-$ & 0.7 & 0.7 & 0.0 & 2.0 & 0.6 & 0.5 & 0.0 & 3.0 \\
\hline Subsidy & $-/ /-$ & 96.5 & 188.5 & 0.0 & 1694.0 & 130.0 & 270.2 & 0.0 & 2980.0 \\
\hline ArableLand & $-/ /-$ & 990.7 & 1090.0 & 0.1 & 17707 & 2282.9 & 2450.0 & 0.1 & 74892 \\
\hline Herd & $-/ /-$ & 132.1 & 150.2 & 2.0 & 2705.0 & 173.3 & 189.5 & 2.0 & 2400.0 \\
\hline Spec & $-/ /-$ & 0.3 & 0.2 & 0.0 & 0.9 & 0.2 & 0.1 & 0.0 & 1.0 \\
\hline Dairies $50 \mathrm{~km}$ & $-/ /-$ & 4.4 & 2.2 & 0.0 & 11.0 & 4.9 & 2.1 & 0.0 & 14.0 \\
\hline Rlivestock & $-/ /-$ & 267.4 & 87.4 & 0.9 & 920.1 & 551.9 & 276.3 & 0.0 & 7090.0 \\
\hline DistRegCenter & $-/ /-$ & 8.06 & 4.33 & 0.0 & 21.47 & 8.44 & 4.37 & 0.0 & 27.20 \\
\hline
\end{tabular}

Source: Own presentation; Note: $1 U S D=5.3 U A H$ 
Figure 5.3: Order-m efficiency and TFP growth estimates distributions

a) tech. efficiencies, $2004 / 05$

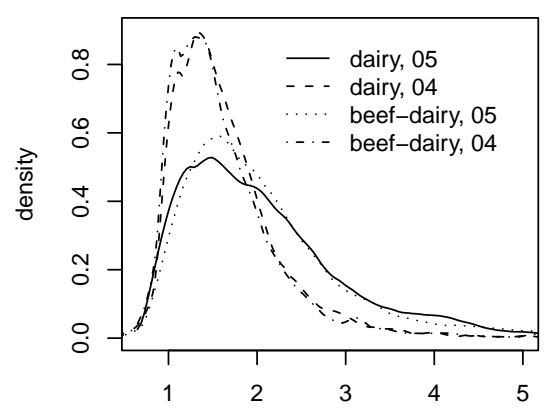

c) tech. change, $2004 / 05$

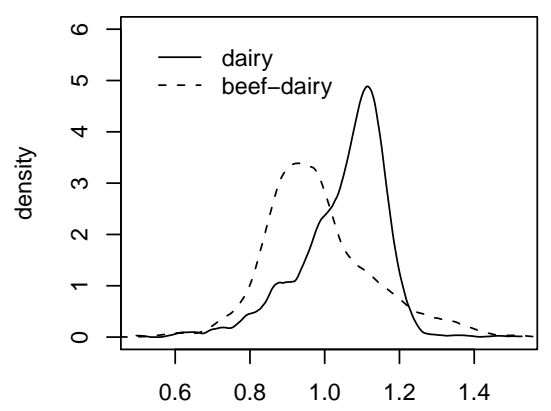

b) efficiency change, $2004 / 05$

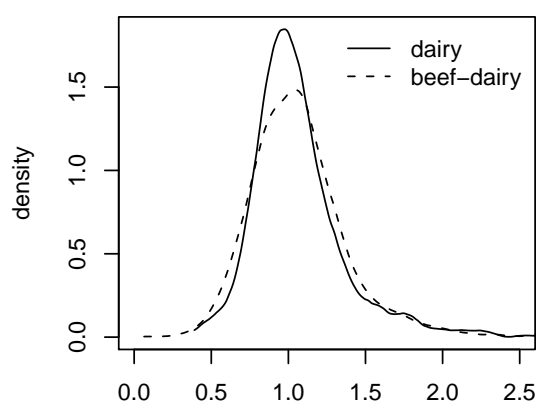

d) tfp change, 2004/05

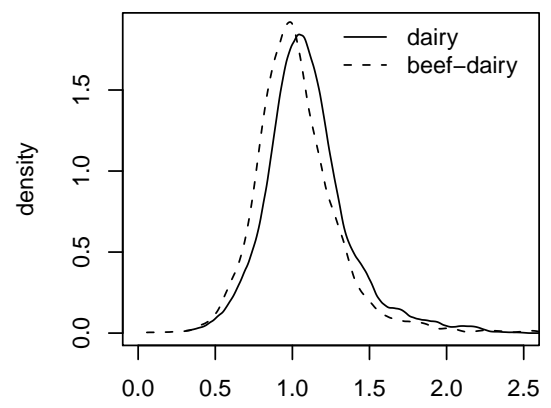

Source: own calculation.

identified using the LISA test (Anselin, 1995). Here the cluster are denoted by different symbols demonstrate whether the nearest neighbors have sufficiently similar scores (at the 5\% Bonferroni-adjusted significance level using saddlepoint approximation of the test-statistics ${ }^{5}$ ). In all plots the dairy zone is colored in orange, while beef-dairy zone is in light-blue. Figure 5.4 demonstrates a very similar spatial pattern of order-m efficiency clusters in both periods. In many cases the high performing cluster in 2004 have also successfully performed in 2005. These persistently high performing clusters are concentrated mainly in the Western (Lvivska and Volynska oblast) and North-Central (close to the capital - Kyiv and in Chernihivska oblast) parts of Ukraine. In the East and South, though, there are also persistently high performing clusters.

In Figure 5.5 the dairy zone is dominated by ' + ' crosses (clusters of technical regress), while the crosses ' $x$ ' dominate the beef-dairy zone (clusters of tech-

\footnotetext{
${ }^{5}$ Bivand et al. (2009) shows that using conventional normal approximation for the distribution of local Moran's I usually leads to over- and rarely also underconfidence when testing for local clusters. Saddlepoint approximation performs well in this respect.
} 
Figure 5.4: Spatial Clustering of efficiency scores, 2004/05

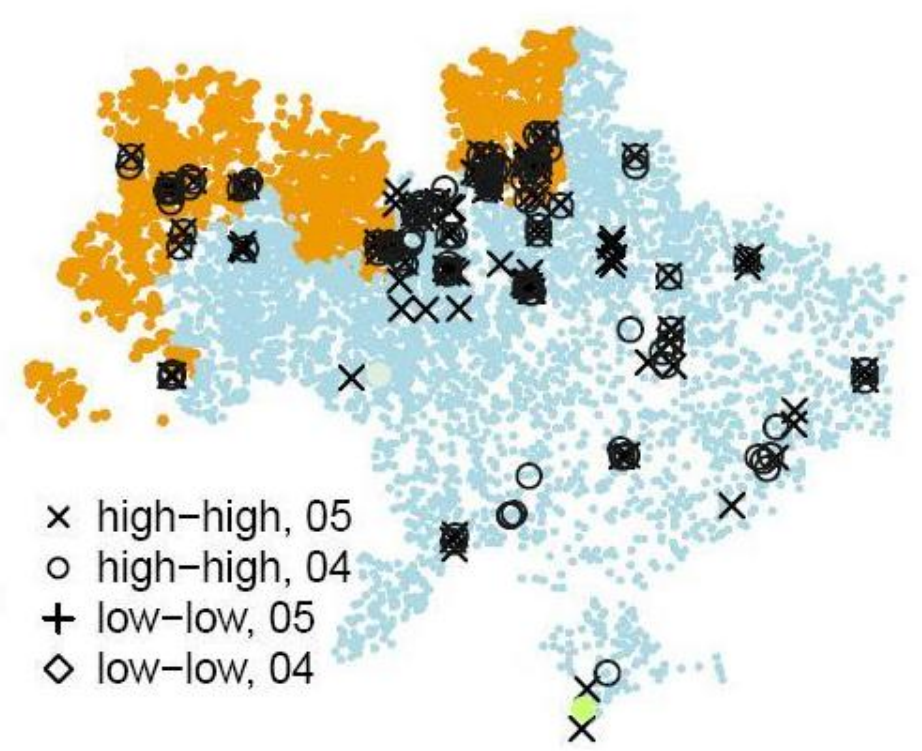

Source: own exposition using spdep package in $R$ (Bivand et al., 2008).

Notes: dairy zone dots (farms) are colored in orange, beef-dairy zone dots (farms) are colored in light-blue color. Crosses $(x)$ or circles (o) denote neighboring observations with significantly similar high scores (at $5 \%$ Bonferroni adjusted significance level); crosses $(+)$ or diamonds $(\diamond)$ denote neighboring observations with significantly similar low scores. We used saddle-point approximation of the test statistics; see Bivand et al. (2009) for details.

nical progress). To explain this remarkable difference between the two zones, more detailed analysis is required. One reason for the cloud of ' $x$ ' crosses in the region of Vinnytsia oblast (Central Ukraine) might be the 'Vinnytsya Dairy Supply Chain Development Project' implemented by IFC in 2005-2008. One of the claimed project's achievements was the assistance to 46 farms in adopting new technologies ${ }^{6}$.

In essence, Figures 5.4 - 5.5 provide evidence of spatial dependence in the estimated technical change and efficiency scores, and thus indicates that spatial dependence should be accounted for in when we model the determinants of performance and technical progress on dairy farms in the next stage of our analysis.

${ }^{6}$ The project worked with dairy farmers producers in the Vinnytsya region of Ukraine to strengthen the milk supply chain. The project together with Loostdorf dairy plant and local authorities and financial institutions help large and household farms improve farm management, access to credit, and increase production of high quality milk. http://www. ifc.org/ifcext/eca.nsf/Content/Ukraine_AdvisoryProjects_Completed 
Figure 5.5: Spatial clustering of technical change scores, 2004/05

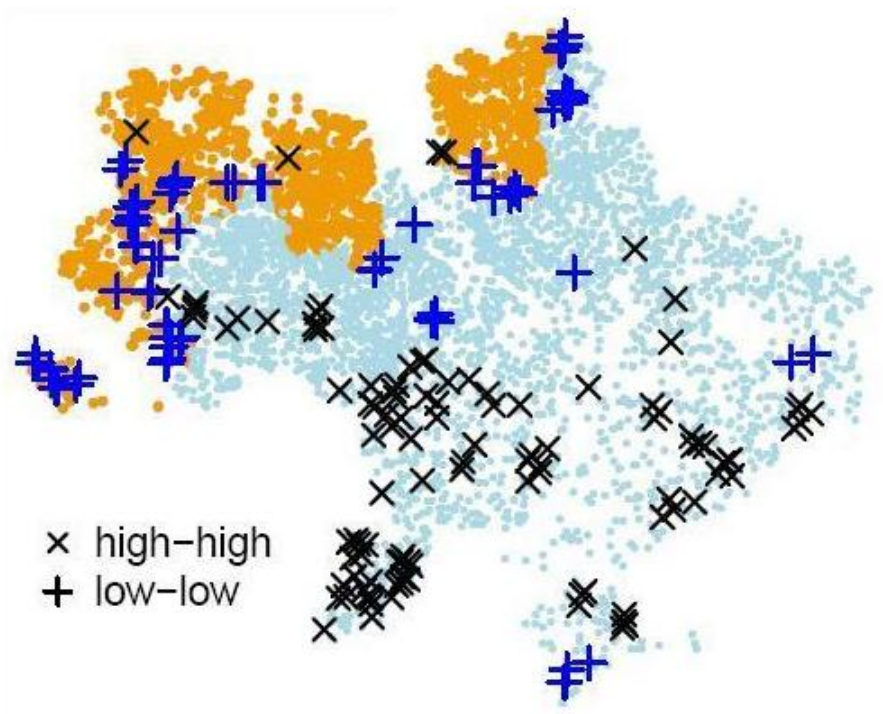

Source: own exposition using spdep package in $R$ (Bivand et al., 2008).

Notes: dairy zone dots (farms) are colored in orange, beef-dairy zone dots (farms) are colored in light-blue color. Crosses $(x)$ denote neighboring observations with significantly similar high scores (at 5\% Bonferroni adjusted significance level); crosses (+) denote neighboring observations with significantly similar low scores. We used saddle-point approximation of the test statistics; see Bivand et al. (2009) for details.

\section{Model selection and estimation results}

In this section we present the results of modeling the determinants of technical change and efficiency patterns in the presence of spatial dependence. For this we use the SAR model 5.1 in section 5.3. The spatial weight matrix $W$ in (1) can be constructed in many ways. Following a theoretical point of view (see Getis, 2009), it is natural to believe that the interaction between the farms decays with a distance. So we assign the weights in the matrix using the inverse squared distance function, $w_{i j}=\frac{1}{d_{i j}^{2}}$, where $d_{i j}$ is the distance between dairy farms $i$ and $j$.

Two important points should be mentioned before proceeding with the results. First, due to restructuring of agricultural sector in Ukraine over the last years we cannot trace some farms from 2004 into 2005. Some farms might be acquired by larger so-called 'agro-holdings' and therefore cease to exist in the registry of agricultural enterprises. In their places, new agricultural enterprises emerge as units of their corresponding agro-holdings in the registry, but it is extremely difficult to link the newly registered farms to their old predecessors (Ilienko and Lapa, 2009). In other cases less efficient farms might simply 
cease milk production and automatically fall out of the sample in subsequent years. The panel of dairy farm data is thus unbalanced. Since in the technical progress models below the farms should be observed in both periods, and since the mechanism that determines which farms remain in the sample is not clear, potentially we face a selection bias problem.

To check and correct for this we apply a Heckman selection procedure. In the first stage we estimate a probit model generating the probability that a farm is observed in both periods, conditional on a set of explanatory variables. The variables that might explain the selection mechanism include some of the variables discussed in the section 5.3: price supports (Subsidy), investment activity of the closest dairy plant (InvDairy), agglomeration (Rlivestock), distance to the regional center (DistRegCenter), farm efficiency (Eff), market access $(\text { Dairies } 50 \mathrm{~km})^{7}$. In the second stage we estimate the technical progress SAR model with the estimated inverse Mills ratio as an additional explanatory variable $^{8}$. Since this variable turns out to be insignificant there is no evidence of selection bias. We therefore restrict our attention to the model without correction for selection bias in the following.

In the performance model we could use panel SAR model, since we have two cross-sections. However, the fixed effect SAR (Elhorst, 2003) would wipe out all explanatory time-invariant variables, e.g. market access and competition (Dairies50km), distance to the regional center (DistRegCenter), and investment activity of the closest dairy plant (InvDairy). These variables are the key ones in our application, so we opt for another estimation strategy ${ }^{9}$. We estimate separately the SAR model for each cross section, and see whether results are similar.

Another issue is that Simar and Wilson (2007) heavily criticize the conventional two-stage estimation strategy in which DEA/FDH estimated efficiency scores are regressed on environmental variables. Their main objection is that conventional inference is invalid in this setting due to complicated, unknown serial correlation among the estimated DEA/FDH efficiencies. Since order-m estimator is more robust to extreme values, noise or outliers (Cazals et al., 2002), we expect that serial correlation should not be as acute as with DEA/FDH estimator. To the best of our knowledge, this issue has not been addressed in the literature so far. Moreover, even if serial correlation exists, it disappears more quickly in the order-m than in the DEA/FDH context. Finally, by using the SAR approach we explicitly model at least the spatial component of any correlation between performance measures.

Table 5.4 presents the results of the technical progress and performance models' estimations. The models are able to explain about $22-53 \%$ of the variation in the target variables. This is a good result for a cross-sectional regression.

\footnotetext{
${ }^{7}$ Spatial autoregressive probit model (LeSage, 2000) showed no significant spatial effects in the model, so we proceeded with a standard probit model.

${ }^{8}$ These results are available from the authors on request.

${ }^{9}$ The random effects spatial model, as an alternative to fixed effects model, is difficult to justify in our application because unobservable factors that influence performance (efficiency) such as management quality, education, policy variables are likely correlated with the independent variables in the model.
} 
Price Support, Performance and Technical Progress in Ukrainian Dairy Farms: a Spatial

Table 5.4: SAR regressions results

\begin{tabular}{|c|c|c|c|c|c|c|}
\hline & \multicolumn{2}{|c|}{$\begin{array}{l}\text { Technical pro- } \\
\text { gress models. } \\
\text { Dependant vari- } \\
\text { able: Logged } \\
\text { Tech. Change } \\
\text { (L.TC) }\end{array}$} & \multicolumn{4}{|c|}{$\begin{array}{l}\text { Performance models. Dependant vari- } \\
\text { able: Logged order-m Efficiency } \\
\text { (L.Eff) }\end{array}$} \\
\hline & Dairy & Beef- & \multirow{2}{*}{\multicolumn{2}{|c|}{ Dairy zone }} & \multirow{2}{*}{\multicolumn{2}{|c|}{ Beef-Dairy zone }} \\
\hline & \multirow{2}{*}{\multicolumn{2}{|c|}{$2004 / 05$}} & & & & \\
\hline & & & 2004 & 2005 & 2004 & 2005 \\
\hline Const. & $0.062^{* * *}$ & -0.003 & $0.571^{\text {*l*k }}$ & $0.580^{* * * *}$ & $0.435^{* * *}$ & $0.442^{\text {**** }}$ \\
\hline InvDairy, dummy & $0.011^{* * *}$ & -0.003 & 0.000 & -0.016 & 0.008 & 0.001 \\
\hline Subsidy (std) & $-0.072 * * *$ & $0.011 * *$ & $0.339 * * *$ & $0.349 * * *$ & $0.362 * * *$ & $0.222 * * *$ \\
\hline ArableLand (std) & $-0.021 * * *$ & $0.030 * * *$ & $0.059^{* * * *}$ & $0.112 * * *$ & $0.094^{* * *}$ & $0.084 * * *$ \\
\hline ArableLand2 (std) & 0.001 & $-0.004 * * *$ & $0.009^{* * * *}$ & $0.008 * *$ & $-0.002 *$ & -0.002 *** \\
\hline Herd (std) & $0.060^{* * *}$ & $-0.044^{* * *}$ & $0.070^{\text {**** } * \text { * }}$ & $0.090^{* * * *}$ & $-0.038^{* * *}$ & 0.004 \\
\hline $\operatorname{Herd} 2$ (std) & $-0.016 * * *$ & $0.008 * * *$ & 0.002 & 0.002 & $0.015^{* * *}$ & $0.010^{* * * *}$ \\
\hline $\operatorname{Herd}($ std $) \times$ Subsidy $($ std $)$ & $0.017 * * *$ & $-0.005 * * *$ & $-0.092^{* * * *}$ & $-0.110^{* * *}$ & $-0.067 * * *$ & $-0.041 * * *$ \\
\hline Spec (std) & $0.060^{* * *}$ & $-0.076^{* * *}$ & $-0.046^{* * * *}$ & $-0.045^{* * *}$ & $0.052^{* * *}$ & $0.020^{* * *}$ \\
\hline Spec2 (std) & $-0.025 * * *$ & $0.023 * * *$ & $0.035^{\text {**** }}$ & $0.042 * * *$ & -0.002 & -0.002 \\
\hline EffD 4 & 0.002 & $0.023^{* * *}$ & - & - & - & - \\
\hline Dairies $50 \mathrm{~km}$ & -0.003 & $-0.009 * * *$ & $0.022^{* *}$ & 0.013 & 0.005 & -0.002 \\
\hline Dairies $50 \mathrm{~km} 2$ & -0.000 & $0.001 * *$ & $-0.002 * *$ & -0.001 & -0.000 & 0.000 \\
\hline Rlivestock (std) & 0.003 & 0.002 & $0.015^{*}$ & $0.021 * *$ & -0.004 & $0.008^{*}$ \\
\hline DistRegCenter & $0.003^{* *}$ & $-0.045^{* * *}$ & -0.004 & -0.002 & $-0.007^{* *}$ & $-0.008^{\text {*** }}$ \\
\hline DistRegCenter 2 & 0.000 & $0.000 * * *$ & 0.000 & 0.000 & 0.000 & $0.000^{* *}$ \\
\hline SpilloverEff & $0.072 * * *$ & $0.023 * *$ & $0.140^{* * *}$ & $0.128 * * *$ & $0.094^{* * *}$ & $0.089 * * *$ \\
\hline$R^{2}$ & 37.3 & 22.4 & 50.9 & 51.7 & 24.1 & 27.8 \\
\hline N of observations & 1364 & 3077 & 1454 & 1448 & 3406 & 3364 \\
\hline
\end{tabular}

Source: Own estimation using LeSage spatial models package for Matlab, available at www. spatial-econometrics. com.

Note: ***, **, *: significance at 1\%, 5\%, 10\%; (std) means that a variable is measured in standard deviations from the mean 


\section{Agglomeration}

The estimated coefficients on the spatial lag term SpilloverEff demonstrate significant positive spatial dependence across the models, reflecting the extent of spatial spillovers across the neighbouring dairy farms. This confirms the results of the LISA test we demonstrated in Figures 5.4 - 5.5. That means that dairy farms that are similar in terms of performance and technical progress tend to cluster in space and they do benefit from spatial proximity via unobserved factors as (knowledge) spillovers, easier information and technology diffusion etc. This also mean that an effect of explanatory variables in models is attributed to some practice styles or behaviours among the nearest neighbouring farms. For instance the coefficients on the spatial lag term in the performance model in the dairy zone equal $0.14-0.13$. This means that each 1 unit change in explanatory variables derives about $15-16 \%$ of their impact from some common unobserved neighbouring behavioural pattern (the spatial multiplier is $\frac{1}{1-\rho}$ ). One might interpret this as dairy farmers to some extent 'look over the fence' and 'imitate' their neighbors. In the dairy zone, though, the spatial interaction among dairy farms is stronger than in the beef-dairy zone.

The effect of Rlivestock variable across the models suggests that farms benefit from local or sector specific infrastructure. In the technical progress models the effect of Rlivestock variable is positive but not significant. In the performance models the effect of Rlivestock variable is consistently and significantly positive, except for a beef-dairy zone in 2004 .

Farms seem to benefit from proximity to investing dairy plants (InvDairy) in terms of technology improvements, which supports the hypothesis proposed at the beginning of the paper. Although this variable is not significant in the beef-dairy zone, in the dairy zone it is statistically significant. Each additional investing dairy plant in the proximity to a farm increases the rate of technical change of the farms by $1.1 \%$. Across the performance models the variable (In$v$ Dairy) has no significant impact.

Distance to the closest region center (DistRegCenter) has a significant negative effect in the performance models. For instance every $\mathrm{km}$ away from the regional center decreases the efficiency of a farm by $0.1 \%$ in the beef-dairy zone. The magnitude of this impact is very similar across the performance models. Quadratic terms only moderate the impact in the higher range of distance values. In the technical progress models the impact of distance is zone-specific. In the beef-dairy zone it is the same as across the performance models, and opposite to the impact in the dairy zone.

\section{Market access and competition}

Market access and competition variable (Dairies50km) shows some consistency in terms of the impact ( $\bigcap$-shaped) across the performance models, but it is statistically significant only in the dairy zone in 2004 . This means that too many dairy plants (more than 6-8, according to the performance models results) in proximity to farms adversely affect farms' performance. In the technical progress models the impact of (Dairies50km) variable is U-shaped, but it is statistically significant only in the beef-dairy zone. This basically means that farms tend to improve their technology provided they have a sufficient number of dairy plants in the neighborhood (more than 7 ). 


\section{Farm Specific Variables}

The impact of the herd size (Herd) is positive and statistically significant across the performance models, although it shows a sign of U-shaped impact in the beef-dairy zone. The magnitude of the impact (one standard deviation from the mean and at the mean subsidies volume) is comparable across the models and ranges from $2 \%$ to $9 \%$ of efficiency increase ${ }^{10}$. The impact of the herd size on technology change is statically significant but zone-specific. In the dairy zone it is $\bigcap$-shaped, while it is opposite in the beef-dairy zone.

Specialization, as expected, shows a sign of a positive impact on the performance of dairy farms. Remember, that we proxy specialization as a percentage of raw milk in the total farm receipts. Since we found a statistically significant U-shaped impact in the dairy zone, this suggests that a positive impact starts from a certain degree of specialization in dairy farming. This turning point for the dairy zone is in the range $50-65 \%$. For the beef-dairy zone the impact is positive non-linear. Interesting, that in the technical progress models specialization 'works' in opposite direction. The resulting coefficients are very similar in absolute values, but opposite in signs.

Arable land in general, as expected, increases the efficiency of dairy farming, though non-linearly. Depending on a zone, an increment of arable land by one standard deviation from the mean, increases dairy farm efficiency by $8-13 \%$. In the beef-dairy zone the impact is moderated by a significant squared term in the higher range of agricultural land values and it turns into negative at about 43,000 ha. The same type of behavior is observed in the technical progress model for the beef-dairy zone, while the impact is opposite in the dairy zone. The efficiency variable (Eff04) demonstrates a strong positive impact on technical improvement in the beef-dairy models, suggesting that better performing farms are also more successful in technical progress. For the dairy zone this impact is not significant.

\section{Price Supports}

The effect of price support is the same across the performance models and in the technical progress model for the beef-dairy zone. At the mean herd size the impact of price supports is strongly positive. The magnitude of the impact, though, is different for each zone. At the mean herd size (150 and 180 cows in the dairy and beef-dairy zones, respectively), a one standard deviation increase in the volume of subsidies received increases the efficiency of a dairy farm by $34-35 \%$ and $22-36 \%$ in the dairy and beef-dairy zones respectively. However, as the cross term $\operatorname{Herd}(s t d) \times$ Subsidy(std) demonstrates, the impact gets weaker as the herd size increases (holding Subsidy and all other variables constant) and becomes negative, for example, at a herd size of about 1,000 (550-800) cows in the performance models for the dairy (beef-dairy) zone. The impact of subsidies is the opposite in the technical progress model for the dairy zone, i.e. at the mean herd size subsidies negatively influence the technical change, while it vanishes and turns into positive as the herd size increases.

\footnotetext{
${ }^{10}$ In the beef-dairy zone model for 2004 the marginal effect falls into this range for herd size greater than 550 cows
} 


\subsection{Conclusions}

The successful completion of WTO negotiations, combined with expected FTA negotiations with the EU, will take Ukraine's agriculture into a new phase of its development. These two big challenges imply further significant structural changes in Ukraine's agriculture sector as well as adjustments at the farm level to achieve greater efficiency and productivity levels. Using the dataset of 11,353 farms producing raw milk over the period 2004-2006, we perform a spatial analysis of the determinants of performance and technical progress in the dairy farming sector of Ukraine. In particular we looked at the impact of price supports and benefits from the agglomeration economies in the sector. We differentiate between the performance and technology spillovers due to 'location and urbanization economies'. Location economies arise from farms' proximity and some local, sector-specific infrastructure, information and services, while urbanization economies arise from a more general livestock infrastructure, as well as from up- and downstream linkages. In later context we test whether the location near to dairy plants that have been investing has a positive impact on dairy farms performance.

Technical progress in dairy farms is measured by the technical change component in the order-m TFP growth, while the performance is measured by order-m output efficiency. In the analysis we differentiate between two technologies (dairy and beef-dairy technologies) that are identified according to agro-climatic zones. The distributions of estimated efficiency scores demonstrate a noticeable improvement in performance of dairy farms in the period considered. $64 \%$ and slightly less than $50 \%$ of dairy farms in the dairy and beef-dairy zones, respectively experienced an improvement in TFP growth. Technical change was the main source of TFP change in 2004-2005 periods.

The spatial analysis (using LISA test) revealed a substantial spatial dependence in the technical change and efficiency patterns. In particular, we identified only high efficiency clusters in each zone, and these clusters tend to persist over time. On the technical change side, each zone has clusters of high and low performers. The dairy zone is characterized mainly by low technical change clusters, while the beef-dairy zone is characterized mainly by high technical change clusters. Using a spatial autoregressive model we then analyze the determinants of technical change and efficiency patterns in Ukrainian dairy farming. The results across all the models confirm that there is a spatial dependence in the independent variables and farms benefit in terms of technical change and efficiency from proximity. The magnitude of spatial interaction is not substantial though. The value of the spatial lag coefficient ranges from 0.023 to 0.14 . Better sectorspecific infrastructure and services also show a sign of benefiting dairy farms in both zones. The location near to dairy plants that have been investing, channels a positive impact on dairy farms mainly via technical progress.

The impact of other variables is consistent across the performance models, while somewhat controversial in the technical change models. As expected, arable land, herd size, and specialization have positive (non-linear) impact on farms' efficiency in both regions. There seems to be a consistent pattern regarding the impact of a farm's distance from the regional centers. Dairy farms benefit more the closer they are located to the market centers (regional centers in our application). Price support is positively associated with dairy farms' efficiency at the mean herd size. However, the efect diminishes with increasing 
Price Support, Performance and Technical Progress in Ukrainian Dairy Farms: a Spatial

Analysis

herd size and even turns into negative. For instance, the combined effect of subsidies turns to negative for herd size greater than 1,000 (550-800) cows in the performance models for the dairy (beef-dairy) zone.

As for the determinants of the technical change (additional to the agglomeration economies we talked in the previous paragraph), they demonstrate mainly the opposite impacts across zones. For instance, in the dairy zone the price support is negatively associated with technical change at the mean herd size, while the association is positive in the beef-dairy zone. The same concerns the arable land, herd size, and specialization variables. Better market access proved to be important driver of technical change in both zones.

\subsection{References}

Anselin, L. (1988). Spatial Econometrics: Methods and Models. Kluwer Academic Publishers, Dordrecht, The Netherlands.

Anselin, L. (1995). Local indicators of spatial association - LISA, Geographical Analysis, 27(2):93-115.

Balassa, B. (1975). Trade, Protection, and Domestic Production: A Comment. In P.B. Kennen ed., International Trade and Finance: Frontiers of Research. Cambridge University Press.

Bergsman, J. (1974). Commercial Policy, Allocative Efficiency, and X-efficiency. Quarterly Journal of Economics, 88, pp. 409-33.

Bivand, R. and contributors (2008). spdep: Spatial dependence: Weighting schemes, statistics and models. $R$ package version 0.4-21. http://www . r-project.org/

Bivand, R., Müller, W. G., And Reder, M. (2009). Power calculations for global and local Moran's I. Computational Statistics and Data Analysis, 53, pp. 2859-2872

Brümmer, B., T. Glauben, and G. Thijssen (2002). Decomposition of Productivity Growth Using Distance Functions: The Case of Dairy Farms in Three European Countries. American Journal of Agricultural Economics, 84(3): 628-644.

Cazals C., Florens J.P., Simar L. (2002) Nonparametric frontier estimation: a robust approach. Journal of Econometrics, 106: 1-25

Chambers, Robert G. (1988). Applied production analysis: a dual approach. Cambridge University Press

Chavas, J.-P. (2001). Structural Change in Agricultural Production: Economics, Technology and Policy. In: Gardner, B.L., And Rausser, G.L. (eds.): Handbook of Agricultural Economics. Vol. 1A. Amsterdam: NorthHolland

EBerts, R.W., AND D.P.McMillen (1999) Agglomeration Economies and Urban Public Infrastructure. In CheshiRe., P. AND Mills, E.S. eds.: Handbook of Regional and Urban Economics, Vol 3 Applied Economics, Chap. 38. New York: North-Holland, 1999.

Elhorst, J. Paul (2003). Specification and estimation of spatial panel data models. International Regional Science Review, 26(3):244-268.

FAO/EBRD (2008). Fighting food inflation through sustainable investments. 10 March, London

Färe, R., Grosskopf, S., Norris, M., And Zhang, Z. (1994). Productiv- 
ity Growth, Technical Progress, and Efficiency Change in Industrialized Countries. American Economic Review, March, 84(1), pp. 66-83.

Galushko, V., B. Brümmer and S. Demyanenko (2004), Measuring the Productive Efficiency of Ukrainian Farms. In: von Cramon-Taubadel, S., S. Demyanenko \& A. Kunn (eds.): Ukrainian Agriculture - Crisis and Recovery, Shaker, Aachen.

Getis, A (2009). Spatial Weights Matrices, Geographical Analysis, 41, pp. 404-410.

Giannakas, K., R. Schoney, V. Tzouvelekas (2001). Technical Efficiency, technological change and output growth of wheat farms in Saskatchewan. Canadian Journal of Agricultural Economics, 49, pp. 135-152. Holovko O.M. (ed) (2003) Otraslevoy spravochnik Molochnaya promyshlennost Ukrainy, Kyiv Zorya, S. (2006) Improving Agricultural Fiscal Policy in Ukraine. Background paper, public expenditure review, Ukraine 2005-06, World Bank, Washington DC http: //siteresources . worldbank . org/INTUKRAINE/Resources / 328335-1158937917927/AgriculturalFiscalPolicyEng ·pdf

IlienkO, I., AND LAPA, V. (2009). Super-large farms in Ukraine and their integration into international markets. Paper presented at the 3d Green Week conference, Berlin.

Kalaitzandonakes, N.G. And M.E. Bredahl (1994). Market Liberalization and Productivity Growth: An Empirical Analysis. In: I. SHELDON, AND P. Aвотт, ED. Empirical Studies of Industrial Organization and Trade in the Food and Related Industries. Westview Press.

Kalaitzandonakes, N.G. And M.E. Bredahl (1993). Protectionism, Efficiency, and Productivity Growth, In: M. Schmitz, And H. von Witzke, ed. Agricultural Trade and Economic Integration in Europe and North America. Wissenschaftersverlag vaulk, Kiel.

LAsaAd, L. (1994). Subsidies, Endogenous Technical Efficiency and the Measurement of Productivity Growth, Journal of Agricultural and Applied Economics, 26 (1), July, 1994: 299-310

Leibenstein, H. (1966). Allocative efficiency vs X-efficiency, American Economic Review, 56, pp. 392-415.

LeSAge, James P. (2000). Bayesian Estimation of Limited Dependent variable Spatial Autoregressive Models, Geographical Analysis, Vol. 32, pp. 19-35. LeSage, James P. (1997). Bayesian Estimation of Spatial Autoregressive Models, International Regional Science Review, Vol. 20, pp. 113-129.

LischKa, G. (2004). Farm Management Challenges in Ukrainian Agriculture. In: von Cramon-Taubadel, S., S. Demyanenko \& A. Kuhn (eds.): Ukrainian Agriculture - Crisis and Recovery. Shaker, Aachen.

Lissitsa, A., AND M. Odening (2005). Efficiency and total factor productivity in Ukrainian agriculture in transition. Agricultural Economics, Vol. 32(3): 311-325.

McCloud, N., And Kumbhakar, S.C. (2007). Does Subsidy Drive Productivity? A Cross-Country Analysis of Nordic Dairy Farms. In: Siddhartha Chib, Gary Koop, and Bill Griffiths (eds.): Advances in Econometrics: Bayesian Econometrics. Vol. 23.

Nivievskyi, O. and von Cramon Taubadel, S. (2008). The Determinants of the Dairy Farming Competitiveness in Ukraine, Presented at the XIIth Congress of the European Association of Agricultural Economics in Belgium 26-29 August 2008, Ghent - Belgium 
Paul, Catherine J.Morrison (2003) Productivity and Efficiency Measurement in Our "New Economy": Determinants, Interactions, and Policy Relevance, Journal of Productivity Analysis, 19, 161-177

Pingali, P. (2007). Agricultural Mechanization: Adoption Patterns and Economic Impact. In: Evenson, R., And Pingali, P. (eds.): Handbook of Agricultural Economics. Vol. 3. Elsevier Science B.V., Amsterdam: NorthHolland

Popova, O. (2007). Mlechnyy Put (Milky Way). Biznes 11/12.03.07

Roe, B., Irwin, Elena G., and Sharp, Jeff S. (2002) Pigs in Space: Modeling the Spatial Structure of Hog Production in Traditional and Nontraditional Production Regions. American Journal of Agricultural Economics, 84(2), p. 259-278

Rosenblatt, M. (1956). Remarks on Some Nonparametric Estimates of a Density Function, Annals of Mathematical Statistics, 27, pp. 643-669.

SABluck, P (ed): Agropromyslovyy complex Ukrayiny: stan, tendenciyi ta perspektyvy rozvytku (Agriculture Sector in Ukraine: situation, trends and perspectives of development). Institute for Agricultural Economics: Kyiv, 2003.

Simar L. (2003): Detecting Outliers in Frontier Models: A Simple Approach. Journal of Productivity Analysis, 20, 391-424

Simar, L. And P.W. Wilson (1998). Productivity Growth in Industrialized Countries. Institut de Statistique, Discussion Paper, Belgium.

Simar, L. AND P.W. Wilson (2007). Estimation and inference in two-stage, semi-parametric models of production process. Journal of Econometrics, 136, pp. $31-64$

Shephard, R. W. (1970). The Theory of Cost and Production Functions. Princston: Prinston University Press.

Sunding, D., And Zilberman, D. (2001). The Agricultural Innovation Process: Research and Technology Adoption in a Changing Agricultural Sector. In: Gardner, B.L., And Rausser, G.L. (eds.): Handbook of Agricultural Economics. Vol. 1A. Elsevier Science B.V., Amsterdam: North-Holland von Cramon Taubadel, S., Nivievskyi, O., and Gruenninger, M. (2008). Ukraine: Agricultural Competitiveness. World Bank Policy Note No. 44843-UA.

WheElock, D.C. And P.W. Wilson (2003): Robust Nonparametric Estimation of Efficiency and Technical Change in U.S. Commercial Banking. Working paper, Department of Economics, University of Texas, Austin.

Wilson, P.W. (2008): FEAR 1.0: A Package for Frontier Efficiency Analysis with R. Socio-Economic Planning Sciences, Vol. 42: 247-254.

World BAnK/IBRD (2009): World Developing Report: Reshaping Economic Geography. The World Bank, Washington DC. 


\section{Chapter 6}

\section{Belarus: Agricultural Productivity and Competitiveness. Impact of State Support and Market Intervention $^{1}$}

\subsection{Aggregate output}

Measured in terms of aggregate output, agriculture in Belarus has performed well in comparison with other transformation economies and in particular other CIS countries such as Kazakhstan, Russia and Ukraine, but less well than those now forming part of the European Union (Poland, Romania). The initial reduction in production due to the 'transformation crisis' in the 1990s was less severe in Belarus (roughly - 35\%) than in these CIS countries (- 40 to - 60\%), and the recovery since has been more complete (Figure 6.1). On the other hand, compared with countries in Central and Eastern Europe such as Poland or Romania, Belarus did experience a more pronounced and sustained initial decline in its agricultural output in the course of transition. While Belarus faced challenges similar to those faced by other CIS countries (disintegration of the Soviet economic system and transition from centrally planned to market economy, and the start of political reform processes), its experience is rather distinct in that the economy continues to be heavily state-controlled. But also, and most notably, Belarus has experienced strong economic growth that was broadly shared, leading to a reduction in the poverty headcount from 27.1 percent of the population in 2003 to 7.7 percent in 2007 and a gini coefficient of 25.3 percent that is on par with the Czech Republic, Sweden and Japan. The fact that Belarusian agriculture has performed well (in output terms) compared with its CIS peers, even though its agricultural policy has been much less market-oriented and its farm sector has undergone much less restructuring, is one facet of what is sometimes referred to as the 'Belarus puzzle'. While output is clearly important, a comprehensive picture of performance must consider productivity (i.e. the relationship between input use and output) and whether production is internationally competitive. To cast more light on the performance of agriculture in Belarus and the factors that influence it, the following

\footnotetext{
${ }^{1}$ Copyright c 2009 The World Bank. Reproduced by permission.
} 
Figure 6.1: Gross agricultural output in Belarus and selected transition countries $(1990=100)$

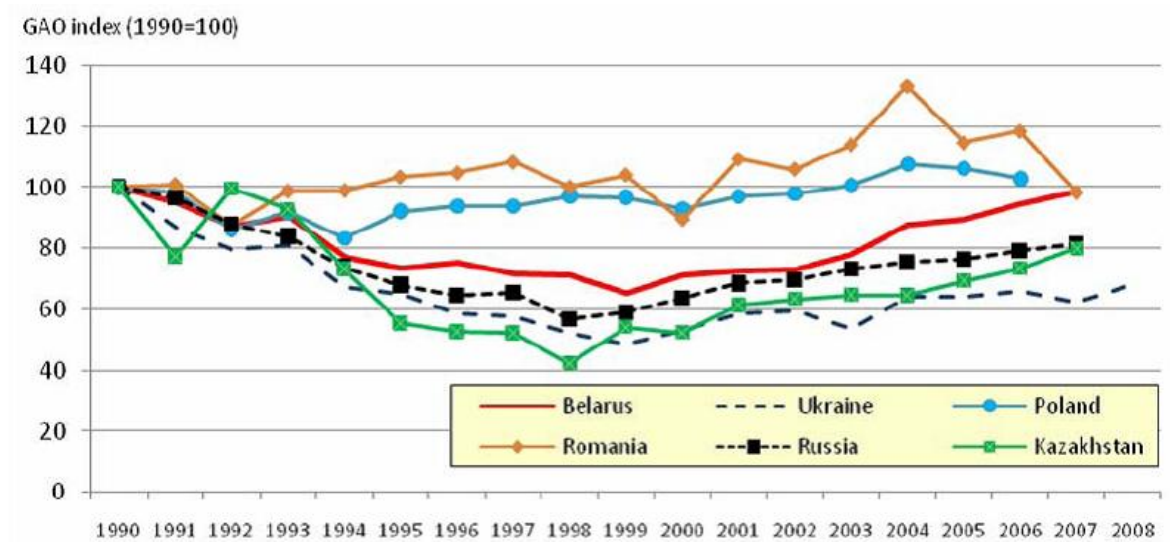

Source: EBRD (2009); own calculations.

sections present the results of detailed analyses of productivity, efficiency and competitiveness.

\subsection{Productivity}

\section{Partial productivity indicators at farm level}

Productivity $^{2}$ can be measured in different ways depending on whether partial productivity (output per unit of a specific input) or total productivity (output per unit of aggregated input) is of interest, and whether it is measured at the sector or enterprise level. At the farm level, yields (tons per hectare, milk per cow) are commonly used as partial indicators of productivity. Figure 6.4 presents distributions of the main crop yields in tons per hectare and the milk yield in tons per cow on the large commercial farms in Belarus from 2003 to 2007, and Table 6.1 presents information on average yields in each of these years.

Average crop yields have increased substantially in recent years, yet with considerable annual variation. Average yields are generally higher in 2005-2007 than in 2000-2002 (Table 6.1). In Figure 6.4, presenting the farm level distribution of yields, the 2007 distribution generally lies to the right of the distributions from earlier years, suggesting a trend towards higher yields. However, crop yields vary considerably from year to year due to weather conditions. Milk yields have increased strongly, almost doubling on average from 2.2 to 4.1 tons per cow and year between 2000 and 2007, and increasing steadily year

\footnotetext{
"Productivity" is commonly defined as a ratio of a volume measure of output to a volume measure of input use. While this generic notion is broadly agreed, the productivity literature shows a wide range of applications and specific definitions with implications for its measurement. In agriculture, productivity is often measured as output - in physical or monetary units - per unit of fixed input (factor), for example kg wheat harvested per ha land cultivated, or $\mathrm{kg}$
} 
Figure 6.2: Dynamics of wheat yields in Belarus, averages across all farm types (t/ha)

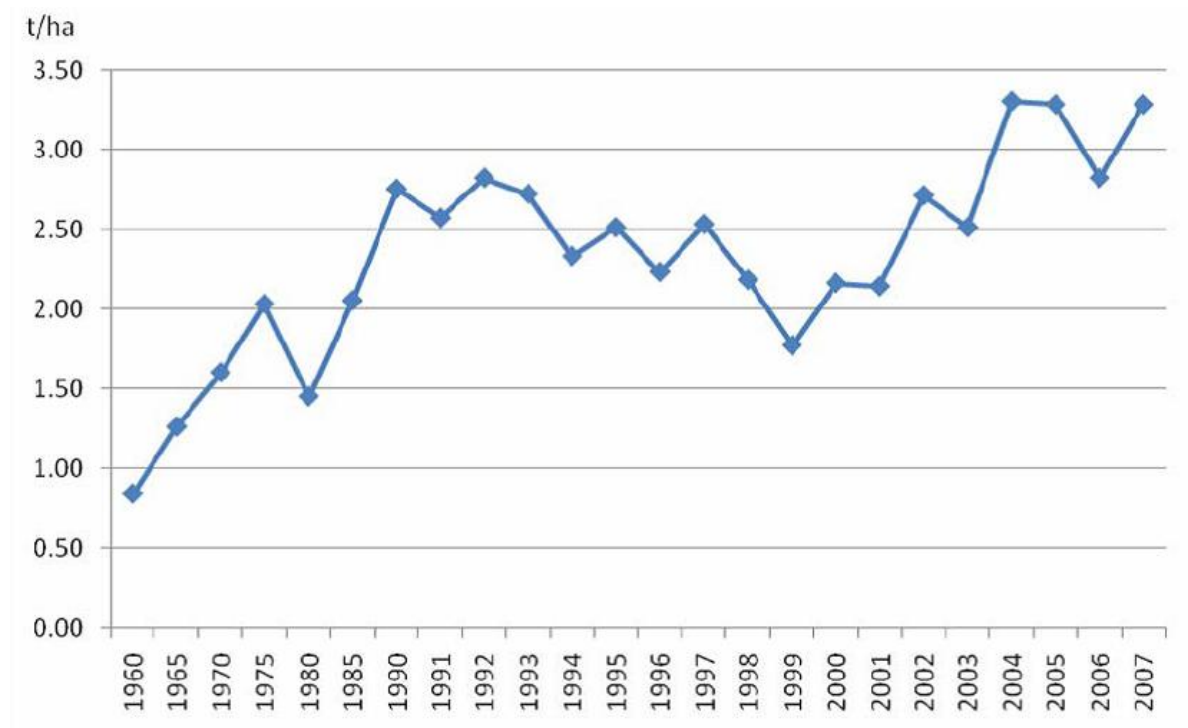

Source: National Statistics Committee of the Republic of Belarus (2008a).

Figure 6.3: Labor and fixed capital productivity in Belarusian agriculture relative to the rest of the economy

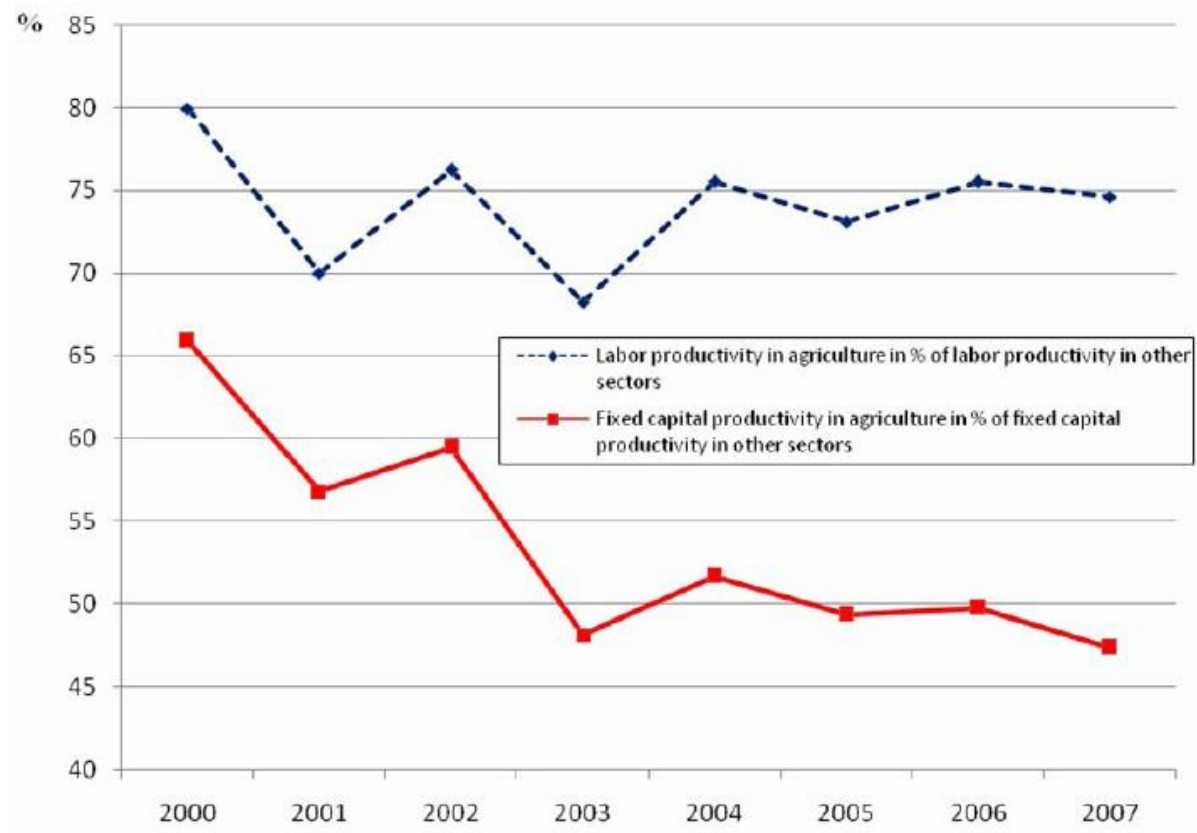

Source: National Statistics Committee of the Republic of Belarus (2008a); own calculations. 
Table 6.1: Crop yields (tons per hectare) and milk yields (tons per cow) on large commercial farms in Belarus

\begin{tabular}{lrrrrrrrr}
\hline & $\mathbf{2 0 0 0}$ & $\mathbf{2 0 0 1}$ & $\mathbf{2 0 0 2}$ & $\mathbf{2 0 0 3}$ & $\mathbf{2 0 0 4}$ & $\mathbf{2 0 0 5}$ & $\mathbf{2 0 0 6}$ & $\mathbf{2 0 0 7}$ \\
\hline Wheat & 2.18 & 2.13 & 2.70 & 2.47 & 3.33 & 3.28 & 2.79 & 3.28 \\
Barley & 1.93 & 2.28 & 2.52 & 2.52 & 3.27 & 3.04 & 2.66 & 2.81 \\
Sugar beet & 29.3 & 31.4 & 22.8 & 27.6 & 36.9 & 31.6 & 37.6 & 38.7 \\
Potato & 13.5 & 10.0 & 9.7 & 14.4 & 18.9 & 14.6 & 16.5 & 18.4 \\
Rapeseed & 0.71 & 0.88 & 0.82 & 0.90 & 1.17 & 1.23 & 1.07 & 1.22 \\
Milk & 2.154 & 2.408 & 2.507 & 2.611 & 3.102 & 3.685 & 4.019 & 4.112 \\
\hline
\end{tabular}

Source: National Statistics Committee of the Republic of Belarus (2008a) and National Statistics Committee of the Republic of Belarus (2009b).

Figure 6.4: Distributions of yield (tons of crop/hectare and tons of milk/cow) on the large commercial farms in Belarus, 2003-2007
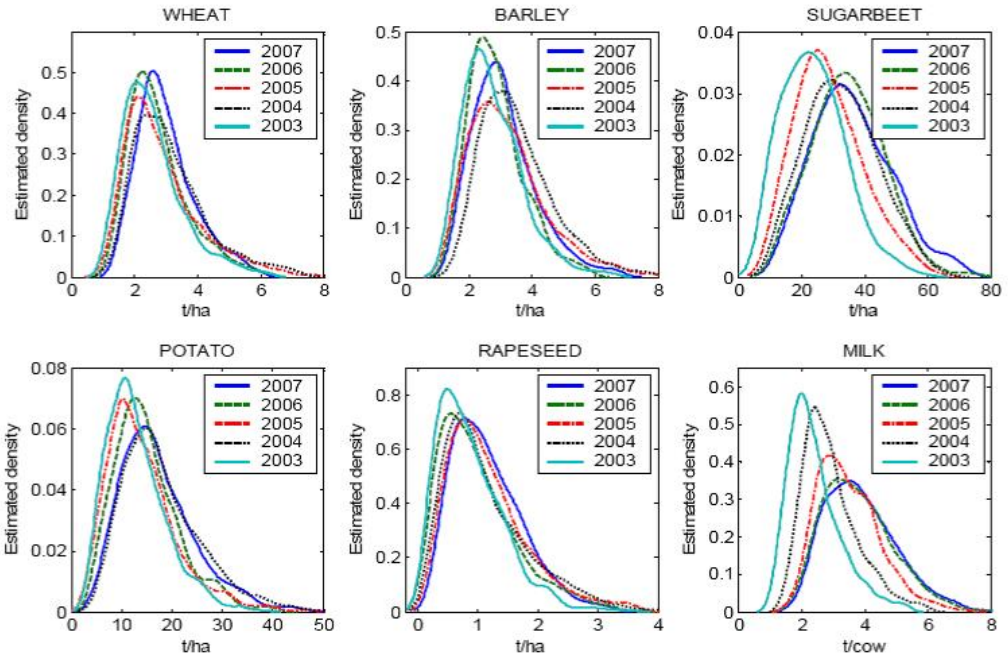

Source: Own calculations with Belarusian farm data base.

for year. The milk yields increased more steadily than field crops given that dairy production is somewhat less dependent on year-to-year weather variability (Table 6.1 and Figure 6.4).

\section{Aggregate (partial) sector productivity}

Labor productivity $^{3}$ in agriculture in Belarus has increased in absolute terms since 2000, but it has remained well below the average labor productivity in the rest of the economy. The calculations in Table 16 highlight the amount of labor or capital needed to produce one unit of GDP in Belarus, in agriculture and in the rest of the economy, with GDP measured in constant 2000 BYR. Figure 6.3 presents the development of these productivities in agriculture relative to the

\footnotetext{
${ }^{3}$ Calculated as the ratio of agricultural GDP divided by total number of persons employed in agriculture.
} 
Table 6.2: Share of agriculture in GDP, employment, and capital in Belarus, and corresponding measures of labor and capital productivity

\begin{tabular}{|c|c|c|c|c|c|c|c|c|c|c|}
\hline & Item & Calculation & 2000 & 2001 & 2002 & 2003 & 2004 & 2005 & 2006 & 2007 \\
\hline a & GDP (bill. 2000 BYR) & & 9,134 & 9,563 & 10,041 & 10,744 & 11,969 & 13,094 & 14,404 & 15,585 \\
\hline b & Labor force ('000 workers) & & 4,441 & 4,417 & 4,381 & 4,339 & 4,316 & 4,350 & 4,402 & 4,445 \\
\hline c & Fixed capital (trill. 2000 BYR) & & 86.6 & 86.3 & 87.2 & 88.8 & 90.1 & 91.9 & 94.2 & 95.7 \\
\hline d & Share of agriculture in GDP (\%) & & 11.6 & 9.7 & 9.5 & 8.0 & 8.3 & 7.9 & 7.9 & 7.5 \\
\hline e & Share of agriculture in total employment (\%) & & 14.1 & 13.3 & 12.1 & 11.3 & 10.7 & 10.5 & 10.2 & 9.8 \\
\hline $\mathrm{f}$ & Share of agriculture in fixed capital (\%) & & 16.6 & 15.9 & 15.0 & 15.3 & 14.9 & 14.8 & 14.7 & 14.6 \\
\hline g & $\begin{array}{l}\text { Labor productivity in agriculture (mill. } 2000 \\
\text { BYR/worker) }\end{array}$ & $\left(a^{*} d\right) /\left(b^{*} e\right)$ & 1.69 & 1.58 & 1.80 & 1.75 & 2.15 & 2.26 & 2.53 & 2.68 \\
\hline $\mathrm{h}$ & $\begin{array}{l}\text { Labor productivity in rest of the economy (mill. } \\
2000 \mathrm{BYR} / \text { worker) }\end{array}$ & $\begin{array}{l}{\left[a^{*}(100-\right.} \\
\text { d) }] /\left[b^{*}(100-e)\right]\end{array}$ & 2.12 & 2.25 & 2.36 & 2.57 & 2.85 & 3.10 & 3.36 & 3.60 \\
\hline $\mathrm{i}$ & Relative labor productivity in agriculture (\%) & $g / h * 100$ & 79.9 & 70.0 & 76.3 & 68.3 & 75.5 & 73.1 & 75.5 & 74.6 \\
\hline j & Fixed capital productivity in agriculture (BYR/BYR) & $\left(a^{*} d\right) /\left(c^{*} f\right)$ & 0.074 & 0.068 & 0.073 & 0.063 & 0.074 & 0.076 & 0.082 & 0.084 \\
\hline k & $\begin{array}{l}\text { Fixed capital productivity in rest of the economy } \\
\text { (BYR/BYR) }\end{array}$ & $\begin{array}{l}{\left[a^{*}(100-\right.} \\
d)] /\left[c^{*}(100-f)\right]\end{array}$ & 0.112 & 0.119 & 0.123 & 0.131 & 0.143 & 0.154 & 0.165 & 0.176 \\
\hline 1 & $\begin{array}{l}\text { Relative fixed capital productivity in agriculture } \\
(\%)\end{array}$ & $j / k * 100$ & 65.9 & 56.8 & 59.5 & 48.1 & 51.7 & 49.4 & 49.8 & 47.4 \\
\hline $\mathrm{m}$ & $\begin{array}{l}\text { Capital/labor ratio in agriculture (mill. } 2000 \\
\text { BYR/agricultural worker) }\end{array}$ & $\left(c^{*} f\right) /\left(b^{*} e\right)$ & 22.96 & 23.34 & 24.68 & 27.70 & 29.07 & 29.78 & 30.84 & 32.08 \\
\hline n & $\begin{array}{l}\text { Capital/labor ratio in rest of the economy (mill. } \\
2000 \text { BYR/worker) }\end{array}$ & $\begin{array}{l}{\left[c^{*}(100-\right.} \\
\left.\text { f) } 1 / b^{*}(100-e)\right]\end{array}$ & 18.93 & 18.94 & 19.25 & 19.54 & 19.89 & 20.11 & 20.33 & 20.38 \\
\hline
\end{tabular}

Source: National Statistics Committee of the Republic of Belarus (2008a) and National Statistics Committee of the Republic of Belarus (2009b); own calculations.

rest of the economy. Real productivity of labor in agriculture increased by $57 \%$ from 1.69 million BYR/worker in 2000 to 2.68 million BYR/worker in 2007. Over the same period, however, labor productivity in the rest of the Belarusian economy increased by $70 \%$ from 2.12 to 3.60 million BYR/worker. As a result of these trends, the productivity of labor in agriculture as proportion of labor productivity in the rest of the economy has broadly remained at around 75 percent.

Similarly, while capital productivity ${ }^{4}$ experienced a slight increase in the agriculture sector between 2000 and 2007, this increase was much stronger in the economy overall. In the agriculture sector, capital productivity increased by 13.5 percent, whereas in the rest of the economy it increased by 57.1 percent, from 11.2 percent to 17.6 percent. The combined effect of these changes is illustrated by the reduction in the ratio of capital productivity in agriculture to the productivity of capital in the rest of the economy from $66 \%$ to $47 \%$.

The government's policies supporting agriculture in pursuit of food self-sufficiency targets have led to a notable increase in agricultural output, but this result could only be achieved at considerable cost to the economy overall. The fact that capital is less than one-half as productive in agriculture as in the rest of the economy suggests that the government policies that have channeled large amounts of capital into agriculture have led to an inefficient allocation of resources from an economic perspective.

Figure 6.5 showed that the share of agriculture in fixed capital investment in Belarus has increased sharply in recent years. Policies such as investment subsidies and directed state investments that have encouraged this trend have

\footnotetext{
${ }^{4}$ Calculated as the ratio of agricultural GDP divided by total fixed capital in agriculture.
} 
Figure 6.5: The shares of agriculture and the food industry in Belarus in GDP, employment, and fixed assets in Belarus (2000-2007, in \%)

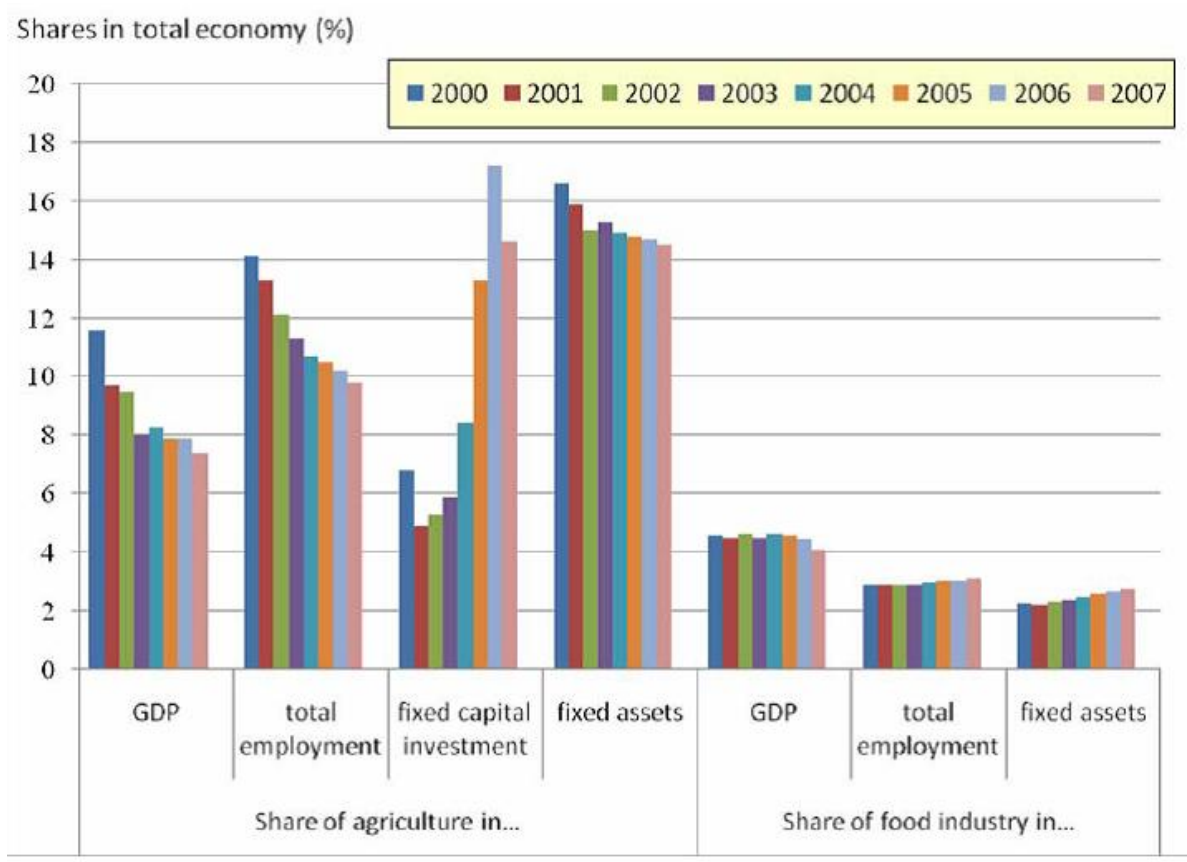

Source: National Statistics Committee of the Republic of Belarus (2008a); own calculations.

Note: Fixed asset shares refer to stocks as of the end of the year.

effectively drawn capital away from alternative uses that, by 2007 , were on average twice as productive. Due to these policies, the capital/labor ratio in agriculture increased considerably from 23 to 32 million 2000 BYR between 2000 and 2007, while the capital/labor ratio in the rest of the economy increased much less (from 19 to 20 million 2000 BYR) (Table 6.2). Despite this massive reallocation of capital into agriculture, agricultural labor productivity stagnated at around $75 \%$ of its level in the rest of the economy. It seems that Belarus' current choice of policy objectives and related mechanisms for resource allocation prevents the country from increasing the efficiency of state expenditures.

\section{Total factor productivity}

Partial measures of productivity such as those outlined above can be misleading because they only consider one input in isolation, while farms use a variety of input to produce more than one output simultaneously. What matters most for competitiveness is how efficiently farms convert inputs into output. The 'Total Factor Productivity' (TFP) is a measure of the relationship between a farm's aggregate input use and its aggregate output. Measuring TFP is not trivial because input and output prices, quantities and qualities change over time, making aggregation and comparison a challenging task. Nevertheless, 
methods for estimating TFP and for decomposing it into different components have been developed. Intuitively one can envision that there are three such TFP components: TFP can increase because i) farms become more efficient (they use a given level of inputs and a given technology more effectively and produce more output as a result), ii) they scale their operations up or down to move closer to the optimal scale of production, or iii) they implement a new technology that is able to produce more output from a given amount of inputs than the previous technology. This chapter presents the results of a TFP analysis using the detailed farm-level accounting data for commercial farms in Belarus in the years 2003 through 2007.

Over the period 2003-2007, the majority (58 percent) of the large commercial farms in Belarus experienced an increase in technical (pure) efficiency ${ }^{5}$ (Figure 6.6). This means that these farms got closer to the best-practice frontier in 2007 than they were in 2003. The distribution of pure efficiency changes is relatively symmetric, with the modal or most frequent change at 0.99 . This means that on average the farms in Belarus stayed at about the same distance from the best practice frontier in 2007 compared to 2003. However, variation is considerable: while many farms became much better, many farms became much worse.

The technical efficiency distributions generated with the DEA model confirm the observation of gradual (technical, pure) efficiency increases on many farms. The technical efficiency (TE), calculated as a static score for each individual year between 2003 and 2007 using a DEA model ${ }^{6}$ and depicted in Figure 6.7 and Table 6.3 , is the ratio of the best-practice output that a farm could produce to the output that it actually did produce. Hence, a score of 1 indicates that the farm in question is on the best practice frontier and producing $100 \%$ of the maximum possible output at a given technology and its level of input, while a score of 2, for example, indicates that the farm is only producing one half of the best-practice output. In the period 2003-2007, one half of the farms in Belarus produced no more than about $60-70 \%$ of the best-practice output, and one quarter produced no more than $50-60 \%$ of this output. However, the efficiency distribution did improve over this period, illustrated (in Figure 6.7) by distributions that become increasingly concentrated on values closer to 1 over time and by TE scores for the boundaries of the upper quartiles (in Table 6.3) that become systematically smaller (despite a couple of years with insignificant changes).

About equal numbers of commercial farms in Belarus experienced improvements/reductions in scale efficiency ( 51 and $49 \%$, respectively). The distribution is symmetric and very tight, compared to other TFP components distributions; the modal scale efficiency change equals 1.00 which means that the scale efficiency of the most common type of farm did not change between 2003 and 2007. However, about one half of the farms moved further away from the

\footnotetext{
5"Efficiency" measures the extent to which a maximum possible output has been achieved with a given level of resources. The ratio of actual output to maximum output would be a measure of efficiency. Similarly to the definition of "productivity", the term "efficiency" has experiences a wide range of applications and related methods of calculation. In agriculture, the ratio of variable input (factor) per unit output is a frequently used concept of efficiency, e.g. $\mathrm{kg}$ rice harvested per $\mathrm{m} 3$ irrigation water applied. The total factor productivity calculations in this paper apply a different and more complex concept of efficiency, explained in some detail in Technical Appendix 1 in section 6.6.

${ }^{6}$ Refer to Technical Appendix 1 in section 6.6 for more details on the methodology.
} 
Figure 6.6: Changes in total factor productivity and its components for commercial farms in Belarus between 2003 and 2007 (order-m model)
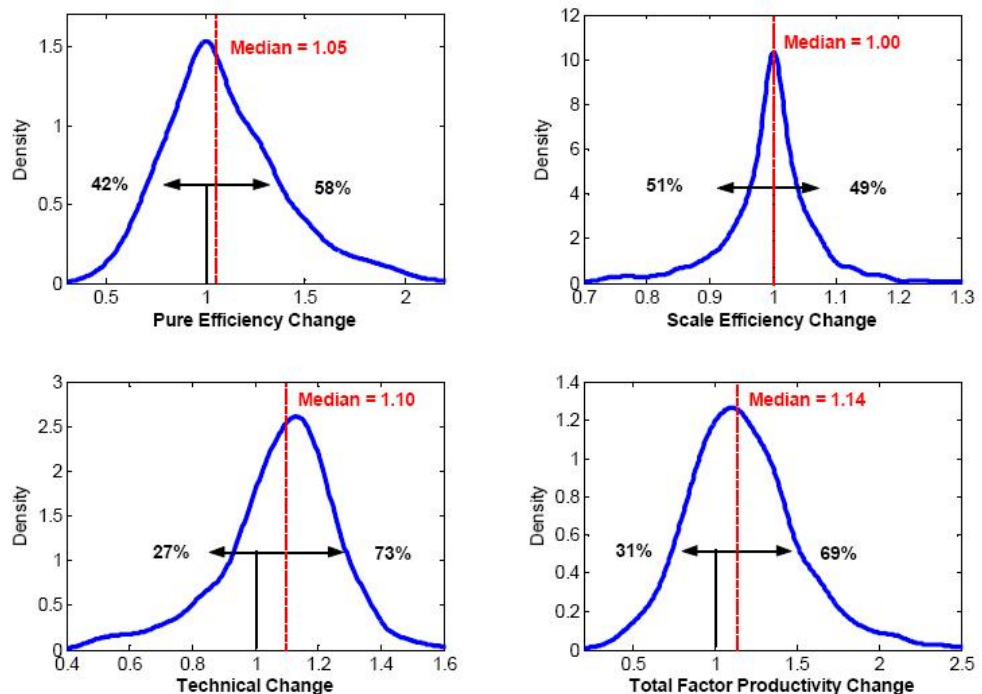

Source: Own calculations with Belarusian farm data base.

Table 6.3: Ranges of technical efficiency (TE) scores by quartile of the efficiency distribution

\begin{tabular}{|c|c|c|c|c|}
\hline \multirow{2}{*}{ Year } & \multicolumn{4}{|c|}{ Quartile of the efficiency distribution, from the most to the least efficient } \\
\hline & $0-25 \%$ & $25-50 \%$ & $50-75 \%$ & $75-100 \%$ \\
\hline 2003 & $1<\mathrm{TE} \leq 1.32$ & $1.32<\mathrm{TE} \leq 1.63$ & $1.63<\mathrm{TE} \leq 1.94$ & $1.94<\mathrm{TE} \leq 5.86$ \\
\hline 2004 & $1<\mathrm{TE} \leq 1.24$ & $1.24<\mathrm{TE} \leq 1.49$ & $1.49<\mathrm{TE} \leq 1.75$ & $1.75<\mathrm{TE} \leq 3.28$ \\
\hline 2005 & $1<\mathrm{TE} \leq 1.27$ & $1.27<\mathrm{TE} \leq 1.53$ & $1.53<\mathrm{TE} \leq 1.81$ & $1.81<\mathrm{TE} \leq 4.23$ \\
\hline 2006 & $1<\mathrm{TE} \leq 1.27$ & $1.27<\mathrm{TE} \leq 1.52$ & $1.52<\mathrm{TE} \leq 1.80$ & $1.80<\mathrm{TE} \leq 3.90$ \\
\hline 2007 & $1<\mathrm{TE} \leq 1.22$ & $1.22<\mathrm{TE} \leq 1.43$ & $1.43<\mathrm{TE} \leq 1.65$ & $1.65<\mathrm{TE} \leq 3.53$ \\
\hline
\end{tabular}

Source: Own calculations using Belarusian farm data base.

optimal scale of operations.

Against the background of rather constant farm sizes in Belarus, while restructuring has led to smaller farm sizes throughout Central and Eastern Europe and the CIS (Table 6.4), the nature of the scale efficiency changes suggests that many farms in Belarus are too big and have not been able to scale down their operations to make the best possible use of available technologies. In general, large farms are expected to increase efficiency through scale effects, but many large commercial farms in Belarus do not seem to have evolved in the direction of more efficient size. Under more market-oriented conditions, not the complete break-up but some downsizing of some of the large commercial farms in Belarus would be expected to take place as a result of competitive forces. The result would be more manageable units in which it is easier to monitor complex operations (such as field work and herd management) and motivate workers, 
Figure 6.7: Technical efficiency distributions for commercial farms in Belarus

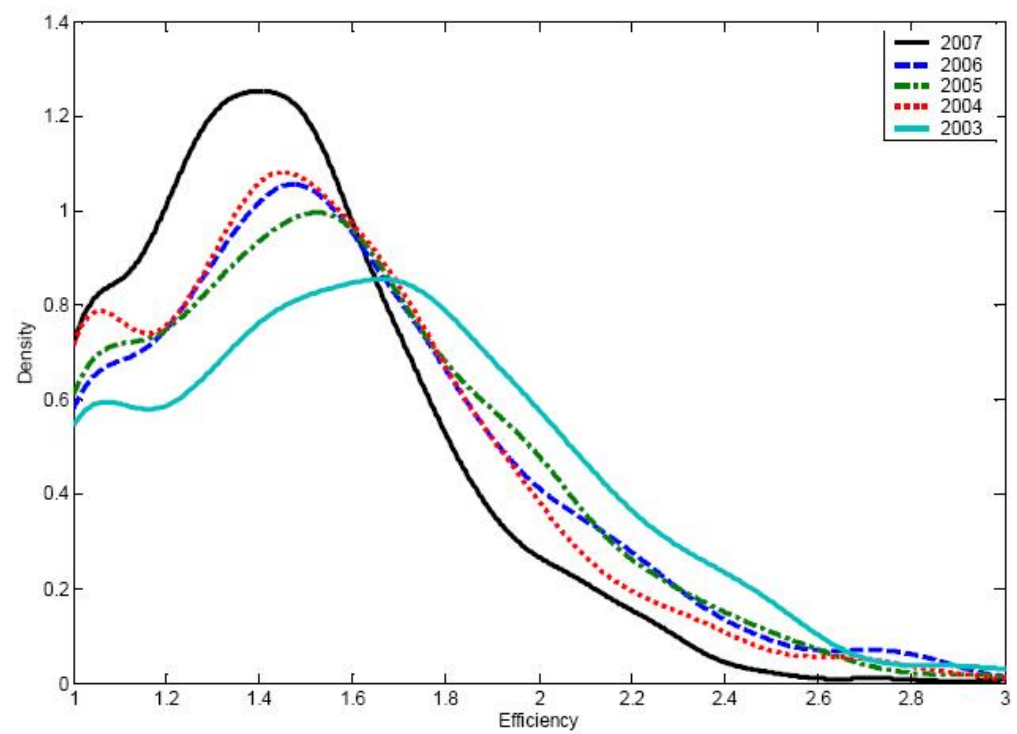

Source: Own calculations with Belarusian farm data base.

Table 6.4: The average size of large commercial farms in selected CIS countries (in hectares)

\begin{tabular}{lrrrr}
\hline Country & 1990 & 2000 & 2006* & $\begin{array}{c}\text { Change } \\
\text { 1990-2006 }\end{array}$ \\
\hline Belarus & 3,482 & 3,824 & 3,985 & $+14.4 \%$ \\
Moldova & 2,200 & 950 & 918 & $-58.3 \%$ \\
Russia & 8,100 & 5,400 & 5,298 & $-34.6 \%$ \\
Ukraine & 2,900 & 2,100 & 1,326 & $-54.3 \%$ \\
\hline
\end{tabular}

Source: Lerman et al. (2004, p. 129); Cimpoies et al. (2008, p. 5); World Bank (1994, Table 12); Ministry of Agriculture of the Russian Federation (2008).

* 2007 for Belarus, 2003 for Moldova.

with the ultimate effect of increased efficiency. At the same time, restructuring might also lead to more specialization. If a large crop farm is encouraged or even obliged to maintain a dairy herd, for example, because local authorities are eager to maintain a supply of milk for the local dairy processing plant, the result can be a loss of overall efficiency as resources are taken from one area (e.g. crop production) to support the other (e.g. milk production). In this case, the freedom to specialize in crop production alone could lead to increased scale efficiency, not because the farm in question moves closer to its optimal scale of operations by becoming smaller in hectare terms, but because the optimal scale of specialized crop production is larger and closer to the farm's current size. 
Three quarters $(73 \%)$ of all large commercial farms experienced positive technical change, meaning that they were employing more productive technologies in 2007 than they were in 2003. The distribution of technical changes is slightly skewed to the right, with the modal value at 1.14 , which indicates that the most frequent or 'typical' technical change was positive. Only $27 \%$ of the commercial farms in Belarus did not experience technical progress.

Together, these effects resulted in total factor productivity improvements for 69 percent of all large commercial farms between 2003 and 2007 and a 14 percent increase in total factor productivity for the median commercial farm in Belarus between 2003 and 2007, or roughly 3.3\% per year over this period. This increase is a remarkable performance comparable to that of China (at least for the five years covered in this analysis). For the period 1970 to 2001, Rao et al. (2004, p. 22) measure TFP increase in global agriculture of $1.5 \%$ per year, with North America and Australasia registering a rate of $2.2 \%$, China $3 \%$, Europe $1.9 \%$, and Sub-Saharan Africa and Asia without China $0.3 \%$ per year. Rao et al. (2004) also present TFP calculations for the transition countries, but they stress that the results must be interpreted with caution because the composition of this group changes (i.e. the USSR ceases to exist while successor states such as Belarus enter the dataset) and there were major changes in accounting practices in some transition countries over the study period. For 1990-2000, Rao et al. (2004, p. 27) report annual average TFP growth of $1.2 \%$ for the transition countries as a group. Of course, this decade saw major reductions in agricultural production in these countries, while the results presented here for Belarus alone are for a much shorter period of time, and one in which Belarusian agriculture was rebounding from the reduction of the 1990s. Nevertheless, the results presented here point to above-average TFP growth in global comparison, and are similar to/slightly above the results achieved in other industrialized, temperate zone countries. The results on TFP change from the alternative DEA model confirm the findings from the order-m model (see Figure 6.16).

These results reinforce several observations made above. In particular, the large positive technical change reflects the impact of significant investment in agriculture and the resulting increases in the capital stock and the capital/labor ratio in Belarusian agriculture discussed above. Figure 6.6 shows that the median farm realized a positive technical change of $10 \%$ between 2003 and 2007. The farms that define the best-practice frontier have been able to take advantage of the availability of new technologies to increase their productivity considerably. Many farms have not been able to keep up with the pace of technical change as evidenced by the distribution of the pure efficiency change. The 42 percent of farms for which the pure efficiency decreased may have better machines, animals, plant varieties and variable inputs at their disposal today than they did 5 years ago, but they are producing a smaller percentage of the maximum output that is possible with these machines, etc. than they did with the old machines and other inputs at their disposal in 2003. On these farms, it seems that management ability, training and education are not keeping pace with the rate of technical change. But there is another, even larger group of farms where pure efficiency was positive. For both the winners and losers in pure efficiency, the variability between farms appears to be considerable, which implies that the levels of skills and knowledge on farms - and the related management attention to staff training and overall modernization - vary accordingly. 
The medial 14\% increase in TFP over the period 2003-2007 masks strong performance by the best farms (the $25 \%$ of farms with the highest TFP changes realized increases of at least $36 \%$, or over $8 \%$ per year), but also poor performance by $31 \%$ of the farms that experienced net reductions in TFP. The $25 \%$ of farms with the worst TFP performance realized TFP reductions of at least $5.5 \%$, or $1.4 \%$ per year. Many of the farms in this bottom quartile realized positive technical change: since only $27 \%$ farms in the data base realized negative technical change, and assuming that these farms all experienced negative TFP growth, there remain almost $4 \%(31 \%-27 \%)$ that experienced reductions in TFP despite positive technical change. On these farms, positive technical change was more than neutralized by reductions in pure and scale efficiency over the same period.

For these underperforming farms in particular, but also sector-wide, managerial ability and the freedom to engage (or lack thereof) in substantive restructuring appear to be much more limiting factors in Belarus' agricultural development than physical capital. Further improvements in physical capital would then lead to only limited, if any, improvements in farm performance (comp. Liebig's Law of the Minimum). The results also reinforce the finding (see Table 6.2 above) that the productivity of capital in Belarusian agriculture has declined considerably in recent years and is now less than one-half as high as the productivity of capital in the rest of the economy.

\subsection{Competitiveness}

\section{Crop production in general}

The competitiveness of crop production in Belarus shows large differences between crops, farms and years (Table 6.5, Table 6.6, Figure 6.10). Wheat was Belarus' most competitive crop in 2007, capturing this position from barley and potatoes which saw a decline in competitiveness between 2003 and 2007. In 2007, about 65 percent of farms producing wheat did so competitively, accounting for 69 percent of the wheat production (by volume). However this share varies considerably from year to year and was as low as approximately $11 \%$ just one year earlier, in 2006. This variation in competitiveness is - to a large degree - a reflection of variation in the world market price of wheat that saw a considerable increase in 2007/2008 (Figure 6.8). The best results for barley were recorded in 2005 , when about $77 \%$ of the production (number of farms) in Belarus was competitive; in the other years this share varies between roughly $22 \%$ and $65 \%$. The share of competitive production varies between $19 \%$ and $33 \%$ for rapeseed, and between 26 percent and 69 percent for potatoes. Corn and sugar beet production, however, display very low levels of competitiveness (close to zero) in all years.

This low level of competitiveness in crop production at economic prices contrasts with considerably higher levels of profitability at financial prices. This indicates that the net effect of market and price distortions on agricultural input and output markets in Belarus is to subsidize production. The share of crop production that is profitable at financial prices and costs is almost always larger than the share that is competitive at economic prices and costs (Table 6.5). The only notable exception is potato production which was implicitly taxed in the years 2003, 2004 and 2006. However, even under these 
Figure 6.8: Global price fluctuation and medium-term development for selected crops, daily data, 2000-2009

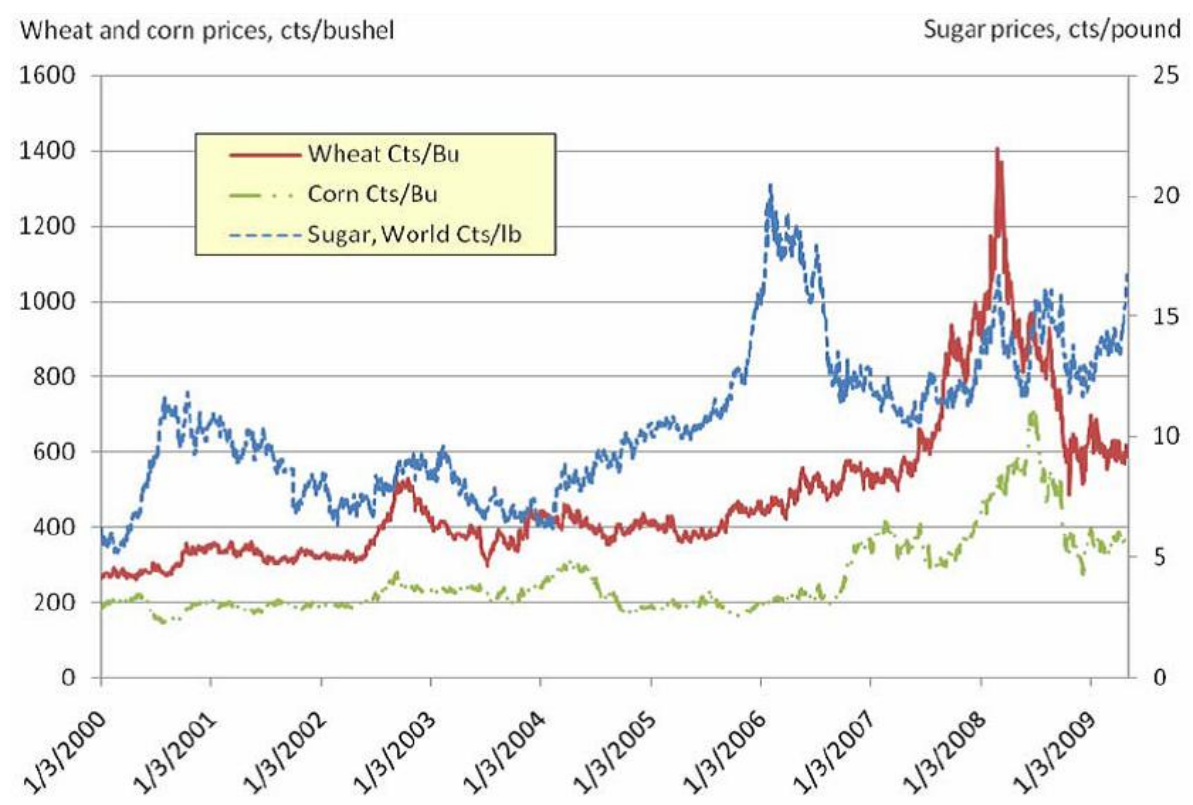

Source: World Bank (2009b), own presentation.

Table 6.5: The shares of farms with competitive crop production in Belarus that are competitive at financial $(0<\mathrm{PCB}<1)$ and economic $(0<\mathrm{SCB}<1)$ prices in costs (in \%, 2003-2007)

\begin{tabular}{lrrrrr}
\hline \multicolumn{7}{c}{ Profitable at } & financial prices & (0<PCB<1) & & \\
\hline Crop & $\mathbf{2 0 0 3}$ & $\mathbf{2 0 0 4}$ & $\mathbf{2 0 0 5}$ & $\mathbf{2 0 0 6}$ & $\mathbf{2 0 0 7}$ \\
\hline Wheat & 84.4 & 93.8 & 80.7 & 63.2 & 78.7 \\
Corn* & 0.0 & 0.0 & 68.6 & 60.4 & 80.0 \\
Barley & 72.5 & 86.0 & 56.6 & 39.7 & 53.5 \\
Sugar beet & 57.1 & 71.7 & 54.9 & 55.4 & 61.0 \\
Potato & 46.0 & 34.0 & 49.0 & 49.3 & 48.3 \\
Rapeseed & 66.2 & 74.5 & 63.9 & 44.1 & 51.5 \\
\hline \multicolumn{7}{c}{ Crop } & Competitive at economic prices (0<SCB<1) & & \\
\hline Wheat & $\mathbf{2 0 0 3}$ & $\mathbf{2 0 0 4}$ & $\mathbf{2 0 0 5}$ & $\mathbf{2 0 0 6}$ & $\mathbf{2 0 0 7}$ \\
Corn* & 28.3 & 25.0 & 11.2 & 10.5 & 64.7 \\
Barley & 0.0 & 0.0 & 1.0 & 2.2 & 10.5 \\
Sugar beet & 64.9 & 45.6 & 77.4 & 33.9 & 22.1 \\
Potato & 0.0 & 0.0 & 0.2 & 2.7 & 0.0 \\
Rapeseed & 59.8 & 69.2 & 25.6 & 64.7 & 47.5 \\
\hline
\end{tabular}

Source: Own calculations with Belarusian farm data base, see Technical Appendix 2 in section 6.7 .

* For corn in 2003 and 2004 there are not enough observations for the estimation of a distribution. 
Table 6.6: The shares of crop production (by marketed volumes of production) in Belarus that is competitive at financial $(0<\mathrm{PCB}<1)$ and economic $(0<$ $\mathrm{SCB}<1$ ) prices in costs (in \%, 2003-2007)

\begin{tabular}{lrrrrr}
\hline \multicolumn{7}{c}{ Profitable at financial costs $(0<$ PCB<1) } \\
\hline Crop & $\mathbf{2 0 0 3}$ & $\mathbf{2 0 0 4}$ & $\mathbf{2 0 0 5}$ & $\mathbf{2 0 0 6}$ & $\mathbf{2 0 0 7}$ \\
\hline Wheat & 94.1 & 97.7 & 90.7 & 73.7 & 89.5 \\
Corn* & 0.0 & 0.0 & 74.7 & 51.4 & 89.0 \\
Barley & 72.2 & 91.5 & 65.7 & 40.2 & 59.2 \\
Sugar beet & 79.2 & 88.4 & 68.6 & 73.2 & 78.4 \\
Potato & 66.9 & 45.5 & 67.5 & 60.7 & 64.0 \\
Rapeseed & 78.5 & 87.5 & 79.9 & 62.4 & 66.6 \\
\hline \multicolumn{7}{c}{ Crop } & Competitive at economic costs (0<SCB<1) & & $\mathbf{2 0 0 7}$ \\
\hline Wheat & $\mathbf{2 0 0 3}$ & $\mathbf{2 0 0 4}$ & $\mathbf{2 0 0 5}$ & $\mathbf{2 0 0 6}$ & 69.4 \\
Corn* & 26.8 & 16.8 & 12.6 & 11.5 & 13.5 \\
Barley & 0.0 & 0.0 & 0.1 & 0.3 & 20.7 \\
Sugar beet & 60.2 & 51.4 & 81.2 & 30.3 & 0.0 \\
Potato & 0.0 & 0.0 & 0.0 & 5.9 & 62.1 \\
Rapeseed & 78.7 & 83.2 & 42.4 & 74.7 & 29.8 \\
\hline
\end{tabular}

Source: Own calculations with Belarusian farm data base, see Technical Appendix 2 in section 6.7 .

* For corn in 2003 and 2004 there are not enough observations for the estimation of a distribution.

subsidized conditions, a considerable share of crop production is financially unprofitable, with losses covered from the governmental budget. In 2007, for example, roughly $50 \%$ of the barley, potato and rapeseed producing farms in Belarus were making financial losses, as were about $40 \%$ of the sugar beet and approximately $20 \%$ of the wheat and corn producing farms.

\section{The special case of sugar beet}

Sugar beet production is not competitive in Belarus, but the large share of farms and production that are financially profitable illustrate the preferential treatment and governmental support that this sub-sector receives. Sugar beet was identified further above as the agricultural product with the largest rate of growth in production in Belarus since the mid-1990s (Figure 6.9) and shows a financial profitability between 55 percent and 72 percent (between 2003 and 2007). The sub-sector's economic competitiveness, however, was zero for four of the five years analyzed, and only 3 percent in the fifth (and that even though world sugar prices were exceptionally high in that year, see Figure 6.8). While these numbers show the effectiveness of state support to boost production in a selected sub-sector, they also point to a particularly large policy-induced distortion in incentives for agricultural producers in Belarus. Under the given support scheme, sugar beet production is attractive for many farmers (in fact, they are expected to produce sugar beet), and productive resources are allocated in this direction. These resources, however, would add more ${ }^{7}$ value to the economy (society) overall if reallocated to alternative production processes.

${ }^{7}$ In fact, they currently deduct value from the overall economic result. 
Figure 6.9: Changes in the production of major agricultural products in Belarus - three-year averages (1995-1997, 2000-2002 and 2005-2007) $(1995-1997=100)$

Production (1995/97 = 100) (based on amounts)

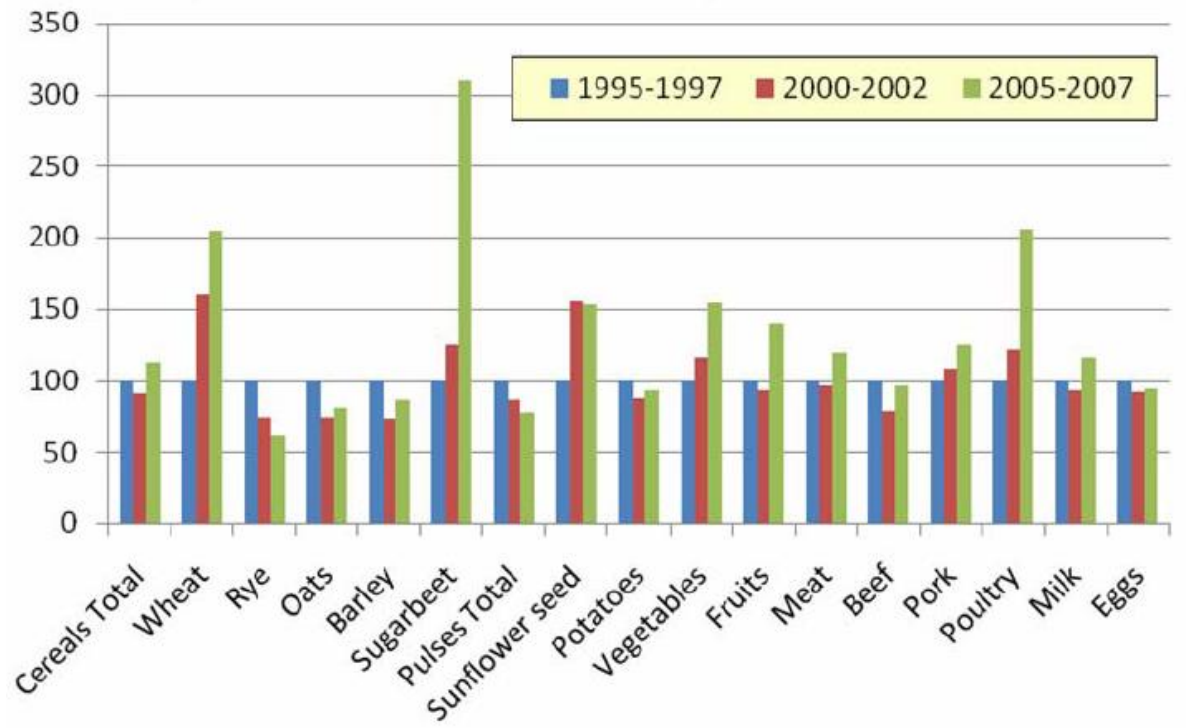

Source: Own calculations with data in Table 6.25.

\section{Livestock production}

In general, livestock production in Belarus is less competitive than crop production from both the economic and financial perspectives. With the exception of milk, the share of farms producing livestock products competitively has never been above 13 percent in the five years analyzed (or 33 percent in terms of production volume). Financial profitability has been higher, indicating governmental support, but has never exceeded 43 percent of farms (again with the exception of milk) (Table 6.7, Table 6.8, Figure 6.11). As was the case for crop production, the net effect of market and price distortions is to subsidize production. With the (minor) exception of beef production between 2003 and 2005 , the share of livestock production that is profitable at financial prices and costs is always larger than the share that is competitive at economic prices and costs.

\section{The special case of dairy production}

Three quarters of dairy farms produced milk with financial profits, but only in the year 2007 has the economic competitiveness climbed as high as 45 percent from 5-14 percent in the four years before. Like sugar beet, dairy production has increased considerably over the last decade, with milk productivity ( $\mathrm{kg}$ milk per cow and year) nearly doubling between 2000 and 2007 (Table 6.1). This impressive performance, however, was achieved through massive governmental support to dairy farms and despite an implicit taxation through artificially low product prices set by the government ("foot on the gas pedal and the brake 
Figure 6.10: Social cost benefit (SCB) distributions for crop products in Belarus (2003-2007)
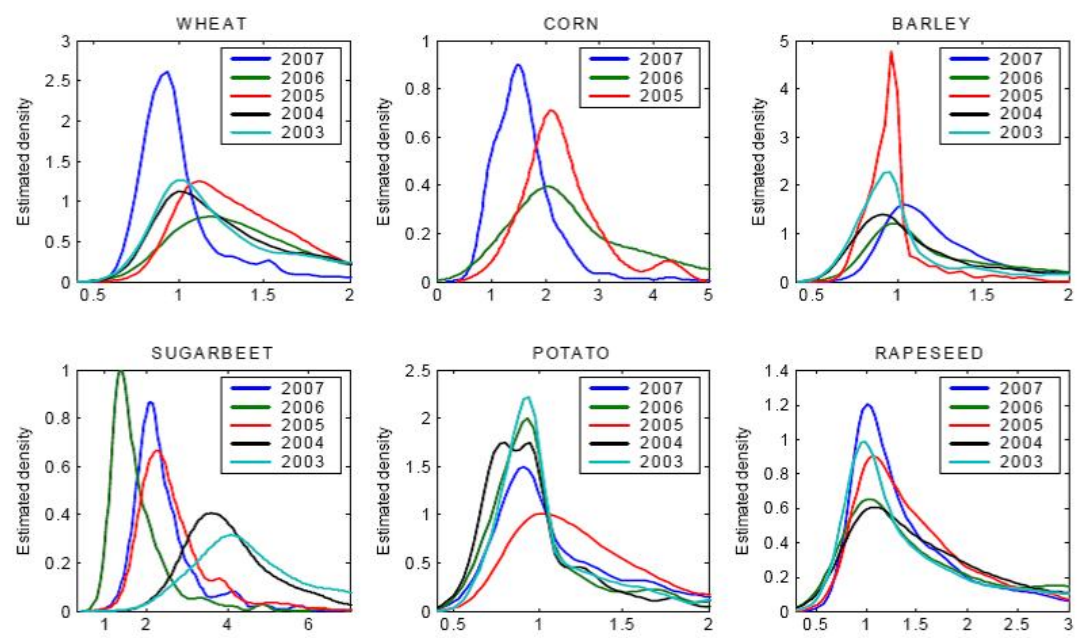

Source: Own calculations with Belarusian farm data base. For details and assumptions, see Technical Appendix 2 in section 6.7.

Figure 6.11: Social cost benefit (SCB) distributions for livestock products in Belarus (2003-2007)
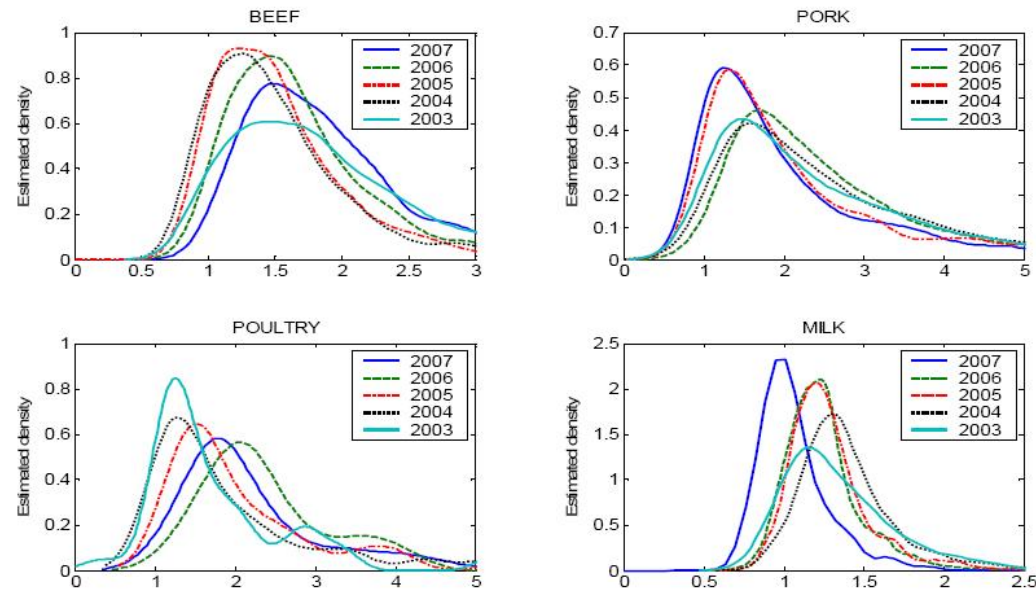

Source: Own calculations with Belarusian farm data base. For details and assumptions, see Technical Appendix 2 in section 6.7. 
Belarus: Agricultural Productivity and Competitiveness. Impact of State Support and Market Intervention

Table 6.7: The shares of farms with competitive livestock production in Belarus that are competitive at financial $(0<\mathrm{PCB}<1)$ and economic $(0<\mathrm{SCB}<1)$ prices in costs (in \%, 2003-2007)

\begin{tabular}{lrrrrr}
\hline \multicolumn{7}{c}{ Profitable at financial costs } & (0<PCB $<1)$ \\
\hline Product & $\mathbf{2 0 0 3}$ & $\mathbf{2 0 0 4}$ & $\mathbf{2 0 0 5}$ & $\mathbf{2 0 0 6}$ & $\mathbf{2 0 0 7}$ \\
\hline Beef & 3.7 & 6.7 & 7.0 & 6.1 & 4.2 \\
Pork & 17.3 & 18.8 & 26.9 & 23.9 & 21.5 \\
Poultry & 23.5 & 26.2 & 42.9 & 37.8 & 31.7 \\
Milk & 40.8 & 77.1 & 75.7 & 73.4 & 74.8 \\
\hline \multicolumn{7}{c}{ Product } & Competitive at economic costs & $(\mathbf{0}<$ SCB $<1)$ \\
\hline Beef & $\mathbf{2 0 0 3}$ & $\mathbf{2 0 0 4}$ & $\mathbf{2 0 0 5}$ & $\mathbf{2 0 0 6}$ & $\mathbf{2 0 0 7}$ \\
Pork & 6.7 & 13.4 & 10.4 & 4.2 & 1.2 \\
Poultry & 2.5 & 1.5 & 6.2 & 0.9 & 7.0 \\
Milk & 7.4 & 4.9 & 0.0 & 0.0 & 0.0 \\
\hline
\end{tabular}

Source: Own calculations with Belarusian farm data base, see Technical Appendix 2 in section 6.7 .

Table 6.8: The shares of livestock production (by marketed volume of production) in Belarus that is competitive at financial $(0<\mathrm{PCB}<1)$ and economic $(0<\mathrm{SCB}<1)$ prices in costs (in \%, 2003-2007)

\begin{tabular}{|c|c|c|c|c|c|}
\hline \multicolumn{6}{|c|}{ Profitable at financial costs $(0<P C B<1)$} \\
\hline Product & 2003 & 2004 & 2005 & 2006 & 2007 \\
\hline Beef & 16.2 & 21.9 & 22.9 & 18.9 & 15.3 \\
\hline Pork & 56.4 & 73.1 & 84.6 & 82.2 & 74.5 \\
\hline Poultry & 46.0 & 65.6 & 88.2 & 74.5 & 74.1 \\
\hline Milk & 57.7 & 86.3 & 84.7 & 83.0 & 82.9 \\
\hline \multicolumn{6}{|c|}{ Competitive at economic costs $(0<\mathrm{SCB}<1)$} \\
\hline Product & 2003 & 2004 & 2005 & 2006 & 2007 \\
\hline Beef & 23.9 & 32.7 & 26.5 & 14.0 & 7.2 \\
\hline Pork & 12.7 & 2.7 & 23.0 & 0.2 & 26.2 \\
\hline Poultry & 11.0 & - & - & - & - \\
\hline Milk & 22.6 & 9.2 & 9.9 & 15.1 & 58.5 \\
\hline
\end{tabular}

Source: Own calculations with Belarusian farm data base, see Technical Appendix 2 in section 6.7.

at the same time") which provides the dairy processing industry with cheap inputs. The net effect, as illustrated by the difference between the PCB and SCB ratios of Table 6.7, was clearly in favor of dairy farms, taxing the rest of the economy. In 2007, like in the three years before, about 75 percent of dairy farms operated with financial profits, while - assessed at economic prices - only about 45 percent of the farms were actually competitive. Unusually high milk prices in that year, however, raised the share of competitiveness above the more typical level of around 10 percent (5.2 to 13.6 percent between 2003 and 2006). This means that in 2007,39 percent of the financially profitable dairy farms would not have been profitable if economic prices had prevailed, i.e. in the absence of currently existing divergences (distorting policies and market failures). And in the more typical year 2006, this proportion would even have 
reached 85 percent $^{8}$. Given that milk and milk products are Belarus's main agricultural export products, the striking discrepancy between competitiveness at economic prices and financial profitability has another important implication in addition to its impact on governmental expenditure. With nearly half (46 percent in 2007) of its dairy products being exported, much of Belarus' state support provided to dairy production effectively becomes an export subsidy and - due to Russia's large share in Belarus' dairy trade - (to some extent) a subsidy paid by Belarusian taxpayers to Russia ${ }^{9}$. Current plans foresee an expansion of Belarus' dairy production by 118 farms, which will increase the amount of milk produced (and exported) and hence transfer even more resources from Belarusian taxpayers to Russia.

\subsection{The impact of subsidies on performance at the farm level}

One of the main objectives of the SRDP for 2005-2010 is the creation of a macro and micro economic business environment which allows for a stable increase in the efficiency of agriculture. The following paragraphs present a preliminary analysis of the extent to which extent the high level of state support provided to the agriculture sector was able to increase the performance of farms. While it is recognized that investments made in one year need time to become visible in improved performance, the 6-year time period covered in the analysis should allow seeing at least some partial effects.

There is no evidence of 'across the board' improvements in competitiveness in Belarusian agriculture between 2003 and 2007. The distributions of SCB ratios across all farms do not shift systematically towards the left (i.e. in the direction of greater competitiveness) over the 2003-2007 period (Figure 6.10 and Figure 6.11). For poultry there is even some indication of a loss of competitiveness, as the SCB distributions appear to shift to the right over the study period. In the two cases in which the 2007 distribution is clearly further to the left than the earlier distributions (wheat and milk), this was likely caused by high international prices in that year (2006 in the case of sugar beet). High prices also shift the 2007 distribution for corn sharply to the left, but even in that year, only about $10 \%$ of the corn production in Belarus is competitive (Table 6.5). These results may seem surprising, given the broad improvements in TFP described above. However, while the link between TFP change and SCB ratios is methodologically challenging, a few fundamental characteristics should be noted: (i) farms that start at a very low level of competitiveness may experience a positive TFP change without reaching the 'tipping point' (yet) where the production would become internationally competitive; (ii) SCBs are calculated at the crop level, whereas TFP changes are calculated at the farm level; (iii) SCBs include global reference price data; (iv) Overall, there are other factors beyond on-farm efficiency that influence international competitiveness and those factors may not evolve into the same direction.

There is, however, a significant link between the volume of subsidies that a farm

\footnotetext{
${ }^{8}$ Assuming that all economically competitive farms are among the financially profitable farms. For 2006: $(73.4 \%-10.9 \%) / 73.4 \%=85.1 \%$.

${ }^{9}$ To the extent that the additional supply affects the price level in the importing country/region.
} 
Belarus: Agricultural Productivity and Competitiveness. Impact of State Support and Market Intervention

Table 6.9: Regression of TFP change and its components on farm characteristics and subsidies received by farms

\begin{tabular}{|c|c|c|c|c|c|c|c|c|}
\hline \multirow{2}{*}{$\begin{array}{l}\text { Dependent variable } \\
\text { Independent variable }\end{array}$} & \multicolumn{2}{|c|}{$\begin{array}{c}\Delta \text { (Pure } \\
\text { efficiency) }\end{array}$} & \multicolumn{2}{|c|}{$\begin{array}{c}\Delta \text { (Scale } \\
\text { efficiency) }\end{array}$} & \multicolumn{2}{|c|}{$\Delta$ (Technology) } & \multicolumn{2}{|c|}{$\Delta($ TFP $)$} \\
\hline & Coeff. & $\begin{array}{c}\mathrm{p}- \\
\text { value }\end{array}$ & Coeff. & $\begin{array}{c}\text { p- } \\
\text { value }\end{array}$ & Coeff. & $\begin{array}{c}\mathrm{p}- \\
\text { value }\end{array}$ & Coeff. & $\begin{array}{c}\text { p- } \\
\text { value }\end{array}$ \\
\hline Constant & 1.12 & 0.00 & 1.00 & 0.00 & 1.10 & 0.00 & 1.19 & 0.00 \\
\hline Total subsidy received $2003-07$ & 0.12 & 0.00 & 0.00 & 0.19 & 0.01 & 0.20 & 0.10 & 0.00 \\
\hline Arable land & -0.02 & 0.32 & 0.00 & 0.84 & 0.00 & 0.69 & 0.00 & 0.84 \\
\hline$(\text { Arable land })^{2}$ & -0.01 & 0.41 & 0.00 & 0.54 & 0.00 & 0.73 & -0.02 & 0.01 \\
\hline Animal units & 0.25 & 0.00 & -0.03 & 0.00 & -0.05 & 0.02 & 0.18 & 0.00 \\
\hline$(\text { Animal units) })^{2}$ & -0.01 & 0.00 & 0.00 & 0.00 & 0.00 & 0.04 & -0.01 & 0.00 \\
\hline Arable land * Total subsidy & 0.01 & 0.67 & 0.00 & 0.09 & 0.00 & 0.63 & 0.03 & 0.12 \\
\hline Animal units * Total subsidy & 0.00 & 0.95 & 0.01 & 0.00 & -0.01 & 0.47 & -0.02 & 0.16 \\
\hline Capital/labor ratio & 0.00 & 0.25 & 0.00 & 0.21 & 0.00 & 0.04 & 0.00 & 0.58 \\
\hline Animal units / hectare & 0.00 & 0.81 & 0.00 & 0.14 & 0.00 & 0.91 & 0.01 & 0.30 \\
\hline Crop costs as $\%$ of total costs & -0.02 & 0.14 & -0.01 & 0.00 & 0.06 & 0.00 & 0.05 & 0.00 \\
\hline Order-m Efficiency score in 2003 & -0.23 & 0.00 & 0.00 & 0.00 & 0.02 & 0.00 & -0.23 & 0.00 \\
\hline Order-m Scale efficiency in 2003 & 0.00 & 0.00 & 0.02 & 0.00 & 0.00 & 0.00 & 0.00 & 0.00 \\
\hline $\mathrm{R}^{2}$ & \multicolumn{2}{|c|}{$31.1 \%$} & \multicolumn{2}{|c|}{$17.6 \%$} & \multicolumn{2}{|c|}{$19.7 \%$} & \multicolumn{2}{|c|}{$27.0 \%$} \\
\hline Number of observations & \multicolumn{2}{|c|}{1151} & \multicolumn{2}{|c|}{1080} & \multicolumn{2}{|c|}{1113} & \multicolumn{2}{|c|}{1142} \\
\hline
\end{tabular}

Source: Own calculations. Coefficients in bold type are significant at the 5\% level.

Figure 6.12: Scatter plots of TFP change and its components against the volume of subsidies received between 2003 and 2007
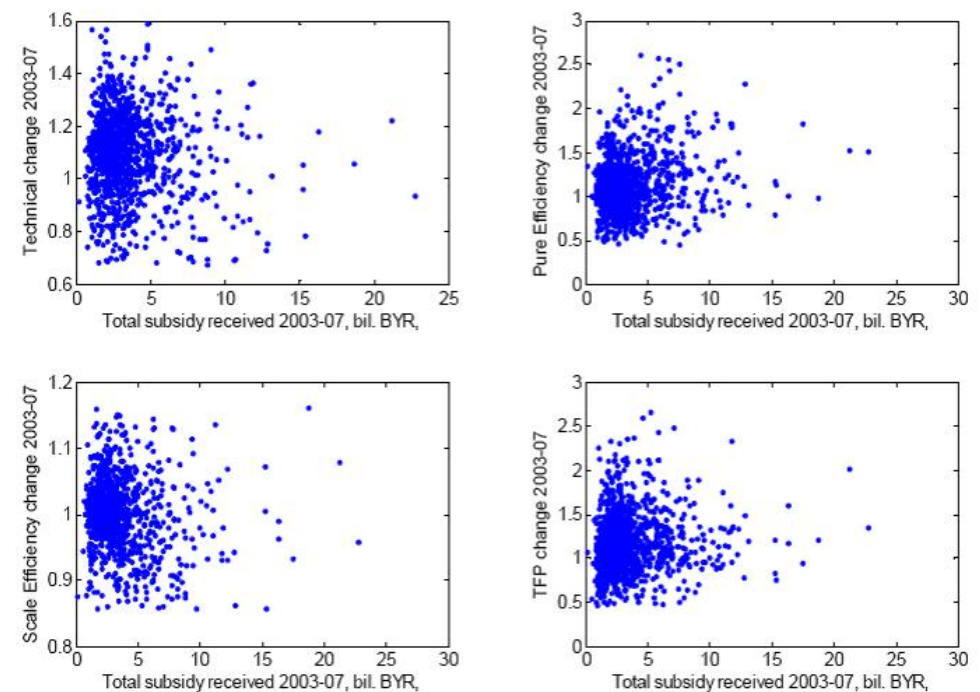

Source: Own calculations with Belarusian farm database. 
received between 2003 and 2007 and its performance in terms of TFP change over the same period ${ }^{10}$. Table 6.9 presents the coefficients with significant contributions to TFP change. Budgetary support received between 2003 and 2007 had a significant and positive effect on pure (technical) efficiency change (i.e. moving closer to their best-practice frontiers) and overall TFP change, but, somewhat surprisingly, not on technical change. Figure 6.12 presents scatter plots of the relationship between subsidies received and TFP change as well as its components, providing visual impression of the result. Furthermore, the impact of the efficiency score in 2003 on pure (technical) efficiency change and overall TFP change is statistically significant and negative. Recall, however, that higher efficiency scores are associated with lower efficiency. Hence, this result suggests that farms that were less efficient in 2003 experienced less pure efficiency change and overall TFP between 2003 and 2007. This means that the further away from its best-practice frontier a farm was operating in 2003, the less TFP improvements it was able to realize until 2007, resulting in an increasing efficiency disparity. While these results can only be considered as preliminary, requiring further in-depth analyses, they seem to indicate that budgetary support might be well-targeted towards the more-efficient farms. On the other side of the spectrum, the less efficient farms would then fall further and further behind and eventually need to exit from production. However, some of the statistically significant coefficients are small in magnitude ${ }^{11}$, and the low coefficients of determination $\left(\mathrm{R}^{2}\right)$ of the regressions indicate that the few significant effects identified here explain only a very small portion of the variation in changes in TFP and its components.

\subsection{References}

alpmedia.net (2002): EU-Kommission regt Umorientierung der Agrarpolitik an. alpmedia Newsletter 19/2002, p. 1. www.alpmedia.net.

Alston, J., M. Marra, P. Pardey and P. Wyatt (2000): Research Return Redux: A Meta-Analysis and the Returns of R\&D. Australian Journal of Agricultural Economics, Vol. 44: 1364-85.

Balassa, B. (1965). Trade Liberalisation and 'Revealed' Comparative Advantage. The Manchester School, Vol. 33: 99-123.

Balance, R., H. Forstner and T. Murray (1987). Consistency Tests of Alternative Measures of Comparative Advantage. Review of Economics and Statistics, Vol. 69: 157-161.

Blandford, D. And T. Josling (2007): Should the Green Box be Modified? IPC Discussion Paper, International Food \& Agricultural Trade Policy Council. http://www.agritrade.org/Publications/DiscussionPapers/Green_ Box.pdf.

\footnotetext{
${ }^{10}$ For methodological details see the Technical Appendix 1 in section 6.6 and Tables 6.9 6.10 .

${ }^{11}$ Since the corresponding independent variables are measured in standard deviations from their means, large changes in these variables are needed to have a noticeable impact on the dependent variable in question. For example, a one standard deviation increase in subsidies will produce 10 percent more TFP change over the period 2003-2007. For comparison: In 2007, for example, the 1523 large commercial farms for which subsidy information is available received an average of BYR 1,612 million in a range of BYR 0 - 30,474 million, with a standard deviation of BYR 1,640 million, and with 67 percent of farms receiving less than BYR 1,640 million.
} 
Belarus: Agricultural Productivity and Competitiveness. Impact of State Support and Market Intervention

Borodina, O. (2006): Derzhavna pidtrymka silskogo gospodarstva: koncepcia, mekhanismy,effektyvnist (State Support to Agriculture: concept, mechanisms, and efficiency). Ekonomika ta Prognozuvannia, Vol. 1: 106-125.

Cazals, C., J.P. Florens and L. Simar (2002): Nonparametric frontier estimation: A robust approach. Journal of Econometrics, Vol. 106: 1-25.

Charnes, A., W.W. Cooper, And E. Rhodes (1978): Measuring the Inefficiency of Decision Making Units. European Journal of Operational Research, Vol. 2(6): 429-444.

Cimpoies, D, A. Muravschi and A. Racul (2008): Structural Changes in Moldovan Agriculture: Problems and Perspectives. Paper presented at the IAMO Forum 2008, Halle. http://www.iamo.de/uploads/media/2b.3_ Cimpoies_CD.pdf.

CIS (2009).http://www. cisstat.com/rus/index.htm.

Cooper, W.W., L.M. Seiford and T. KaOru (2007): Data Envelopment Analysis. A Comprehensive Text with Models, Applications, References and DEA-Solver Software. 2nd edition, Springer.

Daraio, C. And L. Simar, L. (2007): Advanced Robust and Nonparametric Methods in Efficiency Analysis: Methodology and Applications. Springer, New York.

Deprins, D., L. Simar and H. Tulkens (1984): Measuring Labor Ineffciency in Post Offices. In Marchand, M., P. Pestieau and H. Tulkens (eds.): The Performance of Public Enterprises: Concepts and Measurements. NorthHolland, Amsterdam, pp. 243-267.

Doing Business (2009). http://www.doingbusiness.org/.

EBRD (2009 - regularly updated): Selected Economic Indicators. London. http://www.ebrd.com/country/sector/econo/stats/sei.xls.

FAO (2009 - regularly updated): FAOSTAT. Rome. http://faostat.fao. org.

Färe, R., S. Grosskopf And C.A.K. Lovell (1985): The Measurement of Efficiency of Production. Boston, Kluwer-Nijhoff Publishing.

Färe, R., And S. Grosskopf (1996): Intertemporal Production Frontiers: With Dynamics DEA, Boston: Kluwer Academic Publishers.

Färe, R., S. Grosskopf And M. Norris (1997): Productivity Growth, Technical Progress, and Efficiency Change in Industrialized Countries: Reply. American Economic Review, Vol. 87(6): 1040-1043.

Farrell, M.J. (1957): The Measurement of Productive Efficiency. Journal of the Royal Statistical Society, Vol. 120(3): 253-290.

GiUcCI, R., AND KiRChNeR, R. (2007): Energy shocks and macroeconomic management: policy options for Belarus. Policy Paper PP/02/07. German Economic Team in Belarus, Minsk. http://research.by/pdf/pp2007e02. pdf.

Government of the Republic of Belarus (2005). State Program for the Revitalization and Development of Rural Areas, 2005-2010.

GUSAKOV (ED.) (2007): Ekonomika organizaciy I otrasley agropromyshlennogo kompleksa (Economics of organizations and sectors in agriculture). Minsk. Belorusskaya nauka.

Huelsbergen ET AL. (2001). A method of energy balancing in crop production and its application in a long-term fertilizer trial. Agriculture, Ecosystems and Environment, Vol. 86 (2001): 303-321.

Institute for Systemic Research in Agriculture of the National 
Academy of Sciences of Belarus (2008-2009). Personal communication IBRD/World BAnK (2008): Doing Business 2009. London and Washington. http: //www . doingbusiness.org.

Lerman, Z., C. Csaki And G. Feder (2004): Agriculture in Transition Land Policies and Evolving Farm Structures in Post-Soviet Countries. Lexington Books, Oxford.

Liesner, H.H. (1958): The European Common Market and British Industry. Economic Journal, Vol. 68: 302-16.

López, R. (2005): Why Governments Should Stop Non-Social Subsidies: Measuring Their Consequences for Rural Latin America. Department of Agricultural and Resource Economics, University of Maryland at College Park.

López, R. AND A. Islam (2008): Government Spending and Economic Growth in a Context of Market Imperfections. Department of Agricultural and Resource Economics, University of Maryland at College Park. http://papers . ssrn.com/sol3/papers.cfm?abstract_id=1168048

Ministry of Agriculture of the Russian Federation (2008): Agropromyshlenny komplex Rosii v 2007 godu (Agriculture of Russia in 2007). Moscow. http://www.mcx.ru/documents/document/show/7782.164.htm

Ministry of Agriculture and Food of the Republic of Belarus (2008): Agropromyshlenny complex (Agro-Industrial sector). Minsk.

Monke, E. A. And S. R. Pearson (1989). The Policy Analysis Matrix for Agricultural Development, Ithaca NY: Cornell University Press.

Moreddu, C. (2007): Effective Targeting of Agricultural Policies - Best Practices for Policy Design and Implementation. OECD, Paris.

National Statistics Committee of the Republic of Belarus (2008a): Agriculture of the Republic of Belarus - Statistical Book. Minsk.

National Statistics Committee of the Republic of Belarus (2008b): Statistical Yearbook. Minsk.

National Statistics Committee of the Republic of Belarus (2009 - regularly updated): Official Statistics. Minsk. http://belstat.gov.by/ homep/en/main.html

National Statistics Committee of the Republic of Belarus (2009b): personal communication.

OECD (1996): Factors Conditioning the Transfer Efficiency of Agricultural Support. OECD, Paris.

OECD (2006): Adjustment Options and Strategies in the Context of Agricultural Policy Reform and Trade Liberalization. OECD paper AGR/CA/APM(2005)18/FINAL. OECD, Paris.

OECD (2008): OECD's Producer Support Estimate and Related Indicators of Agricultural Support: Concepts, Calculations, Interpretation and Use (The PSE Manual). Paris. http://www.oecd.org/dataoecd/18/31/41121738. pdf.

OECD (2009 - regularly updated): Producer and Consumer Support Estimates, OECD Database 1986-2007. Paris. http://www. oecd.org/document/59/0, 3343, en_2649_33773_39551355_1_1_1_37401,00.html

Park, B.U., Simar, L. And Weiner C. (2000), The FDH Estimator for Productivity Efficiency Scores: Asymptotic Properties, Econometric Theory, $16,855-877$.

Pavel, F., And Yuzefovych, I. (2008): How to deal with 'European gas prices' in Ukraine? Policy paper 06/2008. German Advisory Group in Ukraine 
Belarus: Agricultural Productivity and Competitiveness. Impact of State Support and Market Intervention

and IER, Kiev. http://ierpc.org/ierpc/papers/pp_06_en.pdf.

Psacharopoulos, G. (1994): Returns to investment in education: a global update. World Development, Vol. 22: 1325-1343.

Psacharopoulos, G. and H. Patinos (2002): Returns to Investment in Education: A Further Update. World Bank Policy Research Working Paper \#2881, Washington D.C.

RaO, D.S.P., T.J. Coelli and M. Alauddin (2004): Agricultural productivity growth, employment and poverty in developing countries, 1970-2000. International Labor Organization Employment Strategy Paper 2004/9/, Geneva. Rosenblatt, M. (1956): Remarks on Some Nonparametric Estimates of a Density Function. Annals of Mathematical Statistics, Vol. 27: 643-669.

SheAther, S.J. AND M.C. Jones (1991): A reliable data-based bandwidth selection method for kernel density estimation. Journal of the Royal Statistical Society B, Vol. 53: 684-690.

Shephard, R.W. (1970): Theory of Cost Production Functions, Princeton University Press, Princeton.

Silverman, B.W. (1986): Density Estimation for Statistics and Data Analysis. Chapman and Hall, London.

Simar, L. and P.W. Wilson (1998): Productivity Growth in Industrialized Countries. Université Catholique de Louvain. http://citeseerx.ist.psu. edu/viewdoc/download?doi=10.1.1.21.8587\&rep=rep1\&type=pdf.

Simar, L. (2003): Detecting Outliers in Frontier Models: A Simple Approach. Journal of Productivity Analysis, 20, 391-424

Tochitskaya, I.(2007): Quasi-Fiscal Activity in the Energy Sector in Belarus. Policy Paper PP/08/07. German economic team in Belarus, Minsk. http://pdc.ceu.hu/archive/00003768/01/quasi_fiscal_activity.pdf. USDA (2009): WTO Domestic Support Notifications. USDA Economic Research Service Data Sets. Washington D.C. http://www.ers.usda.gov/db/ Wto/AMS_database/Default. asp?ERSTab=2.

UN COMTRADE database, SITC Rev. 3 nomenclature (volumes in US\$, fob). Database accessed through World Integrated Trade Solution (WITS).

UNCTAD (2009). UNCTAD TRAINS databse. All tariff lines in SITC Rev. 3 nomenclature.

WheELOCK, D.C. AND P.W. WILSON (2003): Robust Nonparametric Estimation of Efficiency and Technical Change in U.S. Commercial Banking. Working paper, Department of Economics, University of Texas, Austin. http: //research.stlouisfed.org/wp/2003/2003-037.pdf.

Wilson, P.W. (2008): FEAR 1.0: A Package for Frontier Efficiency Analysis with R. Socio-Economic Planning Sciences, Vol. 42: 247-254.

World Bank (1994): Belarus Agriculture and Food Sector Review. Washington D.C.

World BAnK (2005): Belarus: Window of Opportunity to Enhance Competitiveness and Sustain Economic Growth - A Country Economic Memorandum for the Republic of Belarus. Report No. 32346-BY. Washington D.C.

World Bank (2008): Ukraine: Agricultural Competitiveness. Report No. 44843-UA. Washington D.C.

World BAnK (2009a): World Development Indicators. World Bank (2009b):

Global Economic Monitor. Commodities.xls.

WORLD BANK (2009c). World Trade Indicators, see: http://www . worldbank. org/wti2008. 
World BAnK (2009d). World Trade Indicators. Trade-at-a-Glance.

World Economic Forum (WEF) (2006). Global Competitiveness Report 2006-2007.

WTO (2009). Tariff Profiles (http://stat.wto.org). Tariff data at the HS 2007 6-digit level.

\subsection{Technical Appendix 1: Total factor productivity (TFP) analysis}

\section{Overview}

The change in TFP for each farm between 2003 and 2007 is calculated based on an order-m frontier estimator concept proposed by Cazals et. al (2002) with a 2 outputs and 12 inputs model, using the detailed farm-level accounting data for commercial farms in Belarus in the years 2003 through 2007. Also, as consistency check, the TFP change was estimated using a conventional DEA model with 2 outputs and only 6 inputs. The analysis, however, is primarily based on the order-m TFP changes, since - compared to the DEA methodology - (i) more information on inputs used (12 inputs) is employed without incurring the 'curse of dimensionality' problem, and (ii) it avoids the problem of finding proper inputs and outputs aggregation tools to reduce the dimension of the model (Daraio and Simar, 2007, Ch.6).

The change in TFP $(\triangle \mathrm{TFP})$ is decomposed into the following three components:

1. Pure efficiency change $(\triangle \mathrm{PE})$ measures how far a farm is from the 'bestpractice' maximum output level that it could produce given current technology and the level of inputs it uses. This best practice is defined by the most efficient farms in the dataset, i.e. the farms that define the production 'frontier'. $\triangle \mathrm{PE}$ ranges from 0 to infinity; a value less than 1 indicates that the farm has moved away from the best-practice frontier (i.e. become less efficient), while a value greater than 1 indicates that it has moved closer to this frontier. For example, a value of 1.5 indicates that the farm's inefficiency has been reduced by $50 \%$.

2. Scale efficiency change $(\Delta \mathrm{SE})$ measures whether or not the farm has moved closer to the optimal scale of production. $\Delta \mathrm{SE}$ also ranges between 0 and infinity, with an interpretation similar to $\triangle \mathrm{PE}$ : a value less than (greater than) 1 indicates that the distance between the farm's actual scale and its optimal scale has increased (decreased).

3. Technical change $(\Delta \mathrm{TC})$ measures whether the best-practice frontier has shifted due to the introduction of a new technology such as an improved variety of seed. $\Delta \mathrm{TC}$ ranges between 0 and infinity as well, and values greater (less) than 1 reflect technological progress (regress). Note that while it may seem difficult to imagine that technological regress can occur, farms can choose or be forced to return to older, less productive technologies, and over time varieties of plants and animals can lose resistance to certain diseases, or weeds, pests and diseases can develop resistance to agri-chemicals or medicines designed to combat them. Hence, a certain 
amount of research and development $(\mathrm{R} \& \mathrm{D})$ is required simply to maintain productivity in agriculture, and technical regress can occur in the absence of this maintenance R\&D. The change in TFP $(\triangle T F P)$ for each farm is equal to the product of its PE, SE and TC changes, or: $\triangle \mathrm{TFP}$ $=\Delta \mathrm{PE} * \Delta \mathrm{SE} * \Delta \mathrm{TC}$.

The links between TFP change and a set of explanatory variables describing the farms, including the subsidies received, were analyzed using regression methods. Specifically, the change in a farm's TFP between 2003 and 2007, and each of the three components of this change discussed above, are regressed on a set of farm characteristics that includes the total volume of subsidies received by the farm between 2003 and 2007, the size of the farm in hectares and head of livestock, its capital/labor ratio, its specialization (measured as the share of crop production costs in total costs) and its efficiency in the initial year 2003. The choice of these independent variables is based on numerous previous studies that have analyzed the link between farm characteristics (such as size, specialization and efficiency) and TFP. Descriptive statistics for the raw data are presented in Table 6.10. All independent variables are measured in units of standard deviation from the mean to facilitate the interpretation of the regression coefficients. This means that the estimated coefficients measure the impact of a one standard deviation increase in the explanatory variable in question on TFP change or the corresponding component.

\section{Measurement of farm-level individual technical efficiency.}

Assume $n$ firms operate in the sector at question. Each firm $k(k=\overline{1, n})$ uses $N$ inputs, $x^{k}=\left(x_{1}^{k}, \ldots, x_{N}^{k}\right) \in \Re_{+}^{N}$, to produce M outputs, $y^{k}=\left(y_{1}^{k}, \ldots, y_{M}^{k}\right) \in \Re_{+}^{M}$. We assume that all $n$ firms have access to the same technology $T$, defined as

$$
T \equiv\left\{\left(x^{k}, y^{k}\right): x^{k} \text { can produce } y^{k}\right\}
$$

that satisfies standard regularity axioms of production theory (Färe et al., 1985). Under these assumptions, the output-oriented distance function $D_{O}^{k}$ : $\Re_{+}^{N} \times \Re_{+}^{M} \rightarrow \Re_{+}^{1} \cup\{\infty\}$, defined as

$$
D_{o}^{k}\left(x^{k}, y^{k}\right) \equiv \inf \left\{\theta:\left(x^{k}, y^{k} / \theta\right) \in T\right\}
$$

measures how far each firm $k$ produces from the best-practice frontier $f\left(x^{k}\right)$, the outer bound of the technology set $T$ (Shephard, 1970).

$$
T E_{o}^{k}\left(x^{k}, y^{k}\right) \equiv \max \left\{\theta:\left(x^{k}, y^{k} \theta\right) \in T\right\}=1 / D_{o}^{k}\left(x^{k}, y^{k}\right)
$$

then defines a firm's Farrell (1957) output-oriented technical efficiency.

A simple illustration for the case of a technology with one input and one output is illustrated in Figure 6.13, in which the Farrell output-oriented technical efficiency (TE) for a firm operating at point $\mathrm{B}$ is computed as $\mathrm{TE}=\mathrm{AC} / \mathrm{AB}$. This measure relates what the firm could produce given the level of inputs it uses (the amount $\mathrm{AC}$, in the numerator) to what it actually produces (the amount $\mathrm{AB}$, in the denominator). Whenever $D_{o}^{k}\left(x^{k}, y^{k}\right)=1\left(\right.$ or $\left.T E_{o}^{k}\left(x^{k}, y^{k}\right)=1\right)$, firm $k$ is technically efficient; $T E_{o}^{k}>1$ means that the firm is technically inefficient. A firm's TE can also be represented in percentages, i.e. $\left[1 / T E_{o}\left(x^{k}, y^{k}\right)\right] * 100 \%$ and its inefficiency score would then be then $\left[1-1 / T E_{o}\left(x^{k}, y^{k}\right)\right] * 100 \%$. 
Table 6.10: Descriptive statistics for the variables used in the regression analysis of order-m TFP change and its components

\begin{tabular}{|c|c|c|c|c|}
\hline Variable & Mean & $\begin{array}{l}\text { Standard } \\
\text { deviation }\end{array}$ & Minimum & Maximum \\
\hline$\Delta$ (Pure efficiency) & 1.1 & 0.3 & 0.4 & 2.6 \\
\hline Total farm subsidy 2007-2003 (mill. BYR) & 4661.1 & 3550.7 & 692.0 & 42010.0 \\
\hline Arable land (ha) & 2358.5 & 1125.2 & 253.4 & 10549.0 \\
\hline Animals (animal units) & 3115.5 & 4019.1 & 287.6 & 107320.0 \\
\hline $\begin{array}{l}\text { Capital/abor ratio (mill. BYR/000 man- } \\
\text { hours) }\end{array}$ & 33.0 & 23.6 & 6.7 & 523.2 \\
\hline Crop costs share, in total farm costs & 0.4 & 0.1 & 0.2 & 0.6 \\
\hline Order-m Efficiency score in 2003 & 1.1 & 0.6 & 0.4 & 7.2 \\
\hline$\Delta$ (Scale efficiency) & 1.0 & 0.1 & 0.9 & 1.2 \\
\hline Total farm subsidy $2007-2003$ (mill. BYR) & 4628.6 & 3332.5 & 830.0 & 28724.0 \\
\hline Arable land (ha) & 2361.6 & 1127.5 & 253.4 & 10549.0 \\
\hline Animals (animal units) & 3111.7 & 4002.9 & 287.6 & 107320.0 \\
\hline $\begin{array}{l}\text { Capital/labor ratio (mill. BYR'000 man- } \\
\text { hours) }\end{array}$ & 32.9 & 23.6 & 6.7 & 523.2 \\
\hline Crop costs share, in total farm costs & 0.4 & 0.1 & 0.2 & 0.6 \\
\hline Order-m Scale Efficiency score in 2003 & 1.1 & 0.1 & 1 & 1.8 \\
\hline$\Delta$ (Technology) & 1.1 & 0.2 & 0.7 & 1.6 \\
\hline Total farm subsidy 2007-2003 (mill. BYR) & 4654.2 & 3253.2 & 176.0 & 39282.0 \\
\hline Arable land (ha) & 2383.3 & 1128.5 & 375.2 & 10549.0 \\
\hline Animals (animal units) & 3107.0 & 3776.0 & 287.6 & 107320.0 \\
\hline $\begin{array}{l}\text { Capital/labor ratio (mill. BYR'000 man- } \\
\text { hours) }\end{array}$ & 32.7 & 24.3 & 4.8 & 628.9 \\
\hline Crop costs share, in total farm costs & 0.4 & 0.1 & 0.2 & 0.6 \\
\hline Order-m Efficiency score in 2003 & 1.0 & 0.4 & 0.4 & 5.4 \\
\hline$\Delta($ TFP $)$ & 1.2 & 0.3 & 0.5 & 2.7 \\
\hline Total farm subsidy $2007-2003$ (mill. BYR) & 4778.7 & 3427.2 & 176.0 & 39282.0 \\
\hline Arable land (ha) & 2410.6 & 1147.8 & 409.0 & 10549.0 \\
\hline Animals (animal units) & 3187.6 & 3877.7 & 287.6 & 107320.0 \\
\hline $\begin{array}{l}\text { Capital/labor ratio (mill. BYR'000 man- } \\
\text { hours) }\end{array}$ & 32.9 & 24.8 & 4.8 & 628.9 \\
\hline Crop costs share, in total farm costs & 0.4 & 0.1 & 0.2 & 0.6 \\
\hline Order-m Efficiency score in 2003 & 1.0 & 0.5 & 0.3 & 5.4 \\
\hline
\end{tabular}

Source: Own calculation

\section{Estimators used in the study}

The best-practice frontier, and hence TE scores, are commonly estimated using the Free Disposal Hull (FDH) method (Deprins et al., 1984) or the Data Envelopment Analysis (DEA) method (Charnes et al., 1978). The DEA frontier is simply a convex hull of the FDH frontier, and it is estimated by solving the following linear optimization problem for each observation or firm in the sample

$$
\begin{aligned}
T E_{o}\left(x^{j}, y^{j}\right) \equiv & \max \left\{\theta: \theta y^{j} \leq \sum_{k=1}^{K} z^{k} y_{m}^{k} ; x^{j} \geq \sum_{k=1}^{K} z^{k} x_{n}^{k} ;\right. \\
& \sum_{k=1}^{K} z^{k}=1 ; z^{k} \geq 0 ; \\
& k=\overline{1, K} ; m=\overline{1, M} ; n=\overline{1, N}\}
\end{aligned}
$$


Figure 6.13: The distance function

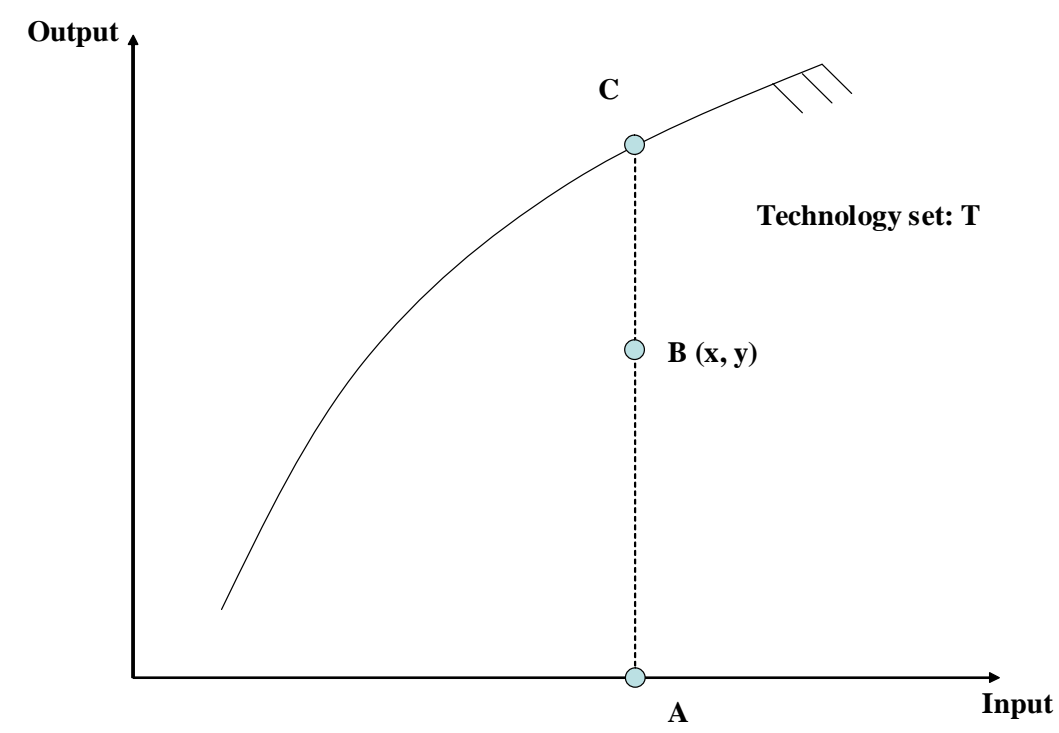

Source: Own presentation.

where the $z^{k}$ are variables that show the intensity with which each firm is used in order to construct the best-practice frontier, $y_{m}^{k}$ is the $m^{\text {th }}$ output of the $k^{t h}$ firm and $x_{n}^{k}$ is the nth input employed by firm $k$.

The main limitations of the FDH and DEA methods are the curse of dimensionality and sensitivity to outliers (Daraio and Simar, 2007). For many applications these problems are potentially acute. As an alternative, partial or so-called robust frontiers can be estimated based on the order-m expected maximum output frontier proposed by Cazals et al (2002). The main idea of this method is to estimate a frontier which does not envelop all the data points, making it is robust to outliers. In the one-output, one-input case, the order-m frontier is defined as $\varphi_{m}(x)=E[\max (Y) \mid X \leq x]$. It represents the expected maximum value of the output among a fixed number of $m$ farms drawn from the population of farms with at most the level $\mathrm{x}$ of input use. The parameter $m$ can be treated as a trimming parameter. If $m=100$, for example, then is the estimated maximum possible output among 100 random farms that use no more than input level $x_{i}$. These partial frontier are robust to the extreme points and do not suffer from the curse of dimensionality problem shared by DEA and FDH estimators. The order-m estimator converges at a rate of $n^{-1 / 2}$, while the DEA and FDH estimators only converge at rates of $n^{-2 /(p+q+1)}$ and $n^{-1 /(p+q)}$, respectively, where $p$ and $q$ are the numbers of outputs and inputs, respectively. As $m$ increases, the order-m estimator approaches FDH estimator. The advantages of the order-m method are summarized by Daraio and Simar (2007). 


\section{Dynamic efficiency}

The order-m concept is especially useful in applications that examine dynamic changes in productivity and efficiency. In the case of only one input and one output, productivity can be measured by the ratio of output to input, and changes in productivity can be examined by comparing a firm's output-input ratios at different points in time. However, when a firm produces multiple outputs with multiple inputs, as is generally the case in agriculture, this simple approach can be misleading. Furthermore, in a dynamic setting analysis must account for the fact that the best-practice frontier can shift over time. For example, a firm using a fixed amount of input may produce more in the course of time but nevertheless become less efficient if the best-practice frontier is shifting out due to technical change faster than the firm's output increases. The Malmquist index is typically used to examine productivity changes in such settings (Färe and Grosskopf, 1996). This index is typically defined as the product of 'catch-up' (efficiency) and 'frontier-shift' (technical changes) terms. Catchup refers to the degree to which a farm improves or worsens its efficiency, while frontier-shift reflects shifts in the best-practice frontier technology between two time periods.

The catch-up effect from period $s$ to $t$ is equal to the ratio of the efficiency of $\left(x_{t}, y_{t}\right)$ with respect to the period $\mathrm{t}$ frontier to the efficiency of $\left(x_{s}, y_{s}\right)$ with respect to the period $\mathrm{s}$ frontier. A simple example for the one-input, oneoutput case is illustrated in Figure 6.14, where the firm in question moves from point $P\left(x_{s}, y_{s}\right)$ to point $Q\left(x_{t}, y_{t}\right)$, and the best-practice frontier shifts outward between time $s$ and time $t$. The catch-up effect can be computed as $(\mathrm{AQ} / \mathrm{AD}) /(\mathrm{BP} / \mathrm{BC})$. Catch-up $>1$ indicates progress in relative efficiency from period $s$ to $t$, while catch-up $<1$ indicates regress.

In addition to this catch-up term, however, one must account for the frontiershift effect in order to fully evaluate a firm's productivity change. In Figure 6.14 , the reference point for production point $\mathrm{P}$ (which is $\mathrm{C}$ on the best-practice frontier in period $\mathrm{s}$ ) shifts out to point $\mathrm{E}$ on the best-practice frontier in period t. Thus, the frontier-shift effect at point $\mathrm{P}$ equals $\alpha 1=\mathrm{BE} / \mathrm{BC}$. This is equivalent to $\alpha 1=(\mathrm{BP} / \mathrm{BE}) /(\mathrm{BP} / \mathrm{BC})$, which is the ratio of the efficiency of point $\mathrm{P}$ with respect to the period $\mathrm{s}$ frontier to the efficiency of this point with respect to the period t frontier. Similarly, the frontier-shift at point $Q$ is expressed by $\alpha 2=(\mathrm{AQ} / \mathrm{AD}) /(\mathrm{AQ} / \mathrm{AF})$. The overall frontier-shift effect is defined as the geometric mean of $\alpha 1$ and $\alpha 2$. Frontier-shift $>1$ indicates progress in a firm's best-practice frontier technology from period $s$ to $t$, while frontier-shift $<1$ indicates regress in the frontier technology. The Malmquist index or total factor productivity change $(\triangle \mathrm{TFP})$ is computed as the product of the catch-up (efficiency change) and frontier-shift (technical change) components:

$$
\Delta T F P=(\text { catch }- \text { up }) \times(\text { frontier }- \text { shift })
$$

These two components can further be decomposed into additional components (see Simar and Wilson, 1998) that provide additional information about the sources of productivity change. Here, for simplicity, we adopt the decomposition approach of Färe et al. (1997), whereby the catch-up or efficiency change component is further decomposed into measures of 'pure efficiency change' 
Figure 6.14: TFP components: Catch-up and frontier-shift

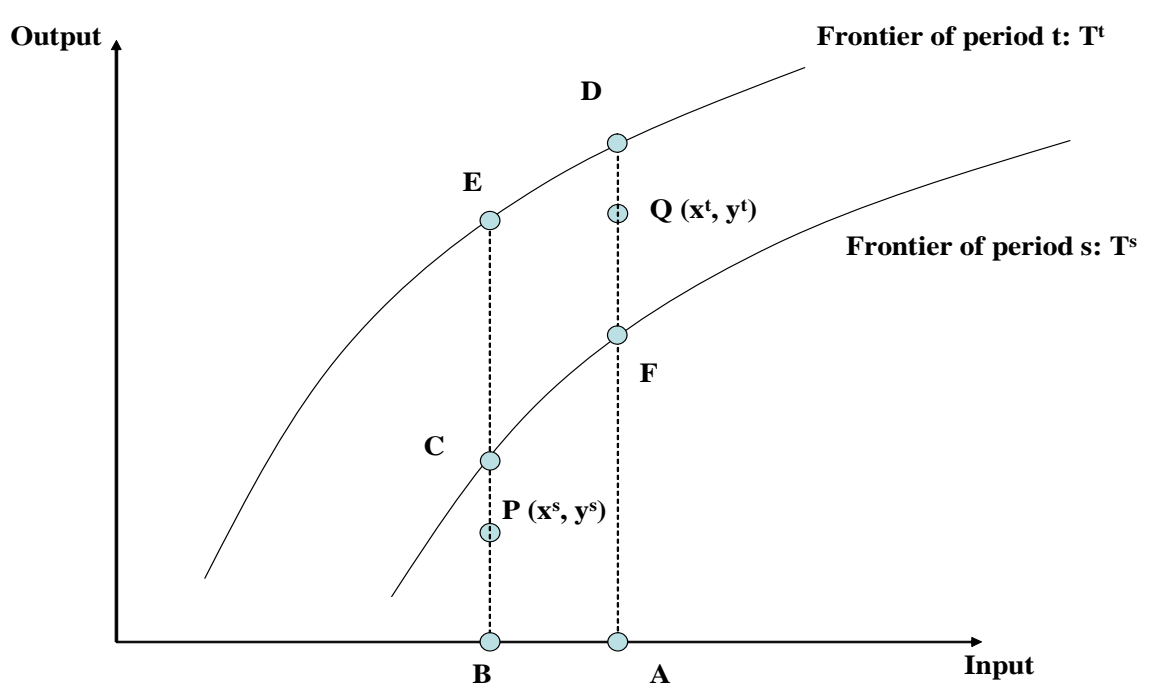

Source: Own presentation based on Cooper et al (2007; p 329)

$(\Delta \mathrm{PE})$ and 'scale efficiency change' $(\Delta \mathrm{SE})$ according to the following formula:

$$
\begin{aligned}
T F P_{t s}\left(x_{s}^{k}, y_{s}^{k}, x_{t}^{k}, y_{t}^{k}\right)= & \underbrace{\left(\frac{D_{t}^{k}\left(x_{t}^{k}, y_{t}^{k}\right)_{V R S}}{D_{s}^{k}\left(x_{s}^{k}, y_{s}^{k}\right)_{V R S}}\right)}_{=\Delta P E} \\
& \times \underbrace{\left(\frac{D_{t}^{k}\left(x_{t}^{k}, y_{t}^{k}\right)_{C R S} / D_{t}^{k}\left(x_{t}^{k}, y_{t}^{k}\right)_{V R S}}{D_{s}^{k}\left(x_{s}^{k}, y_{s}^{k}\right)_{C R S} / D_{s}^{k}\left(x_{s}^{k}, y_{s}^{k}\right)_{V R S}}\right)}_{=\Delta S E} \\
& \times \underbrace{\left(\frac{D_{s}^{k}\left(x_{t}^{k}, y_{t}^{k}\right)_{C R S}}{D_{t}^{k}\left(x_{t}^{k}, y_{t}^{k}\right)_{C R S}} \times \frac{D_{s}^{k}\left(x_{s}^{k}, y_{s}^{k}\right)_{C R S}}{D_{t}^{k}\left(x_{s}^{k}, y_{s}^{k}\right)_{C R S}}\right)^{1 / 2}}_{=\Delta T C}
\end{aligned}
$$

In this equation, $\Delta \mathrm{TC}$ refers to the frontier-shift (technical change) component. The decomposition of efficiency change into 'pure' and 'scale' components accounts for the fact that a firm can become more efficient both by moving closer to its best-practice frontier and by changing the scale of its production so that it is closer to the optimal 'constant returns to scale' technology. In the presentation above, efficiency has only been discussed in terms of moving vertically closer to a given frontier, but the 'scale' component captures the possibility a firm might also become more efficient by moving horizontally (i.e. by using more or less inputs) to a point at which its scale of operation permits more efficient use of the existing technology.

For each of the resulting three components of $\Delta \mathrm{TFP}(\Delta \mathrm{PE}, \Delta \mathrm{SE}$ and $\Delta \mathrm{TC})$, 
values greater than 1 indicate increased productivity. The Malmquist index is typically estimated by replacing the unknown frontier technology $T_{j}^{i}(i=$ $s, t ; j=V R S, C R S)$ by the DEA estimator of this technology. Consequently, the resulting Malmquist index and its decomposition suffer from the same problems (curse of dimensionality, sensitivity to outliers) as the DEA estimator. We therefore employ an order-m Malmquist index to measure productivity change relative to (the conical hull of) the frontier of the expected order-m production set. For details we refer to Wheelock and Wilson (2003).

\section{Data and model description}

The efficiency and productivity analysis described above is carried out using Belarus-wide farm-level accounting data provided by the State Statistics Committee of Belarus. This dataset is an unbalanced panel of 9232 observations over the period 2003-2007.

Based on the share of crop production costs in total farm production costs, we eliminated highly specialized farms (either crop or livestock) from the dataset. The eliminated farms accounted for less than $5 \%$ of the total sample. The share of crop production costs in total farm production costs in the remaining farms was in the range $20-62 \%$.

We defined 2 outputs and 12 inputs (listed in Table 6.11).Although we have over 1000 observations in each year, the samples are too small for DEA and FDH estimation, given the high dimensionality of application (2 outputs and 12 inputs). A rough comparison of equivalent sample sizes provides an idea of the potential curse of dimensionality in DEA and FDH estimation. Recall that the order-m, DEA, and FDH estimators converge at rates of $n^{-1 / 2}, n^{-2 /(p+q+1)}$, and $n^{-1 /(p+q)}$, respectively, where $p$ and $q$ are the numbers of outputs and inputs. Hence, the DEA estimator would require $\left(100^{-1 / 2}\right)^{-15 / 2}=10^{7.5}$ observations to achieve the same convergence in estimation as an order-m estimator with only 100 observations, and the FDH estimator would require $\left(100^{-1 / 2}\right)^{-14}=10^{14}$ observations. Or, with 14 dimensional DEA model, we would have the rate of convergence $1305^{-2 / 15}$, which roughly equivalent to having $1305^{4 / 15}$, or 6 observations in a fully parametric model, where the rate of convergence is $n^{-1 / 2}$. Using the FEAR package in $\mathrm{R}$ (Wilson, 2008), we computed order-m output oriented efficiencies for all farms in each year from 2003 to 2007 ( 2 outputs by 12 inputs model). Values of $m$ ranging from 15 to 300 were tested.

Figure 6.15 presents kernel estimates of the densities of the order-m efficiencies estimates for 2007 and 2003, and for $m=15,30,50,75$, and 150. The estimated order-m frontier approaches the FDH frontier as $\mathrm{m}$ increases (Cazals et al, 2002). Since almost all farms in our case has an FDH efficiency estimate equal to 1 in each year, it is necessarily the case that all farms in each year of our sample lie on or above the contemporaneous estimated order-m frontier. So the contemporaneous order-m efficiency estimates are equal to or greater than 1 in every case. For the kernel density estimation, we used the reflection method described in Silverman (1986) to avoid the problem of bias in kernel density estimation near boundaries of support. The Gaussian kernel was used, with the bandwidth estimated using the Sheather and Jones (1991) two-stage plug-in procedure. As expected, the densities shift to the left and collapse toward 1 as $m$ increases. Based on these results, the order-m TFP analysis was 
Belarus: Agricultural Productivity and Competitiveness. Impact of State Support and Market Intervention

Table 6.11: Data description and summary statistics

\begin{tabular}{|c|c|c|c|c|c|c|c|c|c|}
\hline \multirow{2}{*}{ Item } & \multirow{2}{*}{ Units } & \multicolumn{4}{|c|}{2007} & \multicolumn{4}{|c|}{2003} \\
\hline & & Mean & Std_dev. & Min. & Max. & Mean & Std. dev. & Min. & Max. \\
\hline \multicolumn{10}{|c|}{ Outputs } \\
\hline Crop revenues & $\begin{array}{l}\text { mill. } \\
\text { BYR }\end{array}$ & 563 & 685 & 0 & 10,241 & 294 & 455 & 0 & 10,108 \\
\hline $\begin{array}{l}\text { Livestock } \\
\text { revenues }\end{array}$ & $\begin{array}{l}\text { mill. } \\
\text { BYR }\end{array}$ & 1,350 & 1,579 & 1 & 21,215 & 651 & 956 & 1 & 17,829 \\
\hline \multicolumn{10}{|c|}{ Inputs } \\
\hline Arable land & ha & 2,634 & 1,355 & 118 & 14,676 & 2,013 & 1,064 & 61 & 12,396 \\
\hline $\begin{array}{l}\text { Hays } \quad \& \\
\text { pastures }\end{array}$ & ha & 1,733 & 1,061 & 1 & 9,805 & 1,288 & 775 & 0 & 7,697 \\
\hline Soil quality & points & 31 & 6 & 16 & 50 & 31 & 6 & 15 & 50 \\
\hline $\begin{array}{l}\text { Breeding and } \\
\text { feeder animals }\end{array}$ & $\begin{array}{l}\text { animal } \\
\text { units }\end{array}$ & 1,968 & 10,500 & 0 & 376,500 & 1,170 & 1,206 & 0 & 13,364 \\
\hline $\begin{array}{l}\text { Purchased } \\
\text { seeds }\end{array}$ & mill. & 56 & 65 & 0 & 733 & 27 & 37 & 0 & 660 \\
\hline Fertilizers & $\begin{array}{l}\text { mill. } \\
\text { BYR }\end{array}$ & 247 & 180 & 10 & 1,822 & 106 & 98 & 1 & 1,090 \\
\hline $\begin{array}{l}\text { Agro- } \\
\text { chemicals }\end{array}$ & $\begin{array}{l}\text { mill. } \\
\text { BYR }\end{array}$ & 145 & 154 & 0 & 1,594 & 68 & 91 & 0 & 1,174 \\
\hline $\begin{array}{l}\text { Purchased } \\
\text { feed }\end{array}$ & $\begin{array}{l}\text { mill. } \\
\text { BYR }\end{array}$ & 232 & 447 & 0 & 5619 & 85 & 216 & 0 & 3,200 \\
\hline Energy & $\begin{array}{l}\text { mill. } \\
\text { BYR }\end{array}$ & 401 & 302 & 32 & 3601 & 199 & 176 & 4 & 2,036 \\
\hline Depreciation & $\begin{array}{l}\text { mill. } \\
\text { BYR }\end{array}$ & 426 & 397 & 12 & 4312 & 212 & 211 & 5 & 2,730 \\
\hline $\begin{array}{l}\text { Other } \\
\text { materials }\end{array}$ & $\begin{array}{l}\text { mill } \\
\text { BYR }\end{array}$ & 565 & 917 & 29 & 18162 & 326 & 517 & 3 & 1,2924 \\
\hline Labor & $\begin{array}{l}\text { mill } \\
\text { BYR }\end{array}$ & 545 & 420 & 43 & 5389 & 380 & 369 & 27 & 5,147 \\
\hline \multicolumn{2}{|c|}{ Number of observations } & \multicolumn{4}{|c|}{1,305} & \multicolumn{4}{|c|}{1,806} \\
\hline
\end{tabular}

Source: Own calculation using Belarusian farm data base.

based on order-15 efficiencies.

To check the results of our order-m model, we also computed conventional DEA TFP and its components changes. Due to the potential curse of dimensionality discussed above, we reduced the original 14 dimensional model to 8 dimensions. Using the formulas on the rate of convergence above, this would correspond as if we had 24 observations. From the other side, Park et al (2000) recommend at least 1000 observations for 5 dimensional FDH model, which would correspond to 9 dimensional DEA model with 1305 observation to reach that rate of convergence. So 8 dimensions is rather acceptable size for our DEA model given the number of farms we have in the sample. 12 inputs in the original model we combined into $6:$ i) arable land, in points*ha( = arable land * soil quality); ii) hays and pastures, in ha; iii) purchased inputs, in mill. BYR (= sum of purchased seeds, feed, energy, agrochemicals, fertilizers, and other materials); iv) breeding and feeder animals, in animal units; v) labor, mill. BYR; vi) depreciation, mill. BYR. Before running the DEA model, we applied a semi-automatic outlier's detection methodology proposed by Simar (2003), which is basically an application of the 'order-m frontier' of Cazals et al (2002). Figure 6.16 shows that the DEA model qualitatively supports the results of the order-m model. 
Figure 6.15: Kernel Estimates of Density of Order-m Efficiency
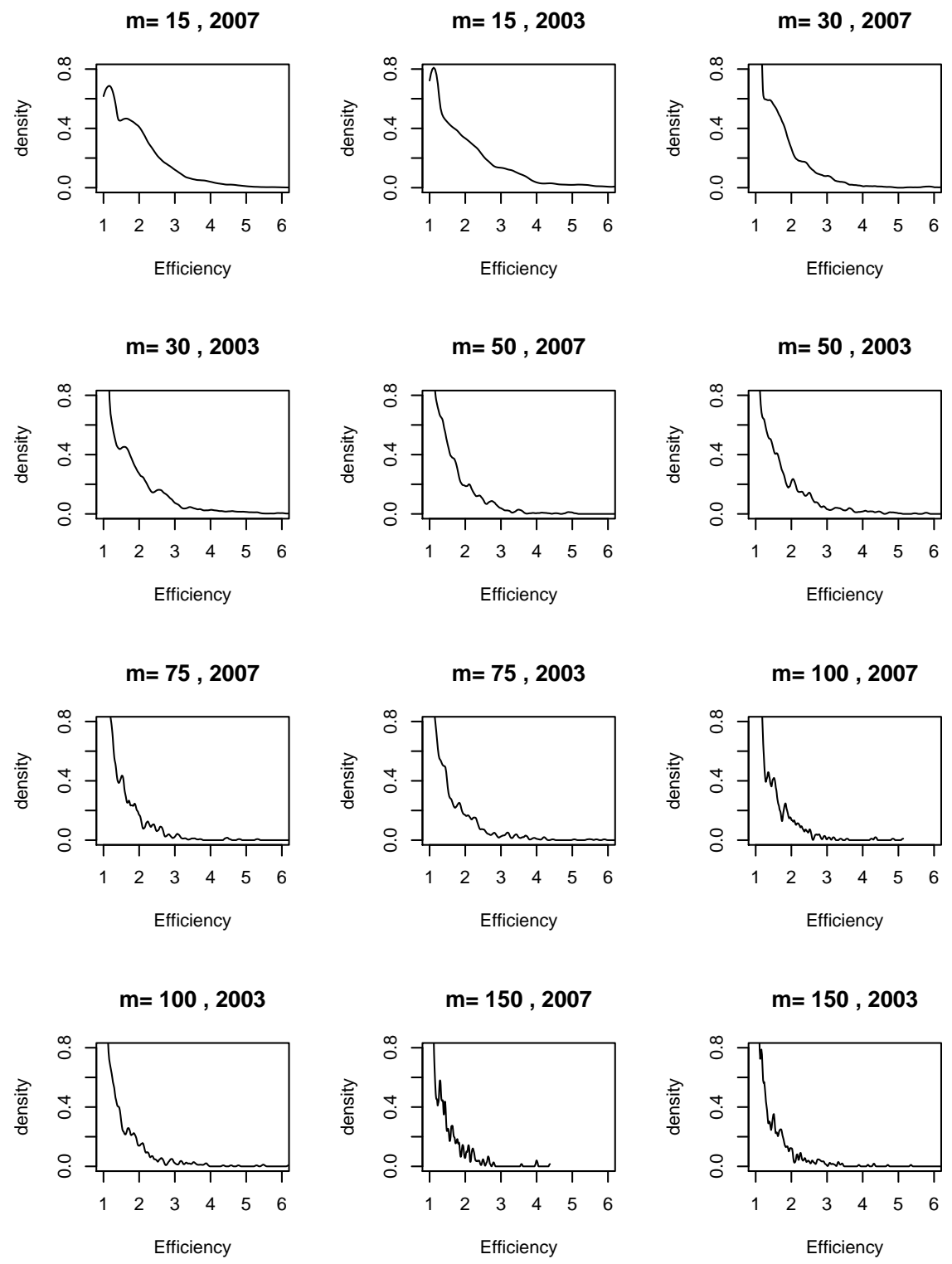

Source: Own calculation. 
Figure 6.16: Changes in total factor productivity and its components for commercial farms in Belarus between 2003 and 2007 (DEA model)
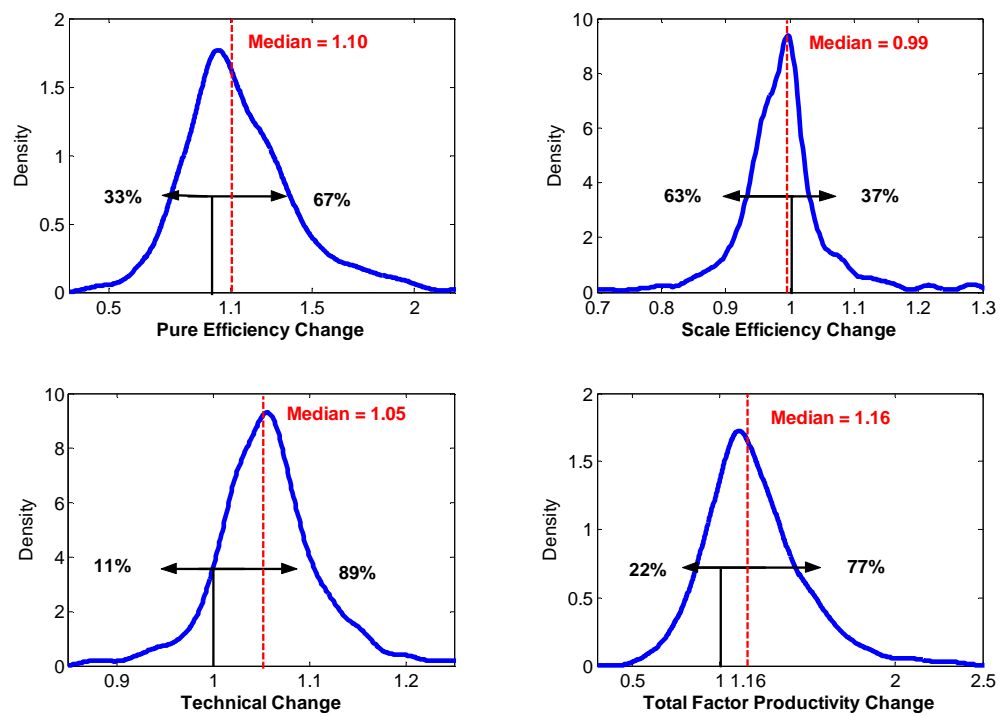

Source: Own calculation.

\subsection{Technical Appendix 2: Analysis of farm competitiveness}

\section{Overview}

Numerous indicators of competitiveness have been developed and applied. One approach, going back to seminar work by Liesner (1958) and Balassa (1965) is based on the idea that competitiveness will be 'revealed' by a country's actual trade performance compared with other countries, regions or the world. A variety of 'Revealed Comparative Advantage' (RCA) indices have been developed based on this idea. RCA indices are usually justified on the grounds that most policy-induced distortions are on the import side, and that export performance will therefore provide a genuine reflection of competitiveness. To the extent that this is true, the almost complete dependence of Belarusian agricultural exports on the Russian market (Table 6.12) would appear to reflect a lack of broader international competitiveness. However, given Belarus' particular regime of government-set prices and governmental funding of agricultural production, the basic assumption might not be entirely applicable to Belarus. RCA analysis is therefore not expected to produce many differentiated insights into agricultural competitiveness in Belarus and is therefore not pursued here. A second approach to measuring competitiveness is causal and attempts to measure factors that influence competitiveness, such as the institutional environment, infrastructure, macroeconomic stability and cost structures. At an aggregated level, this has led to indices such as the 'Growth Competitiveness Indicator' (GCI) developed by Sachs and McArthur, and the 'Business Com- 
Table 6.12: Total Belarusian agricultural exports (thousand tons), and the share of these exports that is destined for Russia (\%), by product

\begin{tabular}{|c|c|c|c|c|c|c|c|c|}
\hline Product & 2000 & 2001 & 2002 & 2003 & 2004 & 2005 & 2006 & 2007 \\
\hline \multirow{2}{*}{ Frozen beef } & 6 & 16.1 & 23.8 & 32.1 & 43.5 & 46.6 & 58.4 & 48.1 \\
\hline & $100 \%$ & $100 \%$ & $100 \%$ & $100 \%$ & $100 \%$ & $100 \%$ & $100 \%$ & $87 \%$ \\
\hline \multirow{2}{*}{ Pork } & 14.4 & 28.6 & 16.9 & 13.6 & 14.7 & 23.4 & 36.8 & 14.9 \\
\hline & $100 \%$ & $100 \%$ & $100 \%$ & $100 \%$ & $100 \%$ & $94 \%$ & $100 \%$ & $99 \%$ \\
\hline \multirow{2}{*}{ Poultry } & 6.8 & 7.5 & 7.6 & 15.7 & 13.2 & 10.5 & 9 & 7.9 \\
\hline & $100 \%$ & $99 \%$ & $100 \%$ & $100 \%$ & $100 \%$ & $100 \%$ & $97 \%$ & $100 \%$ \\
\hline \multirow{2}{*}{ Condensed milk \& cream } & 49.9 & 57.6 & 57.6 & 75.7 & 94.3 & 119 & 153 & 161 \\
\hline & $57 \%$ & $73 \%$ & $82 \%$ & $98 \%$ & $97 \%$ & $93 \%$ & $90 \%$ & $73 \%$ \\
\hline \multirow{2}{*}{ Butter } & 17 & 27.4 & 29.7 & 29.7 & 46.8 & 51.3 & 53.6 & 49.5 \\
\hline & $100 \%$ & $100 \%$ & $100 \%$ & $100 \%$ & $100 \%$ & $99 \%$ & $100 \%$ & $97 \%$ \\
\hline \multirow{2}{*}{ Cheese $\&$ cottage cheese } & 16.9 & 25.8 & 28.3 & 38.3 & 53.5 & 65.1 & 82.6 & 99 \\
\hline & $98 \%$ & $98 \%$ & $97 \%$ & $98 \%$ & $100 \%$ & $100 \%$ & $100 \%$ & $100 \%$ \\
\hline \multirow{2}{*}{ Eggs (million) } & 908.4 & 766.8 & 523.9 & 515.9 & 531 & 441.8 & 516.4 & 437.9 \\
\hline & $99 \%$ & $100 \%$ & $100 \%$ & $99 \%$ & $98 \%$ & $100 \%$ & $100 \%$ & $100 \%$ \\
\hline \multirow{2}{*}{ Sugar } & 256.3 & 244.7 & 332.1 & 311.8 & 383.9 & 481.6 & 250.5 & 272.1 \\
\hline & $76 \%$ & $53 \%$ & $100 \%$ & $100 \%$ & $97 \%$ & $100 \%$ & $95 \%$ & $66 \%$ \\
\hline \multirow{2}{*}{ Confectionery of sugar } & 31.4 & 30.3 & 25.9 & 24.6 & 25.8 & 21.1 & 18.1 & 12.4 \\
\hline & $100 \%$ & $99 \%$ & $99 \%$ & $99 \%$ & $99 \%$ & $98 \%$ & $96 \%$ & $84 \%$ \\
\hline \multirow{2}{*}{ Potatoes } & 101 & 41 & 17.7 & 49.9 & 103 & 16.9 & 9.9 & 31.1 \\
\hline & $89 \%$ & $95 \%$ & $97 \%$ & $93 \%$ & $98 \%$ & $97 \%$ & $56 \%$ & $71 \%$ \\
\hline
\end{tabular}

Source: National Statistics Committee of the Republic of Belarus (2009), own calculations.

petitiveness Indicator' (BCI) developed by Porter, both of which can be found in the World Economic Forum's Global Competitiveness Report (e.g. WEF, 2006). These are 'broad brush' measures, however, that reflect a country's competitive environment as a whole. While this environment will certainly influence agriculture as well, such measures will fail to capture many important agriculture-specific factors, such as the prevailing agricultural policy regime.

The Policy Analysis Matrix (PAM) framework developed by Monke and Pearson (1989) is a product of two accounting identities, one that defines profitability as the difference between revenues and costs, and another that measures the effects of divergences (distorting policies and market failures) as the difference between actually observed financial values and economic values that would prevail if the divergences were removed.

If profitability is calculated at financial prices, it provides an indication of the extent to which the production of a specific good or production in a sub-sector overall is profitable from the perspective of the enterprises themselves since this calculation is based on actually observed prices. The "Private Cost Benefit ratio" $(\mathrm{PCB})^{12}$ is a simple parameter capturing this financial profitability.

\footnotetext{
${ }^{12}$ The terms "private cost benefits" and "social cost benefits" are commonly used in the literature and hence maintained here when referring to the PCB and SCB as a parameter. However, for the broader concept of private vs. social prices (opportunity cost concept), adjustments to the terminology were made in order to avoid misunderstandings. In Belarus' largely centrally planned economy, prices often serve a "social" function. A "social price" might therefore be perceived as a price set by the government (below market level) for such a social purpose (which would be the exact opposite of the international concept of social pricing, i.e. pricing in the absence of governmental interference). Hence, throughout the
} 
It is calculated as the ratio of the sum of tradable and domestic input costs for the production of a particular good, assessed at actually observed (financial) prices divided by the revenue (price) of that good.

The comparison of revenues and costs at economic prices captures to which extent the production of this good or in this sub-sector is desirable from an entire economy's perspective. It takes into account that, for example, subsidized input costs that lower the input price for the producer are actually funded through transfers from other sectors of the economy; that means the economy as a whole pays the financial price plus this transfer. Similarly, if a farm's output prices are artificially reduced by policy measures (such as governmentset procurement prices), the farm's financial profits will be depressed while the economy as a whole benefits from the full value of the product (assessed using border reference prices, assuming export). This "economic profitability" is most easily calculated as the "Social Cost Benefit ratio" (SCB). The SCB is a cost/ revenue ratio calculated as the sum of tradable and domestic input costs for a particular good, assessed at economic prices, divided by this goods economic revenue. Since all costs are calculated on a per unit of output basis, the SCB compares the economic cost of producing a unit of output with the value of that unit for the economy as a whole (i.e, its economic price). The SCB is always greater than 0 , and a SCB less than (greater than) 1 indicates that total input costs are less than (greater than) revenue and that production is (is not) competitive.

Since this calculation considers the costs and benefits to the economy as a whole, the SCB is a convenient indicator of competitiveness of that sub-sector ${ }^{13}$. The assessment of competitiveness in agricultural sub-sectors in this Note is based on the SCB. The Note also uses the comparison of PCBs and SCBs for an assessment of the degree of subsidization provided to the respective sub-sector. If indicators based on the PAM are calculated on the basis of average or 'typical' data for a sector or industry, conclusions become progressively weaker as the heterogeneity of the underlying population grows ${ }^{14}$. Numerous studies that apply empirical efficiency analysis techniques (data envelopment analysis - DEA; stochastic frontier analysis - SFA) to farm level data in CIS countries, however, find significant heterogeneity, with many farms operating at a great distance from the frontier defined by the best-practice farms. The TFP and efficiency analysis of Belarusian agriculture presented in this Note confirms this finding. For this reason, farm-level data is used to calculate SCB distributions for major crop and livestock products in Belarus, analogous to the TFP calcu-

entire document, the term "social" is replaced by "economic" when referring to prices for the economy as a whole (opportunity cost concept), and "private" by "financial" when referring to prices actually observed in markets.

${ }^{13}$ If a sub-sector that produces at the level of costs that it creates to the entire economy and earns revenues assessed at border prices is profitable, then this sub-sector is internationally competitive and it is desirable for an economy (society) to engage in this sub-sector. Conversely, if a sub-sector's export-price-based revenues cannot pay for the actual costs it creates for the economy (society), the sub-sector's production actually subtracts from the value created by the economy and domestic factors employed in this sub-sector would create larger benefits for the economy (society) if transferred to other (sub-)sectors. These considerations do not account for particular social values that a society might attach to the production in a specific sub-sector. But the society should be aware of the economic costs that this decision implies.

${ }^{14} \mathrm{~A}$ sub-sector would be either competitive or not, ignoring the fact that some farms in a non-competitive sector might actually be competitive. 
Figure 6.17: Private and social cost-benefit (PCB, SCB) calculations for a sample farm

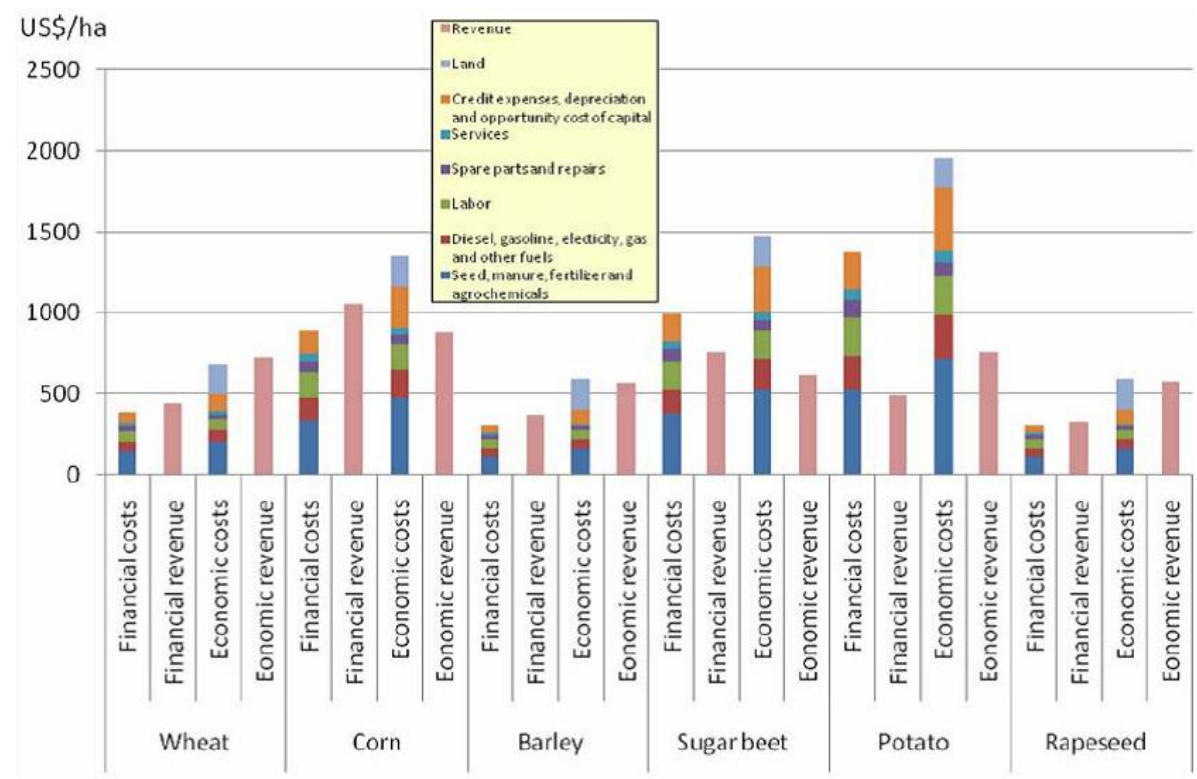

Source: Own presentation based on data from the Belarusian farm data base.

lations mentioned above. This procedure, outlined below, makes it possible to determine for each major farm commodity which proportion of total production volume was produced competitively (i.e. with a SCBs less than 1), and which proportion was not produced competitively (i.e. with a SCBs greater than 1).

\section{Sample calculation, illustrating the SCB methodology}

Calculation is based on the farm with the modal SCB ratio for wheat. While each farm is different, this farm can be considered 'typical' in the sense that it is characterized by the most common SCB for wheat. The results are presented in Figure 6.17; tables with the underlying data are presented in Table 6.13, and information on the conversion of financial into economic prices/costs is presented in Table 6.14.

\section{The Social Cost-Benefit method}

The structure of the PAM, used for the calculation of the PCB and SCB ratios, is presented in (Table 6.15).

The SCB equals the ratio of the sum of tradable and domestic input costs to revenue, or $(\mathrm{F}+\mathrm{G})$ divided by $\mathrm{E}$ in Table 6.15 . Since all costs are calculated on a per unit of output basis, the SCB compares the economic cost of producing a unit of output $(\mathrm{F}+\mathrm{G})$ with the value of that unit (its economic price $\mathrm{E})$. The SCB is always greater than 0 , and a SCB less than (greater than) 1 indicates that total input costs are less than (greater than) revenue and that production 
Table 6.13: Private and social cost benefit (PCB, SCB) calculations for a sample farm (US\$/hectare)

\begin{tabular}{|c|c|c|c|c|c|c|c|c|c|c|}
\hline \multirow[b]{2}{*}{ Product } & \multirow[b]{2}{*}{ Perspective } & \multicolumn{7}{|c|}{ Costs } & \multirow[b]{2}{*}{ Revenue } & \multirow[b]{2}{*}{$\begin{array}{r}\text { Cost- } \\
\text { benefit } \\
\text { ratio }\end{array}$} \\
\hline & & $\begin{array}{r}\text { Seed, manure, } \\
\text { fertilizer and } \\
\text { agro-chemicals }\end{array}$ & $\begin{array}{r}\text { Diesel, gas, } \\
\text { gasoline, } \\
\text { electricity, and } \\
\text { other fuels }\end{array}$ & Labor & $\begin{array}{r}\text { Spare } \\
\text { parts } \\
\text { and } \\
\text { repairs }\end{array}$ & Services & $\begin{array}{r}\text { Credit expenses, } \\
\text { depreciation and } \\
\text { opportunity cost } \\
\text { of capital }\end{array}$ & Land & & \\
\hline \multirow{2}{*}{ Wheat } & Financial & 146.9 & 58.8 & 67.8 & 29.3 & 19.8 & 63.9 & & 444.2 & 0.87 \\
\hline & Economic & 205.6 & 74.4 & 67.8 & 24.9 & 19.8 & 109.3 & 187.7 & 723.9 & 0.95 \\
\hline \multirow[b]{2}{*}{ Corn } & Financial & 340.5 & 136.5 & 157.3 & 67.9 & 45.9 & 148.3 & & $1,057.0$ & 0.85 \\
\hline & Economic & 476.8 & 172.5 & 157.3 & 57.7 & 45.9 & 253.5 & 187.7 & 877.4 & 1.54 \\
\hline \multirow{2}{*}{ Barley } & Financial & 118.4 & 47.4 & 54.7 & 23.6 & 16.0 & 51.6 & & 367.3 & 0.85 \\
\hline & Economic & 165.8 & 60.0 & 54.7 & 20.1 & 16.0 & 88.2 & 187.7 & 569.4 & 1.04 \\
\hline \multirow{2}{*}{$\begin{array}{l}\text { Sugar } \\
\text { beet }\end{array}$} & Financial & 377.2 & 151.2 & 174.2 & 75.2 & 50.8 & 164.3 & & 755.3 & 1.32 \\
\hline & Economic & 528.1 & 191.1 & 174.2 & 63.9 & 50.8 & 280.8 & 187.7 & 620.1 & 2.38 \\
\hline \multirow{2}{*}{ Potato } & Financial & 523.4 & 209.7 & 241.7 & 104.3 & 70.5 & 227.9 & & 492.1 & 2.80 \\
\hline & Economic & 719.8 & 265.2 & 241.7 & 88.7 & 70.5 & 389.6 & 187.7 & 758.9 & 2.59 \\
\hline \multirow{2}{*}{ Rapeseed } & Financial & 118.2 & 47.4 & 54.6 & 23.6 & 15.9 & 51.5 & & 329.7 & 0.94 \\
\hline & Economic & 165.5 & 59.9 & 54.6 & 20.0 & 15.9 & 88.0 & 187.7 & 580.3 & 1.02 \\
\hline
\end{tabular}

Source: Own calculations with Belarusian farm data base. For details and assumptions, see Technical Appendix 2 in section 6.7. Information on the conversion of financial into economic prices/costs is presented in Table 6.14.

Table 6.14: Factors for converting financial to economic costs in SCB analysis*

\begin{tabular}{|c|c|c|c|c|c|c|c|}
\hline Category & Item & Wheat & Corn & Barley & Sugar beet & Potato & Rapeseed \\
\hline \multirow{4}{*}{$\begin{array}{l}\text { Seed, manure, } \\
\text { fertilizers and agro- } \\
\text { chemicals }\end{array}$} & Seed & 0.95 & 0.95 & 0.95 & 0.95 & 0.8503 & 0,95 \\
\hline & Manure, litter, etc. & 1 & 1 & 1 & 1 & 1 & 1 \\
\hline & Fertilizers & 1.95 & 1.95 & 1.95 & 1.95 & 1.95 & 1,95 \\
\hline & Agro-chemicals & 0.95 & 0.95 & 0.95 & 0.95 & 0.95 & 0,95 \\
\hline \multirow{4}{*}{$\begin{array}{l}\text { Diesel, gas, gasoline, } \\
\text { electricity and other } \\
\text { fuels }\end{array}$} & Diesel, gasoline & 1.25 & 1.25 & 1.25 & 1.25 & 1.25 & 1,25 \\
\hline & Electricity & 1.925 & 1.925 & 1.925 & 1.925 & 1.925 & 1,925 \\
\hline & & 3.2 & 3.2 & 3.2 & 3.2 & 3.2 & 3,2 \\
\hline & Other fuels & 1 & 1 & 1 & 1 & 1 & 1 \\
\hline \multicolumn{2}{|l|}{ Labor } & 1 & 1 & 1 & 1 & 1 & 1 \\
\hline \multicolumn{2}{|l|}{ Spare parts, repairs } & 0,85 & 0.85 & 0.85 & 0.85 & 0.85 & 0.85 \\
\hline \multicolumn{2}{|l|}{ Services } & 1 & 1 & 1 & 1 & 1 & 1 \\
\hline \multirow{4}{*}{$\begin{array}{l}\text { Credit expenses, } \\
\text { depreciation and } \\
\text { capital }\end{array}$} & Depreciation & 1 & 1 & 1 & 1 & 1 & 1 \\
\hline & Credit expenses & 1 & 1 & 1 & 1 & 1 & 1 \\
\hline & Opportunity costs of capital & 0.81 & 0.81 & 0.81 & 0.81 & 0.81 & 0,81 \\
\hline & Other expenses & 1 & 1 & 1 & 1 & 1 & 1 \\
\hline \multicolumn{2}{|l|}{ Land (in USS/hectare) } & 187.7 & 187.7 & 187.7 & 187.7 & 187.7 & 187.7 \\
\hline \multicolumn{2}{|l|}{ Revenue } & 1.63 & 0.83 & 1.55 & 0.82 & 1.54 & 1.76 \\
\hline
\end{tabular}

* These factors are multiplied with financial prices/costs to determine economic prices/costs. Hence, the factor of 1.63 for wheat revenues indicates that the economic price of wheat is $63 \%$ higher than the financial price actually received by farms in Belarus. Land is the only exception to this; see the explanation in the next note.

** The financial cost of land is zero. To calculate the economic cost of land, first the economic profit (revenue at economic prices minus economic costs) without land costs is calculated for each product. The average of the resulting positive profits (i.e. excluding products for which the profit without land considering land costs is negative) is then used as the economic price of land. The value of 187.7 US\$/hectare in this table is specific to the sample farm depicted in Table 6.13 and varies from farm to farm depending on how profitably they are able to produce the considered crops. 
Table 6.15: The Policy Analysis Matrix (PAM)

\begin{tabular}{|c|c|c|c|c|}
\hline & \multirow[t]{2}{*}{ Revenue } & \multicolumn{2}{|c|}{ Costs } & \multirow[t]{2}{*}{ Profits } \\
\hline & & Tradable inputs & Domestic factors & \\
\hline $\begin{array}{l}\text { Accounting in Private } \\
\text { (Financial) Prices }\end{array}$ & $\boldsymbol{A}=P_{t}^{P}$ & $B=\sum_{j=1}^{k} a_{j} P_{j}^{p}$ & $C=\sum_{j=k+1}^{n} a_{j} V_{j}^{p}$ & $D=A-B-C$ \\
\hline $\begin{array}{l}\text { Accounting in Social } \\
\text { (Economic) Prices }\end{array}$ & $E=P_{i}^{s}$ & $F=\sum_{j=1}^{k} a_{t j} P_{j}^{s}$ & $G=\sum_{j=k+1}^{n} a_{b j} V_{j}^{s}$ & $H=E-F-G$ \\
\hline $\begin{array}{c}\text { Effects of Policy and } \\
\text { Market Failures }\end{array}$ & $I=A-E$ & $J=B-F$ & $K=C-G$ & $\begin{array}{l}L=D-H= \\
=I-J-K\end{array}$ \\
\hline
\end{tabular}

Source: Monke and Pearson (1989)

Notes: the subscript $i$ refers to outputs and the subscript $j$ to inputs;

$a_{i j}$ for $(j=1$ to $k$ ) are technical coefficients for traded inputs in the production of $i$;

$a_{i j}$ for $(j=k+1$ to $n$ ) are technical coefficients for domestic inputs in the production of $i$;

$P_{i}^{*}$ is the price of output $i$, evaluated privately $(" * "=p)$ or socially (" * " $=s$ );

$P_{j}^{*}$ is the price of traded input $j$, evaluated privately ("* $"=p$ ) or socially ("* " $=s$ );

$V_{j}^{*}$ is the price of domestic input $j$, evaluated privately $(" *=p$ ) or socially (" * " $=s)$;

I measures output transfers;

$J$ measures input transfers;

$K$ measures factor transfers;

$D(=A-B-C)$ measures net private profits;

$H(=E-F-G)$ measures net social profits; and

$L$ measures net transfers.

is (is not) competitive. The SCB method has the advantage of being intuitively clear, reasonably easy to use and well established in applied economics. But it can suffer from several weaknesses. In particular, it is based on the assumption of fixed technical coefficients. Hence, it ignores possible factor substitution and cross price effects that could be expected to result from shifting production away from the observed point of production characterized by financial prices, to the hypothetical point characterized by economic prices. Depending on the strength of these effects, the SCB will be biased.

As discussed in the body of this paper, there is ample evidence that the farms in CIS countries are highly heterogeneous. Calculating average or typical SCB ratios would therefore be of dubious value. For this reason - and following similar analysis for Ukraine (World Bank, 2008) - we use detailed farm level data to calculated SCB distributions for major crop and livestock products in Belarus. For each farm in the dataset employed (see below), SCB ratios are calculated for each of its major crop and livestock products. For each product, an estimate of the resulting univariate density function of SCBs across all relevant farms is calculated using the kernel-based estimate proposed by Rosenblatt (1956).

\section{Data and assumptions}

The empirical analysis described above is carried out using Belarus-wide farmlevel accounting data provided by the State Statistics Committee of Belarus. 
Table 6.16: Data description

\begin{tabular}{|c|c|c|c|c|c|c|c|c|c|c|}
\hline & 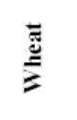 & 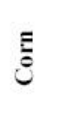 & 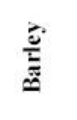 & 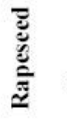 & 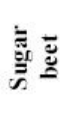 & 悉 & ্ֻّ & $\stackrel{\doteqdot}{\grave{0}}$ & $\frac{\vec{E}}{\bar{\Xi}}$ & $\stackrel{\overline{\underline{E}}}{2}$ \\
\hline \multicolumn{11}{|c|}{ Number of farms producing } \\
\hline 2003 & 1,108 & 8 & 821 & 585 & 1,460 & 949 & 2,090 & 944 & 68 & 2,084 \\
\hline 2004 & 1,076 & 11 & 1,111 & 604 & 1,290 & 1,276 & 1,854 & 825 & 61 & 1,847 \\
\hline 2005 & 1,302 & 118 & 1,575 & 608 & 1,168 & 1,256 & 1,653 & 728 & 50 & 1,644 \\
\hline 2006 & 1,250 & 227 & 1,540 & 578 & 1,039 & 1,174 & 1,574 & 679 & 45 & 1,566 \\
\hline 2007 & 1,184 & 803 & 1,440 & 477 & 966 & 1,312 & 1,473 & 614 & 41 & 1,467 \\
\hline \multicolumn{11}{|c|}{ Inputs used } \\
\hline Seeds & + & + & + & + & + & + & - & - & - & - \\
\hline Fertilizers & + & + & + & + & + & + & - & - & - & - \\
\hline Sanitary and phytosanitary measures & + & + & + & + & + & + & + & + & + & + \\
\hline Diesel and gasoline & + & + & + & + & + & + & + & + & + & + \\
\hline Gas & + & + & + & + & + & + & + & + & + & + \\
\hline Electricity & + & + & + & + & + & + & + & + & + & + \\
\hline Spare parts, renovation costs & + & + & + & + & + & + & + & + & + & + \\
\hline Labor & + & + & + & + & + & + & + & + & + & + \\
\hline Other inputs (manure, litter etc) & + & + & + & + & + & + & + & + & + & + \\
\hline Land & + & + & + & + & + & + & - & - & - & - \\
\hline Capital & + & + & + & + & + & + & + & + & + & + \\
\hline Fodder & - & - & - & - & - & - & + & + & + & + \\
\hline
\end{tabular}

Source: Own presentation.

This dataset is an unbalanced panel of 9232 observations over the period 20032007. For each observation in the dataset (representing a farm in one of the five years), information on total input costs for each farm product is available, as is information on the breakdown of input costs for each of the output aggregates 'crop' and 'livestock' products. In order to generate disaggregated input use data for each individual farm product, the share of each individual product in total farm costs is used. In other words, if the data show that wheat accounted for $25 \%$ of total input costs in crop production for a specific farm, then $25 \%$ of the labor allocated to crop production on that farm is assumed to have been spent on wheat, $25 \%$ of the fertilizer, etc. An alternative would be to allocate inputs according to acreage shares, but this would i) probably be less accurate as is known that some more profitable crops (sugar beet, for example) tend to be produced more intensively than others, and ii) not be helpful for acreageindependent livestock products.

Table 6.16 provides an overview of the resulting data structure and numbers of observations, and Table 6.17 provides information on average input cost shares for crop and livestock production in the sample of farms employed in the SCB analysis. Table 6.14 provides an overview of the factors used to convert financial costs into economic costs.

Conversion from financial to economic prices and costs is based on a variety of assumptions and sources of data:

- Factors for converting revenue from the sale of agricultural output from a financial to an economic price basis are calculated using OECD methodology for the Market Price Support estimation in PSE tables (OECD, 2008). Border reference prices (border prices corrected for marketing costs) are compared with 
Table 6.17: Cost shares for inputs in crop and livestock production in Belarus, $2007(\%)$

\begin{tabular}{|c|c|c|c|}
\hline Input & All & Crop & Livestock \\
\hline Labor & 20.5 & 19.3 & 21.3 \\
\hline Seeds and grafts & 3.4 & 9.2 & - \\
\hline Fodder & 31.1 & - & 55.9 \\
\hline Other inputs (manure, litter, eggs for incubation etc) & 2.1 & 3.5 & 1.5 \\
\hline Fertilizers & 5.5 & 15.1 & - \\
\hline Sanitary and phytosanitary measures & 3.5 & 7.0 & 1.7 \\
\hline Fuel: diesel and gasoline & 7.6 & 14.2 & 3.7 \\
\hline Electricity & 1.3 & 0.8 & 1.5 \\
\hline Fuel: gas & 0.5 & 0.6 & 0.3 \\
\hline Spare parts, renovation & 0.5 & 0.7 & 0.3 \\
\hline Outside services employed & 4.7 & 6.8 & 2.9 \\
\hline Other material costs & 2.4 & 3.8 & 1.5 \\
\hline Depreciation & 4.8 & 1.5 & 1.0 \\
\hline Other costs & 10.1 & 15.6 & 6.8 \\
\hline of which credit costs & 2.0 & 2.2 & 1.6 \\
\hline
\end{tabular}

Source: Own presentation.

Table 6.18: Financial (farm gate) prices, economic (border) prices, and the calculation of conversion factors for revenues (prices in BYR/ton)

\begin{tabular}{|c|c|c|c|c|c|c|c|c|c|c|}
\hline & Wheat & Barley & Corn & Rapeseed & Sugar beet & Potato & Beef & Pork & Poultry & Milk \\
\hline \multicolumn{11}{|c|}{2007} \\
\hline Financial price & 312,000 & 233,000 & 439,581 & 412,590 & 468,750 & 264,742 & $2,385,000$ & $3,402,000$ & $3,200,000$ & 506,466 \\
\hline Economic price & 558,714 & 396,891 & 401,114 & 798,085 & 422,933 & 448,651 & $2,973,959$ & $3,643,514$ & $2,199,863$ & 637,092 \\
\hline Conversion factor & 1.79 & 1.70 & 0.91 & 1.93 & 0.90 & 1.69 & 1.25 & 1.07 & 0.69 & 1.26 \\
\hline \multicolumn{11}{|c|}{2006} \\
\hline Financial price & 243,000 & 175,000 & 321,658 & 368,930 & 580,357 & 264,742 & $2,065,000$ & $3,175,000$ & $2,798,000$ & 437,899 \\
\hline Economic price & 273,761 & 274,387 & 229,869 & 535,595 & 567,847 & 448,651 & $2,790,571$ & $3,061,285$ & $1,685,744$ & 403,749 \\
\hline Conversion factor & 1.13 & 1.57 & 0.71 & 1.45 & 0.98 & 1.69 & 1.35 & 0.96 & 0.60 & 0.92 \\
\hline \multicolumn{11}{|c|}{2005} \\
\hline Financial price & 230,000 & 166,000 & 306,341 & 358,453 & 543,155 & 206,604 & $1,861,000$ & $3,012,000$ & $2,512,000$ & 402,831 \\
\hline Economic price & 232,262 & 282,209 & 211,426 & 425,130 & 317,768 & 239,378 & $2,536,918$ & $3,506,420$ & $1,871,583$ & 400,650 \\
\hline Conversion factor & 1.01 & 1.70 & 0.69 & 1.19 & 0.59 & 1.16 & 1.36 & 1.16 & 0.75 & 0.99 \\
\hline \multicolumn{11}{|c|}{2004} \\
\hline Financial price & 225,000 & 179,000 & 300,334 & 337,830 & 543,155 & 131,814 & $1,507,000$ & $2,380,000$ & $1,742,000$ & 369,519 \\
\hline Economic price & 252,912 & 222,007 & 302,249 & 423,206 & 196,213 & 285,060 & $2,132,872$ & $2,589,637$ & $1,609,127$ & 325,992 \\
\hline Conversion factor & 1.12 & 1.24 & 1.01 & 1.25 & 0.36 & 2.16 & 1.42 & 1.09 & 0.92 & 0.88 \\
\hline \multicolumn{11}{|c|}{2003} \\
\hline Financial price & 178,000 & 121,000 & 238,360 & 292,480 & 483,631 & 174,703 & $1,119,000$ & $1,768,000$ & $1,536,000$ & 261,949 \\
\hline Economic price & 216,970 & 239,058 & 233,251 & 460,038 & 156,869 & 260,198 & $1,447,553$ & $2,110,678$ & $1,552,451$ & 263,338 \\
\hline Conversion factor & 1.22 & 1.98 & 0.98 & 1.57 & 0.32 & 1.49 & 1.29 & 1.19 & 1.01 & 1.01 \\
\hline
\end{tabular}

Source: See description in text.

farmgate prices to calculate conversion factors that are multiplied with actual reported revenues to estimate hypothetical economic revenues. The resulting conversion factors are presented in Table 6.18, and more details on their calculation is provided in section 6.7 of this appendix below. The case of sugar is somewhat more complicated because farmers sell sugar beet while world trade is in raw or white sugar. Technical extraction coefficients are used to convert a border price for white sugar into a sugar beet price, and comparison with the corresponding farm gate price produces the corresponding conversion factor.

- Economic costs for seeds and fodder are based on financial costs corrected for the impact of tariff. Tariffs are taken from official tariff schedules. For all seeds a conversion factor of 0.95 is used in all years (in other words, $5 \%$ import tariff is corrected). For fodder, conversions factors of 0.95 are used in all years. 
Table 6.19: Calculation of conversion factors for fertilizers

\begin{tabular}{l|rrrrr}
\hline Potassium: & $\mathbf{2 0 0 3}$ & $\mathbf{2 0 0 4}$ & $\mathbf{2 0 0 5}$ & $\mathbf{2 0 0 6}$ & $\mathbf{2 0 0 7}$ \\
\hline $\begin{array}{l}\text { farm prices, Br/t } \\
\text { 'Belaruskaliy' potassium plant sales price: } \\
\text { in Br/t }\end{array}$ & 85,763 & 106,640 & 107,380 & 111,055 & 114,730 \\
$\quad$ in USD/Br & 149,400 & 226,539 & 321,114 & 319,799 & 363,164 \\
Exchange rate, USD/Br & 72 & 105 & 149 & 149 & 169 \\
Discount: & 2,075 & 2,164 & 2,155 & 2,146 & 2,149 \\
$\quad$ Potassium, 46.2\% & & & & & \\
$\quad$ Other, 53.8\% & 0.74 & 1.12 & 1.99 & 1.88 & 2.17 \\
Weighted average discount & -0.10 & -0.10 & -0.10 & -0.10 & -0.10 \\
\hline
\end{tabular}

Source: Own calculations using information on potassium plant sales prices from various news articles available at www.naviny.by, and official prices for fertilizers supplied to farms.

- Conversion factors for fertilizers correct financial costs for several distortions. The purchase of fertilizers by farms is subsidized via direct subsidies and at below the market prices. As Table 6.19 shows, farmers received potassium fertilizers at least at 74\% discount over 2003-2007. For other fertilizers we assume a $10 \%$ downward correction for the import tariff. After accounting for the shares of fertilizers application, calculated using Gusakov et.al (2007, p.293), we come up with weighted discounts.

- Capital input is measured as the sum of depreciation (i.e. the reduction in the value of assets arising from wear and tear), and the forgone return on financial capital tied up in the value of assets. A conversion factor for capital costs is calculated as the product of a conversion factor for capital assets value and a conversion factor for capital recovery (see Monke and Pearson (1989) for details). The factor for capital assets value is assumed to equal 0.9 based on information about tariffs applied to agricultural machinery and equipment imports. The forgone return is calculated using the economic capital assets value and the economic interest rate. The economic interest rate (Table 6.20) is estimated using macroeconomic data (GDP and factor income shares) based on the assumption that under competitive conditions the ratio of a factor's marginal to average value product should equal its share of total income (Monke and Pearson, 1989).

- Economic valuation of land is estimated as in Monke and Pearson (1989) by comparing economic profits before land costs for as many crops as possible on each farm, and setting farm-specific economic land costs equal to the average of all the positive profits before land costs. According to this method, a crop must compete with other economically profitable crops on the farm in order to enter into the crop rotation. This is unrealistic to the extent that it can lead to rotations that include only one or two competitive crops, whereas in reality the next best one or two (non-competitive) crops with SCBs of over one would also enter into the rotation for agronomic and scheduling/organizational reasons. More sophisticated programming techniques could be used to model on-farm land allocation and pricing, but would produce no major additional insights into competitiveness. 
Table 6.20: The calculation of economic interest rates

\begin{tabular}{l|rrrrr}
\hline & $\mathbf{2 0 0 3}$ & $\mathbf{2 0 0 4}$ & $\mathbf{2 0 0 5}$ & $\mathbf{2 0 0 6}$ & $\mathbf{2 0 0 7}$ \\
\hline GDP, bln. Bel. rub & 36,565 & 49,992 & 65,067 & 79,267 & 96,165 \\
Labor income, bln. Br (1) & 15,979 & 22,116 & 29,974 & 37,834 & 44,398 \\
Capital income, bln. Br (2) & 20,585 & 27,876 & 35,093 & 41,397 & 51,702 \\
Value of capital stock (4) trln. Br & 153 & 193 & 235 & 243 & 297 \\
Average Rate of Return, \% (5) = (2)/((4)*1000)*100\% & 13.5 & 14.5 & 14.9 & 17.0 & 17.4 \\
Marginal rate of return, \% (6)=(2)/GDP*(5) & 7.6 & 8.1 & 8.0 & 8.9 & 9.4 \\
Marginal rate of return, net of depreciation & 4.9 & 5.2 & 5.1 & 5.5 & 5.9 \\
\hline
\end{tabular}

Source: Own calculations.

Table 6.21: Calculation of conversion factors for gas costs

\begin{tabular}{l|rrrrr}
\hline & $\mathbf{2 0 0 3}$ & $\mathbf{2 0 0 4}$ & $\mathbf{2 0 0 5}$ & $\mathbf{2 0 0 6}$ & $\mathbf{2 0 0 7}$ \\
\hline EU price*, USD/tm3 & 130 & 135 & 220 & 300 & 320 \\
Import price for Belarus, USD/tm3 & 36.9 & 47.68 & 47.68 & 47.68 & 100 \\
CF & 3.52 & 2.83 & 4.61 & 6.29 & 3.20 \\
\hline
\end{tabular}

Source: Own calculations with Pavel and Yuzefovych (2008), Giucci and Kirchner (2007), and World Bank (2005). * German gas import price.

- Financial fuel costs are corrected for two types of distortion to arrive at a economic valuation. The first distortion is due to the fact that Belarus has paid considerably less than world market prices for gas as a result of special arrangements with Russia. Pavel and Yuzefovych (2008) argue that an economically justifiable gas pricing is based on the concept of netback value, i.e. the replacement value of gas at the delivery point based on priced of competing fuels. For Belarus this price can be calculated as the EU market price minus the cost of gas transit from Belarus to the EU. According to this calculation, the price in Belarus in 2007 should have been about $320 \mathrm{US} \$ / \mathrm{tm}^{\mathbf{3}}$ rather than the actual $100 \mathrm{US} \$ / \mathrm{tm}^{3}$. On this basis, financial-to-economic cost conversion factor for gas use is determined to be 3.2 in 2007 . Table 6.21 shows calculations for the rest period. The second distortion is the result of supplying diesel and gasoline to agricultural enterprises at about $20 \%$ discount. This information is based on various news articles available under www .naviny.by.

- Electricity prices for agriculture are set below the cost recovery cost and significantly lower than in other sectors of economy Table 6.22. We assume that these sectors pay the market rates, so the ratio of industry to agriculture electricity prices gives us the conversion factor to adjust the financial electricity costs to the economic level.

- Economic costs are assumed to equal financial costs for labor.

- Finally, economic costs are also assumed to equal financial costs for other inputs such as manure and litter. 
Table 6.22: Calculation of conversion factors for electricity costs

\begin{tabular}{l|rrrrrr}
\hline & $\mathbf{2 0 0 3}$ & $\mathbf{2 0 0 4}$ & $\mathbf{2 0 0 5}$ & $\mathbf{2 0 0 6}$ & $\begin{array}{r}\mathbf{1}^{\text {st }} \mathbf{h a l f} \\
\mathbf{2 0 0 7}\end{array} \mathbf{2}^{\text {nd }} \mathbf{2 0 0 7}^{\text {half }}$ \\
\hline Costs, US cents/ $\mathbf{k W h}$ & 2.32 & 3.21 & 3.5 & 4.4 & 5.86 & - \\
Agriculture, US cents/kWh & 2.44 & 2.66 & 2.66 & 2.9 & 4.32 & 5.18 \\
Industry, US cents/kWh & 4.41 & 6.02 & 6.02 & 6.7 & 9.21 & 8.91 \\
CF & 1.81 & 2.26 & 2.26 & 2.33 & 2.13 & 1.72 \\
\hline
\end{tabular}

Source: Own calculations with Tochitskaya (2007).

\section{Calculation of conversion factors based on OECD methodology}

The calculation of the reference border prices and conversion factors in Table 6.18 is performed using OECD (2008) methodology for Market Price Support estimation. All values are expressed in local currency (LC), specifically in rubles (BYR), if not otherwise specified.

\section{Producer prices}

- Wheat, corn, potato, and rapeseed: Annual average of farm gate prices (all qualities). Source: Ministry of Agriculture and Food of the Republic of Belarus (MAFRB, 2008); Ministry of Statistical Analysis of the Republic of Belarus (MASRB, 2008).

- Sugar: Annual average of sugar beet prices at farm gate converted to white sugar equivalent by dividing sugar beet price by the sugar extraction ratio from sugar beet. Source: MAFRB (2008); NSC (2008).

- Milk: Annual average farm gate prices of cow milk. Source: MAFRB (2008); NSC (2008).

- Beef and veal: Annual average farm gate prices for all categories of adult bovine animals for slaughter, live weight. Source: MAFRB (2008); NSC (2008). - Pigmeat: Annual average farm gate prices for all pigs for slaughter, live weight. Source: MAFRB (2008); MSARB (2008).

- Poultry: Annual average farm gate prices of live chickens. Source: MAFRB (2008); MSARB (2008).

\section{Border prices}

- Wheat, corn, and barley: Ukrainian export unit values. Source: OECD (2009); State Statistics Committee of Ukraine (SSCU).

- Rapeseed: Ukrainian export unit values. Source: SSCU.

- Sugar beet, white sugar: EU export price of white sugar, Bourse de Paris (daily prices), fob Europe, calendar year. Source: OECD (2009).

- Milk (reference price): The 'implicit' price of milk at the border is calculated from the unit export values of milk products exported from Belarus. The products considered are butter, cheese, and skimmed milk powder. The values and volumes of these products were converted into milk equivalents. The border price of milk is the weighted average of these unit export values of milk products in milk equivalents. Source: MAFRB (2008) and MSARB (2008). The reference price of milk at the farm gate is the implicit milk border price net of 
processing costs. The processing margin is the average of processing margins in Australia, the EU, New Zealand and the US. Source: OECD (2009).

- Beef, pork and poultry meat: Belarusian export unit values for frozen beef carcasses, converted into live weight. Source: MAFRB (2008); MSARB (2008).

\section{Handling and processing costs, margins}

- Handling costs, processing costs and margins in Belarus are assumed equal those in Ukraine. According to IBRD/World Bank (2008), the costs of exporting and importing products in Belarus have been persistently somewhat higher than in Ukraine. The absolute value of handling and processing costs and margin in a given year for a given product was subtracted (for exported products) from the border price to bring the border price to the farm gate level (OECD, 2009). For imported products, the border price is assumed to equal the farm-gate price. Since information on border-wholesale and farm gate-wholesale margins are not available, it is assumed that these are roughly equal, so that the amount by which the import parity wholesale price lies above the border price equals the amount by which the farm gate price lies below the wholesale price.

Detailed data and the determination of the conversion factors are presented in Table 6.23 and Table 6.24. 
Belarus: Agricultural Productivity and Competitiveness. Impact of State Support and Market Intervention

Table 6.23: Market price support tables for selected crop products

\begin{tabular}{|c|c|c|c|c|c|c|}
\hline & Units & 2003 & 2004 & 2005 & 2006 & 2007 \\
\hline \multicolumn{7}{|c|}{ WHEAT } \\
\hline II. Producer price (at farm gate) & $\mathrm{LC} / \mathrm{t}$ & 178,000 & 225,000 & 230,000 & 243,000 & 312,000 \\
\hline VII. Reference price (at farm gate) & $\mathrm{LC} / \mathrm{t}$ & 216,970 & 252,912 & 232,262 & 273,761 & 558,714 \\
\hline 1. Border reference price (f.o.b. or c.i.f.) & $\mathrm{USD} / \mathrm{t}$ & 89 & 113 & 109 & 128 & 260 \\
\hline 2. Handling and processing costs & $\mathrm{LC} / \mathrm{t}$ & 53,724 & 59,492 & 56,404 & 60,126 & 67,402 \\
\hline 3. Quality adjustment & ratio & 1.17 & 1.03 & 0.99 & 1.00 & 1.00 \\
\hline 4. Official exchange rate & LC/USD & 2,075 & 2,164 & 2,155 & 2,146 & 2,149 \\
\hline VIII. Market price differential/Conversion factor & ratio & 1.22 & 1.12 & 1.01 & 1.13 & 1.79 \\
\hline \multicolumn{7}{|c|}{ CORN } \\
\hline II. Producer price (at farm gate) & $\mathrm{LC} / \mathrm{t}$ & 238,360 & 300,334 & 306,341 & 321,658 & 439,581 \\
\hline VII. Reference price (at farm gate) & $\mathrm{LC} / \mathrm{t}$ & 233,251 & 302,249 & 211,426 & 229,869 & 401,114 \\
\hline 1. Border reference price (f.o.b. or c.i.f.) & $\mathrm{USD} / \mathrm{t}$ & 110 & 137 & 96 & 105 & 183 \\
\hline 2. Handling and processing costs & $\mathrm{LC} / \mathrm{t}$ & 53,724 & 59,492 & 56,404 & 0 & 0 \\
\hline 3. Quality adjustment & ratio & 1.02 & 1.02 & 1.02 & 1.02 & 1.02 \\
\hline 4. Official exchange rate & LC/USD & 2,075 & 2,164 & 2,155 & 2,146 & 2,149 \\
\hline VIII. Market price differential / Conversion factor & ratio & 0.98 & 1.01 & 0.69 & 0.71 & 0.91 \\
\hline \multicolumn{7}{|c|}{ BARLEY } \\
\hline II. Producer price (at farm gate) & $\mathrm{LC} / \mathrm{t}$ & 121,000 & 179,000 & 166,000 & 175,000 & 233,000 \\
\hline VII. Reference price (at farm gate) & $\mathrm{LC} / \mathrm{t}$ & 239,058 & 222,007 & 282,209 & 274,387 & 396,891 \\
\hline 1. Border reference price (f.o.b. or c.i.f.) & $\mathrm{USD} / \mathrm{t}$ & 109 & 100 & 127 & 123.9 & 179 \\
\hline 2. Handling and processing costs & $\mathrm{LC} / \mathrm{t}$ & 44,770 & 49,305 & 47,143 & 50,255 & 56,336 \\
\hline 3. Quality adjustment & ratio & 1.06 & 1.03 & 1.03 & 1.03 & 1.03 \\
\hline 4. Official exchange rate & LC/USD & 2,075 & 2,164 & 2,155 & 2,146 & 2,149 \\
\hline VIII. Market price differential / Conversion factor & ratio & 1.98 & 1.24 & 1.70 & 1.57 & 1.70 \\
\hline \multicolumn{7}{|c|}{ RAPESEED } \\
\hline II. Producer price (at farm gate) & $\mathrm{LC} / \mathrm{t}$ & 292,480 & 337,830 & 358,453 & 368,930 & 412,590 \\
\hline VII. Reference price (at farm gate) & $\mathrm{LC} / \mathrm{t}$ & 460,038 & 423,206 & 425,130 & 535,595 & 798,085 \\
\hline 1. Border reference price (f.o.b. or c.i.f.) & USD/t & 254 & 234 & 242 & 297 & $\begin{array}{r}424.5267 \\
135\end{array}$ \\
\hline 2. Handling and processing costs & $\mathrm{LC} / \mathrm{t}$ & 66,182 & 83,533 & 95,550 & 101,856 & 114,181 \\
\hline 3. Quality adjustment & ratio & 1.00 & 1.00 & 1.00 & 1.00 & 1.00 \\
\hline 4. Official exchange rate & LC/USD & 2,075 & 2,164 & 2,155 & 2,146 & 2,149 \\
\hline VIII. Market price differential / Conversion factor & ratio & 1.57 & 1.25 & 1.19 & 1.45 & 1.93 \\
\hline \multicolumn{7}{|c|}{ SUGAR (REFINED EQUIVALENT) } \\
\hline II. Producer price (at farm gate, refined equivalent) & $\mathrm{LC} / \mathrm{t}$ & 483,631 & 543,155 & 543,155 & 580,357 & 468,750 \\
\hline 1. Sugar beet & & 65,000 & 73,000 & 73,000 & 78,000 & 63,000 \\
\hline 2. Sugar extraction rate from sugar beet & & 0.134 & 0.134 & 0.134 & 0.134 & 0.134 \\
\hline $\begin{array}{l}\text { VII. Reference price (at farm gate, refined } \\
\text { equivalent) }\end{array}$ & $\mathrm{LC} / \mathrm{t}$ & 156,869 & 196,213 & 317,768 & 567,847 & 422,933 \\
\hline 1. Border reference price (f.o.b. or c.i.f.) & Euro $/ \mathrm{t}$ & 190 & 193 & 234 & 334 & 225 \\
\hline 2. Handling and processing costs & $\mathrm{LC} / \mathrm{t}$ & 59,564 & 71,308 & 83,343 & 88,844 & 99,594 \\
\hline 3. Reference price at the wholesale level & $\mathrm{LC} / \mathrm{t}$ & 506,571 & 588,956 & 710,510 & 987,490 & 761,875 \\
\hline 4. Wholesale-to farmgate margin & $\mathrm{LC} / \mathrm{t}$ & 349,702 & 392,743 & 392,743 & 419,643 & 338,942 \\
\hline 5. Quality adjustment & ratio & 1 & 1 & 1 & 1 & 1 \\
\hline 6. Official exchange rate & LC/Euro & 2,353 & 2,684 & 2,681 & 2,692 & 2,937 \\
\hline VIII. Market price differential / Conversion factor & ratio & 0.32 & 0.36 & 0.59 & 0.98 & 0.9 \\
\hline
\end{tabular}

Source: Own calculations with OECD (2008) methodology. 
Table 6.24: Market price support tables for selected livestock products

\begin{tabular}{|c|c|c|c|c|c|c|}
\hline & Units & 2003 & 2004 & 2005 & 2006 & 2007 \\
\hline \multicolumn{7}{|c|}{ MILK } \\
\hline II. Producer price (at farm gate) & $\mathrm{LC} / \mathrm{t}$ & 261,949 & 369,519 & 402,831 & 437,899 & 506,466 \\
\hline VII. Reference price (at farm gate) & $\mathrm{LC} / \mathrm{t}$ & 263,338 & 325,992 & 400,650 & 403,749 & 637,092 \\
\hline $\begin{array}{l}\text { 1. Border reference price }=\text { New Zealand } \\
\text { price of milk }\end{array}$ & $\mathrm{USD} / \mathrm{t}$ & 164 & 192 & 230 & 236 & 349.6 \\
\hline 2. Processing costs, milk equivalent & $\mathrm{LC} / \mathrm{t}$ & 77,303 & 88,434 & 95,509 & 101,812 & 114,132 \\
\hline 9. Exchange rate & LC/USD & 2,075 & 2,164 & 2,155 & 2,146 & 2,149 \\
\hline VIII. Market price differential / Conversion factor & ratio & 1.01 & 0.88 & 0.99 & 0.92 & 1.26 \\
\hline \multicolumn{7}{|c|}{ BEEF AND VEAL } \\
\hline II. Producer price (at farm gate) (carcass equiv.) & $\mathrm{LC} / \mathrm{t}$ & $1,119,000$ & $1,507,000$ & $1,861,000$ & $2,065,000$ & $2,385,000$ \\
\hline VII. Reference price (at farm gate) & $\mathrm{LC} / \mathrm{t}$ & $1,447,553$ & $2,132,872$ & $2,536,918$ & $2,790,571$ & $2,973,959$ \\
\hline 1. Border reference price (f.o.b. or c.i.f.) & Euro/t & 1,337 & 1,663 & 2,006 & 2,203 & 2,138 \\
\hline 2. Handling and processing costs & $\mathrm{LC} / \mathrm{t}$ & 276,407 & 334,131 & 434,814 & 463,512 & 478,125 \\
\hline 3. Quality adjustment & ratio & 1 & 1 & 1 & 1 & 1 \\
\hline 4. Official exchange rate & LC/Euro & $2,343.62$ & $2,697.49$ & $2,693.91$ & 2686.0626 & 2936.1208 \\
\hline VIII. Market price differential / Conversion factor & ratio & 1.29 & 1.42 & 1.36 & 1.35 & 1.25 \\
\hline \multicolumn{7}{|c|}{ PIGMEAT } \\
\hline II. Producer price (at farm gate) (carcass equiv.) & $\mathrm{LC} / \mathrm{t}$ & $1,768,000$ & $2,380,000$ & $3,012,000$ & $3,175,000$ & $3,402,000$ \\
\hline VII. Reference price (at farm gate) & $\mathrm{LC} / \mathrm{t}$ & $2,110,678$ & $2,589,637$ & $3,506,420$ & $3,061,285$ & $3,643,514$ \\
\hline 1. Border reference price (f.o.b. or c.i.f.) & Euro/t & 1,296 & 1,378 & 1,858 & 1,672 & 1,805 \\
\hline 2. Handling and processing costs & $\mathrm{LC} / \mathrm{t}$ & 319,231 & 384,250 & 498,374 & 531,266 & 595,550 \\
\hline 3. Quality adjustment & ratio & 1 & 1 & 1 & 1 & 1 \\
\hline 4. Official exchange rate & LC/Euro & 2,344 & 2,697 & 2,694 & 2,686 & 2,936 \\
\hline VIII. Market price differential / Conversion factor & ratio & 1.19 & 1.09 & 1.16 & 0.96 & 1.07 \\
\hline \multicolumn{7}{|c|}{ POULTRY } \\
\hline II. Producer price (at farm gate) (carcass equiv.) & $\mathrm{LC} / \mathrm{t}$ & $1,536,000$ & $1,742,000$ & $2,512,000$ & $2,798,000$ & $3,200,000$ \\
\hline VII. Reference price (at farm gate) & $\mathrm{LC} / \mathrm{t}$ & $1,552,451$ & $1,609,127$ & $1,871,583$ & $1,685,744$ & $2,199,863$ \\
\hline 1. Border reference price (f.o.b. or c.i.f.) & Euro/t & 836 & 754 & 878 & 795 & 947 \\
\hline 2. Border-to-wholesale transportation & $\mathrm{LC} / \mathrm{t}$ & 76,304 & 89,237 & 110,703 & 118,009 & 132,288 \\
\hline 3. Reference price at the wholesale level & & $2,035,943$ & $2,121,937$ & $2,476,279$ & $2,253,009$ & $2,913,303$ \\
\hline 4. Wholesale-to farmgate margin & & 76,304 & 88,422 & 109,440 & 116,663 & 130,780 \\
\hline 5. Quality adjustment & ratio & 1 & 1 & 1 & 1 & 1 \\
\hline 6. Official exchange rate & LC/Euro & $2,343.62$ & $2,697.49$ & $2,693.91$ & 2686.0626 & 2936.1208 \\
\hline VIII. Market price differential / Conversion factor & ratio & 1.01 & 0.92 & 0.75 & 0.6 & 0.69 \\
\hline
\end{tabular}

Source: Own calculations with OECD (2008) methodology. 


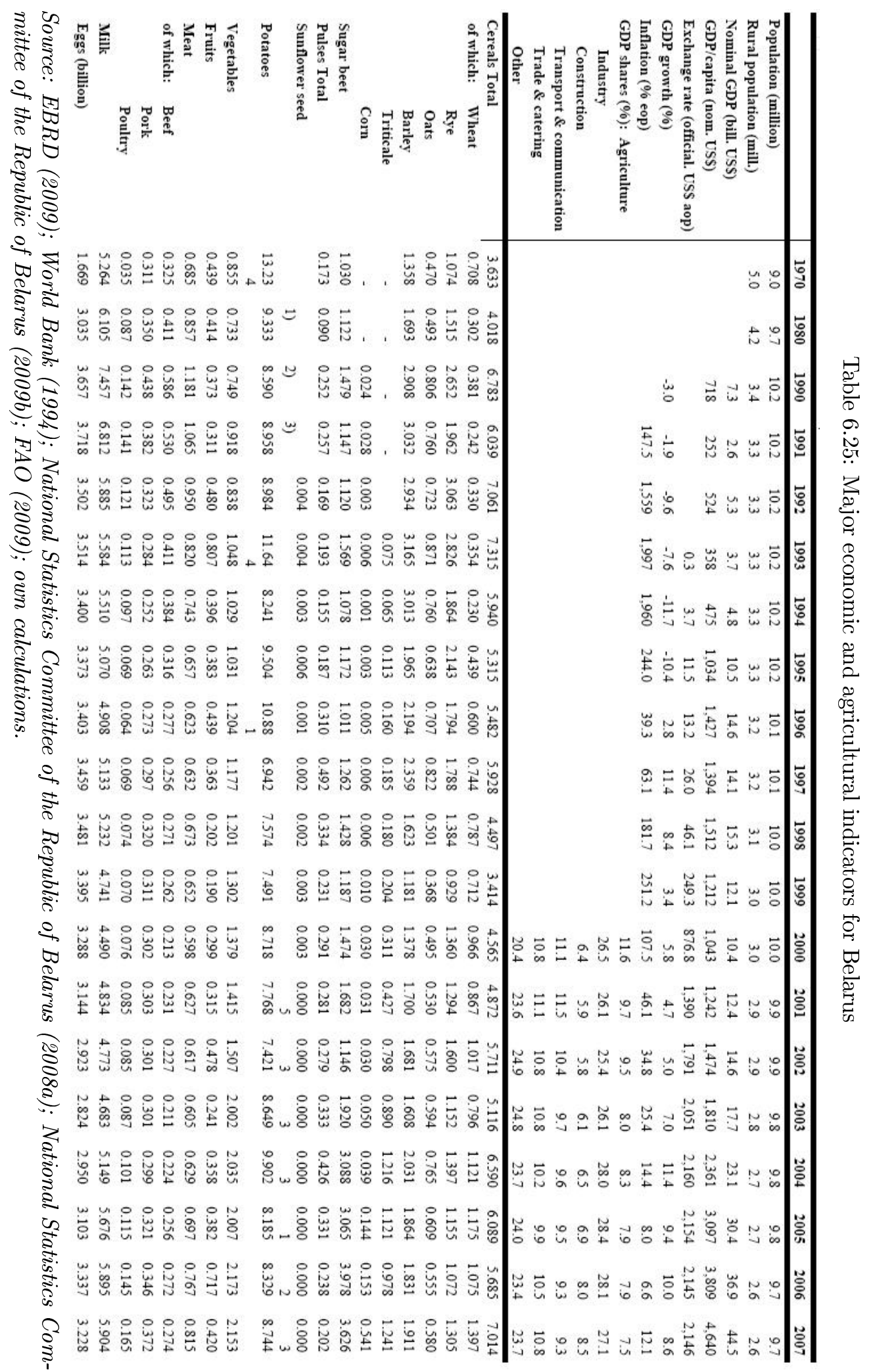




\title{
Chapter 7
}

\section{Measuring and Comparing the Competitiveness of Heterogeneous Production Systems in Agriculture: a Note ${ }^{1}$}

\begin{abstract}
The measurement of competitiveness in agriculture is often based on data for average or 'typical' farms. However, if the farms that are summarised in this manner are highly heterogeneous, inferences based on this measurement can be very misleading. We propose the calculation of competitiveness indicator distributions based on micro data. This procedure makes it possible to determine for each product a) what proportion of the farms producing it is competitive, and b) what proportion of total production/output value of this product occurs on competitive / uncompetitive farms. Furthermore, we propose and contrast distribution- and aggregate-based approaches for ranking the activities.

JEL classification: Q12; Q17

Keywords: competitiveness; heterogeneous production systems; Ukraine
\end{abstract}

\section{$7.1 \quad$ Introduction}

The measurement of competitiveness in agriculture is often based on Domestic Resource Cost (DRC) and Social Cost-Benefit (SCB) ratios as indicators (e.g. Liefert, 2002). One of the well-known disadvantages of these indicators that they are usually calculated using data for average or 'typical/representative' farms. As Monke and Pearson (1989) have shown, several representative systems may exist simultaneously for a given population of farms, depending on the policy or research question at hand. Therefore, competitiveness scores and rankings will be conditioned on which of these systems is selected and inter/intra-country comparison of production systems will produce ambiguous conclusions about comparative advantage as a result. Furthermore, if the farms that are summarised in this manner are highly heterogeneous, inferences based

${ }^{1}$ Copyright c 2009 IP Publishing Ltd. Reproduced by permission. 
on aggregated measures of competitiveness can be very misleading. Further statistical inference about the determinants of competitiveness is hardly possible in this setting.

Accounting for the heterogeneity of firms has become an important part of the research agenda. Recently Melitz (2003) has developed a dynamic industry model with heterogeneous firms to analyse the intra-industry impact of international trade. He shows that increased exposure to international competition can generate benefits in the form of intra-industry resource reallocations that lead to increases in aggregate industry productivity. In the same vein although using a different trade model and motivation, Bernard et al (2003) introduce firm-level heterogeneity and also demonstrate trade-induced intra-sector reallocations.

Sector heterogeneity is especially important for transition and developing economies. Evidence from numerous studies that apply empirical efficiency analysis techniques (data envelopment analysis - DEA; stochastic frontier analysis - SFA) to farm level data in Ukraine and other Former Soviet Union (FSU) countries, for instance, points to significant heterogeneity, with many farms operating at a great distance from the frontier defined by the best-practice farms (e.g. Galushko et al. (2004), Kurkalova and Jensen (2002), Lissitsa and Odening (2005)).

In the following section we suggest calculating distributions of competitiveness indicator based on micro-data using kernel methods. We illustrate this method using data on the population of crop farms in Ukraine. The proposed procedure makes it possible to determine for each product a) what proportion of the farms producing it is competitive, and b) what proportion of the total production/output value of this product occurs on competitive farms. Then we suggest how to draw statistical inferences about estimates of these proportions that are derived from sample data.

Often, policy makers and applied researches are interested in the competitiveness ranking of sectors' or/and groups of producers. So, in the second part of the paper we suggest two approaches for generating such rankings based on micro-data. The first is a distribution-based method that directly derives from the competitiveness distribution and uses proportions as a ranking criterion. The other method is aggregates-based. It allows estimating the aggregate competitiveness score as well as corresponding confidence intervals. The third section contrasts these approaches subject to policy making relevance using the population data on crop farms in Ukraine. Conclusions close the paper.

\subsection{Competitiveness Measurement: Open Questions}

\section{Distributions versus averages}

The DRC and/or SCB ratios are both calculated using the Policy Analysis Matrix (PAM) framework developed by Monke and Pearson (1989). The PAM combines two accounting identities; one defining profitability as the difference between revenues and costs; and the other measuring the effects of divergences (distorting policies and market failures) as the difference between observed private values and social values that would exist if the divergences were removed. The structure of the PAM is presented in Table 7.1.

The DRC is calculated as the ratio of $\mathrm{G}$ to $(\mathrm{E}-\mathrm{F})$ in the Table 7.1. Hence, it 
Table 7.1: The Policy Analysis Matrix (PAM)

\begin{tabular}{|c|c|c|c|c|}
\hline & \multirow[t]{2}{*}{ Revenue } & \multicolumn{2}{|c|}{ Costs } & \multirow[t]{2}{*}{ Profits } \\
\hline & & Tradable inputs & Domestic factors & \\
\hline $\begin{array}{l}\text { Accounting in Private } \\
\text { (Financial) Prices }\end{array}$ & $\boldsymbol{A}=P_{i}^{P}$ & $B=\sum_{j=1}^{k} a_{j} P_{j}^{p}$ & $\boldsymbol{C}=\sum_{j=k+1}^{n} a_{j} V_{j}^{p}$ & $D=A-B-C$ \\
\hline $\begin{array}{l}\text { Accounting in Social } \\
\text { (Economic) Prices }\end{array}$ & $E=P_{i}^{s}$ & $F=\sum_{j=1}^{k} a_{t j} P_{j}^{j}$ & $G=\sum_{j=k+1}^{n} a_{b j} V_{j}^{s}$ & $H=E-F-G$ \\
\hline $\begin{array}{c}\text { Effects of Policy and } \\
\text { Market Failures }\end{array}$ & $I=A-E$ & $J=B-F$ & $K=C-G$ & $\begin{array}{l}L=D-H= \\
=I-J-K\end{array}$ \\
\hline
\end{tabular}

Source: Monke and Pearson (1989)

Notes: the subscript $i$ refers to outputs and the subscript $j$ to inputs;

$a_{i j}$ for $(j=1$ to $k$ ) are technical coefficients for traded inputs in the production of $i$;

$a_{i j}$ for $(j=k+1$ to $n$ ) are technical coefficients for domestic inputs in the production of $i$;

$P_{i}^{*}$ is the price of output $i$, evaluated privately $(" * "=p)$ or socially (" * " $=s$ );

$P_{j}^{*}$ is the price of traded input $j$, evaluated privately ("* $"=p$ ) or socially ("* " $=s$ );

$V_{j}^{*}$ is the price of domestic input $j$, evaluated privately $(" *=p$ ) or socially (" * " $=s)$;

I measures output transfers;

$J$ measures input transfers;

$K$ measures factor transfers;

$D(=A-B-C)$ measures net private profits;

$H(=E-F-G)$ measures net social profits; and

$L$ measures net transfers.

compares the cost of domestic resources measured at social prices (in the numerator) to value added measured at social prices (in the denominator). The use of social prices throughout ensures that DRC measures whether employing scarce domestic inputs in the production of a good $i$ generates a positive return. $0<$ DRC $<1$ indicates comparative advantage: the social opportunity cost of domestic resources used is smaller that the corresponding social gain (value added). The opposite is true for the $\mathrm{DRC}>1$. If the $\mathrm{DRC}$ is smaller than 0 , then the denominator $(\mathrm{E}-\mathrm{F})$ must be negative, in which case revenue does not even suffice to cover tradable input costs, let alone domestic inputs. In this case, production of the good in question is clearly not competitive. Note that the DRC is discontinuous at 0 , with values slightly greater than 0 reflecting very competitive farms, and values slightly below reflecting very uncompetitive farms.

The SCB ratio, introduced by Masters and Winter-Nelson (1995), is based on the same PAM components as the DRC. It equals the ratio of the sum of tradable and domestic input costs to the price of the good in question, or $(\mathrm{F}+$ $\mathrm{G}$ ) divided by $\mathrm{E}$ in Table 7.1 above. The SCB ratio is always greater than 0 , and a SCB less than (greater than) 1 indicates that total input costs are less than (greater than) revenue and that production is (is not) competitive. The SCB ratio has no discontinuity, it is not sensitive to the classification of inputs into domestic and tradable, and it provides more accurate rankings of comparative advantages of alternative activities since ranking based on the DRC ratio is biased against activities that use few tradable inputs (Masters 
Figure 7.1: DRC and SCB ratios distributions for wheat and sunflower seeds in Ukraine, 2005
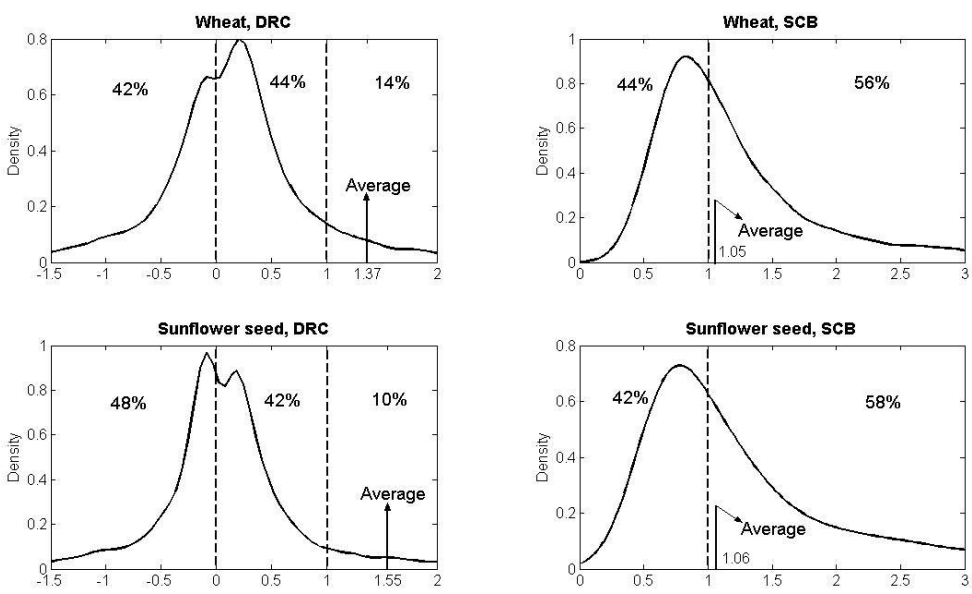

Source: Own calculations

Notes: Numbers in the figures indicate the proportions of the farms between the cut-off values. For the details on average DRC and SCB calculation, see the second section.

and Winter-Nelson, 1995). Nevertheless, unlike the DRC, the SCB cannot distinguish between uncompetitive production that is unable to cover the opportunity costs of domestic factors (DRC $>1$ ), and uncompetitive production that is not even able to cover the costs of tradable inputs (DRC $<0)$.

Based on 2005 Ukraine-wide farm-level accounting data provided by the State Statistics Committee of Ukraine we demonstrate the DRC and SCB analysis for wheat and sunflower seed production (in the third section we cover more products). This dataset contains 7631 wheat and 4319 sunflower seed producing farms. Estimates of univariate DRC and SCB density functions across all producing farms are calculated using the kernel-based estimate proposed by Rosenblatt (1956). Von Cramon-Taubadel and Nivievskyi (2008) provide a more detailed description of the methodology and calculations, as well as results for products other than wheat and sunflower seeds. Results of the DRC and SCB analysis are presented in Figure 7.1. The DRC distributions reveal that $44 \%$ of farms produced wheat competitively in 2005 . These farms produced about $54.2 \%$ of the total production volume of wheat (Table 7.2). Both SCB and DRC distributions are consistent in terms of the shares of farms with competitive and uncompetitive productions. Note that the kernel-based algorithm used to estimate the DRC distributions presented in this paper smoothes the discontinuity of DRC distribution at 0 and, hence, creates the false impression of a relatively high frequency of observations close to and equal to 0 .

Figure 7.1 also contains the estimates of competitiveness produced using average data over all farms in each cost and revenue category (see the second section for a detailed explanation of the aggregation method). Based on average data we would conclude that wheat and sunflower seed production is not competi- 
Table 7.2: Summary of DRC results for wheat

\begin{tabular}{|c|c|c|c|}
\hline & $\mathrm{DRC}<0$ & $0<\mathrm{DRC}<\mathrm{l}$ & $\mathrm{DRC}>1$ \\
\hline \multicolumn{4}{|l|}{$\begin{array}{l}\text { Share of the group in total production } \\
\text { volume, } \% \text { : }\end{array}$} \\
\hline True share (from the population) & 31.1 & 54.2 & 14.7 \\
\hline $\begin{array}{l}\text { Estimated share and } 95 \% \mathrm{BCaCI} \text { (from the } \\
\text { sample) }\end{array}$ & {$\left[\begin{array}{llll}20.0 & 33.9 & 57.6\end{array}\right]$} & {$\left[\begin{array}{lll}33.9 & 51.7 & 68.7\end{array}\right]$} & {$\left[\begin{array}{lll}5.2 & 14.5 & 29.2\end{array}\right]$} \\
\hline \multicolumn{4}{|l|}{$\begin{array}{l}\text { Share of the group in total number of farms, } \\
\% \text { : }\end{array}$} \\
\hline True share (from the population) & 41.7 & 44.1 & 14.1 \\
\hline $\begin{array}{l}\text { Estimated share and } 95 \% \mathrm{BCaCI} \text { (from the } \\
\text { sample) }\end{array}$ & {$\left[\begin{array}{lll}32.9 & 42.5 & 53.9\end{array}\right]$} & {$\left[\begin{array}{lll}34.2 & 43.4 & 56.2\end{array}\right]$} & {$\left[\begin{array}{lll}7.9 & 14.0 & 22.4\end{array}\right]$} \\
\hline
\end{tabular}

Source: Own calculation;

Notes: Estimated share and 95\% bias-corrected and accelerated confidence interval $(\mathrm{BCaCI})$ are produced from the sample of 763 observations based on $10 \%$ draws from the sample, replicated 1000 times.

tive in Ukraine, with average DRC scores equal 1.37 and 1.55 correspondingly. This result conceals the fact that almost one-half of the farms produce competitively. Hence, DRCs and SCBs based on 'average' data provide a misleading picture of sectoral competitiveness.

\section{Accuracy of the estimates}

The distributions in Figure 7.1 are calculated based on the population data. However, in most of the cases researchers only have access to sample data, so the precision of the estimates has to be accounted for. One natural way of dealing with this is to construct confidence intervals around the sample estimates. The nonparametric bootstrap method is of particular interest in our case since it does not require any assumptions about the distribution of the shares. The nonparametric bootstrap is based on the principle that a random sample is an empirical distribution function that estimates the probability distribution of the population (Efron and Tibshirani, 1993, p.31). The bootstrap algorithm for estimating a confidence interval is performed by first drawing a sample of size $\mathrm{n}$ with replacement from the empirical distribution and using it to compute the quantity of interest (in our case, competitiveness scores, proportions of competitive farms, and proportions of production that occur on competitive farms). This procedure (sampling and calculations) is repeated B times (conventionally B should be at least 1000 times, see Efron and Tibshirani, 1993) to produce a bootstrap sample of the quantity of interest. There are several methods to compute confidence intervals from the resulting bootstrap sample. Efron and Tibshirani (1993) recommend using bias-corrected and accelerated (BCa) confidence intervals, an improved version of the standard percentile method. It has both transformation respecting and second-order accuracy properties, which is not the case with other methods (see Efron and Tibshirani, 1993 p.188). The idea of this improved interval is that $\mathrm{BCa}$ interval endpoints $\left(\hat{\theta}_{l o}, \hat{\theta}_{u p}\right)$ of the ordered bootstrap sample depend on two values, $\hat{\alpha}$ and $\hat{z_{0}}$. Hence, $(1-2 \alpha)$ the $\mathrm{BCa}$ interval for the estimate of the proportion of farms/total produc- 
tion between the cut-off values, $\hat{\theta}$, is given by $\left(\hat{\theta}_{l o}, \hat{\theta}_{u p}\right)=\left(\widehat{\theta}^{*\left(\alpha_{1}\right)}, \widehat{\theta}^{*\left(\alpha_{2}\right)}\right)$, where $\alpha_{1}=\Phi\left(\hat{z}_{0}+\frac{\hat{z}_{0}+z^{(\alpha)}}{1-\hat{\alpha}\left(\hat{z}_{0}+z^{(\alpha)}\right)}\right)$, and $\alpha_{2}=\Phi\left(\hat{z}_{0}+\frac{\hat{z}_{0}+z^{(1-\alpha)}}{1-\hat{\alpha}\left(\hat{z}_{0}+z^{(1-\alpha)}\right)}\right) . \Phi(\cdot)$ is the standard normal cumulative distribution function, $z^{(\alpha)}$ and $z^{(1-\alpha)}$ are the $100 \cdot \alpha^{t h}$ and $100 \cdot(1-\alpha)^{t h}$ percentiles of the standard normal distribution. $z^{(\alpha)}$ is calculated from the proportion of bootstrap replications with bootstrap estimates of the proportions $\widehat{\theta}^{*}(b)$ less than the original sample estimate $\widehat{\theta}$, i.e. $\hat{z_{0}}=\Phi^{-1}\left(\frac{\#\left\{\hat{\theta}^{*}(b)<\hat{\theta}\right\}}{B}\right) \cdot \hat{\alpha}$ is calculated using the jackknife procedure, i.e. $\widehat{\alpha}=\frac{\sum_{i=1}^{n}\left(\widehat{\theta}_{(\cdot)}-\widehat{\theta}_{(i)}\right)^{3}}{6\left\{\sum_{i=1}^{n}\left(\widehat{\theta}_{(\cdot)}-\widehat{\theta}_{(i)}\right)^{2}\right\}^{3 / 2}}$, where $\widehat{\theta}_{(\cdot)}=\sum_{i=1}^{n} \widehat{\theta}_{(i)} / n$ and $\widehat{\theta}_{(i)}$ is calculated from the original sample with the $i^{\text {th }}$ observation deleted.

To demonstrate the method we had to construct representative samples from the population. Simple random sampling is likely to omit some groups of producers, so to ensure the representativeness of the samples, we performed stratified sampling (see e.g. Groves et.al., 2004 for methodology description). Agro-climatic zone and the size of the farm (hectares) were selected as the strata. The nonparametric bootstrap method was then applied to different sample sizes to see how the accuracy of the estimates evolves with the sample size. Figure 7.2 demonstrates the estimates of the proportion of the farms with $\mathrm{DRC}<0$, as well as the associated confidence intervals (BCa and standard percentile-based intervals) as a function of the sample size. We see that the $\mathrm{BCa}$ and standard percentile-based confidence intervals contain the true value of the share. $\mathrm{BCa}$ and standard percentile-based confidence intervals differ for smaller samples, but for larger samples they are similar. The estimates appear to stabilize (i.e. confidence intervals become persistently tighter and the estimate for the proportion fluctuates less around the true value) at sample sizes equal to roughly $10 \%$ of the population size. This indicates that in our case a sample of roughly $10 \%$ of the population provides an adequate basis for drawing inferences about the underlying population shares. This cannot be generalized to other cases, however. Table 7.2 compares true proportions of competitive wheat producing farms/competitive wheat production with $\mathrm{BCa}$ intervals based on samples of $10 \%$ of the population size.

\section{Ranking and/or Comparison}

In this section we suggest and contrast two possible approaches to comparing the degrees of competitiveness of alternative activities/farms/groups based on micro-data.

The first approach is the distribution-based method that follows directly from the competitiveness distribution and draws heavily on the discussion in the previous section. We directly can use the proportion of competitive farms (or proportion of total production/output value of this product occurs on competitive farms) as our ranking criteria. This would be adequate if population data was always available. However, if only sample data is available, the proportions should be combined with confidence intervals estimates generated using the BCa method, as discussed in the previous section.

The second approach is based on a more conventional way of ranking activities 
Figure 7.2: The estimated proportion of the sample with $\mathrm{DRC}<0$, and corresponding confidence intervals, for different sample sizes

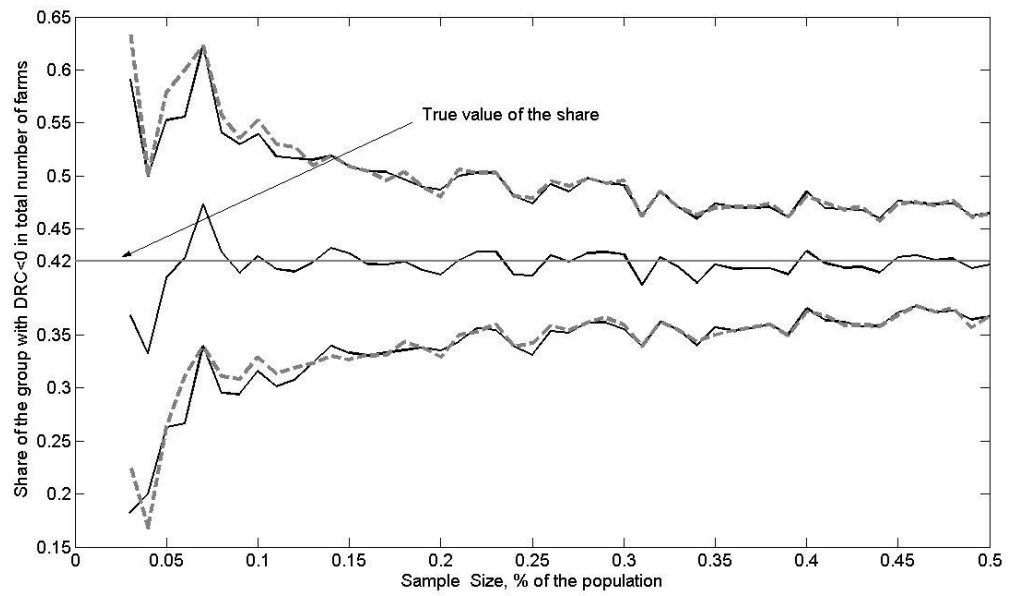

Source: Own calculations.

using aggregated competitiveness scores. This might be more practical and easier to implement if the goal is to produce sub-group aggregate competitiveness scores, e.g. when one is interested in the aggregate scores of farms in a certain range of competitiveness (e.g. all value-subtracting farms with a DRC $<0$, as in Figure 7.2 above) or a certain subset of farms (e.g. cooperatives, agri-holdings, etc.). A question that has not been studied before is how to aggregate and how to draw statistical inferences about such aggregates? Below we summarise the distribution of individual competitiveness scores into an aggregate competitiveness measure by accounting for the relative contribution of each farm to aggregate outcome. Afterwards we describe and demonstrate the method for constructing confidence intervals around aggregate estimates. To generate aggregated DRC and SCB measures we use the following two results. First, a corollary to Koopman's (1957) theorem on profit functions says that the industry maximal profit is the sum of its firms' profits. Second, the project appraisal literature (e.g. Gittinger, 1982) proves that $\mathrm{H}$ in the PAM (sometimes referred to as net social profit) is the ideal measure for comparing mutually exclusive alternatives. Combining these two results produces the following:

$$
H\left(Q_{o}\right)=\sum_{i=1}^{n} H_{i}\left(q_{i o}\right)=\sum_{i=1}^{n}\left(p_{i o} q_{i o}-p_{i d} q_{i d}-p_{i t} q_{i t}\right)
$$

Here we assume that the $i^{\text {th }}$ farm's output $\left(q_{i o}\right)$ is a function of two composite inputs: domestic factors $\left(q_{i d}\right)$ and tradable inputs $\left(q_{i t}\right) ;\left(p_{i o}, p_{i t}, p_{i d}\right)$ is a set of social opportunity costs. Following Masters and Winter-Nelson (1995), we can derive the aggregate DRC and SCB measures as:

$$
D R C=\frac{\sum_{i=1}^{n} p_{i d} q_{i d}}{\sum_{i=1}^{n} p_{i o} q_{i o}-\sum_{i=1}^{n} p_{i t} q_{i t}}=1-\frac{\sum_{i=1}^{n} H_{i}\left(q_{i o}\right)}{\sum_{i=1}^{n} p_{i o} q_{i o}-\sum_{i=1}^{n} p_{i t} q_{i t}}
$$


Measuring and Comparing the Competitiveness of Heterogeneous Production Systems in Agriculture: a Note

$$
S C B=\frac{\sum_{i=1}^{n} p_{i d} q_{i d}+\sum_{i=1}^{n} p_{i t} q_{i t}}{\sum_{i=1}^{n} p_{i o} q_{i o}}=1-\frac{\sum_{i=1}^{n} H_{i}\left(q_{i o}\right)}{\sum_{i=1}^{n} p_{i o} q_{i o}}
$$

The left-hand sides of equations 7.2 and 7.3 are aggregated DRC and SCB measures, respectively. Essentially, we treat the sector as one big farm and calculate its DRC and SCB as we would for an individual farm. Revenues and costs of this 'big farm' equal the sums of revenues and costs of the individual farms in the sector, respectively. This method was used to produce the average DRC and SCB for wheat and sunflower seed depicted in Figure 7.1 and discussed above.

The other way of generating aggregated DRC and SCB measures is to aggregate individual DRC and SCB scores. One can easily derive such aggregates from formulas 7.2 and 7.3. To simplify the exposition, consider a sector consisting of two farms. For DRC aggregation from equation 7.2 we have:

$$
D R C_{A g g r}=\frac{p_{1 d} q_{1 d}+p_{2 d} q_{2 d}}{p_{1 o} q_{1 o}+p_{2 o} q_{2 o}-p_{1 t} q_{1 t}-p_{2 t} q_{2 t}}=\frac{c_{1 d}+c_{2 d}}{v a_{1}+v a_{2}},
$$

where $c_{1 d}=p_{1 d} q_{1 d}, c_{2 d}=p_{2 d} q_{2 d}, v a_{1 d}=p_{1 o} q_{1 o}-p_{1 t} q_{1 t}, v a_{2 d}=p_{2 o} q_{2 o}-p_{2 t} q_{2 t}$. Dividing the denominator and numerator by $v a_{1}$ and $v a_{2}$ gives the following:

$$
D R C_{A g g r}=\frac{c_{1 d}+c_{2 d}}{v a_{1}+v a_{2}}=\frac{\frac{c_{1 d}}{v a_{1} \cdot v a_{2}}+\frac{c_{2 d}}{v a_{1} \cdot v a_{2}}}{\frac{1}{v a_{2}}+\frac{1}{v a_{1}}} .
$$

Since $\frac{c_{i d}}{v a_{i}}=d r c_{i}$ :

$$
D R C_{A g g r}=\frac{\frac{d r c_{1}}{v a_{2}}+\frac{d r c_{2}}{v a_{1}}}{\frac{v a_{1}+v a_{2}}{v a_{1} \cdot v a_{2}}}=d r c_{1} \frac{v a_{1}}{v a_{2}+v a_{1}}+d r c_{2} \frac{v a_{2}}{v a_{2}+v a_{1}} .
$$

A similar result can be derived for the aggregated SCB measure:

$$
S C B_{\text {Aggr }}=\sum_{i=1}^{2} s c b_{i} \frac{p_{i o} q_{i o}}{\sum_{i=1}^{n} p_{i o} q_{i o}} .
$$

Thus, the aggregate DRC is simply a weighted average of the individual farms' DRCs, with each farm's weight equal to its share in total value added. For the aggregated SCB the weights are simply shares in total output value.

To construct confidence intervals for the aggregate competitiveness measures we can again apply the nonparametric bootstrap method introduced above. The only complication is that the nonparametric method will not work for the DRC aggregate because of their discontinuity at 0 . Since Masters and WinterNelson (1995) prove that SCB-based rankings are more accurate, we do not consider methods to overcome this problem and focus exclusively on the SCBbased ranking in the following.

As in the case of proportions above, we apply the method to different sample sizes. Figure 7.3 demonstrates the SCBAggr estimates and associated BCa confidence intervals as a function of the sample size. The figure shows that confidence intervals are non-symmetric, which correspond to the asymmetry of the underlying SCB distribution in Figure 7.1. 
Figure 7.3: Aggregate SCB scores for wheat and corresponding confidence intervals, for different sample sizes

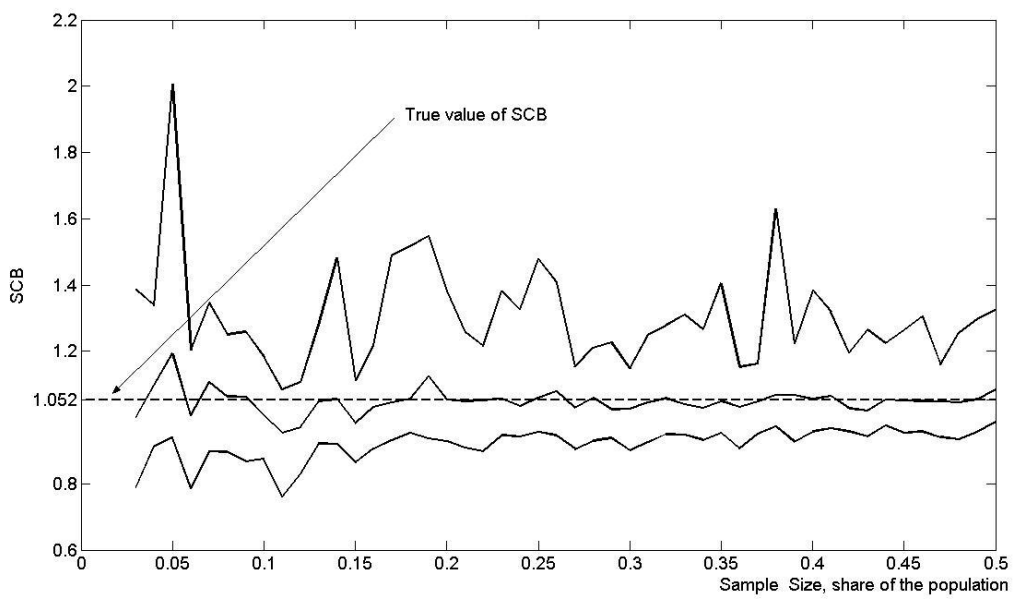

Source: Own calculations.

Notes: below and upper lines denote $95 \%$ bias-corrected and accelerated confdence interval (BCaCI); middle line denotes SCBAggr estimates.

\subsection{Contrasting the Ranking Methods}

In this section we extend the application of these methods to more products (see Table 7.3) in Ukraine and discuss their appropriateness from a policy making perspective. Von Cramon-Taubadel et al (2008) provide a detailed description of the methodology and calculations of the individual competitiveness scores for these products. Table 7.3 summarizes the key results and rankings of the activities according to different criteria.

Table 7.3 illustrates that one can rank the activities differently depending on the ranking criteria chosen. Which criteria is most appropriate? We can first discard the ranking based on the $D R C_{A g g r}$ criterion since, as discussed above, it is distorted by the discontinuity. This leaves the $S C B_{\text {Aggr }}$ and the distribution-based methods. In this regard, note that, as one might expect, the distribution-based ranking does not depend on the competitiveness indicators, while it slightly depends on the proportion criteria. For example based on the "proportion of total production" (PTP) and on the "proportion of total output value" (PTOV) criteria, sunflower seed is the leading crop, while wheat places first according to the "proportion of total farms" (PTF) criterion. Also encouraging is the fact that the $S C B_{A g g r}$ method produces the same ranking as the PTF-based method. So generally speaking, there is not much difference between the distribution-based and $S C B_{\text {Aggr }}$ methods; either one, (or, as a consistency check, both) can be recommended. However, the distributionbased ranking is more flexible and, probably, more attractive. Depending on the objectives of the research, several proportion criteria could be developed to explore an issue from different perspectives. Also, distribution-based ranking is identical to $S C B_{\text {Aggr }}$ ranking based on the PTF criterion. The other obvious 
Measuring and Comparing the Competitiveness of Heterogeneous Production Systems in

Table 7.3: Summary of DRC and SCB results for major crop products for Ukraine, 2005

\begin{tabular}{|c|c|c|c|c|c|c|c|c|c|c|c|}
\hline \multirow[b]{3}{*}{ Wheat: } & \multicolumn{4}{|c|}{$D R C$} & \multicolumn{3}{|c|}{$S C B$} & \multicolumn{2}{|c|}{$D R C_{A_{S g r}}$} & \multicolumn{2}{|c|}{$S C B_{\text {Aggr }}$} \\
\hline & $\mathrm{DRC}<0$ & $0<\mathrm{DRC}<1$ & $\mathrm{DRC}>1$ & Rank & $0 \subset \mathrm{SCB} \subset \mathrm{I}$ & $S C B>1$ & Rank & Value & Rank & Value & Rank \\
\hline & & & & & & & & 1.37 & 1 & 1.05 & 1 \\
\hline PTP & $31.1 \%$ & $54.2 \%$ & $14.7 \%$ & 2 & $54.2 \%$ & $45.8 \%$ & 2 & & & & \\
\hline PTF & $41.8 \%$ & $44.20 \%$ & $14.1 \%$ & 1 & $43.80 \%$ & $56.2 \%$ & 1 & & & & \\
\hline PTOV & $22.6 \%$ & $63.1 \%$ & $14.3 \%$ & 2 & $63.1 \%$ & $36.9 \%$ & 2 & & & & \\
\hline Barley: & & & & & & & & -0.87 & 6 & 1.53 & 3 \\
\hline PTP & $55.9 \%$ & $33.10 \%$ & $11.1 \%$ & 3 & $33.10 \%$ & $66.9 \%$ & 3 & & & & \\
\hline PTF & $65.9 \%$ & $24.6 \%$ & $9.5 \%$ & 3 & $24.2 \%$ & $75.8 \%$ & 3 & & & & \\
\hline PTOV & $46.4 \%$ & $41.80 \%$ & $11.8 \%$ & 5 & $41.80 \%$ & $58.2 \%$ & 5 & & & & \\
\hline Corn & & & & & & & & -1.63 & 7 & 1.69 & 4 \\
\hline PTP & $48.4 \%$ & $32.8 \%$ & $18.8 \%$ & 4 & 32.896 & $67.2 \%$ & 4 & & & & \\
\hline PTF & $80.4 \%$ & $12.6 \%$ & $7.0 \%$ & 4 & $12.5 \%$ & $87.5 \%$ & 4 & & & & \\
\hline PTOV & $33.9 \%$ & $47.1 \%$ & $19.0 \%$ & 3 & 47.196 & $52.9 \%$ & 3 & & & & \\
\hline Sunseed: & & & & & & & & 1.55 & 2 & 1.07 & 2 \\
\hline PTP & $32.5 \%$ & $57.6 \%$ & $9.9 \%$ & 1 & 57.606 & $42.4 \%$ & 1 & & & & \\
\hline PTF & $48.1 \%$ & $41.70 \%$ & $10.2 \%$ & 2 & $41.6 \%$ & $58.4 \%$ & 2 & & & & \\
\hline PTOV & $19.9 \%$ & $70.8 \%$ & $9.3 \%$ & 1 & $70.8 \%$ & $29.2 \%$ & 1 & & & & \\
\hline Soybean: & & & & & & & & -0.24 & 4 & 2.34 & 6 \\
\hline PTP & $62.4 \%$ & $26.90 \%$ & $10.7 \%$ & 6 & $26.9 \%$ & $73.1 \%$ & 6 & & & & \\
\hline PTF & $87.7 \%$ & $8.2 \%$ & $4.1 \%$ & 6 & $8.0 \%$ & $92.0 \%$ & 6 & & & & \\
\hline PTOV & $54.2 \%$ & 32.796 & $13.1 \%$ & 6 & $32.70 \%$ & $67.3 \%$ & 6 & & & & \\
\hline Rapeseed: & & & & & & & & -0.20 & 3 & 1.86 & 5 \\
\hline PTP & $65.3 \%$ & $28.3 \%$ & $6.4 \%$ & 5 & $28.3 \%$ & $71.7 \%$ & 5 & & & & \\
\hline PTF & $87.9 \%$ & $9.5 \%$ & $2.6 \%$ & 5 & $9.5 \%$ & $90.5 \%$ & 5 & & & & \\
\hline PTOV & $49.2 \%$ & 45.206 & $5.6 \%$ & 4 & $45.20 \%$ & $54.8 \%$ & 4 & & & & \\
\hline Sugarbeet: & & & & & & & & -0.47 & 5 & 2.55 & 7 \\
\hline PTP & $86.1 \%$ & 5.790 & $8.2 \%$ & 7 & $5.7 \%$ & $94.3 \%$ & 7 & & & & \\
\hline PTF & $94.4 \%$ & $2.1 \%$ & $3.5 \%$ & 7 & $2.1 \%$ & $97.9 \%$ & 7 & & & & \\
\hline PTOV & $79.5 \%$ & $9.1 \%$ & $11.4 \%$ & 7 & $9.1 \%$ & $90.9 \%$ & 7 & & & & \\
\hline
\end{tabular}

Source: Own calculations.

Notes: PTP - proportion of the group in total production volume; PTF - proportion of the group in total number of farms; PTOV - proportion of the group in total output value. 
advantage is that distribution-based ranking also reveals information about the underlying population.

\subsection{Conclusions}

A weakness of DRC and SCB indicators, as they are usually applied, is that they are calculated using average or 'typical' data. This will provide a distorted picture of sectoral competitiveness, giving a false impression of overall competitiveness or uncompetitiveness. This issue is especially important for transition and developing economies, where evidence from numerous studies points to significant intra-sectoral heterogeneity. To overcome this problem we propose the calculation of competitiveness indicators based on micro-level data. The proposed procedure makes it possible to portray the distribution of competitiveness scores using kernel methods and determine for each product a) what proportion of the farms producing it is competitive, and b) what proportion of total production/output value of this product occurs on competitive farms. We demonstrate this method using data on the population of crop farms in Ukraine. For example, while DRC score based on average revenue and cost data for wheat equal 1.37, suggesting that wheat production is uncompetitive, DRC distributions based on disaggregated data indicate that $44 \%$ of the farms in fact produced wheat competitively in 2005. A further advantage is that statistical inference about such estimates and econometric analysis of the determinants of competitiveness become possible in this setting.

We also propose two approaches for generating competitiveness rankings based on micro-data, which is often of interest to policy makers and researchers. The first is a distribution-based method that directly derives from the competitiveness distribution and uses proportions as a ranking criterion. The other method is an aggregates-based method. It integrates farms in such a way that the relevance of the competitiveness distribution is summarised by an estimated aggregate competitiveness score together with corresponding confidence intervals. The distribution-based ranking is more flexible as it provides the possibility to adjust the ranking to the objectives of the research using different proportion criteria. Also the evidence from Ukraine suggests that distributionbased ranking is able to replicate $S C B_{\text {Aggr }}$ rankings based on the proportion of total farms criterion.

\subsection{References}

Bernard, A. B., Eaton, J., Jenson, J. B., Kortum, S. (2003). Plants and Productivity in International Trade, The American Economic Review, Vol 93, No 4, pp 1268-1290

Efron, B. And Tibshirani, R. J. (1993). An Introduction to the Bootstrap methods, New York: Chapman \& Hall

Galushko, V., B. Brümmer and S. Demyanenko (2004). Measuring the Productive Efficiency of Ukrainian Farms. In: von Cramon-TAUBADEL, S., S. Demyanenko \& A. Kunn (eds.): Ukrainian Agriculture - Crisis and Recovery, Shaker, Aachen.

Gittinger, J.P. (1982). Economic Analysis of Agricultural Progects, 2nd ed. Baltimore MD: John Hopkins University press 
Groves, R.M., Fowler, J.F., Jr., Couper, M.P., Lepkowski, M., Singer, E., Tourangeau, R. (2004). Survey Methodology, John Wiley\&Sons, Inc., Hoboken, New Jersey

Koopman, T. (1957). Three Essays on the State of Economic Science, McGrawHill, New York.

Kurkalova, L., And H. Jensen (2002). Technical Efficiency of Grain Production in Ukraine: An Analysis Using Farm-Level Data, Journal Paper No. J-17036 of the Iowa Agriculture and Home Economics Experiment Station. Liefert, W. (2002). Comparative (Dis?) Advantage in Russian Agriculture, American Journal of Agricultural Economics, Vol 84(3): 762-767.

Lissitsa, A., AND M. ODENING (2005). Efficiency and total factor productivity in Ukrainian agriculture in transition, Agricultural Economics, Vol 32(3): 311-325.

Masters, W.A., And A. Winter-Nelson. (1995). Measuring the Comparative Advantage of Agricultural Activities: Domestic Resource Costs and the Social Cost-Benefit Ratio, American Journal of Agricultural Economics, Vol 77: $243-50$.

Melitz, M. (2003). The Impact of Trade on Intra-Industry Reallocations and Aggregate Industry Productivity, Econometrica, Vol 71, No.6: 1695-1725. Monke, E. A. And S. R. Pearson (1989), The Policy Analysis Matrix for Agricultural Development, Ithaca NY: Cornell University Press

Rosenblatt, M. (1956). Remarks on Some Nonparametric Estimates of a Density Function, Annals of Mathematical Statistics, Vol 27: 643-669.

von Cramon Taubadel, S., Nivyevskiy, O., and M. Grueninger (2008), Ukraine: Agricultural Competitiveness, World Bank Policy Note No. 44843UA. 


\title{
Chapter 8
}

\section{Efficiency, Productivity Growth and Competitiveness: a Note}

\begin{abstract}
'Productivity and efficiency growth enhances competitiveness'. Similarly formulated statements one often might come across in the literature on economic performance of firms, industries and nations. This conventional perception in the economic literature, originating from the trade and growth theory models, however, lacks a clearly defined mathematical formulation. The earlier work of Page (1980) and Nishimizu and Page (1986) provide an elegant way to formalize the relationship between the productivity growth and competitiveness, measured by Domestic Resource Costs (DRC) ratio. Still, the issue on how the technical efficiency and competitiveness levels are related has not been addressed at all in the literature. Moreover, Masters and Winter-Nelson (1995) and Siggel (2006) have shown that DRC gives a biased picture of competitiveness. In this paper we propose a static and dynamc decompositions of the competitiveness measured by unbiased indicator Social Cost Benefit Ratio (SCB) using a distance function approach.
\end{abstract}

\subsection{Introduction}

The literature on the economic performance of firms, industries, or countries has tended to be divided along two lines of analysis. The first strand of the literature focuses on the analysis of comparative advantage and/or competitiveness. Due to ambiguity on the precise meaning of these concepts, a large number of measures of competitive advantage/competitiveness have been developed. Siggel (2006) provides a rather comprehensive survey and discussion of these measures. Among the concepts and measures surveyed, he concludes that the Domestic Resource Cost (DRC) criterion is the only measure that qualifies as a true measure of comparative advantage. DRC is a well-known and widely applied concept (e.g. von Cramon-Taubadel et al, 2008 and 2009) first proposed by Bruno (1965) and incorporated in the Policy Analysis Matrix (PAM) framework by Monke and Pearson (1989). DRC compares the cost of domestic resources measured at social prices to value added measured in social prices. It can be derived from the Recardian comparative advantage framework, as well as the use of social (or equilibrium) prices throughout ensures 
that DRC measures the true comparative advantage (Siggel, 2006).

The second strand of literature focuses on efficiency and productivity analysis, where technical efficiency and Total Factor Productivity (TFP) change concepts have been of the main interest. Krugman (1994), for instance, argues that '... for an economy with very little international trade, 'competitiveness' would turn out to be a funny way of saying 'productivity'. Dollar and Wolf (1993) propose measuring the macroeconomic or national competitiveness in terms of productivity. This approach has also been heavily applied on the micro level (e.g. Zhul et al, 2008). The theoretical background of these concepts is well established (see e.g. Färe and Primont, 1995), and parametric and non-parametric methods for measuring them have been developing and converging rapidly. (e.g. Daraio and Simar, 2007; Kumbhakar et al, 2007; Simar and Zelenyuk, 2008). Inferences on comparative advantages/competitiveness are drawn based on relative rates of TFP change between DMU and/or their distance to the 'best-practice' frontier.

How these two strands of analysis are related to one another? It is often maintained that productivity growth enhances competitiveness (e.g. Link and Siegel, 2003, p.1), but is there a mathematically formulated relationship between a DMU's competitiveness/comparative advantage and its productivity level/growth or technical efficiency? Attempts to relate technical efficiency, productivity and competitiveness go back to Page (1980) and Nishimizu and Page (1986) who proposed a DRC criterion decomposition that formally relates improvements in productivity to improvements in a DMU's comparative advantage, thus supporting the common perception of a link between efficiency/productivity and competitiveness.

Nevertheless, important open questions remain to be addressed. Despite the wide acceptance of DRC as a comparative advantage indicator in policy analysis, it is not perfect. Masters and Winter-Nelson (1995) and Siggel (2006) have shown that DRC understates the competitiveness of activities with intensive usage of domestic factors. To correct for this, Masters and Winter-Nelson (1995) proposed the Social Cost Benefit Ratio (SCB) criterion, which is essentially the unit cost ratio (UCs) proposed by Siggel (2006). This (unbiased) measure compares total domestic costs at social prices to the social value of output. The interesting question in this regard is whether the relationship between DRC and TFP growth derived by Nishimizu and Page (1986) holds for the SCB or UCs criteria. In the following section we explore this question in details and generalize it for the multiple outputs and inputs case.

A final but equally important question, which has not been addressed in the literature so far, regards the formal relationship between levels of technical efficiency and competitiveness. Apart from its theoretical relevance, this issue might be important from a policy analysis perspective. Competitiveness and efficiency analysis place different demands on data, expertise, computation time etc. Deriving a formal relationship between competitiveness and efficiency would help to reduce these requirements. So, in the second part of the paper we derive a relationship between technical efficiency and competitiveness. Conclusions close the paper. 


\subsection{Competitiveness decomposition I}

Numerous indicators of competitiveness have been developed and applied by economists. In a rather comprehensive survey of these measures, Siggel (2006) concludes that the Domestic Resource Cost (DRC) criterion is the only measure that qualifies as a true measure of comparative advantage. He showed that the DRC can be derived from the Ricardian comparative advantage concept. The DRC measure compares the cost of domestic resources at social (shadow) prices to value added at world prices. $0<\mathrm{DRC}<1$ indicates comparative advantage: the social opportunity cost of domestic resources used is smaller that the corresponding social gain (value added). The opposite is true for the $\mathrm{DRC}>1$. If the DRC is smaller than 0 , then the revenue does not even suffice to cover tradable input costs, let alone domestic inputs. In this case, production of the good in question is clearly not competitive.

Masters and Winter-Nelson (1995) identified the problem with using DRC criterion. They showed mathematically that the DRC understates the competitiveness of activities with intensive usage of domestic factors instead of tradable inputs. Activity with the highest level of competitiveness does not necessarily maximize social profits, in other words its input mix is not optimal at given social prices. A bit later and more intuitively, Siggel (2006) showed why DRC is not a perfect measure of competitiveness. First, there are situations when intermediate inputs may also contribute to comparative advantages. The second argument basically corresponds to Masters and Winter-Nelson's (1995) one. To correct for these problems, Masters and Winter-Nelson (1995) proposed the Social Cost Benefit Ratio (SCB) criterion, which is essentially the unit cost ratio (UCs) proposed by Siggel (2006). It is an unbiased measure, since it correctly identifies socially optimal levels of input use.

Assume $n$ firms operate in the sector at question. Each firm $i(i=\overline{1, n})$ uses $K$ inputs, $x^{i}=\left(x_{1}^{i}, \ldots, x_{K}^{i}\right)^{\prime} \in \Re_{+}^{K}$, to produce $M$ outputs, $y^{i}=\left(y_{1}^{i}, \ldots, y_{M}^{i}\right)^{\prime} \in$ $\Re_{+}^{M}$. The SCB criterion of comparative advantages compares the total costs at social prices to the social value of output:

$$
S C B=\frac{w x}{p y}
$$

where $w=\left(w_{1}, \ldots, w_{K}\right)$ and $p=\left(p_{1}, \ldots, p_{M}\right)$ are the shadow (social) price vectors for inputs and outputs respectively. The SCB ratios less or equal one, indicate competitive production: the social opportunity cost of resources used in production is smaller that the corresponding social gain (revenue). The opposite is true for the SCB greater then one.

We assume that all $n$ firms have access to the same technology $T$, defined as $T \equiv\{(x, y): x$ can produce $y\}$, that satisfies standard regularity axioms of production theory (e.g. Färe and Primont, 1995). Following Färe and Grosskopf (1997):

$$
\frac{\pi(p, w)+w x}{p y} \geq \frac{1}{D_{o}(x, y)}
$$

and

$$
\frac{\pi(p, w)-p y}{w x} \geq-\frac{1}{D_{i}(x, y)}
$$

where $\pi(p, w)$ is a profit frontier defined as

$$
\pi(p, w)=\sup \{p y-w x:(x, y) \in T\}
$$


$D_{o}(x, y)$ and $D_{i}(x, y)$ are the Shephard (1970) output and input distance functions

$$
D_{o}(x, y) \equiv \inf \{\theta>0:(x, y / \theta) \in T\}
$$

and

$$
D_{i}(x, y) \equiv \sup \{\lambda>0:(x / \lambda, y) \in T\}
$$

If $D_{o}(x, y)=1\left(D_{i}(x, y)=1\right)$, a firm is technically efficient, otherwise, when $D_{o}(x, y)<1\left(D_{i}(x, y)>1\right)$ it is technically inefficient. The reciprocal of the Shephard distance function is the Farrell (1957) technical efficiency defined as

$$
T E_{o}(x, y)=1 / D_{o}(x, y) \text { and } T E_{i}(x, y)=1 / D_{i}(x, y)
$$

In expressions $(8.5-8.6)$ it is easy to see that

$$
\frac{\pi(p, w)}{p y}+S C B \geq T E_{o}(x, y)
$$

and

$$
\frac{1}{S C B}-\frac{\pi(p, w)}{w x} \geq T E_{i}(x, y)
$$

where SCB is a measure of comparative advantage defined in (8.1).

These two equations could be transformed into equalities by introducing allocative efficiencies, i.e.:

$$
\frac{\pi(p, w)}{p y}+S C B=T E_{o}(x, y) \cdot A E_{o}
$$

and

$$
\frac{1}{S C B}-\frac{\pi(p, w)}{w x}=T E_{i}(x, y) \cdot A E_{i}
$$

Note that $A E_{o}\left(A E_{i}\right)$ should be greater (less) or equal 1. The product of technical and allocative efficiencies in both cases is nothing else than profit efficiency. Isolating SCB in (8.10) and (8.11) we receive the following decompositions:

$$
S C B=T E_{o}(x, y) \cdot A E_{o}-\frac{\pi(p, w)}{p y}
$$

and

$$
\frac{1}{S C B}=T E_{i}(x, y) \cdot A E_{i}+\frac{\pi(p, w)}{w x}
$$

Let us graphically demonstrate the intuition behind expressions (8.12) and (8.13). Figure 8.1 shows the simplest one input and one output case, where a firm is producing at the point B. Using notation in the Figure 8.1 we can express the right-hand side parts of the equation (8.12) by the ratios:

$$
\begin{gathered}
T E_{o}(x, y) \cdot A E_{o}=\frac{O C}{O B} \frac{O D}{O C}=\frac{O D}{O B} \\
\frac{\pi(p, w)}{p y}=\frac{O A}{O B}
\end{gathered}
$$

Substituting expressions (8.14) and (8.15) in (8.10) yields:

$$
S C B=\frac{O D}{O B}-\frac{O A}{O B}=\frac{(O D-O A)}{O B}
$$


Figure 8.1: SCB decomposition output orientation

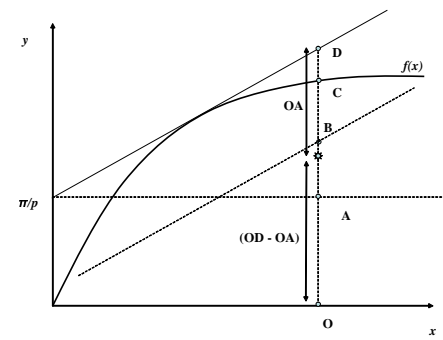

Source: Own presentation..
Figure 8.2: SCB decomposition input orientation

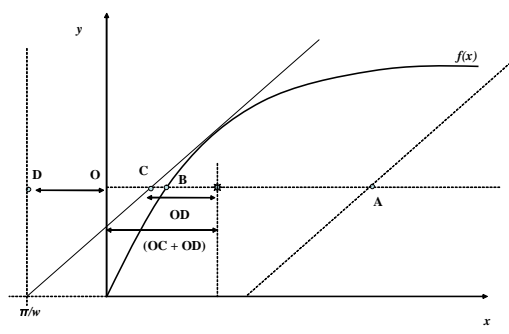

Source:Own presentation

Since $(O D-O A)<O B, S C B<1$ then, thus production at the point $\mathrm{B}$ at given social input and output prices is competitive.

In the same manner, using notation in Figure 8.2 one can see that:

$$
\begin{aligned}
T E_{i}(x, y) \cdot A E_{i} & =\frac{O B}{O A} \frac{O C}{O B}=\frac{O C}{O A} \\
\frac{\pi(p, w)}{w x} & =\frac{O D}{O A}
\end{aligned}
$$

Substituting expressions (8.17) and (8.18) in (8.13) yields:

$$
\frac{1}{S C B}=\frac{O C}{O A}+\frac{O D}{O A}=\frac{(O C+O D)}{O A}
$$

Since $(O C+O D)<O A$, then $\frac{1}{S C B}<1$, or $S C B>1$. Thus, production at the point $\mathrm{A}$ at given social input and output prices is not competitive.

Summarizing a bit the above discussion, we showed analytically that technical efficiency positively contributes to competitiveness. Also, equally important, the equations (8.10) and (8.11) provide information about other two sources of competitiveness. Allocative efficiency tells whether a firm chooses the optimum (profit maximizing) inputs or outputs mix. Technical and allocative efficiencies could be named as micro- or firm-level sources, since they are under the control of firms. $\frac{1}{p y}$ in the second term also qualifies for the micro-level source of competitiveness. Profit frontier, $\pi(x, y)$, in (8.10), could be named as macroor sector-level source. Profit frontier $\pi(x, y)$, as the expression (8.4) shows, is defined by input and output prices and by available technology. Prices in the competitive market setting are given for firms. Technology, by assumption, is accessible to all firms, in other worlds it is given to all firms. To what extend a firm makes use of this technology is reflected in its efficiency terms.

Having estimated the pieces in (8.10) or (8.11), one can get an idea about what causes a firm to be (un)competitive. Whether a farm's (un)competitiveness is mainly due to some firm-specific factors or it is out of the managers' control? Answering this question has different policy implications. If micro-level sources prevail, than, probably, policy makers have nothing to worry about. When a firm operates well below its optimum level, then the competitive market forces 
should automatically adjust the behavior of a firm or force a firm out of the market. If macro-sources prevail, then, probably, there is a reason for policy makers to step in.

The proposed decomposition of the SCB criterion in (8.10) and (8.11) could serve a basic for the statistical inferences about individual firm SCB scores, which was hardly possible before. In expressions (8.10) and (8.11) one may notice that the variation in SCB scores comes from the superposition of the technology and profit frontiers variations.

\subsection{Competitiveness decomposition II}

Using notation of the previous section we can rewrite the SCB criterion in sums form as:

$$
S C B=\frac{\sum_{k}^{K} w_{k} x_{k}}{\sum_{m}^{M} p_{m} y_{m}}
$$

Taking the total differential and rewriting the resulting expression in relative changes, the percentage change in the SCB can be expressed as:

$$
\frac{d S C B}{S C B}=\sum_{k}^{K} s_{k} \frac{d w_{k}}{w_{k}}+\sum_{k}^{K} s_{k} \frac{d x_{k}}{x_{k}}-\sum_{m}^{M} r_{m} \frac{d p_{m}}{p_{m}}-\sum_{m}^{M} r_{m} \frac{d y_{m}}{y_{m}}
$$

Here, $s_{k}=\frac{w_{k} x_{k}}{\sum_{k}^{K} w_{k} x_{k}}$ denotes the cost share of input, and $r_{m}=\frac{p_{m} y_{m}}{\sum_{m}^{M} p_{m} y_{m}}$ denotes the revenue share of output $y_{m}$. The last and the second terms in (8.21) make up nothing else than a (negative) conventional Divisia index of productivity growth. It is defined as for a multi-output, multi-input setting, and equation (8.21) transforms into:

$$
\frac{d S C B}{S C B}=\sum_{k}^{K} s_{k} \frac{d w_{k}}{w_{k}}-\sum_{m}^{M} r_{m} \frac{d p_{m}}{p_{m}}-T \dot{F} P
$$

Bruemmer et al (2002) decompose $T \dot{F} P$ further in different sources of productivity growth. From (8.7), the output distance function is equal to the inverse of the Farrell output efficiency measure. In logarithmic form, this can be expressed as $0=\ln D_{o}-\ln T E_{o}$. If $T E_{o}$ is modeled via a non-negative variable $u, T E_{o}=\exp (-u)$, this can be expressed as $0=\ln D_{o}+u$. Using these definitions, the decomposition of $T \dot{F} P$ takes the following form (Bruemmer et al, 2002):

$$
\begin{aligned}
T \dot{F} P= & \sum_{m}^{M}\left(r_{m}-\mu_{m}\right) \frac{d y_{m}}{y_{m}}+\sum_{k}^{K}\left(\lambda_{k}-s_{k}\right) \frac{d x_{k}}{x_{k}} \\
& +(R T S-1) \sum_{k}^{K} \lambda_{k} \frac{d x_{k}}{x_{k}} \\
& -\frac{\partial \ln D_{o}(\cdot)}{\partial t}-\frac{\partial u}{\partial t}
\end{aligned}
$$


The complete decomposition of SCB growth index looks then as follows:

$$
\begin{aligned}
\frac{d S C B}{S C B}= & \sum_{k}^{K} s_{k} \frac{d w_{k}}{w_{k}}-\sum_{m}^{M} r_{m} \frac{d p_{m}}{p_{m}}-\sum_{m}^{M}\left(r_{m}-\mu_{m}\right) \frac{d y_{m}}{y_{m}} \\
& -\sum_{k}^{K}\left(\lambda_{k}-s_{k}\right) \frac{d x_{k}}{x_{k}}-(R T S-1) \sum_{k}^{K} \lambda_{k} \frac{d x_{k}}{x_{k}} \\
& +\frac{\partial \ln D_{o}(\cdot)}{\partial t}+\frac{\partial u}{\partial t}
\end{aligned}
$$

The equation in (8.24) decomposes SCB growth into the following components. The first two components, using the Nishimizu and Page (1986) language, combine the 'factor costs effect' $\left(\sum_{k}^{K} s_{k} \frac{d w_{k}}{w_{k}}\right)$ and 'term of trade effect' $\left(\sum_{m}^{M} r_{m} \frac{d p_{m}}{p_{m}}\right)$. The next two components identify 'output allocative efficiency effect' $\left(\sum_{m}^{M}\left(r_{m}-\mu_{m}\right) \frac{d y_{m}}{y_{m}}\right)$ and 'output allocative efficiency effect' $\left(\sum_{k}^{K}\left(\lambda_{k}-\right.\right.$ $\left.\left.s_{k}\right) \frac{d x_{k}}{x_{k}}\right)$, where $\mu_{m}=\frac{\partial \ln D_{o}(\cdot)}{\partial \ln y_{m}}$ and $\frac{\partial \ln D_{o}(\cdot)}{\partial \ln x_{k}}=-\lambda_{k} R T S . R T S$ denotes returns to scale (see Färe and Primont, 1994). As Bruemmer et al (2002) explains in details, if firms choose their inputs and output bundles according to the price signals (i.e. maximize profits), then $r_{m}-\mu_{m}=0$ and $\lambda_{k}-s_{k}=0$. Otherwise they allocate their resources inefficiently. A 'scale effect' is captured by the next component $\left((R T S-1) \sum_{k}^{K} \lambda_{k} \frac{d x_{k}}{x_{k}}\right)$. Technical change and efficiency change effects are captured by the last two components, $\frac{\partial \ln D_{o}(\cdot)}{\partial t}$ and $\frac{\partial u}{\partial t}$ respectively.

\subsection{Conclusions}

In the paper we derived a static and dynamic decompositions of competitiveness measured by SCB indicator using a distance function approach. The static decomposition shows a positive relationship between the levels of technical efficiency and competitiveness, thus confirming the conventional perception about the relationship in the economic literature. The sources of (static) (un)competitiveness can be named as firm- and sector-level sources. Firm-level sources are mostly under the firm managers' control, while sector-level sources are mainly the policy makers' focus.

The dynamc decomposition of competitiveness shows a positive relationship between the TFP and competitiveness growth. The sources of competitiveness growth include: i) factor costs effect; ii) terms of trade effect; iii) scale effect; iv) technical change; v) technical efficiency changes; vi) allocative affects.

\subsection{References}

Brümmer, B., T. Glauben, And G. Thijssen (2002). Decomposition of Productivity Growth Using Distance Functions: The Case of Dairy Farms in Three European Countries. American Journal of Agricultural Economics, 84(3): 628-644.

Chambers, R. G., Chung, Y. And R. FÄre (1998) Profit, Directional Distance Functions, and Nerlovian Efficiency. Journal of Optimization Theory and Applications Vol 98(2), pp. 351-364 
Färe, R. And S. Grosskopf (1997) Profit efficiency, Farrell decompositions and the Mahler inequality. Economics Letters Vol 57, pp. 283-287

FÄre, R. And D. PRImont (1995). Multi-Output Production and Duality: Theory and Applicaions. Boston: Kluwer Academic Publishers.

FARrell, M.J. (1957) The Measurement of Productive Efficiency, Journal of Royal Statistical Society, Vol. 129A, pp. 253-281

Krugman, P. B. (1994): Competitiveness: A dangerous obsession. Foreign Affairs, March/April 1994.

Kumbhakar, S.C., Park, B.U., Simar, L. And E.G. Tsionas (2007): Nonparametric stochastic frontiers: a local likelihood approach, Journal of Econometrics, 137, 1, pp. 1-27

Masters, W.A., And A. Winter-Nelson. (1995), Measuring the Comparative Advantage of Agricultural Activities: Domestic Resource Costs and the Social Cost-Benefit Ratio, American Journal of Agricultural Economics, Vol 77: 243-50.

Monke, E. A. And S. R. Pearson (1989), The Policy Analysis Matrix for Agricultural Development, Ithaca NY: Cornell University Press

Nishimizu, M. And J.M. JR. PAge (1986): Productivity change and dynamic comparative advantage. The Review of Economics and Statistics, Vol 68 (2), pp. 241-247

Nivievskyi, O., And S. von Cramon-Taubadel (2009): Measuring and Comparing the Competitiveness of Heterogeneous Production Systems in Agriculture: a Note. Outlook on Agriculture, Vol 38, No 1, 2009, pp 31-37

PAGE, J.M. JR. (1980): Technical efficiency and economic performance: some evidence from Ghana. Oxford Economic Papers, Vol 32(2), pp. 319-339

Shephard, R.W.(1970) Theory of Cost and Production Functions. Princeton Siggel, E. (2006): International Competitiveness and Comparative Advantage: A Survey and a Proposal for Measuremen. Journal of Industry Competition and Trade. Vol 6(2), pp. 137-159

Simar, L. And Zelenyuk, V. (2008): Stochastic FDH/DEA estimator for Frontier Analysis.Discussion Paper 0820, Institut de Statistique, UCL, Belgium.

von Cramon Taubadel, S., Gruenninger M., Nivyevskiy, O., and D. PROKHODKO (2009). Belarus: Boosting agricultural productivity and competitiveness. Options and Impact of State Support. World Bank Policy Note No. 48335-BY.

von Cramon Taubadel, S., Nivyevskiy, O., and M. Grueninger (2008). Ukraine: Agricultural Competitiveness. World Bank Policy Note No. 44843UA.

Zhu1, X., Demeter M. R., A.O. Lansink (2008): Competitiveness of dairy farms in three countries: the role of CAP subsidies. Contributed paper at the EAAE 2008 Conference, Ghent, Belgium. 


\section{Oleg Nivievskyi}

Office Address: Georg-August-Universität Göttingen • Fakultät für Agrarwissenschaften • Department für Agrarökonomie und Rurale Entwicklung・Platz der Göttinger Sieben 5 • 37073 Göttingen • Germany •+49- (0)551- 39- $4804 \cdot$ oniviev@gwdg.de Date of birth: 03.02.1979

Civil status: married, two kids

Permanent Address: Albrecht-Thaer-Weg 24a app. 12 • 37075 Göttingen • Germany

\section{Education}

exp. Feb 2010 Ph.D. Agricultural Economics and Applied Statistics, Georg-August-Universität Göttingen, Germany (Supervisor: Prof. S. von Cramon-Taubadel). PhD program in Applied Statistics and Empirical Methods (Center for Statistics)

M.A. Economics, National University "Kyiv-Mohyla Academy”, EERC/KSE, Ukraine. (Supervisor: Dr. V. Zelenyuk)

2001

Diploma Physics, with High Distinction, Kamyanets-Podilskyi State Pedagogical University, Ukraine (Supervisor: Dr. S. Kryskov).

\section{Employment}

Since

Oct. 2007

\section{Research Associate}

Georg-August-Universität Göttingen, Department for AgriculturalEconomics and Rural Development, Chair Agricultural Policy of Prof. S. von Cramon-Taubadel

\section{Research Associate}

Institute for Economic Research and Policy Consulting, Agricultural Policy Department, Kyiv, Ukraine

2006/07

\section{Senior lecturer}

Kyiv National Economic University, Department of Agricultural Economics, Kyiv, Ukraine.

2001/02

\section{Teacher}

High School No 190, Kyiv, Ukraine.

\section{$\underline{\text { Research Interests }}$}

- $\quad$ Agriculture and Food Policy Analysis

- $\quad$ Productivity and Efficiency Analysis

- $\quad$ Comparative advantages/Competitiveness Analysis

- $\quad$ Spatial Economics and Econometrics 